\title{
DEMOGRAFÍA EXPERIMENTAL DE UN BIVALVO INVASOR, Limnoperna fortunei, EN LA CUENCA DEL PLATA
}

Nicolás Bonel

La Plata

2011 


\title{
DEMOGRAFÍA EXPERIMENTAL DE UN BIVALVO INVASOR, Limnoperna fortunei (Dunker, 1857), EN LA CUENCA DEL PLATA
}

\author{
Nicolás Bonel \\ TRABAJO DE TESIS PARA OPTAR POR EL TÍTULO DE DOCTOR \\ EN CIENCIAS NATURALES
}



"Ciencia, exploración y juego: aprender es la naturaleza del niño; buscar, la necesidad del explorador. Pero aprender, buscar y comprender, esa es la misión del científico puro"

JACQUES COSTEAU

(Los humanos, las orquídeas y los pulpos)

A mis abuelos, Lito y Lidia 


\section{AGRADECIMIENTOS}

Al Dr. Néstor J. Cazzaniga por su constante apoyo, por guiarme en este maravilloso mundo de la ciencia, y por sobre todas las cosas, ser una excelente persona.

A la Dra. Lía C. Solari por su humildad, consejos y aportes fundamentales al desarrollo de esta tesis.

Al Dr. Gustavo A. Darrigran por ofrecerme la oportunidad de trabajar en este tema.

A la Dra. Mirta García y a Verónica Ribelotta (Secretaría de Postgrado - FCNyM - UNLP).

Al Dr. Edmundo C. Drago y a la Prof. Inés Ezcurra de Drago (INALI - Santa Fe) por la ayuda brindada y su calidez humana.

A la División Zoología de Invertebrados (FCNyM - UNLP) por brindarme un lugar de trabajo.

Al Laboratorio de Invertebrados I (DBByF - UNS), por hacerme sentir como en casa.

Al Laboratorio de Toxicología y Química Legal (Exactas - UNLP) por permitirme utilizar sus instalaciones.

Al Consorcio del Puerto La Plata (La Plata) y al Batallón de Ingenieros Pontoneros (Santo Tomé - Santa Fe) por darme acceso a las áreas de muestreo.

A los docentes de la cátedra de Limnología (FCNyM - UNLP) por facilitarme equipamiento y lugar de trabajo.

A la Lic. Mariela Caneo por su apoyo desinteresado.

Al Dr. Diego Zelaya y la Dra. Natalia Bulnes por los mates, charlas y consejos.

A la Dra. Julia Pizá por sus sugerencias estadísticas y aporte bibliográfico.

A la Dra. Paula Marcotegui y el Dr. Luciano La Sala por su apoyo y sugerencias.

A mis amigos.

A mi familia por estar siempre.

A mis fieles compañeros Manolo y Felipe.

A Pili por todo! 


\section{ÍNDICE}

$\begin{array}{ll}\text { Resumen } & 1\end{array}$

$\begin{array}{ll}\text { Abstract } & 4\end{array}$

$\begin{array}{ll}\text { Antecedentes generales } & 7\end{array}$

\section{CAPÍTULO 1}

ANÁLISIS COMPARATIVO DE LAS CONDICIONES LIMNOLÓGICAS

ENTRE DOS AMBIENTES ACUÁTICOS DE LA CUENCA DEL PLATA:

Río Santiago (La Plata) y Río Coronda (Santo Tomé - Santa Fe)

$\begin{array}{lll}1.1 & \text { Introducción } & 13\end{array}$

1.1.1 Área de estudio 14

$\begin{array}{ll}1.1 .2 \text { Objetivos } & 17\end{array}$

$\begin{array}{ll}\text { 1.1.3 Hipótesis } & 17\end{array}$

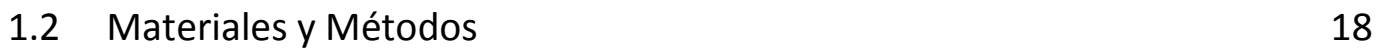

$\begin{array}{lll}1.3 & \text { Resultados } & 21\end{array}$

$\begin{array}{lll}1.4 & \text { Discusión } & 37\end{array}$

\section{CAPÍTULO 2}

ANÁLISIS COMPARATIVO DE LA DENSIDAD LARVAL DE Limnoperna fortunei

EN DOS CUERPOS DE AGUA DE LA CUENCA DEL PLATA

2.1 Introducción

2.1.1 Objetivos

2.1.2 Hipótesis

$\begin{array}{lll}2.2 & \text { Materiales y Métodos } & 47\end{array}$

2.2.1 Características de los sitios de muestreo 47

2.2.2 Recuento y clasificación de los estadios larvales $\quad 47$

2.2.3 Densidad larval $\quad 48$

$\begin{array}{llr}2.3 & \text { Resultados } & 49\end{array}$

$\begin{array}{lll}2.4 & \text { Discusión } & 61\end{array}$ 


\section{CAPÍTULO 3}

DENSIDAD, MORFOMETRÍA Y CRECIMIENTO DE Limnoperna fortunei

EN COLECTORES ARTIFICIALES

$\begin{array}{lll}3.1 & \text { Introducción } & 69\end{array}$

$\begin{array}{ll}3.1 .1 \text { Objetivos } & 71\end{array}$

$\begin{array}{ll}\text { 3.1.2 Hipótesis } & 71\end{array}$

$\begin{array}{ll}3.2 & \text { Materiales y Métodos }\end{array}$

3.2.1 Paneles de Captación - Colectores Artificiales 72

3.2.2 Densidad 73

$\begin{array}{ll}\text { 3.2.3 Morfometría } & 74\end{array}$

$\begin{array}{ll}\text { 3.2.4 Crecimiento } & 75\end{array}$

$\begin{array}{lll}3.3 & \text { Resultados } & 77\end{array}$

$\begin{array}{ll}\text { 3.3.1 Densidad } & 77\end{array}$

$\begin{array}{ll}\text { 3.3.2 Morfometría } & 81\end{array}$

$\begin{array}{ll}\text { 3.3.3 Crecimiento } & 84\end{array}$

$\begin{array}{lll}3.4 & \text { Discusión } & 93\end{array}$

\section{CAPÍTULO 4}

MORFOMETRÍA, CRECIMIENTO E ÍNDICE DE CONDICIÓN DE Limnoperna fortunei

EN JAULAS EXPERIMENTALES

$\begin{array}{lll}4.1 & \text { Introducción } & 104\end{array}$

$\begin{array}{ll}\text { 4.1.1 Objetivos } & 107\end{array}$

$\begin{array}{ll}\text { 4.1.2 Hipótesis } & 107\end{array}$

$\begin{array}{lll}\text { 4.2 } & \text { Materiales y Métodos } & 108\end{array}$

$\begin{array}{ll}\text { 4.2.1 Jaulas experimentales } & 108\end{array}$

$\begin{array}{ll}\text { 4.2.2 Morfometría } & 110\end{array}$

$\begin{array}{ll}4.2 .3 \text { Crecimiento } & 111\end{array}$

4.2.4 Índice de condición 112 
$\begin{array}{lll}4.3 & \text { Resultados } & 114\end{array}$

$\begin{array}{ll}\text { 4.3.1 Morfometría } & 114\end{array}$

$\begin{array}{ll}\text { 4.3.2 Crecimiento } & 119\end{array}$

4.3.3 Índice de condición 133

$\begin{array}{lll}4.4 & \text { Discusión } & 139\end{array}$

$\begin{array}{lr}\text { CONCLUSIONES } & 149\end{array}$

$\begin{array}{ll}\text { REFERENCIAS } & 153\end{array}$

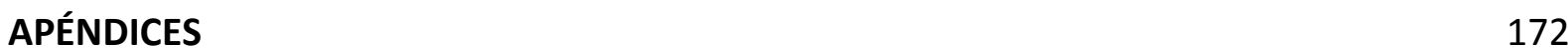




\section{RESUMEN}

El “mejillón dorado" Limnoperna fortunei (Dunker, 1857) ha invadido grandes extensiones de la Cuenca del Plata y se prevé que desarrolle diferentes estrategias reproductivas y de crecimiento en función de la latitud. Por tal motivo, es importante contar con una evaluación de variables ambientales que podrían influir sobre los parámetros biológicos y ecológicos de la especie invasora, en dos ambientes acuáticos hidrográfica y topográficamente diferentes. El primer sitio fue el río Coronda, que forma parte de la red hidrográfica del río Paraná; y el segundo, el río Santiago que forma parte del sistema estuarial del Río de la Plata, ambos pertenecientes a la Cuenca del Plata.

El objetivo en el Capítulo 1 fue establecer si existían diferencias limnológicas significativas entre los dos ambientes de estudio. Las variables ambientales medidas se sometieron a un análisis multivariado y se compararon las que describieron mejor las diferencias limnológicas significativas que se detectaron. El análisis discriminante mostró que el río Coronda tenía una mayor concentración de oxígeno disuelto y aguas significativamente más alcalinas que el río Santiago. A su vez, este último sitio se diferenció del primero por presentar una mayor conductividad, transparencia, mayor concentración de clorofila $a$ y $b$. Las diferencias de oxígeno disuelto y de los niveles de $\mathrm{pH}$ entre ambos ambientes podrían deberse principalmente al elevado nivel de contaminación que presenta el río Santiago. Los valores más altos de conductividad medidos en el río Santiago podrían resultar de los ciclos de marea, que generan una entrada regular de agua marina que avanza en dirección al río. La mayor transparencia medida en el río Santiago podría estar relacionada con la floculación de partículas en la interfase fluvio-marina. La diferencia significativa de concentración de pigmentos entre los dos sitios de estudio podría corresponderse con la diferencia de concentración de nutrientes, disponibilidad de luz, velocidad y tiempo de residencia del agua. A su vez, estaría relacionada con las floraciones algales uniespecíficas registradas en el río Santiago como consecuencia de la eutrofización.

Los períodos de baja tasa de renovación algal (> 5) en el río Santiago indicarían la adición de otros pigmentos; la presencia de productos de descomposición de la clorofila y confirmaría la calidad ambiental deficiente con respecto al río Coronda. 
Dentro de este marco ambiental, se estudió la dinámica de la única especie dulciacuícola que registra la familia Mytilidae, Limnoperna fortunei, que no es nativa de América. Esta especie es única entre los bivalvos de agua dulce de la Cuenca del Plata, ya que el tipo de reproducción y su hábito de vida son típicos de los mejillones marinos. L. fortunei posee fecundación externa y desarrollo indirecto mediante una larva planctotrófica.

El objetivo del Capítulo 2 fue estimar y comparar la densidad larval de L. fortunei en los dos cuerpos de agua de la cuenca del Río de la Plata, que se caracterizaron limnológicamente al principio, y evaluar el efecto de las variables limnológicas diferenciales sobre la densidad larval. Los análisis comparativos mostraron diferencias significativas en la densidad total de larvas presentes en esos cuerpos de agua. La densidad total fue significativamente mayor en el río Coronda respecto de la estimada en el Santiago. En ambos sitios, la densidad mostró una correlación positiva con la temperatura del agua. En los meses en los que la temperatura del agua fue menor que $15-16^{\circ} \mathrm{C}$, la densidad total de larvas fue nula o tuvo valores muy bajos, en coincidencia con el período de reposo y recuperación de la gonada luego de la liberación de gametas. Las diferencias espaciales de la densidad podrían resultar de factores reguladores como la mortalidad masiva de las postlarvas, que puede ser provocada por condiciones inadecuadas de alimento, escasez de sustratos para el asentamiento, o larvifagia interespecífica. Otro factor que podría actuar en la etapa previa al desove es la calidad limnológica desfavorable del río Santiago que habría impactado negativamente en el potencial reproductivo de la población y la subsecuente producción de gametas / larvas.

El objetivo en el Capítulo 3 fue estimar y comparar la dinámica poblacional de $L$. fortunei mediante colectores artificiales sumergidos en los dos ambientes de estudio. Los resultados mostraron variaciones de reclutamiento y densidad entre estaciones del año, así como diferencias significativas entre ambientes. Las variables lineales de las valvas estuvieron significativamente correlacionadas entre sí. Las relaciones morfométricas mostraron diferencias significativas entre las poblaciones; los mejillones del río Coronda tuvieron valvas más alargadas pero menos altas que los del río Santiago. Las tasas de crecimiento entre ambientes fueron distintas, ya que los individuos del río Coronda crecieron significativamente más rápido. Las diferencias de reclutamiento y densidad entre ambientes podrían ser generadas por diferencias en la concentración de sustancias químicas en el agua liberadas por adultos de la misma especie o por biofilms bacterianos que promueven o 
repelen el asentamiento larval. También podrían ser el resultado de la presión de consumo por parte de depredadores como larvas y adultos de peces, o por individuos de la misma especie. Las diferencias morfométricas entre ambientes pueden ser una consecuencia de las densidades poblacionales en cada sitio. El menor crecimiento estimado para la población del río Santiago estaría relacionado con el elevado nivel de eutrofización de ese ambiente.

El primer objetivo en el Capítulo 4 fue evaluar la morfometría valvar, estimar y comparar el crecimiento individual y el índice de condición de individuos colocados en jaulas experimentales sumergidas en dos ambientes de la Cuenca del Plata. El segundo fue comparar los resultados obtenidos en los Capítulos 3 y el 4 . Los resultados de esta experiencia mostraron que los individuos enjaulados produjeron una valva significativamente más alargada que los asentados en los paneles de captación. Los individuos del río Coronda tuvieron un mayor crecimiento respecto de los del río Santiago. Las regresiones alométricas del los ejemplares del río Coronda fueron significativamente mayores a las de aquellos del Santiago. Los valores máximos del índice de condición se hallaron durante los meses de invierno, con disminuciones a finales de primavera. La diferencia observada en la morfometría de los individuos enjaulados respecto de lo asentados en paneles podría ser consecuencia de una mayor densidad poblacional en el interior de las jaulas, debido a las condiciones de mayor protección frente a potenciales depredadores. Los resultados de la comparación del crecimiento entre ambientes concuerdan con lo observado en el capítulo anterior y permiten reafirmar que esta diferencia podría deberse, principalmente, a la calidad ambiental de los sitios de muestreo. A su vez, los resultados del análisis de condición en este estudio apoyan lo planteado anteriormente, por cuanto las condición ambiental desfavorable en el río Santiago también podrían ser un factor determinante en la condición fisiológica de los mejillones y el responsable de las diferencias de peso observadas. Los aumentos del índice de condición (relación entre el peso del individuo y el volumen corporal) en los meses de invierno sería el resultado de un período de recuperación reproductiva, con incremento progresivo del volumen gonadal, mientras que las disminuciones observadas en primaveraverano serían el resultado de los eventos de desove. 


\section{ABSTRACT}

The 'golden mussel' Limnoperna fortunei (Dunker, 1857) has invaded great extentions of del Plata Basin and it is likely that this species could develop different reproductive and growth strategies depending on latitude. Thus, it was essential to evaluate how environmental variables influence biological and ecological aspects of this invasive species in two hydrological and topographical different water bodies. The first study site was Coronda River which belongs to Paraná sub-basin; the second, Santiago River which is associated to the estuarine system of Río de la Plata Basin. Both study sites are located in lower area of the Plata Basin.

The aim of Chapter 1 was to establish if there were significant limnological differences between both study sites. Environmental variables were analized by a multivariate analysis and those variables which described better the limnological differences were compared. Discrimant analysis showed that Coronda River had a higher dissolved oxygen and pH level than Santiago River. In turn, the latter site had a higher conductivity, and a higher chlorophyll $a$ and $b$ concentration. Differences in dissolved oxygen and $\mathrm{pH}$ levels between both environments could be due to the high contamination level and the low water renewal rate in Santiago River. Higher values of conductivity in this site would be due to tidal influence produced by the entry of marine water towards the estuary. The higher values of transparency observed in Santiago River could be a result of the floculation process of the fluvial-marine interface. The difference in pigment concentration observed between both sites could be due to nutrient concentration, light availability, hydrodynamics and time residence of water. Likewise, it could be related to unspecific algal blooms registered in Santiago River as a result of a highly eutrophized habitat. The annual periods of lower algal turnover rate $(>5)$ estimated in Santiago River could indicate addition of other pigments, presence of decomposition products of chlorophyll and support the idea that this site has poorly environmental quality. In this environmental context, the population dynamic of the only freshwater species of the family Mytilidae, Limnoperna fortunei, was studied. This species is unique among freshwater bivalves of the Río de la Plata Basin since it has a typically marine reproduction and life history. It has external fertilization and a larval cycle that completely develops in aquatic milieu. Gametogenic process and spawning in Bivalvia 
are related to changes in environmental temperature. Also, there are other geographic and environmental factors wich may affect distribution, abundance and reproductive activity of mussels, e.g. dissolved oxygen, transparency, salinity, food supply and environmental disruption. Studies of the reproductive cycle of $L$. fortunei influenced by different environmental conditions was proposed as an important tool to improve the knowledge about its ecology, invasion dynamics and impacts, and to evaluate temporal and spatial variations which define this invasive species.

The aim of Chapter 2 was to estimate and to compare larval density of L. fortunei from both water bodies from the Río de la Plata Basin, and to evaluate the influence of such environmental variables upon larval density. Comparative analysis showed that total density was significantly higher in Coronda River than in Santiago River. In both sites, total density was positively correlated with water temperature. Those months where water temperature was lower than $15-16^{\circ} \mathrm{C}$, larvae density was null or low probably related to resting period and gonadal tissue recovery after spawning. The lower spatial density at Santiago River could be a consequence of biotic and abiotic factors like the lack of suitable substrate for settlement, intra larvifagy and massive postlarval mortality, which could be promoted by poor quality food and environmental conditions. Another factor that may act before spawning is the poor water quality of Santiago River, which could negatively affect reproductive potential and gamete / larvae production.

The aim of Chapter 3 was to estimate and to compare population dynamics of $L$. fortunei settled in artificial collectors in both study sites. Results showed significant temporal variations in recruitment and density between sites. Linear measurements were highly correlated between them. Morphometric ratios showed significant differences between mussel populations; mussels from Coronda River had a more elongate but less height shell than those from Santiago River. Growth rates between sites were different since individuals from Coronda grew significantly faster. Differences on recruitment and density between sites could be related to chemical cue concentration in water released by conspecific adults or bacterial biofilms wich promote or repel larval settlement. Likewise, it could be related to selective predation pressure caused by larval and adult fishes, or conspecific individuals. Morphometric differences between sites could be a consequence of population densities in each site. The lower growth rates estimated in individuals from Santigo River would be related to higher level of eutrophization in this site. 
The first goal in Chapter 4 was to evaluate shell morphometry, and to estimate and compare individual growth and condition index of a group of individuals placed inside experimental cages in both water bodys from the Río de la Plata Basin. The second goal was to compare results obtained in Chapter 3 and 4 . Results showed that encaged individuals had a significant more elongate shell than individuals from artificial collectors. Individuals from Coronda grew faster than those from Santiago River. Allometric regressions estimated for Coronda were significantly higher than Santiago. Higher index condition values were found during winter, and then, in late spring, a decreased was observed. Differences on morphometry between encaged and free-living individuals could be a consequence of crowding effect inside cages than in artificial collectors. Comparative results of mussel growth between sites agree with those observed in the previous chapter and support the assumption that differences in growth could be mainly due to differences in water quality from both study sites. Results on condition index also support the hypothesis of weight loss caused by poor water quality conditions in Santiago River. Increase in index condition during winter would be a consequence of the resting period with a progressive increase in gonadal volume, whereas decrease observed during spring-summer would be a consequence of spawning events. 
ANTECEDENTES

GENERALES 


\section{ANTECEDENTES GENERALES}

Una consecuencia de la globalización es la transformación estructural del ambiente natural. La escala geográfica, la frecuencia y el número de especies involucradas en ese cambio ha crecido enormemente en relación directa con la expansión del transporte y del comercio mundial (Darrigran, 2002). Los problemas ambientales se incrementan diferencialmente debido a alteraciones de la calidad del agua, por procesos de polución y eutrofización, al aumento de la movilidad biótica y a la antropocoria. La introducción de especies es la principal causa de pérdida de biodiversidad a nivel global (Bucher et al., 1993; Carlton, 1996).

La invasión de especies exóticas es una real amenaza para la integridad de los sistemas acuáticos. El agua de lastre para estabilizar y dar maniobrabilidad a los barcos de gran porte, es un eficiente medio para la dispersión de organismos marinos y dulciacuícolas. Alrededor de 12 mil millones de toneladas de agua de lastre, en la que se registraron 4.500 especies acuáticas diferentes, son transportadas anualmente por todo el mundo (Oliveira et al., 2006).

Limnoperna fortunei (Dunker, 1857) es un bivalvo de agua dulce y estuarial, originario de China y sudeste de Asia. En 1965, invadió Hong Kong, luego Japón y Taiwán en la década de 1990 (Pastorino et al., 1993; Darrigran, 2002; Orensanz et al., 2002; Boltovskoy et al., 2006, 2009). Se estima que la introducción de L. fortunei en América fue través de agua de lastre de buques transoceánicos (Fig. 1) (Darrigran \& Pastorino, 1995).

El primer registro de esta especie en la región Neotropical fue en 1991 en el Río de la Plata, donde la densidad inicial fue estimada en $4-5$ ind. $\mathrm{m}^{-2}$. Desde su registro inicial, esta especie incrementó su densidad en los sitios del primer asentamiento y amplió significativa-

mente su distribución. En 1992 la densidad alcanzó los 30.000 ind. $\mathrm{m}^{-2}$ y en 1993 los 82.000 ind. $\mathrm{m}^{-2}$ (Pastorino et al., 1993; Orensanz et al., 2002). Ahora es la única especie de bivalvo epifaunal de agua dulce que vive en Sudamérica, con una densidad de 150.000 ind. $\mathrm{m}^{-2}$ en ambientes naturales (Darrigran \& Pastorino, 2004). En 2003, este mejillón ya había colonizado prácticamente toda la cuenca del Río de la Plata, extendiendo su rango hasta el Pantanal a través del río Paraguay, así como a los estados de São Paulo y Minas de Gerais, ambos en Brasil (Boltovskoy et al., 2006; Darrigran \& Mansur, 2006). 


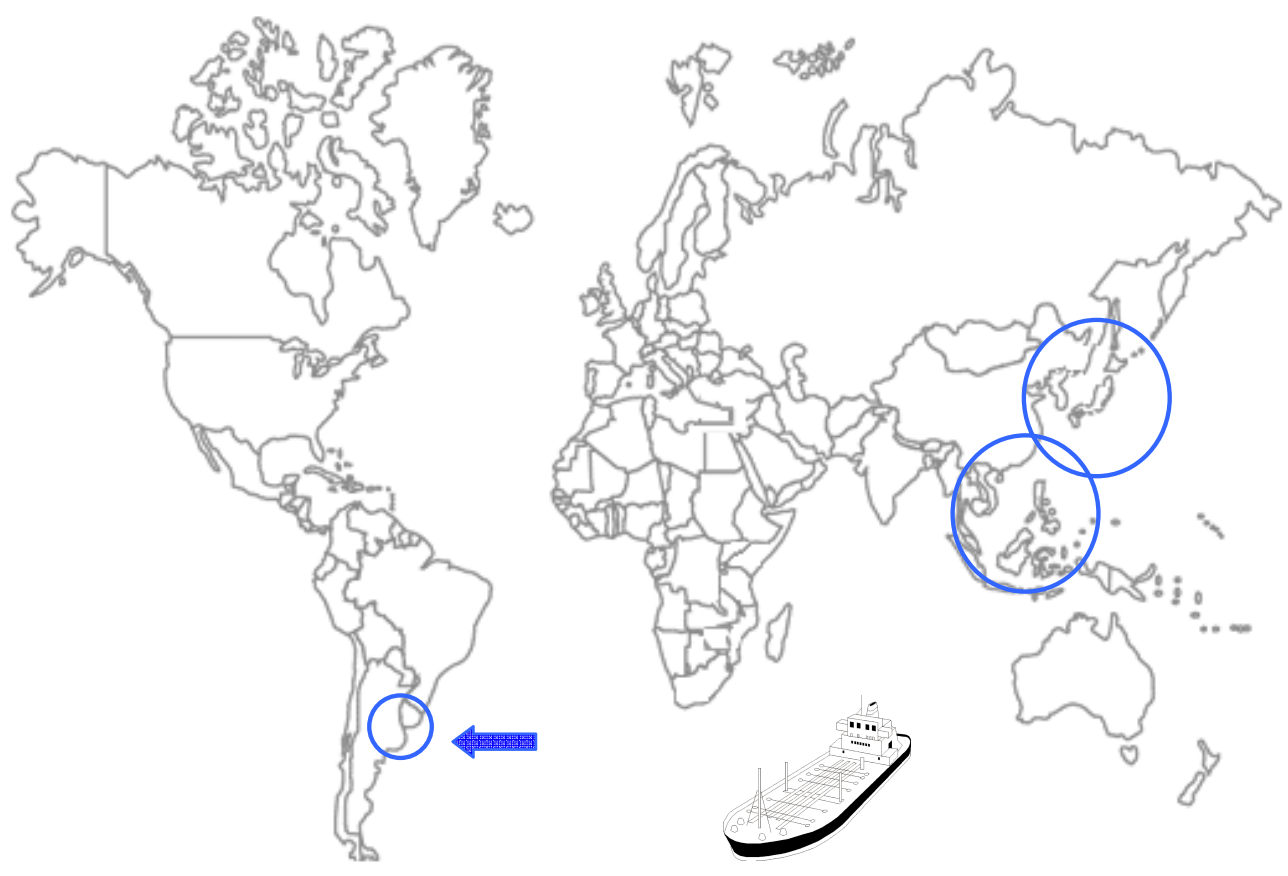

Figura 1. Introducción de Limnoperna fortunei desde su lugar de origen hasta América del Sur por medio del agua de lastre de buques de carga transoceánicos.

Limnoperna fortunei pertenece a la familia Mytilidae $y$, aunque está taxonómicamente separada a nivel de subclase (Peteriomorphia), comparte importantes aspectos biológicos y ecológicos con el bivalvo Dreissena polymorpha (Pallas, 1771) (Heterodonta: Dreissenidae), conocido como "zebra mussel" en el hemisferio norte (Karatayev et al., 2007; Rumi et al., 2008). Ambas especies son atípicas por dulciacuícolas, aunque el tipo de reproducción y su historia de vida sean propios de mejillones marinos (Cataldo \& Boltovskoy, 2000; Cataldo et al., 2005; Darrigran \& Damborenea, 2005; Oliveira et al., 2006; Karatayev et al., 2007; Boltovskoy et al., 2006, 2009). El hábito de vida de L. fortunei es epifaunal bisado, mientras que los bivalvos de agua dulce nativos de la Cuenca del Plata son infaunales (Darrigran, 2002). Esta característica le permite adherirse a sustratos duros naturales como troncos, vegetación acuática y fondos limo-arenosos compactos. También puede hacerlo sobre sustratos artificiales como murallones, espigones, caños, plásticos, vidrios y otros. Es una especie gonocórica, de fecundación externa, con desarrollo indirecto a través de una larva planctónica (Cataldo \& Boltovskoy, 2000; Cataldo et al., 2005; Darrigran \& Damborenea, 2005; Boltovskoy et al., 2006, 2009; Oliveira et al., 2006; Karatayev et al., 2007). Se han detectado casos de hermafrodistimo ocasional (Darrigran et al., 1998a). 
El crecimiento individual de este bivalvo está definido por una longitud máxima teórica de valva $\left(L_{\infty}\right)$ de $36 \mathrm{~mm}$ y una longevidad estimada para regiones templadas de 2 a 3 años (Iwasaky \& Uryu, 1998; Boltovskoy \& Cataldo, 1999; Maroñas et al., 2003). La longitud máxima observada en América del Sur fue de 49 mm, en el río Santa Lucía, República Oriental del Uruguay (Darrigran \& Ezcurra de Drago, 2000). En China central, se reportó para esta especie una longevidad $>10$ años, mientras que en Corea, los estudios de crecimiento estimaron una longevidad de 4 a 5 años, con una longitud máxima de $60 \mathrm{~mm}$ (Iwasaky \& Uryu, 1998).

La dispersión geográfica de L. fortunei está facilitada por la velocidad de corriente de agua que transporta los estadios larvales planctónicos; que a su vez, se fijan a sustratos naturales móviles o sobre sustratos artificiales, o también pueden ser dispersados por zoocoria, como embarcaciones de distinto tipo. El mecanismo de dispersión natural más efectivo es el estadio larval libre ya que se moviliza y dispersa a favor de la corriente (Darrigran \& Damborenea, 2005). Su condición de organismo eurioico le permite dispersarse rápida y efectivamente en distintos tipos de cuerpos de agua, como pone en evidencia su amplia distribución en lagos y ríos. Debido a su amplia tolerancia a la salinidad, este bivalvo es común en las aguas salobres de los estuarios (Ricciardi, 1998).

Limnoperna fortunei genera un impacto ambiental similar al que produce Dreissena polymorpha (Pallas, 1771) en ambientes naturales y humanos de América del Norte, representando un nuevo problema ambiental y económico en los cuerpos salobres y de agua dulce de América del Sur (Boltoskoy \& Cataldo, 1999; Darrigran, 2002). La presencia de este bivalvo en la región Neotropical ha generado un impacto negativo en las comunidades de gasterópodos y bivalvos nativos, y ha modificado la dieta de la fauna ictíca (Darrigran et al., 1998a; Montalto et al., 1999; Penchaszadeh et al., 2000; Cataldo et al., 2002; Orensanz et al., 2002; Darrigran \& Pastorino, 2004; Paolucci et al., 2007, 2009, 2010). Previamente a la invasión, la fauna asociada a sustratos duros era de baja densidad y escasa riqueza. La elevada densidad de L. fortunei y su hábito de vida epifaunal genera microambientes que repercuten en la colonización de ciertas especies y en el desplazamiento de otras (Darrigran et al., 1998b; Montalto et al., 1999; Penchaszadeh et al., 2000; Cataldo et al., 2002; Orensanz et al., 2002; Darrigran \& Pastorino, 2004; Paolucci et al., 2007, 2009, 2010; Darrigran \& Damborenea, 2011). Otro impacto causado por este mejillón sobre la fauna acuática es el 
asentamiento de larvas sobre las valvas de otras especies. La colonización epizoica sobre otros bivalvos es un impacto directo y severo que ocasiona el desplazamiento de bivalvos nativos. La introducción de L. fortunei provocó la eliminación de diferencias regionales en la fauna bentónica, en detrimento de la biodiversidad nativa (Darrigran \& Damborenea, 2005). Asimismo, L. fortunei genera un fuerte impacto negativo en el ambiente humano, que se hace más evidente en las obstrucciones de tuberías y filtros de las plantas potabilizadoras de agua e hidroeléctricas. Esta situación implica la interrupción del servicio para limpieza y cambio de los filtros y tuberías, con elevados costos operativos (Ricciardi, 1998; Boltoskoy \& Cataldo, 1999; Darrigran, 2002; Orensanz et al., 2002).

La mayoría de los estudios relacionados con la biología de L. fortunei se han restringido a sitios específicos, pero es necesario desarrollar experiencias a campo y laboratorio que permitan evaluar el efecto de los factores ambientales en la dinámica poblacional de este bivalvo. También, es esencial realizar estudios comparativos ya que los impactos causados por estas especies varían espacial y temporalmente (Iwasaky \& Uryu, 1998; Boltovskoy et al., 2009). Por tal motivo, es importante contar con una evaluación de variables ambientales que podrían influir sobre los parámetros biológicos y ecológicos de la especie invasora. Por esta razón, las experiencias desarrolladas para esta tesis doctoral pretenden evaluar y comparar la dinámica poblacional de L. fortunei en dos ambientes acuáticos del área inferior de la cuenca del Río de la Plata, hidrológica y topográficamente diferentes. 


\section{CAPÍTULO 1}




\section{CAPÍTULO 1}

\section{ANÁLISIS COMPARATIVO DE LAS CONDICIONES LIMNOLÓGICAS ENTRE DOS AMBIENTES ACUÁticos DE LA CUENCA DEL PLATA: Río Santiago (La Plata) y Río Coronda (Santo Tomé - Santa Fe)}

\subsection{INTRODUCCIÓN}

En extensión, la Cuenca del Plata es la segunda cuenca hidrográfica de América del Sur (3.100.000 $\left.\mathrm{km}^{2}\right)$, después de la cuenca del Amazonas. Su drenaje ocupa parte de cinco países: Argentina, Bolivia, Brasil, Paraguay y Uruguay. Está conformada por tres subcuencas principales: la del Paraná, la del Paraguay y la del Uruguay (López Laborde, 1998; Maheu et al., 2003). La subcuenca del río Paraguay se extiende en sectores de Argentina, Brasil, Bolivia y Paraguay. La subcuenca del río Uruguay tiene un área menor e incluye áreas de Argentina, Brasil y Uruguay.

La subcuenca del Paraná es la más importante de las tres. Su hidrología se caracteriza por una época más lluviosa (diciembre a febrero) y una época más seca (junio a agosto). En promedio, el nivel del agua varía entre 2 y 3 metros, provocando inundaciones estacionales de la planicie aluvial. Estos eventos de inundación van acompañados de un intercambio de gran cantidad de agua y materia en suspensión entre la planicie de inundación y el canal principal del río (Depetris \& Kempe, 1993). La subcuenca del Paraná tiene una longitud de 4.000 km, incluyendo su principal afluente, el río Paranaíba, y se extiende desde aproximadamente los $15^{\circ} \mathrm{S}$ hasta su desembocadura en el estuario del Río de la Plata a $34^{\circ} \mathrm{S}$, donde descarga más de 470 km³ de agua por año (Depetris \& Kempe, 1993; López Laborde, 1998).

El Río de la Plata es un gran sistema fluvial-marino ubicado en la parte sudeste de América del Sur. Nace de la confluencia del brazo principal del Paraná con el río Uruguay, abriéndose en un estuario con forma de embudo. Tiene una longitud de $300 \mathrm{~km}, 40 \mathrm{~km}$ de ancho en la parte más estrecha y $200 \mathrm{~km}$ en su desembocadura al mar. La superficie total del río se estima en unos $30.000 \mathrm{~km}^{2}$ y descarga sus aguas directamente al océano Atlántico sin ningún tipo de barrera en su desembocadura (Boschi, 1988). El estuario del Río de la Plata, 
por su ubicación y características geomorfológicas, es un sistema relevante en el litoral de la provincia de Buenos Aires (Argentina) y del Uruguay, tanto desde el punto de vista físico (agua, clima, sales, sedimentos, etc.) como por su significado ecológico (Ringuelet, 1967; Boschi, 1988). Sus características hidrográficas primarias muestran una gran variabilidad estacional en salinidad y caudal de agua. Tiene salinidad baja, pero variable, y una alta turbidez que refleja la gran carga de sedimento de las cuencas fluviales, que fluyen hacia el sistema y de actividades terrestres aguas arribas (Kurucz et al., 1998). El aporte de agua dulce de la cuenca, a través de los ríos Paraná y Uruguay, es de unos $20.000 \mathrm{~m}^{3} \mathrm{seg}^{-1}$, aproximadamente (Boschi, 1988). El gradiente de aguas salobres, las partículas en suspensión y sedimentos de la cuenca, que son arrastrados por el río hasta la zona estuarial, así como las corrientes de mareas y de derrame, crean un ambiente muy particular (Boschi, 1988). Teniendo en cuenta las características de sus aguas dulces, salobres y marinas, el origen y la calidad de los sedimentos y sus componentes florísticos y faunísticos, el Río de la Plata puede dividirse en tres zonas (interna, media y externa), que tienen cierta superposición y oscilación (Boschi, 1988).

Para el desarrollo de esta tesis se seleccionaron dos ambientes acuáticos hidrográfica y topográficamente diferentes: el río Coronda, que forma parte de la red hidrográfica del Paraná; y el río Santiago, que forma parte del sistema estuarial del Río de la Plata, ambos pertenecientes a la Cuenca del Plata.

\subsection{1 Área de estudio}

El primer sitio de muestreo en el río Coronda ( $31^{\circ} 41^{\prime} 26,88^{\prime \prime} \mathrm{S}-60^{\circ} 44^{\prime} 34,08^{\prime \prime}$ O) se muestra en la figura 1.1.1. Este río nace de la confluencia de la Laguna Setúbal o Guadalupe (que es alimentada por el Paraná a través del Arroyo Leyes), el Arroyo Santa Fe y el Canal de Acceso al Puerto de Santa Fe. Toda el agua proviene, en definitiva, del cauce principal del Paraná. La confluencia se produce a la latitud de la ciudad de Santa Fe. El tramo ubicado entre la desembocadura de la Laguna Setúbal y la desembocadura del río Salado del Norte, lleva el nombre de río Santa Fe. A partir de la desembocadura del Salado del Norte, recibe la denominación de río Coronda, nombre que mantiene hasta aguas abajo de Puerto Gaboto (Santa Fe), donde desemboca en el cauce principal del Paraná, luego de un recorrido de aproximadamente 120 km (Edmundo C. Drago, comunicación personal). El segundo sitio de muestreo se ubicó en el sistema río Santiago ( $34^{\circ} 51^{\prime} 1,46^{\prime \prime} \mathrm{S}-57^{\circ} 53^{\prime} 28,23^{\prime \prime}$ O), donde opera 
el Astillero Río Santiago, junto a los canales de acceso al puerto de La Plata. Este sistema es afluente del Río de la Plata y está alimentado por arroyos de menor jerarquía: El Gato, Saladero, Borzani, La Fama y Doña Flora, canales del Este y del Oeste y barranco Andaluza (Kurucz et al., 1998) (Fig. 1.1.2).
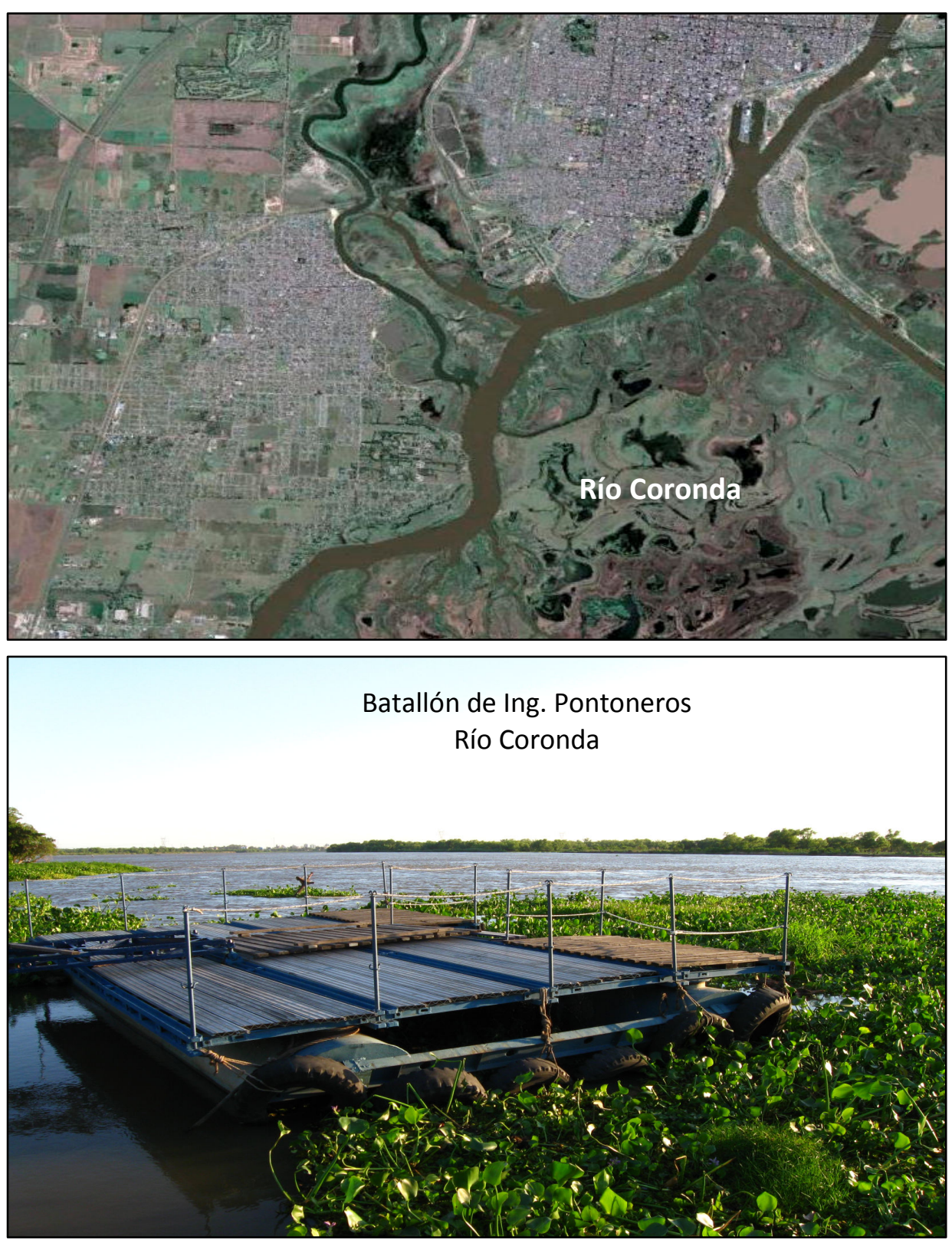

Figura 1.1.1. Río Coronda - Santo Tomé, provincia de Santa Fe. Sitio de estudio, Batallón de Ingenieros Pontoneros, Santo Tomé, provincia de Santa Fe ( $\left.31^{\circ} 41^{\prime} 26,88^{\prime \prime} \mathrm{S}-60^{\circ} 44^{\prime} 34,08^{\prime \prime} 0\right)$. 

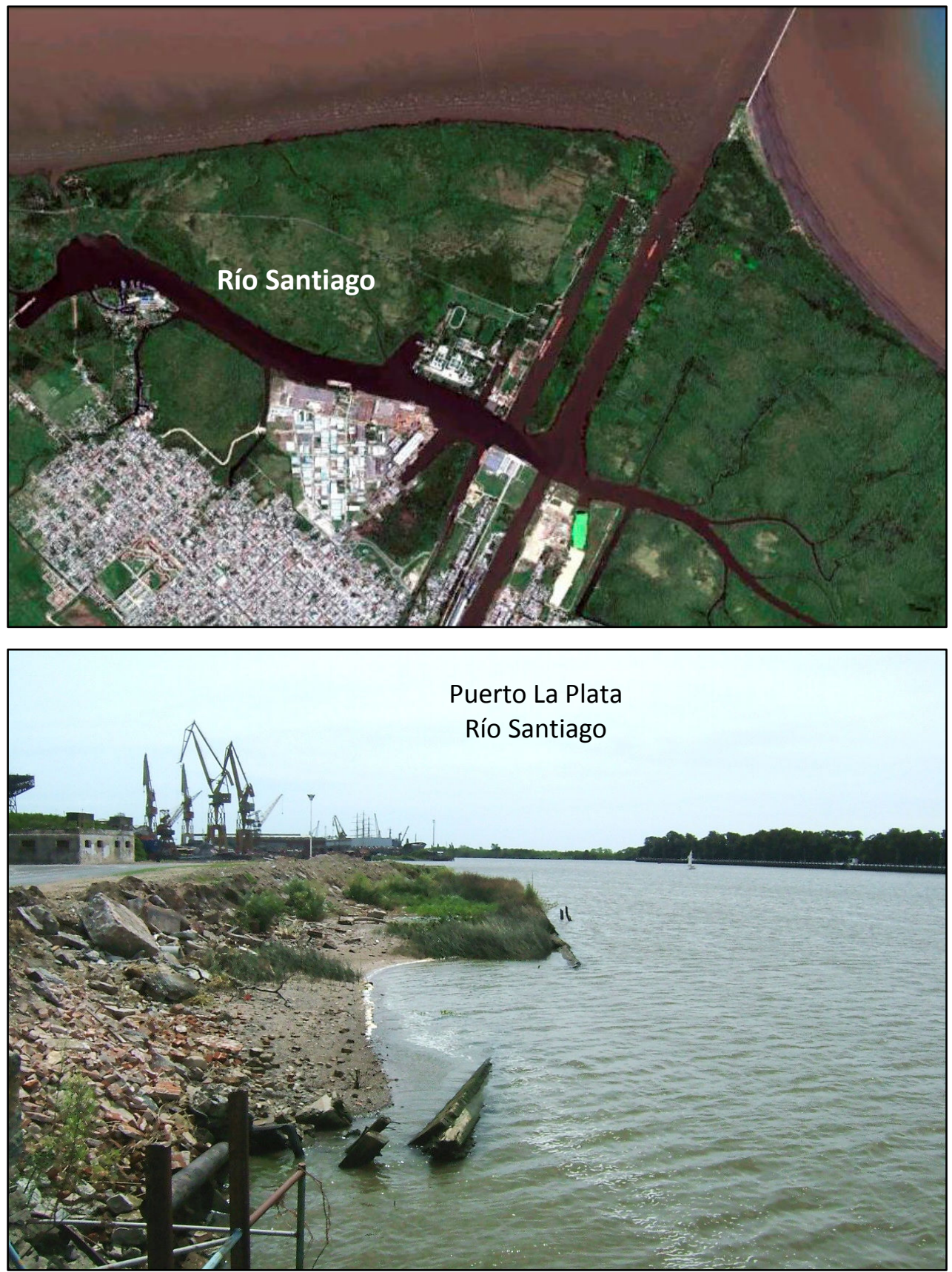

Figura 1.1.2. Sistema hidrográfico del Río Santiago - La Plata, provincia de Buenos Aires. Sitio de estudio: Puerto de La Plata, río Santiago, La Plata ( $34^{\circ} 51^{\prime} 1,46^{\prime \prime}$ S - $57^{\circ} 53^{\prime} 28,23^{\prime \prime}$ O). 


\subsubsection{OBJETIVOS}

Para el desarrollo de este capítulo se plantearon los siguientes objetivos:

- Determinar las condiciones fisicoquímicas y estimar la concentración de pigmentos fotosintéticos (clorofilas $a, b, c$ y feofitina) en dos ambientes acuáticos de la cuenca del Plata.

- Establecer si existen diferencias limnológicas significativas entre los dos ambientes de estudio.

- Determinar qué variables limnológicas describen mejor esas diferencias.

\subsubsection{HIPÓTESIS}

La hipótesis planteada para este capítulo es que existen diferencias significativas entre las variables ambientales (conductividad, $\mathrm{pH}$, transparencia, oxígeno disuelto, concentración de clorofila) entre los sitios de estudio en los ríos Coronda y Santiago.

La información obtenida en esta sección se utilizará en los capítulos siguientes referidos a la dinámica poblacional de Limnoperna fortunei en los ríos Coronda y Santiago. 


\subsection{MATERIALES Y MÉTODOS}

En el río Coronda los muestreos se realizaron de marzo de 2007 a febrero de 2009, mientras que en el río Santiago los muestreos ocurrieron desde abril de 2007 a abril de 2009 (Tabla 2.1).

Tabla 2.1. Fechas de muetreos en los sitios de estudio.

\begin{tabular}{|c|c|c|c|c|c|}
\hline \multicolumn{3}{|c|}{ Río Coronda } & \multicolumn{3}{|c|}{ Río Santiago } \\
\hline 2007 & 2008 & 2009 & 2007 & 2008 & 2009 \\
\hline 30-Mar & $12-\mathrm{Feb}$ & 12-Feb & 26-Mar & 01-Feb & 09-Feb \\
\hline 30-Abr & 17-Mar & & 02-May & 06-Feb & 06-Mar \\
\hline 05-Jun & 24-Abr & & 06-Jun & $25-F e b$ & 12-Mar \\
\hline 11-Jul & 12-Jun & & 18-Jul & 13-Mar & 31-Mar \\
\hline 23-Ago & 31-Jul & & 26-Jul & $03-A b r$ & $15-\mathrm{Abr}$ \\
\hline 20-Sep & 21-Ago & & 09-Ago & 14-Abr & \\
\hline 30-Oct & 25-Sep & & 18-Ago & 23-Abr & \\
\hline 21-Dic & 20-Nov & & 21-Ago & 08-May & \\
\hline & 17-Dic & & 28-Ago & 29-May & \\
\hline & & & 11-Sep & 10-Jun & \\
\hline & & & 25-Sep & 08-Jul & \\
\hline & & & 10-Oct & 14-Ago & \\
\hline & & & 01-Nov & 19-Ago & \\
\hline & & & 06-Nov & 23-Sep & \\
\hline & & & 22-Nov & $22-$-Oct & \\
\hline & & & 27-Nov & $13-\mathrm{Nov}$ & \\
\hline & & & 12-Dic & 26-Nov & \\
\hline & & & 18-Dic & 05-Dic & \\
\hline & & & 24-Dic & 18-Dic & \\
\hline
\end{tabular}

Para estimar la concentración de clorofila se recolectaron 1 a 2 litros de agua en botellas de plástico de color negro para evitar la fotoxidación de los pigmentos. En el laboratorio, se pasaron las muestras por filtros de fibra de vidrio tipo Whatman $\operatorname{GF} / \mathrm{C}(0,7$ $\mu \mathrm{m} ; 47 \mathrm{~mm}$ de diámetro). Los filtros de fibra de vidrio dan los mejores resultados por su capacidad de filtración (1 a 2 litros en 10 minutos) y por su eficiente retención (algas < 0,2 $\mu \mathrm{m})$ (Loez, 1995). El filtrado se efectuó con ayuda de una bomba de vacío. Las muestras filtradas se conservaron en freezer $\left(-10^{\circ} \mathrm{C}\right)$ por más de 24 horas, cubiertas con un papel de aluminio, para favorecer la ruptura de las paredes celulares. Para preparar el extracto de clorofila, se retiró el filtro del freezer y se trituró en un mortero de porcelana, agregando 12$15 \mathrm{ml}$ de solución acuosa de acetona al $90 \%$. La muestra procesada se transfirió a tubos de ensayo para centrífuga de $15 \mathrm{ml}$ de capacidad con tapa a rosca y se guardó a $4^{\circ} \mathrm{C}$ durante 24 
horas. Este procedimiento produce que las células algales se rompan y los pigmentos se disuelvan en la acetona. Transcurridas 24 horas, se centrifugaron los tubos en una centrífuga clínica (Rolco 2070) a 1800-2000 rpm durante 15 minutos, para que precipitaran los restos del filtro (APHA, 1998). La estimación de la concentración de los pigmentos fotosintéticos por metro cúbico de agua se realizó por el método propuesto por APHA (1998). Para calcular la concentración de clorofila activa e inactiva presentes en cada muestra se utilizaron las ecuaciones 1.1 y 1.2 , respectivamente (APHA, 1998):

Clorofila a $\left(\mathrm{mg} \mathrm{m}^{-3}\right)=\frac{26,7\left(664_{\text {antes }}-665_{\text {después }}\right)}{V_{2(L)}} V_{1(\mathrm{ml})}$

Feofitina a $\left(\mathrm{mg} \mathrm{m}^{-3}\right)=\frac{26,7\left[1,7\left(665_{\text {después }}\right)-664_{\text {antes }}\right]}{V_{2(L)}} V_{1(\mathrm{ml})}$

donde:

- $\mathrm{V}_{1}=$ Volumen del extracto en $\mathrm{ml}$;

- $\mathrm{V}_{2}=$ volumen final de la muestra filtrada en litros;

- $\mathrm{L}=$ ancho de la celda;

- $664_{\text {antes }}=$ absorbancia del extracto antes de acidificarlo;

- $665_{\text {después }}=$ absorbancia del extracto después de acidificarlo.

Para determinar la concentración de clorofila $a, b$ y $c$ que había en el extracto, se utilizaron las siguientes ecuaciones propuestas del método tricromático (APHA, 1998):

$\mathrm{Cl} a=11,85\left(\mathrm{DO}_{664}\right)-1,54\left(\mathrm{DO}_{647}\right)-0,08\left(\mathrm{DO}_{630}\right)$

$C l b=21,03\left(\mathrm{DO}_{664}\right)-5,43\left(\mathrm{DO}_{647}\right)-2,63\left(\mathrm{DO}_{630}\right)$

$C l c=24,52\left(\mathrm{DO}_{664}\right)-7,60\left(\mathrm{DO}_{647}\right)-1,67\left(\mathrm{DO}_{630}\right)$

donde:

- $\mathrm{DO}_{664,647,630}$ : densidades ópticas corregidas (para una celda de $1 \mathrm{~cm}$ de paso de luz) a las correspondientes longitudes de onda;

- $\quad C l a, b, c$ : concentraciones de clorofila $a, b, c$, respectivamente, expresadas en $\mathrm{mg} \mathrm{L}^{-1}$. 
A partir de las concentraciones de los pigmentos en el extracto, obtenidas con las ecuaciones 1.3, 1.4 y 1.5, se calculó la cantidad de pigmentos por unidad de volumen mediante la ecuación 1.6:

$$
C l a, b, c\left(m g . m^{-3}\right)=\frac{C l a, b, c}{V_{2(L)}} V_{1(m /)}
$$

El índice de Margalef $\left(\mathrm{DO}_{430} / \mathrm{DO}_{665}\right)$ permite una aproximación al estado de madurez de la asociación algal. Un valor bajo del índice $(\approx 2)$ refleja un predominio absoluto de la clorofila $a$, dando idea de una asociación algal joven, con alta productividad por unidad de biomasa. Una comunidad madura, con baja tasa de renovación, produce valores del índice entre 5 y 7 (Margalef, 1983).

Con un multímetro digital Sper Scientific - 850081, en ambos sitios de muestreo se midieron in situ los siguientes parámetros fisicoquímicos del agua:

- temperatura del agua $\left({ }^{\circ} \mathrm{C}\right)$;

$-\mathrm{pH}$;

- concentración de oxígeno disuelto $\left(\mathrm{mg} \mathrm{L}^{-1}\right)$;

- conductividad $\left(\mathrm{mS} \mathrm{cm}^{-1}\right)$;

- $\quad$ sólidos disueltos totales $\left(\mathrm{mg} \mathrm{L}^{-1}\right)$.

La saturación de oxígeno disuelto (\%) se estimó gráficamente según Wetzel \& Likens (1991). La presencia del ión calcio en el agua posee una capacidad buffer contra los cambios de pH. Su concentración se determinó por el método de EDTA (APHA, 1998; Trichkova et al., 2008). La transparencia del agua se midió con un disco Secchi (Edmonson, 1980).

Los datos se transformaron a $\ln (x)$ y $\ln (x+1)$ para aproximarlos a condiciones de normalidad y homocedasticidad (Zar, 1996). Luego, se realizó un test de Student para comparar los valores medios de las variables ambientales de cada fecha de muestreo y de cada ambiente. El grado de asociación entre las variables medidas en cada ambiente se analizó mediante índices de correlación de Pearson (Zar, 1996).

Los parámetros fisicoquímicos se ordenaron mediante un Análisis Discriminante (SPSS Stastistics 17.0) (Brown, 1988; Hair et al., 1999), en el que las variables ambientales actuaron como variables explicativas de las diferencias existentes entre los dos niveles de la variable categórica (sitios de muestreo) definidas a priori. 


\subsection{RESULTADOS}

La temperatura del agua presentó variaciones estacionales. La amplitud térmica fue de aproximadamente $19^{\circ} \mathrm{C}$, oscilando entre 9 y $28^{\circ} \mathrm{C}$. El test de Student no encontró diferencias significativas entre los dos ambientes ( $t=0,650 ;$ g.I. $=39 ; p=0,520)$ (Fig. 1.3.1, Tabla 1.1).

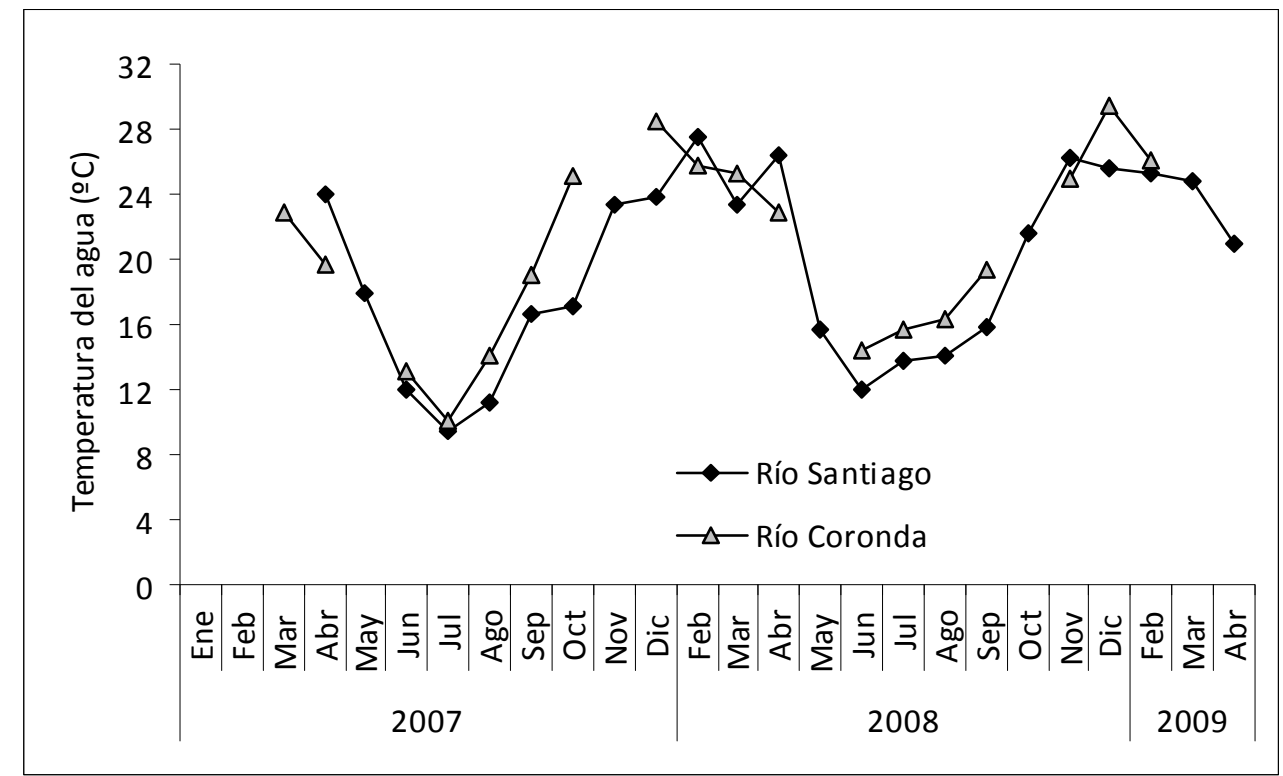

Figura 1.3.1. Variación de la temperatura del agua en los sitios de muestreo.

La saturación y concentración de oxígeno disuelto fueron significativamente distintas entre los dos ambientes (Tabla 1.2). En el río Santiago se registró una saturación promedio para todo el período de estudio del 55,44 $\pm 18,97 \%$ y una concentración media de 5,15 \pm $1,70 \mathrm{mg} \mathrm{L}^{-1}$; los valores máximos se obtuvieron en mayo de 2007 (115\% y 10,3 mg L'respectivamente; Tabla 1.1). En el río Coronda se estimó una saturación promedio más elevada $\left(98,56 \pm 26,34 \%\right.$ ), y una concentración promedio de 8,63 $\pm 2,44 \mathrm{mg} \mathrm{L}^{-1}$ (Fig. 1.3.2); los valores máximos de saturación y concentración se registraron en abril y junio de 2007 (170\% y $14,3 \mathrm{mg} \mathrm{L}^{-1} ; 160 \%$ y $14,8 \mathrm{mg} \mathrm{L}^{-1}$ respectivamente; Tabla 1.1 ). 

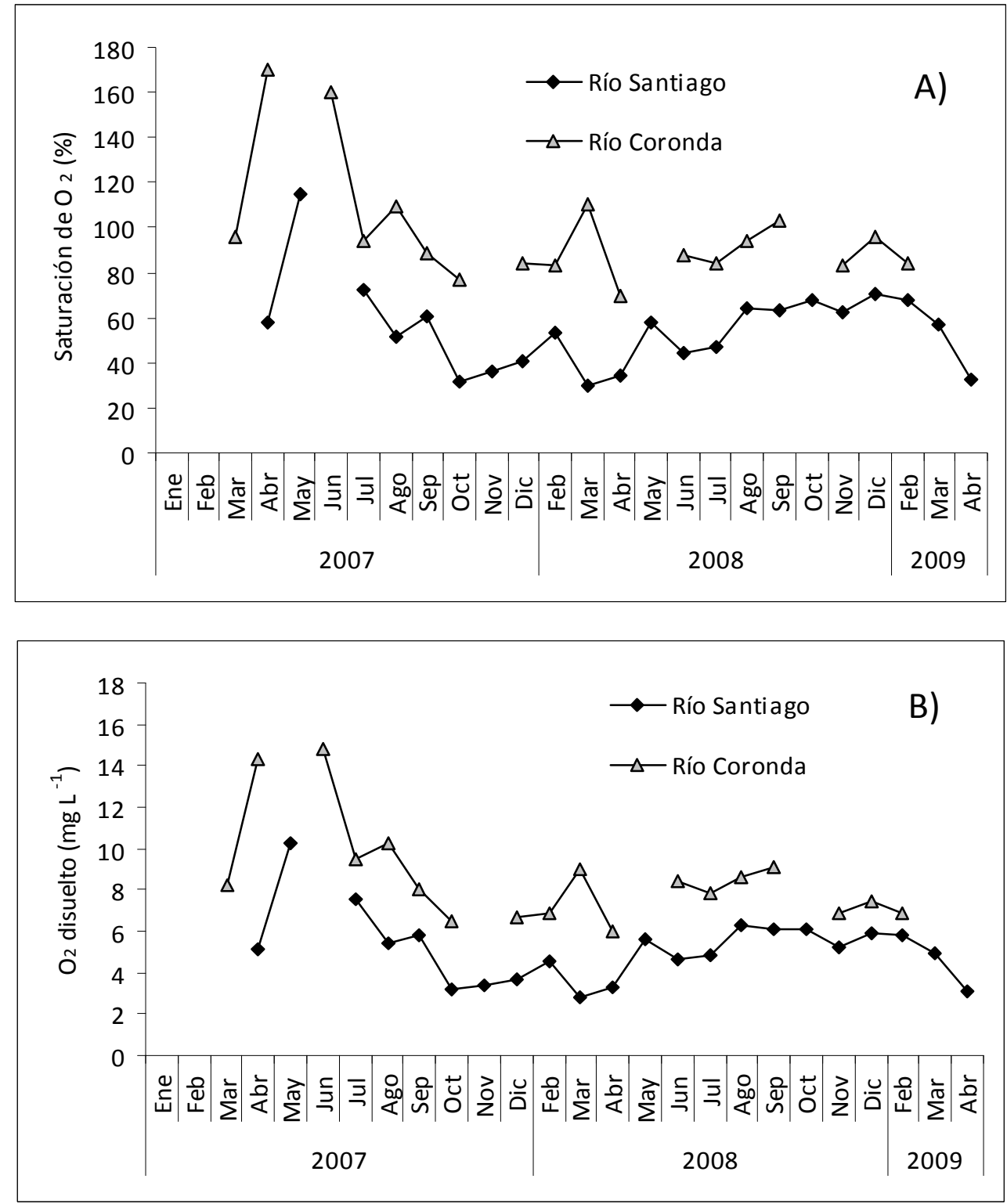

Figura 1.3.2. Variación del oxígeno disponible en el agua en los sitios de muestreo. A) saturación de oxígeno (\%); B) oxígeno disuelto $\left(\mathrm{mg} \mathrm{L}^{-1}\right)$.

Los valores de conductividad y sólidos disueltos totales (TDS) fueron significativamente diferentes entre los ambientes (Tabla 1.2); fueron mayores en el río Santiago que en el río Coronda durante toda la experiencia (excepto en septiembre de 2007, cuando se registraron valores excepcionales en el Coronda). En promedio, la conductividad en el río Santiago fue más de dos veces mayor que la registrada en el Coronda $(0,432 \pm 0,05$ y $0,197 \pm$ $0,1 \mathrm{mS} \mathrm{cm}^{-1}$, respectivamente, sin considerar los valores excepcionales). La diferencia promedio de TDS también fue de más del doble en el río Santiago, con $282 \pm 44 \mathrm{mg} \mathrm{L}^{-1}$, frente a $137 \pm 96 \mathrm{mg} \mathrm{L}^{-1}$ en el Coronda (sin considerar los valores excepcionales; Fig. 1.3.3; Tabla 
1.1). La salinidad estimada a partir de los valores de conductividad fue significativamente distinta entre los dos ambientes (Tabla 1.1 y 1.2 ).
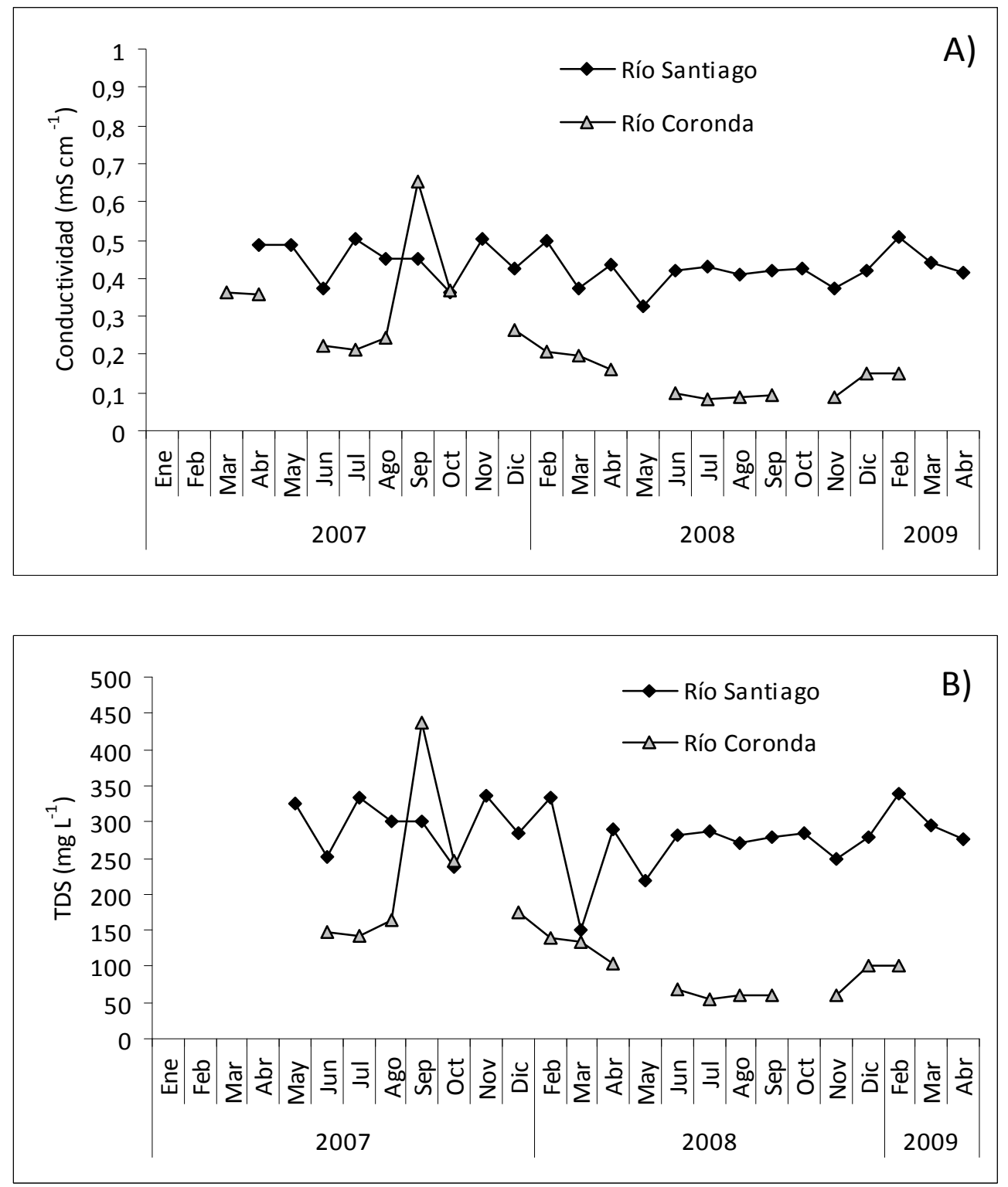

Figura 1.3.3. Valores de conductividad (A) y total de sólidos disueltos (B) registrados para el río Santiago y río Coronda. TDS: sólidos disueltos totales.

Ambos sitios presentaron aguas levemente alcalinas, pero el test de Student mostró diferencias significativas de $\mathrm{pH}$ (Tabla 1.2). El pH en el río Santiago fue menor que el registrado en el río Coronda $(7,41 \pm 0,12$ y 7,55 $\pm 0,22$; respectivamente) (Tabla 1.1). Los valores en el río Coronda tuvieron un mayor rango de amplitud que en el río Santiago (7,16 8 y 7,17 - 7,54; respectivamente) (Fig. 1.3.4). 


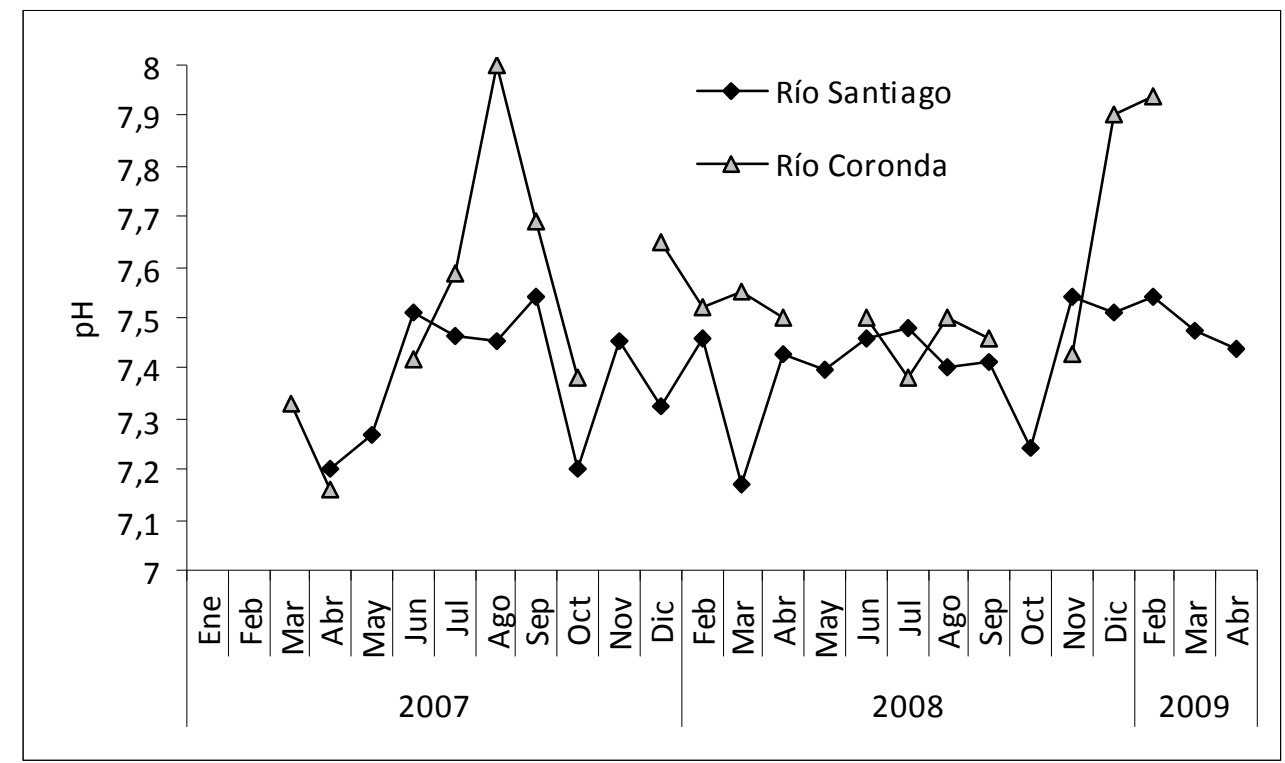

Figura 1.3.4. Valores de $\mathrm{pH}$ registrados durante el período de estudio en los dos sitios de muestreo.

Ambos sitios se caracterizaron por poseer aguas poco transparentes (Fig. 1.3.5, Tabla 1.1), pero la transparencia mostró diferencias significativas entre los dos ambientes (Tabla 1.2) y fue muy variable durante el período de estudio. En el río Santiago los valores mínimos de transparencia se registraron en mayo y agosto de 2008 (0,30 y 0,25 m, respectivamente); los registros más altos se dieron en septiembre de $2007(0,8 \mathrm{~m})$ y septiembre de $2008(0,65$ m) (Tabla 1.1 y 1.2). En el río Coronda, los valores mínimos de transparencia se registraron de febrero a abril de 2008 y en febrero de $2009(0,14 \pm 0,03 \mathrm{~m})$, mientras que los valores máximos se midieron de junio a agosto de $2007(0,48 \pm 0,03 \mathrm{~m})$ y de julio a diciembre de $2008(0,43 \pm 0,04 \mathrm{~m})$. En promedio, las aguas del río Santiago fueron más transparentes que las del Coronda $(0,51 \pm 0,14$ y $0,34 \pm 0,14 \mathrm{~m}$, respectivamente). 


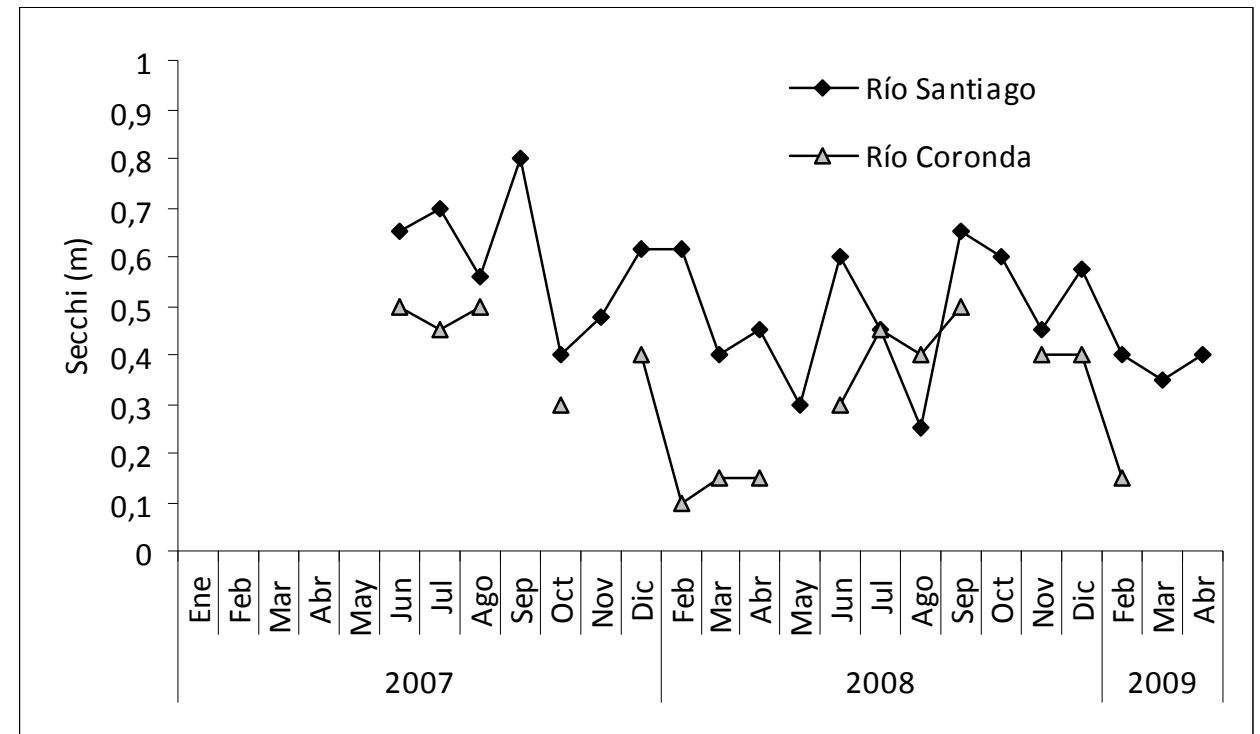

Figura 1.3.5. Variación de la transparencia (Secchi) en los dos sitios de muestreo.

Los valores de calcio no mostraron diferencias significativas entre los dos ambientes (Tabla 1.2). En el río Santiago, el valor promedio de la concentración de calcio fue de $53 \pm 27$ $\mathrm{mg} \mathrm{L}^{-1}$ mientras que en el río Coronda los valores de calcio fueron $48 \pm 46 \mathrm{mg} \mathrm{L}^{-1}$. En este último sitio se registraron valores máximos de concentración en septiembre y octubre de 2007 (180 y $102 \mathrm{mg} \mathrm{L}^{-1}$ ), que no se repitieron en los siguientes meses de muestreo.

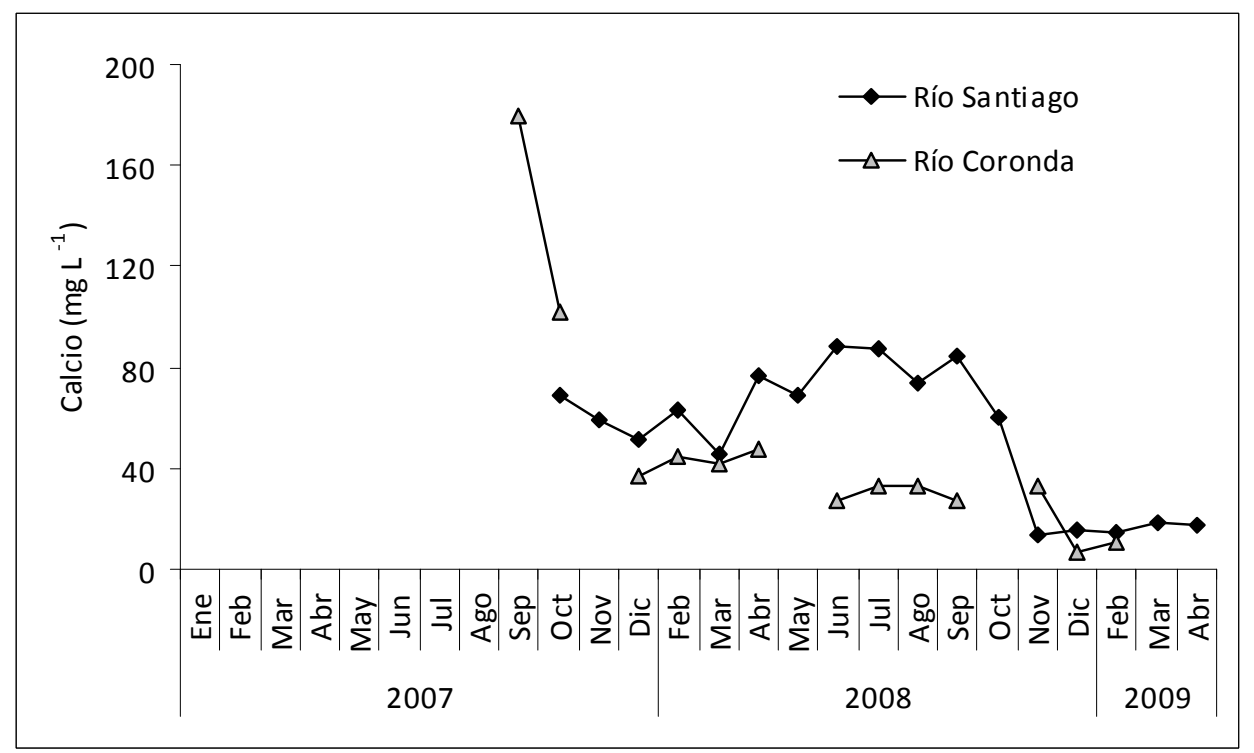

Figura 1.3.6. Variación de la concentración de calcio registrada en los ríos Santiago y Coronda. 
La variación de clorofila activa e inactiva (feopigmentos) durante todo el período de estudio se muestra en la figura 1.3.7. En el río Santiago, la concentración de pigmentos activos fue significativamente mayor que la estimada en el Coronda. En el primero de estos sitios se observaron dos picos máximos de concentración, uno en invierno y otro en verano. En el río Coronda no se observaron picos diferenciados, aunque sí un leve aumento de la concentración en los veranos de 2007 y 2008. No se encontraron diferencias significativas de concentración de pigmentos inactivos entre los ambientes (Tabla 1.1 y 1.2).
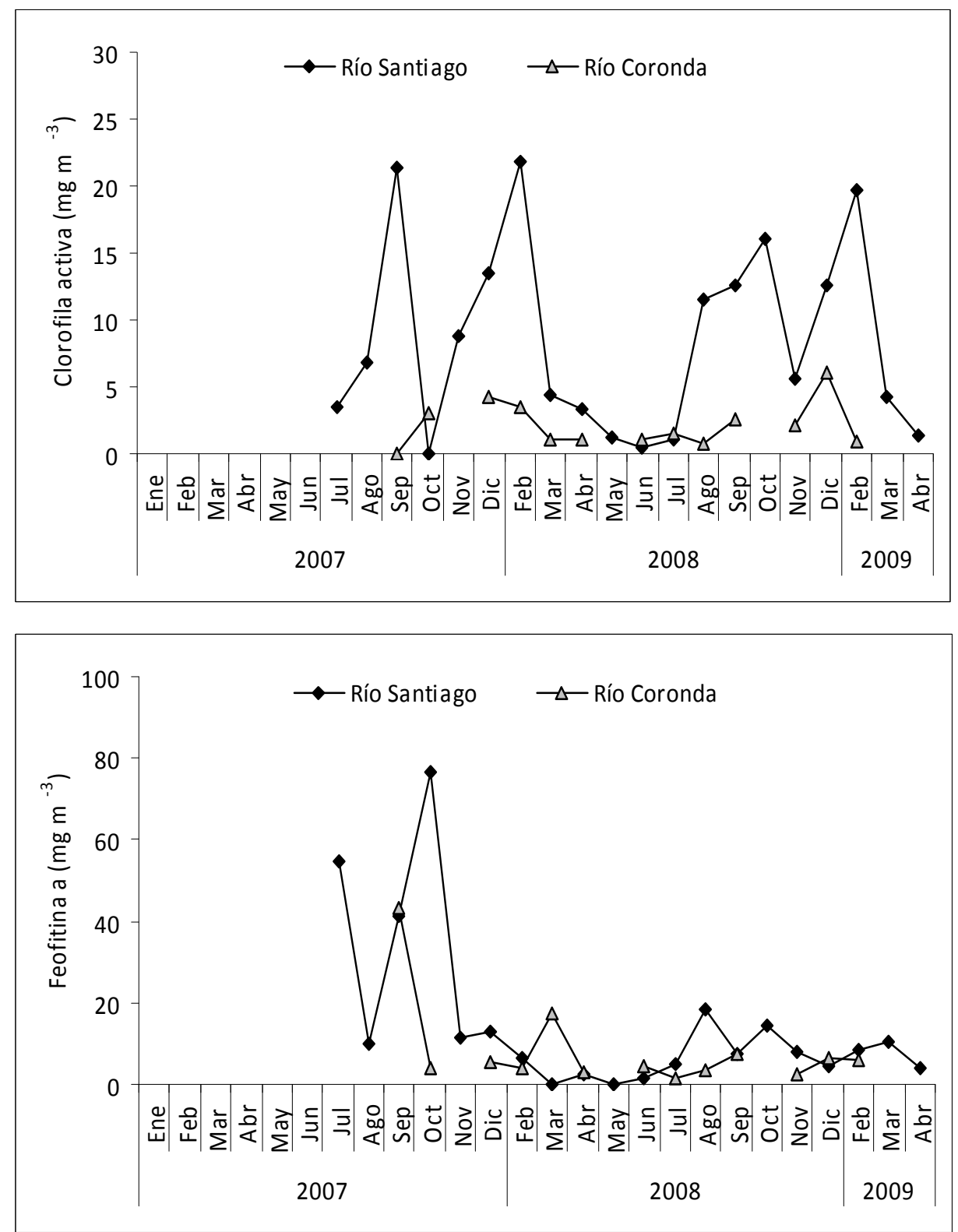

Figura 1.3.7. Concentración de pigmentos activos e inactivos para los dos ambientes de estudio, ríos Santiago y Coronda. 
Se encontraron diferencias significativas en la concentración de clorofila $a$ entre ambos sitios de muestreo (Tabla 1.2). En el río Santiago, la concentración de este pigmento mostró un valor máximo en septiembre de $2007\left(45 \mathrm{mg} \mathrm{m}^{-3}\right)$ y valores mínimos menores que $4 \mathrm{mg} \mathrm{m}^{-3}$ de mayo a julio de 2008 (Fig. 1.3.8, Tabla 1.1). La concentración media estimada para el período de estudio fue de 17,2 $\pm 12,7 \mathrm{mg} \mathrm{m}^{-3}$. En el río Coronda, la concentración media fue de $6,9 \pm 5,6 \mathrm{mg} \mathrm{m}^{-3}$, con un máximo de $22,9 \mathrm{mg} \mathrm{m}^{-3}$ en septiembre de $2007 \mathrm{y}$ menores que $4 \mathrm{mg} \mathrm{m}^{-3}$ de abril a agosto de 2008 (Fig. 1.3.8, Tabla 1.1).

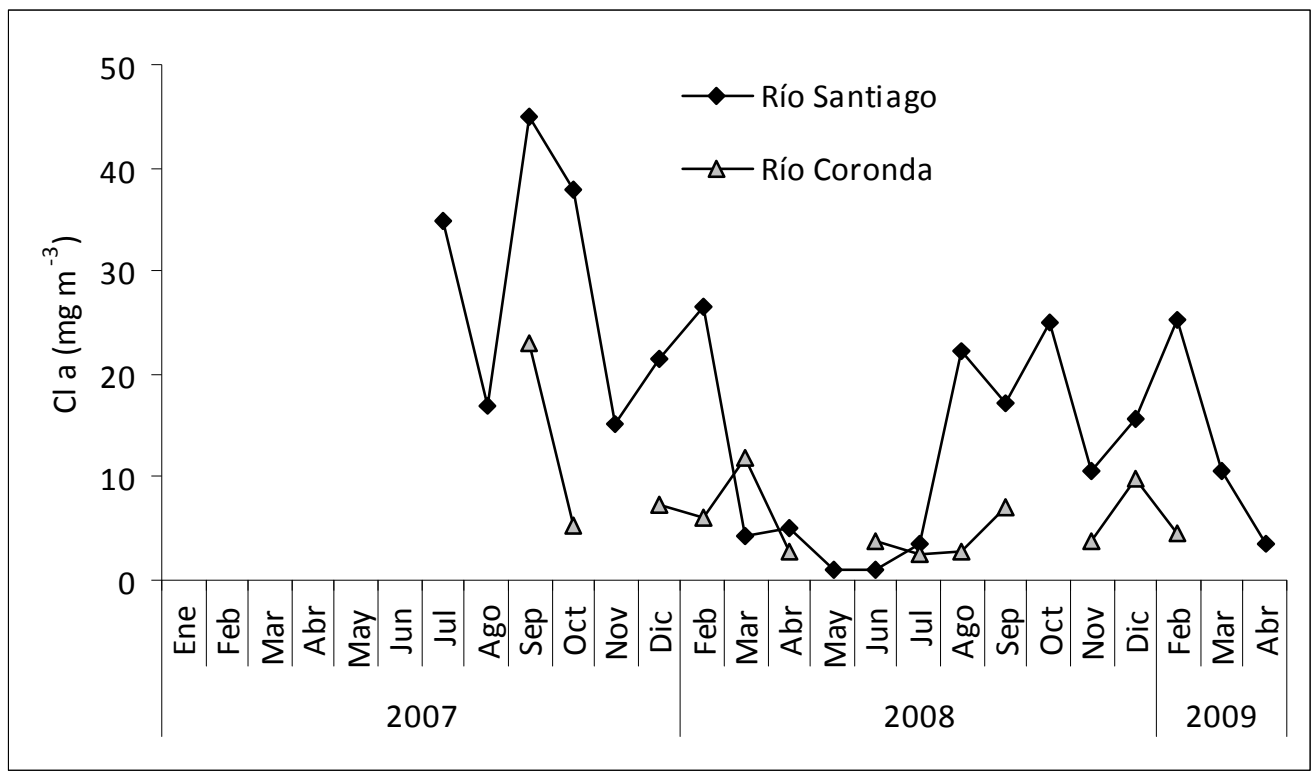

Figura 1.3.8. Variación de la concentración de clorofila $a(\mathrm{Cl}$ a) en el río Santiago y río Coronda para el período de estudio.

Los valores de concentración de clorofila $b$ fueron significativamente distintos entre los ambientes estudiados (Tabla 1.2). La concentración media del río Santiago fue 10,8 \pm $18,26 \mathrm{mg} \mathrm{m}^{-3}$, con un máximo de concentración en octubre de $2007\left(82,1 \mathrm{mg} \mathrm{m}^{-3}\right)$ y una concentración mínima de $0 \mathrm{mg} \mathrm{m}^{-3}$ en marzo de 2008. En el río Coronda, la concentración media de clorofila $b$ para todo el período de estudio fue $3,01 \pm 5,59 \mathrm{mg} \mathrm{m}^{-3}$, con un valor máximo registrado en septiembre de $2007\left(21,1 \mathrm{mg} \mathrm{m}^{-3}\right)$. La concentración mínima fue de 0 $\mathrm{mg} \mathrm{m}^{-3}$, registrada durante febrero y marzo de 2008 (Fig. 1.3.9, Tabla 1.1). 


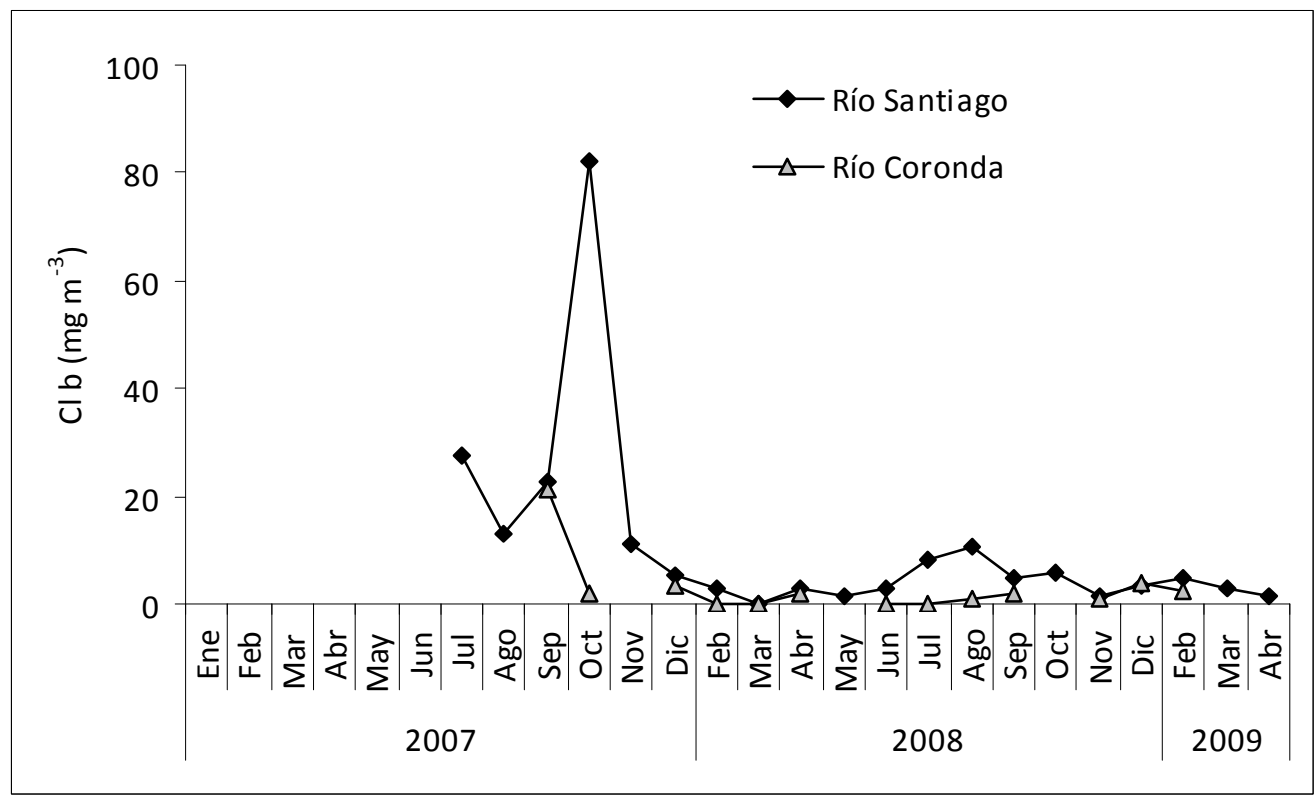

Figura 1.3.9. Variación de la concentración de clorofila $b(\mathrm{Cl}$ b) en los ríos Santiago y Coronda.

No hubo diferencias significativas en la concentración de clorofila c (Tabla 1.2). Este pigmento mostró dos picos importantes de concentración en el río Santiago; el primero en julio de $2007\left(18,7 \mathrm{mg} \mathrm{m}^{-3}\right)$ y el segundo en agosto de $2008\left(12,3 \mathrm{mg} \mathrm{m}^{-3}\right)$. En el Coronda se vio un solo pico importante en marzo de 2008 (12,9 $\mathrm{mg} \mathrm{m}^{-3}$ ) (Fig. 1.3.10, Tabla 1.1).

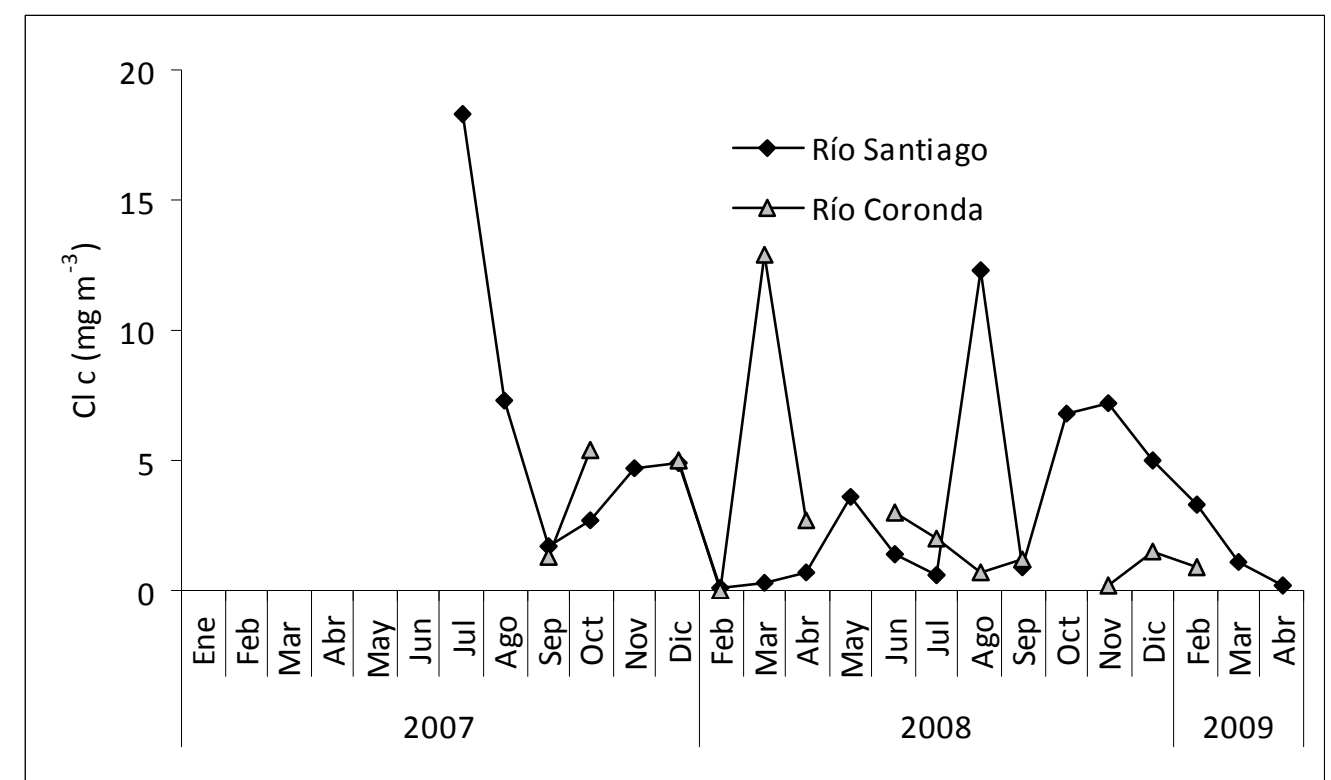

Figura 1.3.10. Variación de la concentración de clorofila $c(\mathrm{Cl}$ c) en el río Santiago y río Coronda para el período de estudio.

Durante 2007 se registraron concentraciones muy altas de pigmentos fotosintéticos, valores excepcionales que no se volvieron a registrar durante los muestreos siguientes. 
El índice de Margalef no mostró diferencias significativas entre los sitios de muestreo (Tabla 1.2). El índice medio estimado para el río Santiago fue $3 \pm 1,6$; para el río Coronda fue $2 \pm 0,7$. Estos valores medios indican que los dos cuerpos de agua albergaron comunidades algales jóvenes, con una alta tasa de productividad. En el río Santiago, desde mayo a junio de 2008 el índice fue mayor que 5, lo que estaría indicando una época del año con baja tasa de renovación algal. En el río Coronda no se observaron períodos en los que la tasa de renovación fuera baja (Fig. 1.3.11, Tabla 1.1).

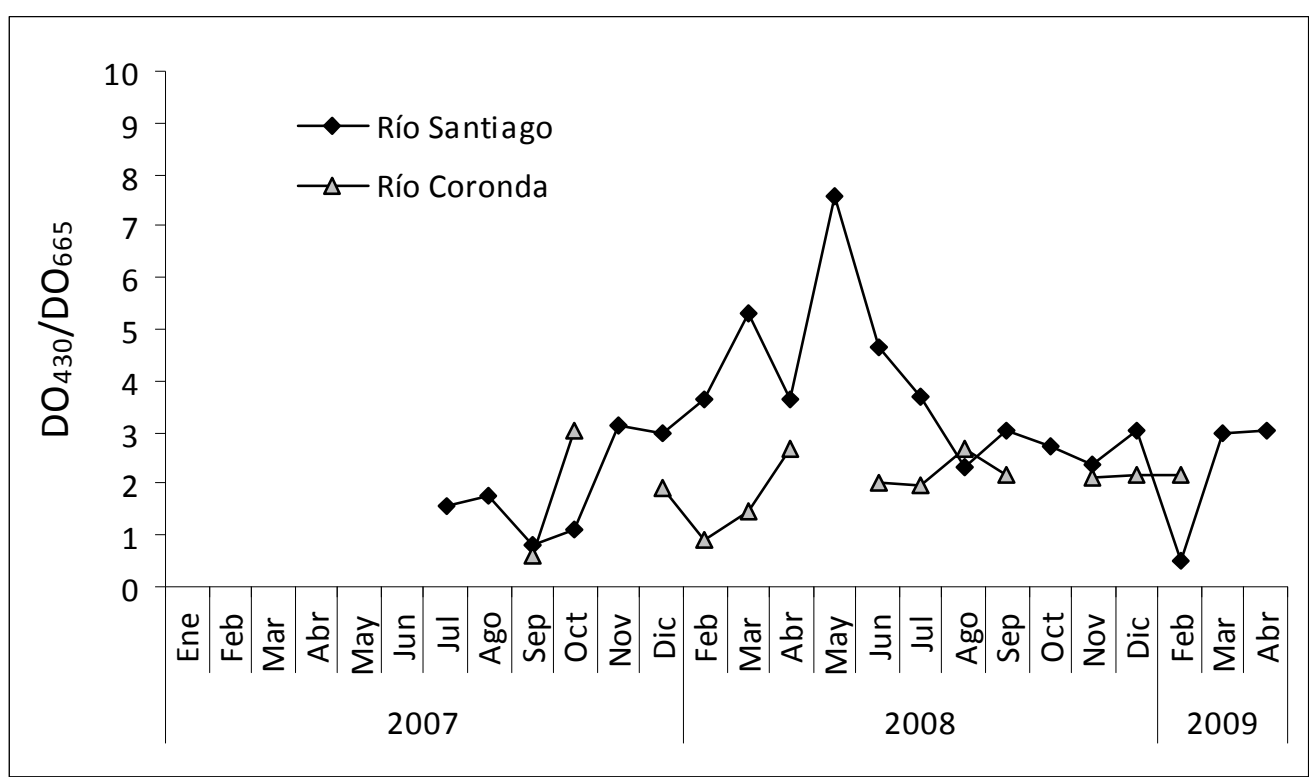

Figura 1.3.11. Variación del índice de Margalef $\left(\mathrm{DO}_{430} / \mathrm{DO}_{665}\right)$ estimado para los ríos Santiago y Coronda. 


\section{CAPÍTULO 1: Análisis comparativo de las condiciones limnológicas}

TABLA 1.1. Valores de los parámetros fisicoquímicos $( \pm \mathrm{DE})$ del agua para cada fecha de muestreo. T: temperatura del agua $\left({ }^{\circ} \mathrm{C}\right)$; Sat_O $\mathrm{O}_{2}$ : saturación de oxígeno $(\%)$; OD: oxígeno disuelto ( $\left.\mathrm{mg} \mathrm{L}^{-1}\right)$; Cond: conductividad $\left(\mathrm{mS} \mathrm{cm}^{-1}\right)$; Salin: Salinidad (\%o); TDS: total de sólidos disueltos ( $\left.\mathrm{mg} \mathrm{L}^{-1}\right)$; Secchi: transparencia ( $\mathrm{m}$ ); Calcio ( $\left.\mathrm{mg} \mathrm{L}^{-1}\right)$; Cl a*:clorofila activa ( $\mathrm{mg} \mathrm{m}$ $\left.{ }^{3}\right)$; Feo $\mathrm{a}^{* *}$ : feofitina $\left(\mathrm{mg} \mathrm{m}^{-3}\right)$; Cl a: Clorofila a $\left(\mathrm{mg} \mathrm{m}^{-3}\right)$; Cl b: Clorofila b $\left(\mathrm{mg} \mathrm{m}^{-3}\right)$; Cl c: Clorofila c $\left(\mathrm{mg} \mathrm{m}^{-3}\right)$; Ind_Marg: índice de Margalef $\left(\mathrm{DO}_{430} / \mathrm{DO}_{665}\right)$; $\mathrm{ND}$ : dato no disponible; ${ }^{*} \mathrm{y}$

${ }^{* *}$ : valores estimados con las ecuaciones 1.1 y 1.2 , respectivamente.

\begin{tabular}{|c|c|c|c|c|c|c|c|c|c|c|c|c|c|c|c|c|}
\hline \multicolumn{17}{|c|}{ A) Río Coronda } \\
\hline & mes & $\mathbf{T}$ & $\mathrm{pH}$ & Sat_O ${ }_{2}$ & OD & Cond & Salin & TDS & Secchi & Calcio & $\mathrm{Cl} \mathrm{a}^{*}$ & Feo a** & $\mathrm{Cl} \mathrm{a}$ & $\mathrm{Cl} \mathrm{b}$ & $\mathrm{Cl} \mathrm{c}$ & Ind_Marg \\
\hline \multirow{8}{*}{2007} & Mar & 22,9 & 7,33 & 96 & 8,2 & 0,365 & 0,26 & ND & ND & ND & ND & ND & ND & ND & ND & ND \\
\hline & Abr & 19,6 & 7,16 & 170 & 14,3 & 0,356 & 0,25 & ND & ND & ND & ND & ND & ND & ND & ND & ND \\
\hline & Jun & 13,1 & 7,42 & 160 & 14,8 & 0,222 & 0,16 & 147 & 0,50 & ND & ND & ND & ND & ND & ND & ND \\
\hline & Jul & 10,1 & 7,59 & 94 & 9,5 & 0,215 & 0,15 & 143 & 0,45 & ND & ND & ND & ND & ND & ND & ND \\
\hline & Ago & 14,1 & 8 & 109 & 10,3 & 0,244 & 0,17 & 163 & 0,50 & ND & ND & ND & ND & ND & ND & ND \\
\hline & Sep & 19 & 7,69 & 89 & 8 & 0,655 & ND & 437 & ND & 180 & 0,00 & 43,16 & 22,91 & 21,14 & 1,33 & 0,60 \\
\hline & Oct & 25,1 & 7,38 & 77 & 6,5 & 0,369 & 0,26 & 247 & 0,30 & 102 & 3,01 & 3,83 & 5,25 & 1,84 & 5,38 & 3,03 \\
\hline & Dic & 28,5 & 7,65 & 84 & 6,7 & 0,263 & 0,19 & 175 & 0,40 & 37 & 4,26 & 5,27 & 7,31 & 3,55 & 4,95 & 1,90 \\
\hline \multirow{9}{*}{2008} & Feb & 25,8 & 7,52 & 83 & 6,9 & 0,208 & 0,15 & 139 & 0,10 & 45 & 3,53 & 3,89 & 6,15 & 0,00 & 0,00 & 0,90 \\
\hline & Mar & 25,3 & 7,55 & 110 & 9 & 0,199 & 0,14 & 133 & 0,15 & 42 & 1,00 & 17,30 & 11,88 & 0,00 & 12,91 & 1,46 \\
\hline & Abr & 22,9 & 7,5 & 70 & 6 & 0,159 & 0,11 & 105 & 0,15 & 48 & 1,09 & 2,89 & 2,72 & 1,93 & 2,73 & 2,68 \\
\hline & Jun & 14,4 & 7,5 & 88 & 8,4 & 0,100 & 0,07 & 67 & 0,30 & 27 & 1,04 & 4,28 & 3,68 & 0,24 & 3,01 & 2,00 \\
\hline & Jul & 15,7 & 7,38 & 84 & 7,8 & 0,081 & 0,06 & 54 & 0,45 & 33 & 1,55 & 1,59 & 2,57 & 0,14 & 2,00 & 1,95 \\
\hline & Ago & 16,3 & 7,5 & 94 & 8,6 & 0,089 & 0,06 & 59 & 0,40 & 33 & 0,78 & 3,34 & 2,76 & 1,00 & 0,66 & 2,66 \\
\hline & Sep & 19,4 & 7,46 & 103 & 9,1 & 0,092 & 0,07 & 61 & 0,50 & 27 & 2,61 & 7,26 & 6,97 & 2,16 & 1,25 & 2,17 \\
\hline & Nov & 25,0 & 7,43 & 83 & 6,9 & 0,089 & 0,06 & 59 & 0,40 & 33 & 2,17 & 2,52 & 3,70 & 1,05 & 0,20 & 2,14 \\
\hline & Dic & 29,5 & 7,9 & 96 & 7,5 & 0,151 & 0,11 & 101 & 0,40 & 6 & 6,07 & 6,35 & 9,86 & 3,83 & 1,52 & 2,19 \\
\hline 2009 & Feb & 26,1 & 7,94 & 84 & 6,9 & 0,15 & 0,11 & 100 & 0,15 & 11 & 0,93 & 5,95 & 4,42 & 2,20 & 0,95 & 2,18 \\
\hline
\end{tabular}


TABLA 1.1. Continuación..

\begin{tabular}{|c|c|c|c|c|c|c|c|c|c|c|c|c|c|c|c|c|}
\hline \multicolumn{17}{|c|}{ B) Río Santiago } \\
\hline & mes & $\mathbf{T}$ & $\mathrm{pH}$ & Sat_ $\mathbf{O}_{2}$ & OD & Cond & Salin & TDS & Secchi & Calcio & $\mathrm{Cl}$ a* & Feo a** & $\mathrm{Cl} \mathrm{a}$ & $\mathrm{Cl} \mathrm{b}$ & $\mathrm{Cl} \mathrm{c}$ & Ind_Marg \\
\hline \multirow{9}{*}{2007} & Abr & 24 & 7,20 & 58 & 5,1 & 0,485 & 0,346 & ND & ND & ND & ND & ND & ND & ND & ND & ND \\
\hline & May & 18 & 7,27 & 115 & 10,3 & 0,487 & 0,348 & 325 & ND & ND & ND & ND & ND & ND & ND & ND \\
\hline & Jun & 12 & 7,51 & ND & ND & 0,374 & 0,267 & 251 & 0,65 & ND & ND & ND & ND & ND & ND & ND \\
\hline & Jul & $9,5 \pm 0,1$ & $7,47 \pm 0,05$ & $72 \pm 33$ & $7,6 \pm 3,2$ & $0,501 \pm 0,043$ & $0,357 \pm 0,031$ & $334 \pm 30$ & 0,70 & ND & 3,6 & 54,8 & 34,8 & 27,4 & 18,3 & 1,6 \\
\hline & Ago & $11,2 \pm 1,1$ & $7,46 \pm 0,04$ & $52 \pm 8$ & $5,4 \pm 0,8$ & $0,451 \pm 0,079$ & $0,322 \pm 0,056$ & $301 \pm 52$ & $0,56 \pm 0,14$ & ND & $6,8 \pm 3,5$ & $9,9 \pm 10,4$ & $16,9 \pm 5,4$ & $13,3 \pm 4,2$ & $7,3 \pm 0,8$ & $1,8 \pm 0,7$ \\
\hline & Sep & $16,6 \pm 0,5$ & $7,54 \pm 0,20$ & $61 \pm 31$ & $5,8 \pm 2,7$ & $0,449 \pm 0,132$ & $0,321 \pm 0,094$ & $300 \pm 88$ & 0,80 & ND & $21,4 \pm 24,7$ & $41,3 \pm 45,1$ & $45 \pm 4$ & $22,9 \pm 12,7$ & $1,7 \pm 2,5$ & 0,8 \\
\hline & Oct & 17,1 & 7,20 & 32 & 3,2 & 0,365 & 0,261 & 237 & 0,40 & 69 & 0 & $76,7 \pm 68,4$ & $38 \pm 37,3$ & $82,1 \pm 104,1$ & $2,7 \pm 3,9$ & $1,1 \pm 0,6$ \\
\hline & Nov & $23,3 \pm 1,0$ & $7,45 \pm 0,07$ & $36 \pm 7$ & $3,4 \pm 0,5$ & $0,504 \pm 0,052$ & $0,360 \pm 0,037$ & $335 \pm 31$ & $0,48 \pm 0,10$ & $59 \pm 2$ & $8,7 \pm 8,4$ & $11,7 \pm 12,1$ & $15,2 \pm 8,9$ & $11 \pm 17,9$ & $4,7 \pm 10,8$ & $3,1 \pm 0,5$ \\
\hline & Dic & $23,8 \pm 0,4$ & $7,33 \pm 0,13$ & $41 \pm 22$ & $3,6 \pm 1,8$ & $0,424 \pm 0,176$ & $0,302 \pm 0,125$ & $283 \pm 118$ & $0,43 \pm 0,13$ & $51 \pm 21$ & $13,5 \pm 1$ & $13,1 \pm 11,3$ & $21,5 \pm 6,8$ & $5,2 \pm 6,2$ & $4,9 \pm 8,9$ & $3 \pm 0,4$ \\
\hline \multirow{12}{*}{2008} & Feb & $27,6 \pm 0,8$ & $7,46 \pm 0,07$ & $54 \pm 10$ & $4,5 \pm 0,8$ & $0,498 \pm 0,020$ & $0,356 \pm 0,014$ & $333 \pm 15$ & $0,62 \pm 0,16$ & $63 \pm 9$ & $21,9 \pm 14,3$ & $6,7 \pm 5,7$ & $26,6 \pm 17,5$ & $2,8 \pm 1,9$ & $0,1 \pm 0,1$ & $3,6 \pm 0,6$ \\
\hline & Mar & 23,4 & 7,17 & 30 & 2,8 & 0,374 & 0,267 & 251 & 0,40 & 46 & $4,4 \pm 0,3$ & 0 & $4,3 \pm 0,6$ & 0 & $0,3 \pm 0,4$ & $5,3 \pm 0,9$ \\
\hline & Abr & $20,3 \pm 1,4$ & $7,43 \pm 0,10$ & $34 \pm 7$ & $3,3 \pm 0,7$ & $0,435 \pm 0,049$ & $0,311 \pm 0,035$ & $290 \pm 32$ & $0,45 \pm 0,17$ & $77 \pm 17$ & $3,4 \pm 1,4$ & $2,7 \pm 1,7$ & $4,9 \pm 1,8$ & $2,8 \pm 3,2$ & $0,7 \pm 1,1$ & $3,6 \pm 1,2$ \\
\hline & May & $15,7 \pm 2,1$ & $7,40 \pm 0,13$ & $58 \pm 51$ & $5,6 \pm 4,7$ & $0,327 \pm 0,212$ & $0,233 \pm 0,151$ & $218 \pm 142$ & 0,30 & $69 \pm 21$ & $1,2 \pm 0,5$ & $0,2 \pm 0,2$ & $0,91 \pm 0,02$ & $1,6 \pm 0,1$ & $3,6 \pm 3,9$ & $7,6 \pm 1,5$ \\
\hline & Jun & 12,1 & 7,46 & 44 & 4,6 & 0,421 & 0,301 & 281 & 0,60 & 88 & $0,5 \pm 0,2$ & $1,4 \pm 0,6$ & $1,1 \pm 0,7$ & $3,1 \pm 1,6$ & $1,4 \pm 2,0$ & $4,6 \pm 1,7$ \\
\hline & Jul & 13,7 & 7,48 & 47 & 4,8 & 0,430 & 0,307 & 287 & 0,45 & 87 & $1,1 \pm 1,6$ & $5 \pm 3,3$ & $3,5 \pm 0,9$ & $8,2 \pm 6,7$ & $0,6 \pm 0,2$ & $3,7 \pm 0,7$ \\
\hline & Ago & $14,1 \pm 0,6$ & $7,40 \pm 0,06$ & $65 \pm 8$ & $6,3 \pm 0,7$ & $0,408 \pm 0,055$ & $0,291 \pm 0,039$ & $271 \pm 40$ & 0,25 & $74 \pm 11$ & $11,5 \pm 1,0$ & $18,3 \pm 15,7$ & $22,3 \pm 10,8$ & $10,6 \pm 12,6$ & $12,3 \pm 30,8$ & $2,3 \pm 1,2$ \\
\hline & Sep & 15,8 & 7,41 & 63 & 6,1 & 0,420 & 0,300 & 280 & 0,65 & 84 & $12,5 \pm 4,5$ & $7,6 \pm 4,7$ & $17,3 \pm 1,7$ & $4,7 \pm 1$ & $0,9 \pm 0,2$ & $3,1 \pm 0,4$ \\
\hline & Oct & 21,6 & 7,24 & 68 & 6,1 & 0,424 & 0,303 & 284 & 0,60 & 60 & $16 \pm 0,4$ & $14,7 \pm 3,7$ & $25 \pm 1,7$ & $6 \pm 0,7$ & $6,8 \pm 0,9$ & $2,7 \pm 0,1$ \\
\hline & Nov & $26,3 \pm 0,7$ & $7,54 \pm 0,06$ & $62 \pm 3$ & $5,2 \pm 0,3$ & $0,373 \pm 0,069$ & $0,266 \pm 0,049$ & $249 \pm 45$ & 0,45 & 14 & $5,7 \pm 1,2$ & $8,2 \pm 3,5$ & $10,7 \pm 3,4$ & $1,4 \pm 1,6$ & $7,2 \pm 6,5$ & $2,4 \pm 0,7$ \\
\hline & Dic & $25,6 \pm 3,8$ & $7,51 \pm 0,01$ & $71 \pm 28$ & $6 \pm 2,3$ & $0,418 \pm 0,007$ & $0,298 \pm 0,005$ & $279 \pm 6$ & $0,58 \pm 0,04$ & $15 \pm 1$ & $12,6 \pm 3,5$ & $4,7 \pm 0,4$ & $15,6 \pm 3,5$ & $3,4 \pm 1,2$ & $5 \pm 9$ & $3 \pm 0,2$ \\
\hline & Feb & 25,3 & 7,54 & 68 & 5,8 & 0,509 & 0,363 & 339 & 0,40 & 14 & $19,7 \pm 1,6$ & $8,4 \pm 0,7$ & $25,2 \pm 2$ & $4,8 \pm 0,9$ & $3,3 \pm 1,3$ & $0,5 \pm 0,1$ \\
\hline \multirow[t]{2}{*}{2009} & Mar & $24,8 \pm 0,6$ & $7,48 \pm 0,01$ & $57 \pm 19$ & $4,9 \pm 1,4$ & $0,443 \pm 0,061$ & $0,316 \pm 0,043$ & $296 \pm 40$ & $0,35 \pm 0,05$ & $19 \pm 3$ & $4,2 \pm 3,5$ & $10,7 \pm 5$ & $10,7 \pm 6,1$ & $2,8 \pm 0,3$ & $1,1 \pm 0,7$ & $3 \pm 0,3$ \\
\hline & Abr & 21,0 & 7,44 & 33 & 3,1 & 0,413 & 0,295 & 275 & 0,40 & 17 & $1,3 \pm 0,9$ & $3,8 \pm 1,4$ & $3,5 \pm 0,1$ & $1,3 \pm 0,3$ & $0,2 \pm 0,3$ & $3 \pm 0,2$ \\
\hline
\end{tabular}


Tabla 1.2. Resultados estadísticos del test de Student (SPSS Stastistics 17.0) para datos transformados: Ln (x). T: temperatura; Sat_O $\mathrm{O}_{2}$ : saturación de oxígeno; OD: oxígeno disuelto; Cond: conductividad; TDS: sólidos disueltos totales; Salin: Salinidad; Secchi: transparencia; Cl_act: clorofila activa; Feo_act: feofitina. Cl a: Clorofila a; Cl b: Clorofila b; Cl c: Clorofila c; Ind_Marg: índice de Margalef; (**): indica diferencias altamente significativas.

\begin{tabular}{|c|c|c|c|c|c|c|c|c|c|c|}
\hline & & \multicolumn{2}{|c|}{$\begin{array}{l}\text { Test de Levene para } \\
\text { igualdad de varianzas }\end{array}$} & \multicolumn{5}{|c|}{ Test t para igualdad de medias } & \multicolumn{2}{|c|}{ Intervalo de confianza al $95 \%$} \\
\hline & & $\mathbf{F}$ & $\mathbf{p}$ & $\mathbf{t}$ & gl & $\mathbf{p}$ (2-colas) & Diferencia de la media & Diferencia de ES & Mín & Máx \\
\hline \multirow{2}{*}{$\mathbf{T}$} & Igualdad de varianzas asumida & 0,302 & 0,586 & $-0,650$ & 39 & 0,520 & $-0,064$ & 0,099 & $-0,265$ & 0,136 \\
\hline & Igualdad de varianzas no asumida & & & $-0,654$ & 37 & 0,517 & $-0,064$ & 0,098 & $-0,264$ & 0,135 \\
\hline \multirow{2}{*}{$\mathrm{pH}$} & Igualdad de varianzas asumida & 4,622 & 0,038 & $-2,670$ & 39 & $0,011^{*}$ & $-0,142$ & 0,053 & $-0,249$ & $-0,034$ \\
\hline & Igualdad de varianzas no asumida & & & $-2,488$ & 24 & $0,020 *$ & $-0,142$ & 0,057 & $-0,259$ & $-0,024$ \\
\hline \multirow{2}{*}{ Sat_O ${ }_{2}$} & Igualdad de varianzas asumida & 3,395 & 0,073 & $-6,531$ & 38 & $0,000 * *$ & $-0,600$ & 0,092 & $-0,785$ & $-0,414$ \\
\hline & Igualdad de varianzas no asumida & & & $-6,767$ & 37 & $0,000 * *$ & $-0,600$ & 0,089 & $-0,779$ & $-0,420$ \\
\hline \multirow{2}{*}{ OD } & Igualdad de varianzas asumida & 1,226 & 0,275 & $-5,791$ & 38 & $0,000^{* *}$ & $-0,532$ & 0,092 & $-0,718$ & $-0,346$ \\
\hline & Igualdad de varianzas no asumida & & & $-5,941$ & 38 & $0,000 * *$ & $-0,532$ & 0,090 & $-0,714$ & $-0,351$ \\
\hline \multirow{2}{*}{ Cond } & Igualdad de varianzas asumida & 10,944 & 0,002 & 6,873 & 39 & $0,000 * *$ & 0,163 & 0,024 & 0,115 & 0,211 \\
\hline & Igualdad de varianzas no asumida & & & 6,206 & 20 & $0,000 * *$ & 0,163 & 0,026 & 0,108 & 0,218 \\
\hline \multirow{2}{*}{ TDS } & Igualdad de varianzas asumida & 18,193 & 0,000 & 6,728 & 36 & $0,000^{* *}$ & 0,880 & 0,131 & 0,615 & 1,145 \\
\hline & Igualdad de varianzas no asumida & & & 5,880 & 17 & $0,000 * *$ & 0,880 & 0,150 & 0,564 & 1,195 \\
\hline \multirow{2}{*}{ Salin } & Igualdad de varianzas asumida & 10,874 & 0,002 & 6,790 & 39 & $0,000^{* *}$ & 0,125 & 0,018 & 0,088 & 0,162 \\
\hline & Igualdad de varianzas no asumida & & & 6,133 & 20 & $0,000 * *$ & 0,125 & 0,020 & 0,083 & 0,168 \\
\hline \multirow{2}{*}{ Transp } & Igualdad de varianzas asumida & 0,770 & 0,386 & 3,380 & 34 & $0,002 * *$ & 0,116 & 0,034 & 0,046 & 0,185 \\
\hline & Igualdad de varianzas no asumida & & & 3,289 & 27 & $0,003 * *$ & 0,116 & 0,035 & 0,044 & 0,188 \\
\hline \multirow{2}{*}{ Calcio } & Igualdad de varianzas asumida & 0,127 & 0,724 & 0,815 & 28 & 0,422 & 0,229 & 0,281 & $-0,347$ & 0,806 \\
\hline & Igualdad de varianzas no asumida & & & 0,797 & 23 & 0,434 & 0,229 & 0,288 & $-0,366$ & 0,825 \\
\hline
\end{tabular}


CAPÍTULO 1: Análisis comparativo de las condiciones limnológicas

Tabla 1.2. Continuación...

\begin{tabular}{|c|c|c|c|c|c|c|c|c|c|c|}
\hline & & \multicolumn{2}{|c|}{$\begin{array}{l}\text { Test de Levene para } \\
\text { igualdad de varianzas }\end{array}$} & \multicolumn{5}{|c|}{ Test t para igualdad de medias } & \multicolumn{2}{|c|}{ Intervalo de confianza al $95 \%$} \\
\hline & & $\mathbf{F}$ & $\mathbf{p}$ & $\mathbf{t}$ & gl & $\mathrm{p}$ (2-colas) & Diferencia de la media & Diferencia de ES & Mín & Máx \\
\hline \multirow{2}{*}{ Cl_act } & Igualdad de varianzas asumida & 5,613 & 0,024 & 2,982 & 31 & $0,006 * *$ & 0,870 & 0,292 & 0,275 & 1,465 \\
\hline & Igualdad de varianzas no asumida & & & 3,347 & 30 & $0,002 * *$ & 0,870 & 0,260 & 0,340 & 1,401 \\
\hline \multirow{2}{*}{ Feo_act } & Igualdad de varianzas asumida & 2,123 & 0,155 & 0,279 & 31 & 0,782 & 0,098 & 0,351 & $-0,617$ & 0,813 \\
\hline & Igualdad de varianzas no asumida & & & 0,303 & 31 & 0,764 & 0,098 & 0,323 & $-0,561$ & 0,757 \\
\hline \multirow{2}{*}{ Cl_a } & Igualdad de varianzas asumida & 4,477 & 0,042 & 2,258 & 31 & $0,031^{* *}$ & 0,659 & 0,292 & 0,064 & 1,254 \\
\hline & Igualdad de varianzas no asumida & & & 2,510 & 31 & $0,018^{* *}$ & 0,659 & 0,263 & 0,123 & 1,194 \\
\hline \multirow{2}{*}{ Cl_b } & Igualdad de varianzas asumida & 0,540 & 0,468 & 2,740 & 31 & $0,010 * *$ & 0,930 & 0,339 & 0,238 & 1,621 \\
\hline & Igualdad de varianzas no asumida & & & 2,850 & 29 & $0,008^{* *}$ & 0,930 & 0,326 & 0,262 & 1,597 \\
\hline \multirow{2}{*}{ Cl_c } & Igualdad de varianzas asumida & 0,913 & 0,347 & 0,833 & 31 & 0,411 & 0,235 & 0,282 & $-0,340$ & 0,809 \\
\hline & Igualdad de varianzas no asumida & & & 0,859 & 28 & 0,397 & 0,235 & 0,273 & $-0,325$ & 0,794 \\
\hline \multirow{2}{*}{ Ind_Marg } & Igualdad de varianzas asumida & 1,929 & 0,175 & 1,868 & 31 & 0,071 & 0,241 & 0,129 & $-0,022$ & 0,504 \\
\hline & Igualdad de varianzas no asumida & & & 2,055 & 31 & 0,05 & 0,241 & 0,117 & 0,002 & 0,480 \\
\hline
\end{tabular}


En el río Coronda, la concentración de oxígeno y la transparencia mostraron una correlación negativa con la temperatura del agua (Apéndice 1.1). La concentración de oxígeno mostró correlación positiva con los valores de transparencia. La conductividad del agua se correlacionó positivamente con las concentraciones de calcio y clorofilas $a$ y $b$. Ambos pigmentos mostraron correlación positiva entre sí (Apéndice 1.1). El resto de las variables no mostró ningún tipo de relación significativa.

Los resultados del análisis de Pearson para el río Santiago mostraron que la temperatura del agua se correlacionó negativamente con las concentraciones de calcio y clorofila $b$. El $\mathrm{pH}$ y el total de sólidos disueltos se correlacionaron positivamente. La concentración de oxígeno mostró una correlación positiva con la concentración de clorofila c. La conductividad tuvo una correlación positiva con la concentración de clorofila $a$. Este pigmento mostró correlación positiva con la concentración de clorofila $b$ (Apéndice 1.2). En ambos sitios de muestreo, variables como oxígeno disuelto y saturación de oxígeno mostraron correlaciones positivas muy fuertes al igual que la conductividad, total de sólidos disueltos y salinidad. Debido a la naturaleza de estas variables, los resultados de correlación obtenidos sugieren un potencial efecto de colinealidad.

El análisis discriminante dio como resultado un 95,1 \% de clasificación correcta. Para el río Santiago se clasificó correctamente el 91,3\% de las muestras, mientras que para el río Coronda este valor fue del 88,9 \%. El coeficiente de correlación canónica (CC) de la función discriminante fue 0,962; es decir que la proporción de la varianza debida a la diferencia entre los grupos (CC ${ }^{2}$ x 100) fue 92,5 \% (Tabla 1.3). Las variables que mostraron mayor potencial discriminante para cada ambiente fueron la conductividad, la transparencia y la concentración de clorofila a y b para el río Santiago; y la concentración de oxígeno y el pH para el río Coronda (Tabla 1.4). La distribución de los scores discriminantes obtenidos para los dos ambientes mostró una ligera superposición de coeficientes debido a los valores excepcionales de conductividad y calcio registrados en septiembre de 2007 en el río Coronda (Fig. 1.3.12). 
Tabla 1.3. Resultado de la función discriminante canónica para las variables ambientales registradas en los ríos Santiago y Coronda. \% Acum: porcentaje acumulado de la varianza explicada; CC: coeficiente de correlación canónica; $X^{2}$ : chi cuadrado; gl: grados de libertad.

\begin{tabular}{cccccccc}
\hline Función & Autovalor & \% Acum & CC & $\boldsymbol{\lambda}$ Wilks & $\mathbf{X}^{\mathbf{2}}$ & $\mathbf{g l}$ & $\mathbf{p}$ \\
\hline 1 & 12,247 & 100 & 0,962 & 0,075 & 58,135 & 9 & 0,000 \\
\hline
\end{tabular}

Tabla 1.4. Coeficientes de estructura ordenados de mayor a menor según su potencia discriminante. Cond: conductividad ( $\left.\mathrm{mS} \mathrm{cm}^{-1}\right)$; OD: oxígeno disuelto $\left(\mathrm{mg} \mathrm{L}^{-1}\right)$; Transp: transparencia $(\mathrm{m})$; $\mathrm{Cl} \_\mathrm{b}$ : Clorofila $\mathrm{b}\left(\mathrm{mg} \mathrm{m}^{-3}\right)$; Cl_a: Clorofila a $\left(\mathrm{mg} \mathrm{m}^{-3}\right)$; Calcio $\left(\mathrm{mg} \mathrm{L}^{-1}\right)$; $\mathrm{T}$ : temperatura del agua $\left({ }^{\circ} \mathrm{C}\right)$; Cl_c: Clorofila c $\left(\mathrm{mg} \mathrm{m}^{-3}\right)$.

\begin{tabular}{cccccccccc}
\hline Variable & Cond & OD & Transp & Cl_b & pH & Cl_a & Calcio & T & Cl_c \\
\hline Coef. estr. & $-0,577$ & 0,319 & $-0,181$ & $-0,169$ & 0,149 & $-0,121$ & $-0,076$ & 0,064 & $-0,008$ \\
\hline
\end{tabular}

La función discriminante quedó expresada de la siguiente forma:

$$
\begin{gathered}
\mathrm{Y}=4,921 \mathrm{~T}+1,288 \mathrm{pH}+3,652 \mathrm{OD}-21,984 \text { Cond }-1,951 \text { Transp }+1,075 \text { Calcio }-0,423 \mathrm{Cl} \_\mathrm{a} \\
+0,362 \mathrm{Cl} \_\mathrm{b}-0,059 \mathrm{Cl} \_\mathrm{c}-27,636
\end{gathered}
$$

Los valores de saturación de oxígeno, total de sólidos disueltos y salinidad, clorofila y feofitina activas, y los valores del índice de Margalef, no fueron tenidos en cuenta para el análisis por posibles efectos de multicolinealidad. 


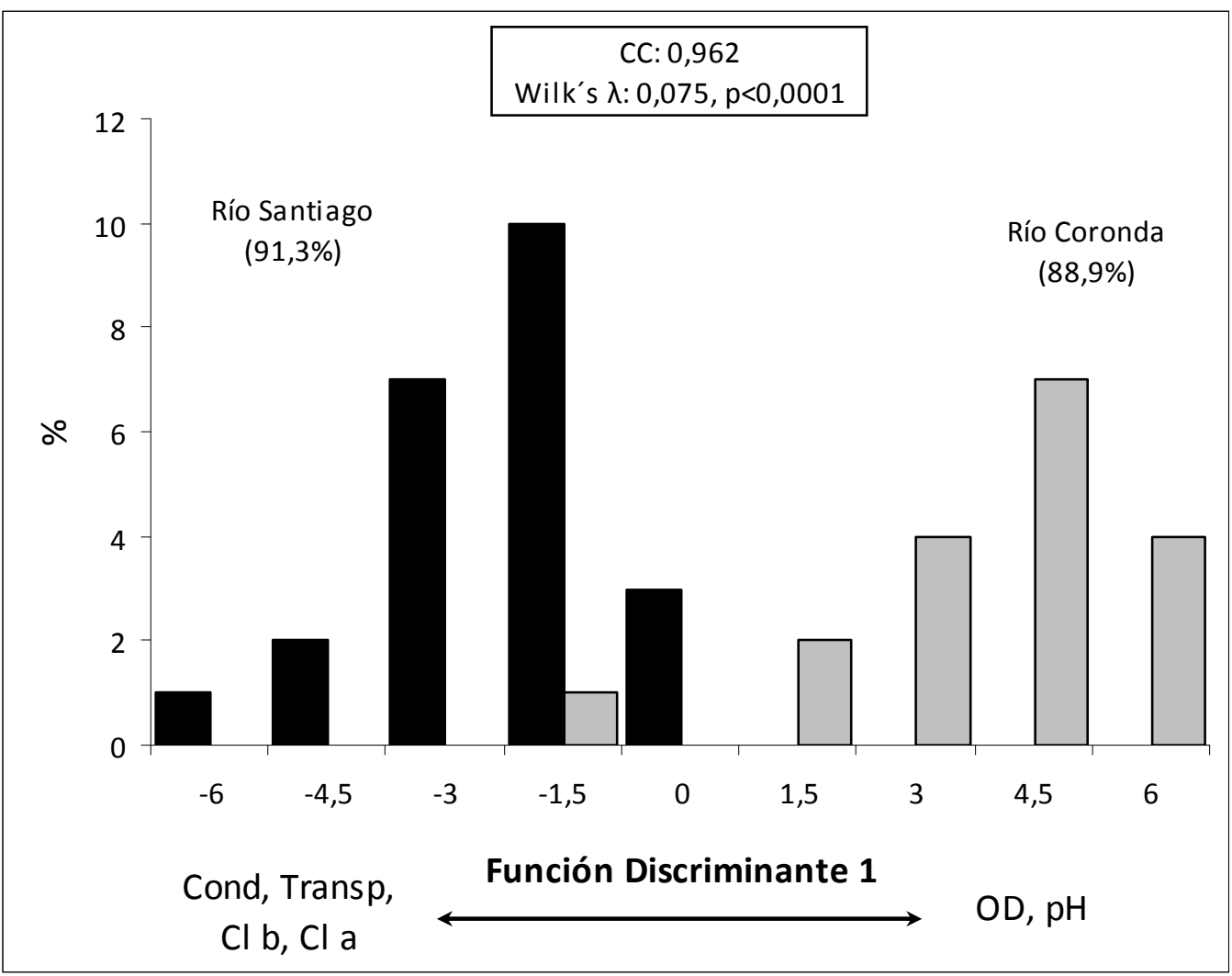

Figura 1.3.12. Distribución de la frecuencia de scores obtenidos para los ríos Santiago y Coronda. 


\subsection{DISCUSIÓN}

Los dos sitios de muestreo seleccionados son topográfica e hidrológicamente distintos y como preveía la hipótesis de trabajo, se encontraron diferencias entre ambos. Hasta la fecha no se han realizado trabajos comparativos sobre las condiciones limnológicas en estos ambientes. Nuestros resultados mostraron diferencias significativas en casi todas las variables medidas. El análisis discriminante dio como resultado que las variables conductividad, transparencia, concentración de clorofila $a$ y $b$, contribuyeron más a la caracterización del río Santiago, mientras que el oxígeno disuelto y el pH lo hicieron con el río Coronda.

Los ecosistemas estuariales son sistemas altamente productivos que están sujetos a las fluctuaciones estacionales y diarias de parámetros fisicoquímicos responsables de los procesos físicos y biológicos (Boschi, 1988; Framiñán \& Brown, 1996; Kurucz et al., 1998, Ronco et al., 2001). Los niveles de oxígeno disuelto (OD) y pH varían en función de la temperatura del agua y debido a los procesos metabólicos y fotosintéticos, y por los ciclos de marea. La mayoría de las condiciones hipóxicas y anóxicas, con sus correspondientes disminuciones en los niveles de $\mathrm{pH}$, ocurren durante los períodos cálidos de verano (Framiñán \& Brown, 1996). Los cambios en la salinidad y los bajos niveles de OD afectan la distribución y el éxito de los organismos béntónicos. El pH es otro factor importante a considerar. La elevada concentración de bicarbonato, calcio, y otros iones poseen una capacidad buffer contra los cambios de $\mathrm{pH}$. Los niveles de $\mathrm{pH}$ del agua de mar van de 7,8 a 8,4 , el $\mathrm{pH}$ en los estuarios es menor que 7,5 e incluso menor que 7,0 en condiciones de extrema acidez. Aunque la magnitud de la disminución parece ser pequeña, el pH está basado en una escala logarítmica y un cambio de 0,2-0,5 unidades tiene importantes consecuencias fisiológicas (Bamber, 1987, 1990; Ringwood \& Keppler, 2002). Las descargas de efluentes cloacales o desechos industriales acidifican el agua en ambientes con poca circulación a causa de la descomposición orgánica (Ringuelet, 1967; Boschi, 1988; Bamber, 1990).

Las diferencias significativas en los niveles de OD entre los ambientes estudiados pueden deberse principalmente al elevado nivel de polución y a la baja tasa de renovación del agua que presenta el río Santiago. Según Margalef (1983), si la dirección de flujo del oxígeno es del aire al agua, los ríos que reciben materia orgánica de los ecosistemas 
terrestres vecinos tienden a ser deficitarios en oxígeno, ya que la absorción de oxígeno atmosférico por el curso de agua define la velocidad con que transcurren las reacciones de descomposición. Otra forma de establecer el grado de contaminación de los cuerpos de agua es la demanda bioquímica de oxígeno (DBO). Si el agua contiene mucha materia orgánica, la demanda de oxígeno para oxidarla es muy elevada (Ringuelet, 1967; Margalef, 1983). Devercelli \& Peruchet (2008) estimaron la DBO para el río Coronda en períodos de aguas bajas (agosto y septiembre de 2005) y aguas altas (marzo y abril de 2006), con los siguientes valores medios (mínimos y máximos) para ambos períodos: $4,3 \mathrm{mg} \mathrm{L}^{-1}(2,9-6,4)$ y $2,3 \mathrm{mg} \mathrm{L}^{-1}$ $(1,1-4,2)$. En cambio, en el río Santiago el valor medio (mínimo y máximo) de DBO estimado de 2004 a 2007 fue 9,2 $\mathrm{mg} \mathrm{L}^{-1}$ (5-17) (datos cedidos por el Departamento de Ingeniería Consorcio de Gestión del Puerto La Plata).

La zona interna del Río de la Plata está afectada por la descarga de efluentes cloacales y tributarios contaminantes, producto de la actividad humana. El crecimiento de las ciudades, el mayor desarrollo industrial, la urbanización, la construcción de rutas y puertos, la actividad recreativa creciente, han cambiado los ambientes naturales contribuyendo a la contaminación de las aguas costeras del Río de la Plata (Boschi, 1988; Framiñán \& Brown, 1996; Kurucz et al., 1998, Ronco et al., 2001). Ringuelet (1967) definió al sector del río Santiago y aguas adyacentes como un área permanente de polución, debido a su proximidad con las industrias petroleras y el Astillero Río Santiago, donde se efectúan reparaciones y lavados de barcos, volcando grandes cantidades de hidrocarburos y metales pesados.

Los sedimentos en suspensión son un componente importante en el ecosistema del Río de la Plata. La masa de agua de este sistema transporta, en promedio, entre 50 y $300 \mathrm{mg}$ $\mathrm{L}^{-1}$ partículas en suspensión provenientes, mayoritariamente, de los sedimentos que aporta el río Paraná (Nagy et al., 1998). La carga de sedimentos en suspensión está estrechamente relacionada con la entrada de agua al sistema. El porcentaje de este material en el río Paraná es mayor (> 75 \%) que en el río Uruguay (Nagy et al., 1998). El drenaje de la subcuenca del Paraná, sumado al aporte de los ríos de la provincia de Buenos Aires y de Uruguay, genera un importante frente de agua dulce que empuja el agua de mar. Sin embargo, debido a la fuerza de los vientos que soplan en el estuario y al régimen de mareas, el agua de mar avanza hacia el río en forma de cuña (Boschi, 1988; Nagy et al., 1998). La acción de las mareas sobrepasa la isla Martín García, llegando hasta San Pedro, en el Paraná, a unos 150 km de la naciente del río (Boschi, 1988). Ecológicamente, un estuario es la manifestación de un proceso de mezcla. 
El agua dulce se mueve hacia fuera en superficie y se mezcla progresivamente con el agua de mar, generándose como compensación una corriente profunda de agua marina que avanza en dirección al río (Margalef, 1983). Este fenómeno podría explicar la diferencia de conductividad y de sólidos disueltos totales encontrada entre los ríos Coronda y Santiago, y es consistente con la clasificación obtenida mediante el análisis discriminante.

Nuestros resultados muestran que los dos sitios de muestreo tuvieron valores bajos de transparencia de agua pero se observaron diferencias significativas, el río Santiago estuvo caracterizado por aguas más transparentes. Esta diferencia podría estar asociada con la mayor salinidad estimada para ese sitio (Tabla 1.1 y 1.2). La elevada masa de sedimentos presentes en el cuerpo de agua afecta la transparencia, características del sustrato, turbiedad, producción primaria y secundaria $y$, en general, a toda la comunidad de organismos de la zona, tanto móvil como sésil y costeros (Pizarro \& Orlando, 1984; Boschi, 1988). La transparencia está inversamente relacionada con la turbidez, y este parámetro y la salinidad tienen un vínculo no-conservativo relacionado con la floculación de partículas en la interfase fluvio-marina (Edzwald et al., 1974; Edzwald \& O'Melia, 1975; Nagy et al., 1998; Thill et al., 2001). Uno de los factores que regulan el grado de floculación es el nivel de salinidad del cuerpo de agua, con consecuencias ecológicas importantes como un notable incremento en la transparencia del agua y una asimilación asociada de nutrientes biológicos (Framiñán \& Brown, 1996; Nagy et al., 1998; Verney et al., 2009). El transporte de las partículas en estuarios está manejado por las corrientes de marea, el flujo del río, el oleaje, la batimetría, el gradiente de salinidad y la materia particulada en suspensión (Verney et al., 2009). En el agua dulce las partículas en suspensión llevan carga negativa y tienden a repelerse unas a otras. En el estuario, el agua dulce se mezcla con el agua de mar cargada iónicamente, las cargas negativas se neutralizan y las partículas comienzan a atraerse. Como resultado de este proceso se produce el agrupamiento de micropartículas, que al hacerse más pesadas se depositan en el fondo (Edzwald et al., 1974; Edzwald \& O’Melia, 1975; Margalef, 1983; Thill et al., 2001).

Los eventos de inundación generan el intercambio de fluído entre zonas de retención hidráulica (zonas muertas o de almacenaje de poblaciones algales) y el cauce principal, posibilitando el enriquecimiento del fitoplancton transportado por los ríos (García de Emiliani \& Devercelli, 2004). El Coronda está acompañado sobre su margen oeste por la llanura aluvial 
del Paraná, que presenta un diseño anastomosado, con una complicada red de drenaje lótico-léntica (Edmundo C. Drago, comunicación personal). Los valores excepcionales de concentración de pigmentos registrados en ambos sitios de muestreo durante 2007, podrían estar relacionados con los eventos de inundación ocurridos en ese año en la cuenca del Paraná, debido a lluvias intensas (Edmundo C. Drago, comunicación personal). La calidad, distribución y relación entre las distintas clases de pigmentos indican el estado fisiológico de la comunidad y la composición del fitoplancton en cuanto a grupos algales (Margalef, 1983). Varios factores hidrológicos (descarga, tiempo de residencia del agua), físicos (condiciones de luz), químicos (concentración de nutrientes) y bióticos (alimentación, competencia) regulan la dinámica del plancton en los ríos. Nuestros resultados muestran diferencias en la concentración de clorofila $a$ y $b$, siendo mayor en el río Santiago que en el río Coronda. El índice de Margalef mostró períodos de baja tasa de renovación algal (> 5) en río Santiago. Estos resultados indicarían la adición de otros pigmentos y la presencia de productos de descomposición de la clorofila que elevan el índice (Margalef, 1983). La diferencia de concentración de pigmentos entre los dos sitios de estudio podría estar relacionada con la diferencia de concentración de nutrientes, disponibilidad de luz, velocidad y tiempo de residencia del agua (Margalef, 1983; Reynolds, 1988; Dervecelli \& Peruchet, 2008). El tiempo de residencia del agua (o retención fluvial) permite explicar diferencias del fitoplancton en distintos ambientes a lo largo del recorrido de un río (García de Emiliani \& Devercelli, 2004; Reynolds, 1988). Los ríos con mayor tiempo de residencia del agua y alta oferta nutritiva favorecen el desarrollo algal, pudiéndose observar alta densidad de fitoplancton, dominancia de distintos grupos algales $y$, en especial, proliferaciones transitorias de cianobacterias en zonas de retención hidráulica (Basu \& Pick, 1996; Everbecq et al., 2001; García de Emiliani \& Devercelli, 2004). En el río Coronda, la velocidad del agua, en el centro del cauce, oscila entre $0,30 \mathrm{~m} \mathrm{seg}^{-1}$ y $1,2 \mathrm{~m} \mathrm{seg}^{-1}$. Durante las grandes crecientes (ENSO - El Niño Southern Oscillation), la velocidadalcanza 1,5-1,8 $\mathrm{m} \mathrm{seg}^{-1}$. En aguas medias, la velocidad es aproximadamente $0,4-0,6 \mathrm{~m} \mathrm{seg}^{-1}$ (Edmundo C. Drago, datos sin publicar). La velocidad de corriente en el Río de la Plata está definida por el volumen de descarga de los ríos Paraná y Uruguay. Para una descarga media de $22.000 \mathrm{~m}^{3} \mathrm{seg}^{-1}$ la velocidad de corriente de deriva es aproximadamente de 0,10 $\mathrm{m} \mathrm{seg}^{-1}$ en la parte interna del estuario; 0,05 $\mathrm{m}^{3} \mathrm{seg}^{-1}$ en la parte media del estuario y $0,01 \mathrm{~m}^{3} \mathrm{seg}^{-1}$ en la parte externa. En general, la velocidad del agua en el Río de la Plata es baja y el tiempo de residencia es mayor que 40 días (Gómez et al., 2004). La 
velocidad de corriente y la extensión de cada zona del estuario permiten estimar el tiempo aproximado de residencia del agua. La parte interna del estuario tiene $55 \mathrm{~km}$ de largo, la intermedia tiene $120 \mathrm{~km}$ y la externa $90 \mathrm{~km}$. Estos valores dan tiempos de residencia de 61/2, 30 y 100 días respectivamente (Menéndez, 2001). Otros autores obtuvieron valores similares de velocidad de la corriente $0,28-0,50 \mathrm{~m} \mathrm{seg}^{-1}$ (AGOSBA-OSN-SIHN, 1994) y 0,5 m seg (Framiñán \& Brown, 1996). Para Pizarro \& Orlando (1984) el tiempo de residencia del agua correspondiente al sector interno es de unos 12 días aproximadamente y 36,6 días en promedio. Sin embargo, inferimos que en el sistema del río Santiago, debido a sus características topográficas, la velocidad y el recambio del agua podrían ser más bajos que lo estimado por otros autores para las distintas zonas del estuario previamente mencionadas.

El crecimiento masivo de algas conocido como floración es un problema ambiental común en represas y cuerpos de agua con elevada retención hidráulica por la eutroficación debida al enriquecimiento por fósforo. Las cianobacterias se incluyen entre los grupos fitoplanctónicos que más frecuentemente producen floraciones (von Rückert et al., 2004). Las floraciones de cianobacterias ocurren en áreas donde la actividad humana o la contaminación son intensas; especialmente cerca de los centros urbanos, donde el aporte antropogénico se realiza mediante descargas domésticas e industriales. Estos factores han sido identificados como la principal causa de eutrofización en el Río de la Plata (Ringuelet, 1967; Boschi, 1988; Kurucz et al., 1998). En la mayoría de los casos las floraciones ocurridas en ese ambiente y zonas aledañas, como el río Santiago, son uniespecíficas, siendo la cianobacteria Microcystis aeruginosa (Kützing, 1846) la principal responsable de las floraciones. La abundancia relativa de esta especie puede ser mayor que el 80 \% e incluso alcanzar valores del 97 \% de abundancia. El nivel de contaminación en el Río de la Plata resulta en un impacto ambiental negativo que implica la pérdida de diversidad fitoplanctónica y favorece el desarrollo de esta cianobacteria (Echenique et al., 2006; Andrinolo et al., 2007; Oteiza et al., 2007). La mortalidad en masa de organismos acuáticos en el ambiente es atribuida a las cianobacterias por los problemas ecológicos y de salud que causan en animales y humanos mediante las toxinas que producen tales como lipopolisacáridos, neurotoxinas y hepatoxinas (Ringuelet, 1967; Vasconcelos, 1999; Juhel et al., 2006). Este tipo de floraciones en el sistema del río Santiago fueron de mayor magnitud en los meses cálidos (Fig. 1.4.1), mientras que en el Coronda no se observaron floraciones algales durante el período de estudio. Los resultados obtenidos en este estudio muestran que las floraciones 
algales que se registran en el río Santiago se evidencian en los picos de clorofila. A su vez, estarían directamente asociadas con un posible mayor tiempo de residencia del agua y una mayor eutrofización del ambiente, esto último confirmado por la baja concentración de oxígeno disuelto y pH más ácido.
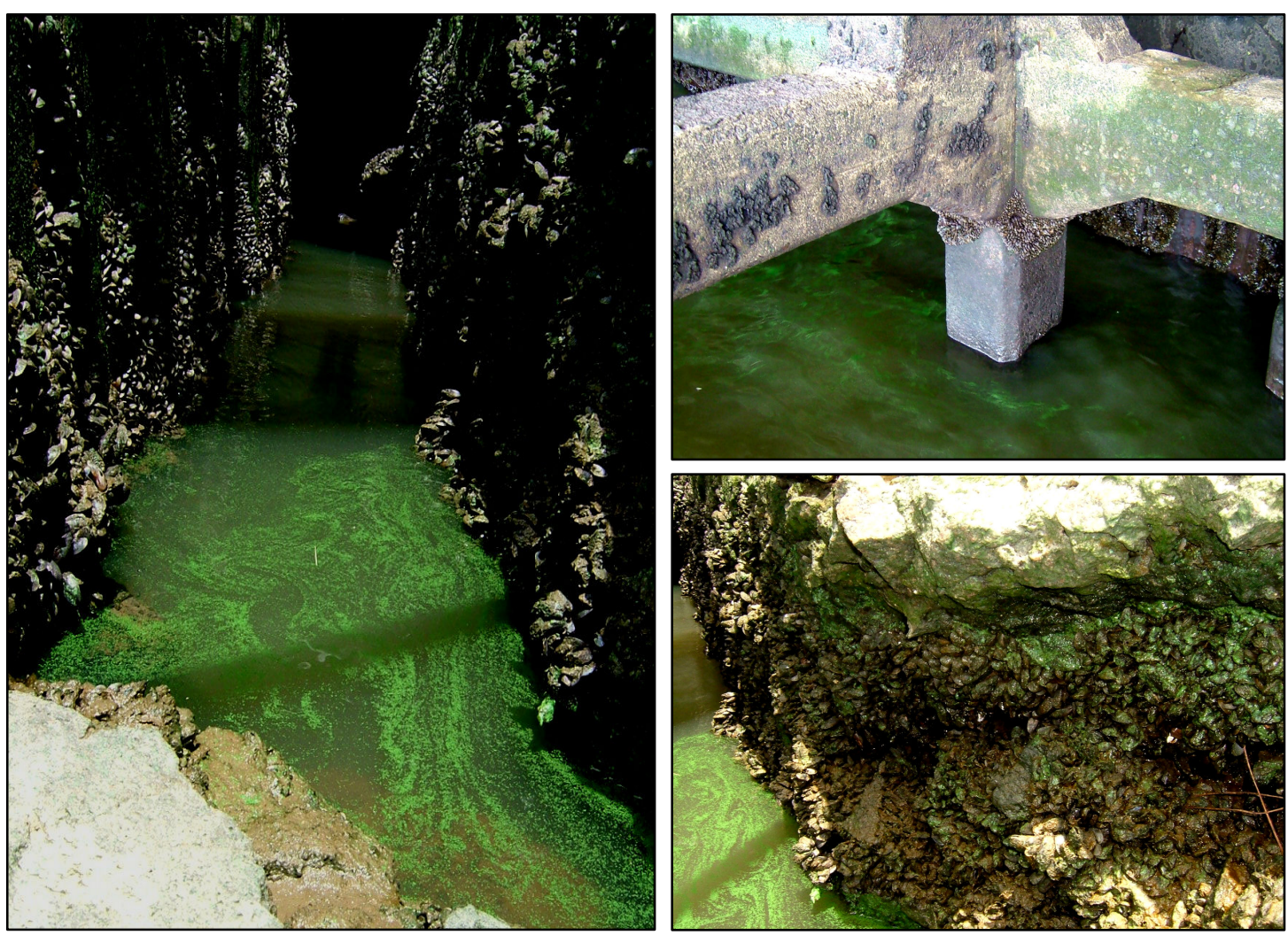

Figura 1.4.1. Floración algal en el río Santiago. 


\section{CAPÍTULO 2}




\section{CAPÍTULO 2}

\section{ANÁLISIS COMPARATIVO DE LA DENSIDAD LARVAL DE Limnoperna fortunei EN DOS CUERPOS DE AGUA DE LA CUENCA DEL PLATA}

\subsection{INTRODUCCIÓN}

La familia Mytilidae posee una única especie dulciacuícola, Limnoperna fortunei (Dunker, 1857), que no es nativa de América. Esta especie es única entre los bivalvos nativos de agua dulce de la Cuenca del Plata por el tipo de reproducción y su hábito de vida, típicos de mejillones marinos. Posee fecundación externa y un ciclo larval que se desarrolla completamente libre en el medio acuático, mediante una larva planctónica nadadora (Ricciardi, 1998; Cataldo et al., 2005; Ezcurra de Drago et al., 2006). El desarrollo larval está caracterizado por dos etapas. La primera corresponde a estadios de sin valvas: huevos, trocóforas y pre-velíger. La segunda etapa involucra a los estadios posteriores, con valvas: velíger-D, preumbonado, umbonado, pedivelíger y plantígrado (Ezcurra de Drago et al., 2006).

Sus características biológicas han facilitado la dispersión y la utilización de sustratos bentónicos sólidos, convirtiéndose en el macroinvertebrado dominante de los sustratos firmes en los $3.000 \mathrm{~km}$ del sistema conformado por los ríos de la Plata, Paraná y Paraguay (Sardiña et al., 2009; Nakano et al., 2010a). Estas características biológicas le permiten ocupar un nicho ecológico que estaba vacante y desempeñarse como ingeniero ecosistémico (Karatayev et al., 2007; Darrigran \& Damborenea, 2011). Paralelamente, L. fortunei comparte varios rasgos biológicos y características ecológicas con Dreissena polymorpha Pallas, 1771 (Dreissenidae) (Ricciardi, 1998).

En bivalvos en general, el ciclo reproductivo se ha dividido típicamente en un período reproductivo, que comienza con la gametogénesis y culmina en la emisión de las gametas, y un período de descanso en el que se acumula la energía necesaria para promover la nueva gametogénesis. El período reproductivo se caracteriza por uno o más ciclos gametogénicos, seguidos por una liberación de gametas cuando los acinos gonadales se vacían parcial o 
completamente (Darrigran et al., 1999, 2003, 2009). La mayoría de las poblaciones de bivalvos que habitan aguas templadas muestra un patrón estacional de reproducción (Seed \& Suchanek, 1992). Generalmente, el proceso de gametogénesis y desove en los Bivalvia se relaciona con cambios de la temperatura ambiente (Morton, 1982; Borcherding, 1991; Chícharo \& Chícharo, 2001; McMahon \& Bogan, 2001; Darrigran et al., 2003, 2009; Boltovskoy et al., 2009). La reactivación de las gónadas en reposo y la gametogénesis comienzan en los meses de invierno. Durante la primavera ocurre un desove parcial, seguido por una rápida recuperación hasta que, a comienzos del verano, las gónadas están completamente maduras (Seed \& Suchanek, 1992).

Estudios sobre densidad larval y reproducción de L. fortunei indican que, en climas templados y subtropicales, la abundancia de larvas en el plancton se correlaciona positivamente con la temperatura del agua. Además, reconocen un período prolongado de producción larval de primavera a otoño y un período de recuperación en el invierno (Morton, 1977, 1982; Cataldo \& Boltovskoy, 1998, 2000; Darrigran et al., 2002; Sylvester et al., 2007; Pestana el al., 2008; Boltovskoy et al., 2009; Nakano et al., 2011). Otros factores que afectan la distribución, abundancia y actividad reproductiva de los bivalvos son geográficos y ambientales, como el oxígeno disuelto, la transparencia del agua, la salinidad, la disponibilidad de alimento y la perturbación ambiental (Morton 1982; Garton \& Haag, 1993; Karatayev et al., 2007; Boltovskoy et al., 2009).

El estudio comparativo del ciclo reproductivo de L. fortunei influido por condiciones ambientales diferentes, es básico para mejorar el conocimiento de la ecología, dinámica de invasión e impacto y para conocer las variaciones espaciales y temporales que sufre la población de esta especie. 


\subsubsection{OBJETIVOS}

Para este capítulo se plantearon los siguientes objetivos:

- Identificar los diferentes estadios larvales de Limnoperna fortunei: velíger-D, preumbonado y umbonado.

- Estimar y comparar la densidad larval del mejillón entre los dos cuerpos de agua de la Cuenca del Plata.

- Determinar cuales son los principales parámetros ambientales en cada ambiente que influyen en la densidad de los distintos estadios larvales de $L$. fortunei.

\subsubsection{HIPÓTESIS}

Las hipótesis planteadas para este capítulo son:

- Existen diferencias significativas entre las densidades larvales estimadas para cada ambiente como consecuencia de las diferencias en las características limnológicas de los sitios de muestreo.

- Existen dos picos de densidad de larvas en cada año de muestreo y en cada ambiente, y están correlacionados con la temperatura del agua. 


\subsection{MATERIALES Y MÉTODOS}

\subsubsection{Características limnológicas de los sitios de muestreo}

Se seleccionaron dos puntos de muestreo localizados en la región inferior de la Cuenca del Plata. El primer sitio es el río Coronda ( $31^{\circ} 41^{\prime} 26,88^{\prime \prime} \mathrm{S}$ - $60^{\circ} 44^{\prime} 34,08^{\prime \prime}$ O), cauce secundario del río Paraná; y el segundo, el río Santiago ( $34^{\circ} 51^{\prime} 1,46^{\prime \prime} \mathrm{S}-57^{\circ} 53^{\prime} 28,23^{\prime \prime}$ O), afluente del Río de la Plata. Ambos sitios presentan características limnológicas diferentes. El Coronda está caracterizado por un pH y una concentración de oxígeno mayor que los registrados en el río Santiago. En cambio, el Santiago está caracterizado por valores de conductividad, concentración de calcio, transparencia, y concentración de pigmentos fotosintéticos mayores que en el río Coronda (para más detalle ver Capítulo 1).

\subsubsection{Recuento y clasificación de los estadios larvales}

En el río Coronda se filtró un total de 15 muestras en un período de 22 meses (abril de 2007 a febrero de 2009), mientras que en el río Santiago se recolectó un total de 14 muestras de agua desde marzo de 2007 a marzo de 2009. En cada sitio de muestreo se filtraron 400-500 L de agua utilizando una bomba de achique y una red de Wisconsin de $47 \mu \mathrm{m}$ de abertura de malla. La red de plancton se sumergió en el agua dejando $20-30 \mathrm{~cm}$ del aro por encima de la superficie para evitar que la presión del agua dañase el material filtrado. El agua filtrada se concentró en un recipiente de 0,5 L y fue conservado en alcohol 40 \% (Darrigran et al., 2002).

Para identificar y contar las larvas se tomaron de cada muestra, luego de su homogeneización, tres a cuatro submuestras de $1 \mathrm{~mL}$ con una pipeta graduada desde la mitad de la columna de agua. Cada submuestra se colocó en una cámara de Sedgwick-Rafter de $1 \mathrm{~mL}$ de capacidad bajo microscopio óptico binocular (Fraleigh et al., 1993; Garton \& Haag, 1993; Claudi \& Mackie, 1994; Dobretsov \& Miron, 2001; Pestana et al., 2008). No hay un acuerdo establecido para establecer las diferentes categorías de larvas de L. fortunei. Algunas de las clasificaciones propuestas son: velíger-D, velíger y umbonados (Cataldo \& Boltovskoy, 2000; Pestana et al., 2008); velíger-D, velíger umbonado y pedivelíger (Cataldo et al., 2005); velíger-D, preumbonados, umbonados (Cataldo \& Boltovskoy, 1998); velíger y postvelíger (Darrigran et al., 2002). A su vez, se han establecido sub-categorías para el 
estadio velíger-D: temprano, medio y tardío (Choi \& Kim, 1985; Choi \& Shin, 1985). La utilización de alcohol 40 \% para la conservación de las muestras no permitió que las estructuras internas, velo y pie se conservaran adecuadamente. Por esta razón, la identificación de estadios se basó principalmente en la forma de la charnela y del umbo. Los estadios larvales se clasificaron en velíger-D (larva de charnela recta), preumbonado (en la que el umbo no sobrepasa el contorno de la valva) y umbonado (el umbo sobresale del contorno de la valva). Esta última categoría incluye al estadio de larva plantígrada (Cataldo \& Boltovskoy, 1998; Ezcurra de Drago et al., 2006).

\subsubsection{Densidad larval}

Para estimar la densidad de larvas por volumen de agua $\left(\mathrm{m}^{3}\right)$ se promediaron los valores obtenidos para las submuestras, corrigiendo la dilución generada por la adición del 40 \% de alcohol.

Los valores de densidad de larvas se transformaron mediante $\sqrt{(X+0,5)}$ y las variables ambientales mediante $\ln (\mathrm{x})$ y $\ln (\mathrm{x}+1)$, para aproximarlos a condiciones de normalidad $\mathrm{y}$ homocedasticidad (Zar, 1996). Se realizó un tests de Student para comparar densidades medias y de correlación de Pearson para evaluar la asociación entre las variables y las densidades estimadas en cada ambiente. 


\subsection{RESULTADOS}

En ambos sitios de muestreo se identificaron los estadios larvales velíger-D, preumbonado y umbonado de L. fortunei (Fig. 2.3.1 a-c). Se estimó la densidad para cada estadio larval y la densidad total para cada fecha de muestreo (Tabla $2.1 \mathrm{~A}-\mathrm{B}$ ).
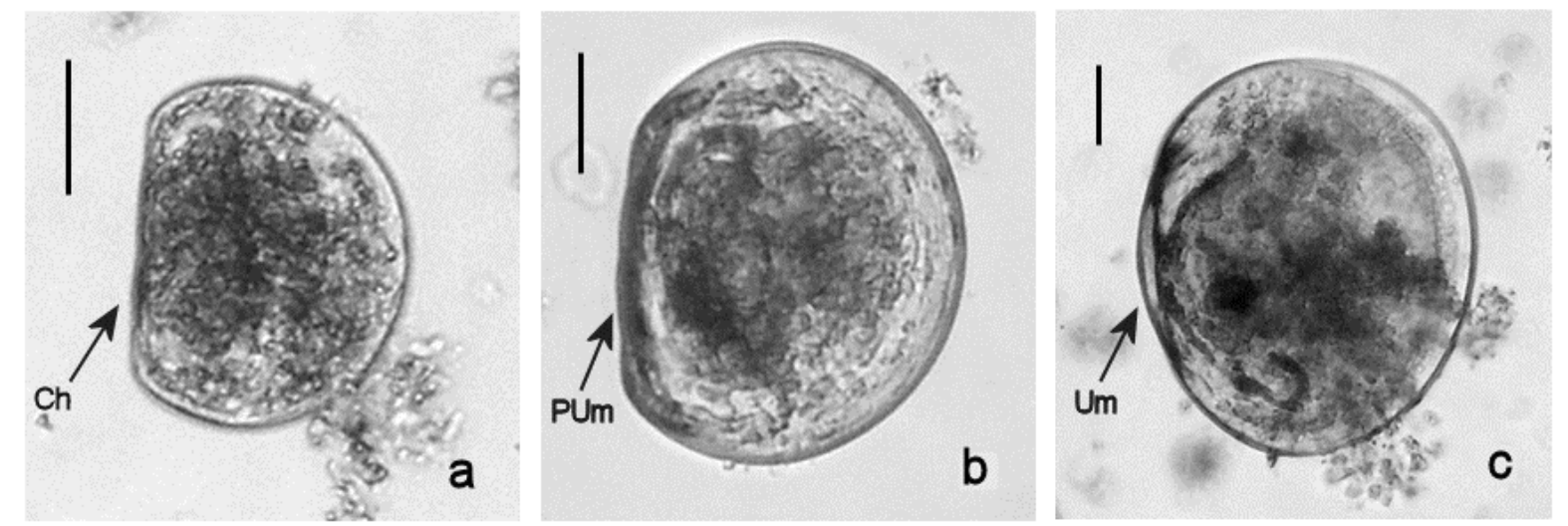

Figura 2.3.1. Estadios larvales de Limnoperna fortunei. a) velíger-D; b) preumbonado; c) umbonado. Ch: Charnela; PUm: preumbo; Um: Umbo. Barra de referencia $=50 \mu \mathrm{m}$. 
Tabla 2.1. Valores estimados de la densidad \pm EE (ind. $\mathrm{m}^{-3}$ ) para cada estadio y total; valores de las variables ambientales para cada fecha de muestreo. $\mathrm{N}$ : número de

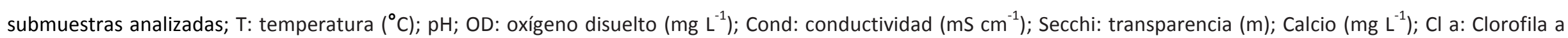
$\left(\mathrm{mg} \mathrm{m}^{-3}\right) ; \mathrm{Cl}$ b: Clorofila b $\left(\mathrm{mg} \mathrm{m}^{-3}\right)$; $\mathrm{Cl} \mathrm{c:} \mathrm{Clorofila} \mathrm{c}\left(\mathrm{mg} \mathrm{m}^{-3}\right)$. ND: dato no disponible.

\section{A) Río Coronda}

\begin{tabular}{|c|c|c|c|c|c|c|c|c|c|c|c|c|c|c|c|}
\hline Año & Meses & Velíger-D & Preumbonado & Umbonado & $\mathbf{N}$ & TOTAL & $T$ & $\mathrm{pH}$ & OD & Cond & Secchi & Calcio & $\mathrm{Cla}$ & $\mathrm{Cl} \mathrm{b}$ & $\mathrm{Cl} \mathrm{c}$ \\
\hline & Abr & 0 & 0 & 0 & 3 & 0 & 19,6 & 7,16 & 14,3 & 0,356 & ND & ND & ND & ND & ND \\
\hline & Jun & 0 & 0 & 0 & 3 & 0 & 13,1 & 7,42 & 14,8 & 0,222 & 0,50 & ND & ND & ND & ND \\
\hline & Jul & 0 & 0 & 0 & 4 & 0 & 10,1 & 7,59 & 9,5 & 0,215 & 0,45 & ND & ND & ND & ND \\
\hline \multirow[t]{7}{*}{2007} & Ago & 0 & 0 & 0 & 3 & 0 & 14,1 & 8 & 10,3 & 0,244 & 0,50 & ND & ND & ND & ND \\
\hline & Sep & $880 \pm 241$ & $1980 \pm 282$ & $880 \pm 241$ & 4 & $3740 \pm 367$ & 19 & 7,69 & 8 & 0,655 & ND & 180 & 22,91 & 21,14 & 1,33 \\
\hline & Oct & $633 \pm 320$ & $1267 \pm 160$ & $1267 \pm 423$ & 3 & $3167 \pm 211$ & 25,1 & 7,38 & 6,5 & 0,369 & 0,30 & 102 & 5,25 & 1,84 & 5,38 \\
\hline & Dic & $920 \pm 289$ & $3680 \pm 289$ & $15640 \pm 764$ & 3 & $20240 \pm 4517$ & 28,5 & 7,65 & 6,7 & 0,263 & 0,40 & 37 & 7,31 & 3,55 & 4,95 \\
\hline & Feb & $760 \pm 300$ & $2280 \pm 300$ & $1013 \pm 173$ & 3 & $4053 \pm 470$ & 25,8 & 7,52 & 6,9 & 0,208 & 0,10 & 45 & 6,15 & 0,00 & 0,00 \\
\hline & Abr & $1013 \pm 441$ & $3800 \pm 577$ & $507 \pm 167$ & 3 & $5320 \pm 1024$ & 22,9 & 7,5 & 6 & 0,159 & 0,15 & 48 & 2,72 & 1,93 & 2,73 \\
\hline & Jun & 0 & $520 \pm 180$ & 0 & 3 & $520 \pm 173$ & 14,4 & 7,5 & 8,4 & 0,100 & 0,30 & 27 & 3,68 & 0,24 & 3,01 \\
\hline \multirow[t]{4}{*}{2008} & Ago & $493 \pm 333$ & $493 \pm 167$ & $247 \pm 167$ & 3 & $1233 \pm 82$ & 16,3 & 7,5 & 8,6 & 0,089 & 0,40 & 33 & 2,76 & 1,00 & 0,66 \\
\hline & Sep & 0 & $820 \pm 204$ & $1025 \pm 239$ & 4 & $1845 \pm 313$ & 19,4 & 7,46 & 9,1 & 0,092 & 0,50 & 27 & 6,97 & 2,16 & 1,25 \\
\hline & Nov & $2007 \pm 441$ & $287 \pm 167$ & $1147 \pm 333$ & 3 & $3440 \pm 497$ & 25,0 & 7,43 & 6,9 & 0,089 & 0,40 & 33 & 3,70 & 1,05 & 0,20 \\
\hline & Dic & $1333 \pm 180$ & $2133 \pm 180$ & $1333 \pm 476$ & 3 & $4800 \pm 267$ & 29,5 & 7,9 & 7,5 & 0,151 & 0,40 & 6 & 9,86 & 3,83 & 1,52 \\
\hline 2009 & Feb & $720 \pm 500$ & $1440 \pm 408$ & $720 \pm 500$ & 4 & $2880 \pm 240$ & 26,1 & 7,94 & 6,9 & 0,15 & 0,15 & 11 & 4,42 & 2,20 & 0,95 \\
\hline
\end{tabular}


Tabla 2.1. Continuación..

B) Río Santiago

\begin{tabular}{|c|c|c|c|c|c|c|c|c|c|c|c|c|c|c|c|}
\hline Año & Meses & Velíger-D & Preumbonado & Umbonado & $\mathbf{N}$ & TOTAL & $\mathbf{T}$ & $\mathrm{pH}$ & OD & Cond & Secchi & Calcio & $\mathrm{Cla}$ & $\mathrm{Cl} \mathrm{b}$ & $\mathrm{Cl} \mathrm{c}$ \\
\hline \multirow{6}{*}{2007} & Mar & $125 \pm 63$ & $875 \pm 157$ & $250 \pm 72$ & 4 & $1250 \pm 232$ & 24,0 & 7,2 & 5,1 & 0,485 & ND & ND & ND & ND & ND \\
\hline & May & $800 \pm 233$ & $1300 \pm 366$ & $900 \pm 248$ & 4 & $3000 \pm 153$ & 18,0 & 7,27 & 10,3 & 0,487 & ND & ND & ND & ND & ND \\
\hline & Sep & 0 & 0 & 0 & 3 & 0 & 16,6 & 7,54 & 5,8 & 0,449 & 0,80 & 69 & 45,02 & 22,94 & 1,75 \\
\hline & Oct & $180 \pm 125$ & $180 \pm 125$ & $540 \pm 239$ & 4 & $900 \pm 120$ & 17,1 & 7,20 & 3,2 & 0,365 & 0,40 & 59 & 37,97 & 82,12 & 2,75 \\
\hline & Nov & $400 \pm 250$ & 0 & $400 \pm 250$ & 4 & $800 \pm 133$ & 23,3 & 7,45 & 3,4 & 0,504 & 0,48 & 51 & 15,18 & 11,04 & 4,67 \\
\hline & Dic & 0 & $800 \pm 300$ & $1800 \pm 492$ & 4 & $2600 \pm 521$ & 23,8 & 7,33 & 3,6 & 0,424 & 0,62 & 60 & 21,55 & 5,23 & 4,91 \\
\hline \multirow{6}{*}{2008} & Ene & $220 \pm 133$ & 0 & 0 & 3 & $220 \pm 73$ & 27,6 & 7,46 & 4,5 & 0,498 & 0,62 & 46 & 26,56 & 2,75 & 0,08 \\
\hline & Abr & $570 \pm 220$ & $1710 \pm 289$ & $1140 \pm 230$ & 4 & $3420 \pm 329$ & 26,3 & 7,43 & 3,3 & 0,435 & 0,45 & 69 & 4,95 & 2,79 & 0,73 \\
\hline & Jul & 0 & 0 & 0 & 3 & 0 & 13,7 & 7,48 & 4,8 & 0,430 & 0,45 & 74 & 3,52 & 8,22 & 0,56 \\
\hline & Sep & 0 & 0 & 0 & 3 & 0 & 15,8 & 7,41 & 6,1 & 0,420 & 0,65 & 60 & 17,28 & 4,69 & 0,94 \\
\hline & Oct & $220 \pm 135$ & $440 \pm 270$ & 0 & 4 & $660 \pm 127$ & 21,6 & 7,24 & 6,1 & 0,424 & 0,60 & 13 & 25,03 & 5,97 & 6,76 \\
\hline & Nov & 0 & $717 \pm 467$ & $358 \pm 233$ & 4 & $1075 \pm 207$ & 26,3 & 7,54 & 5,2 & 0,373 & 0,45 & 15 & 10,67 & 1,45 & 7,18 \\
\hline \multirow{2}{*}{2009} & Feb & $420 \pm 162$ & $210 \pm 140$ & $420 \pm 162$ & 4 & $1050 \pm 70$ & 25,3 & 7,54 & 5,8 & 0,509 & 0,40 & 14 & 25,17 & 4,78 & 3,33 \\
\hline & Mar & $1500 \pm 408$ & $750 \pm 289$ & $375 \pm 250$ & 4 & $2625 \pm 331$ & 24,8 & 7,48 & 4,9 & 0,443 & 0,35 & 19 & 10,68 & 2,82 & 1,14 \\
\hline
\end{tabular}


En el análisis comparativo entre las densidades larvales estimadas para cada ambiente no se tuvieron en cuenta los muestreos en los que la densidad total fue nula ya que su consideración en el análisis generó un error estadístico de Tipo 2. En esas condiciones, las densidades totales entre ambientes mostraron diferencias significativas (Tabla 2.2).

En 2007, la densidad total de larvas para el río Coronda fue nula en la primera mitad del año, mientras que en la segunda mitad la abundancia se incrementó, alcanzó valores máximos en diciembre (20.240 ind. $\mathrm{m}^{-3}$ ). La ausencia de larvas en la primera parte del año pudo estar relacionada con los eventos de inundación ocurridos en ese ambiente (observación personal). En 2008 se observaron dos picos de densidad larval, el primero en abril, con 5.320 ind. $\mathrm{m}^{-3}$; luego disminuyó en junio a un valor de 520 ind. $\mathrm{m}^{-3}$. En la segunda mitad del año, se observó un incremento en la densidad, con un valor máximo total en diciembre (4.800 ind. $\mathrm{m}^{-3}$ ). La densidad estimada en diciembre de 2008 fue cuatro veces menor que la registrada en diciembre de 2007 (Fig. 2.3.2). La densidad de cada estadio larval y la densidad total mostraron una correlación positiva con la temperatura del agua y una correlación negativa con el OD (Tabla 2.3). Los resultados mostraron que a una temperatura del agua menor que $15^{\circ} \mathrm{C}$, la presencia de larvas fue muy baja $\left(<500\right.$ ind. $\left.\mathrm{m}^{-3}\right)$ o nula, mientras que a temperaturas mayores que $15^{\circ} \mathrm{C}$ las densidades se incrementaron hasta valores máximos (Fig. 2.3.2). Los picos máximos de densidad total estuvieron asociados, en promedio, a valores de $\mathrm{OD}=6,8 \pm 0,6 \mathrm{mg} \mathrm{L}^{-1}$. La densidad total fue baja coincidiendo con un valor de OD mayor que $8 \mathrm{mg} \mathrm{L}^{-1}$. Las demás variables no mostraron correlaciones significativas con la densidad total. La transparencia del agua tuvo una correlación negativa con los estadios velíger-D y preumbonado (Tabla 2.3 ). 
Tabla 2.2. Resultados del test de Student (SPSS Stastistics 17.0$)$ para datos transformados: $\sqrt{(X+0,5)}$. Preumb.: Preumbonado; Umbon.: Umbonado; Total; $(*)$ : indica diferencias significativas.

\begin{tabular}{|c|c|c|c|c|c|c|c|c|c|c|}
\hline & & \multicolumn{2}{|c|}{$\begin{array}{c}\text { Test de Levene } \\
\text { para igualdad } \\
\text { de varianzas }\end{array}$} & \multicolumn{5}{|c|}{ Test $t$ para igualdad de medias } & \multicolumn{2}{|c|}{$\begin{array}{c}\text { Intervalo de } \\
\text { confianza al 95\% }\end{array}$} \\
\hline & & $\mathbf{F}$ & $\mathbf{p}$ & $\mathbf{t}$ & gl & p (2-colas) & Diferencia de la media & Diferencia de ES & Mín & Máx \\
\hline \multirow{2}{*}{ Velíger-D } & Igualdad de varianzas asumida & 0,080 & 0,780 & $-1,534$ & 20 & 0,141 & $-8,11$ & 5,29 & $-19,14$ & 2,92 \\
\hline & Igualdad de varianzas no asumida & & & $-1,534$ & 19 & 0,141 & $-8,11$ & 5,29 & $-19,16$ & 2,94 \\
\hline \multirow[t]{2}{*}{ Preumb } & Igualdad de varianzas asumida & 0,257 & 0,618 & $-2,774$ & 20 & $0,012^{*}$ & $-16,83$ & 6,07 & $-29,48$ & $-4,17$ \\
\hline & Igualdad de varianzas no asumida & & & $-2,774$ & 20 & $0,012 *$ & $-16,83$ & 6,07 & $-29,49$ & $-4,16$ \\
\hline \multirow[t]{2}{*}{ Umbon } & Igualdad de varianzas asumida & 0,886 & 0,358 & $-1,466$ & 20 & 0,158 & $-14,98$ & 10,22 & $-36,31$ & 6,34 \\
\hline & Igualdad de varianzas no asumida & & & $-1,466$ & 13 & 0,166 & $-14,98$ & 10,22 & $-37,05$ & 7,09 \\
\hline \multirow[t]{2}{*}{ Total } & Igualdad de varianzas asumida & 0,808 & 0,379 & $-2,366$ & 20 & $0,028^{*}$ & $-23,99$ & 10,14 & $-45,14$ & $-2,84$ \\
\hline & Igualdad de varianzas no asumida & & & $-2,366$ & 14 & $0,033 *$ & $-23,99$ & 10,14 & $-45,74$ & $-2,25$ \\
\hline
\end{tabular}




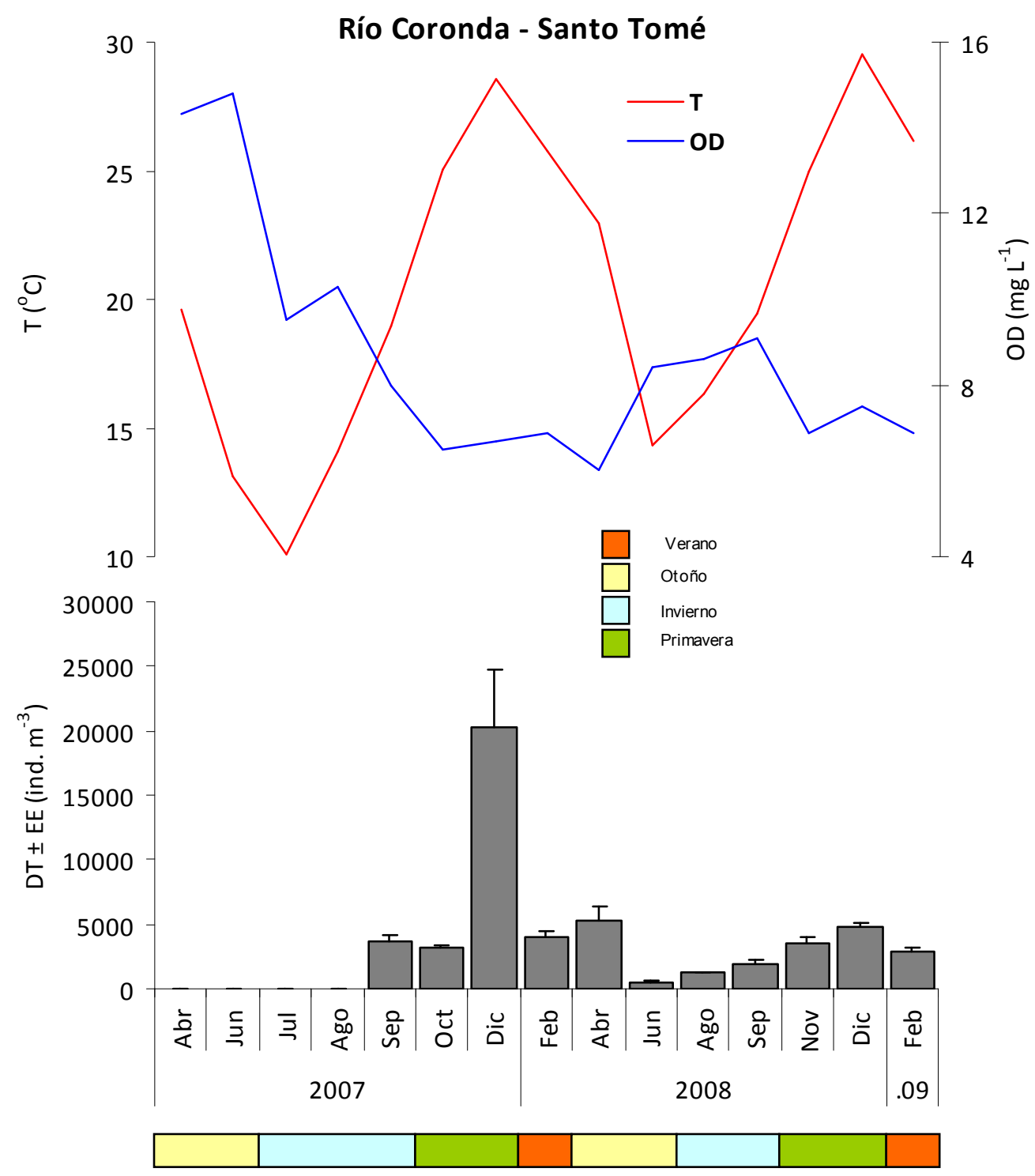

Figura 2.3.2. Variación de la densidad total $(D T) \pm$ error estándar $(E E)$, variación de la temperatura del agua $(T)$ y del oxígeno (OD) durante el período de estudio en el río Coronda. 
Tabla 2.3. Resultados de la correlación de Pearson entre las variables ambientales y la densidad de larvas en el río Coronda. Velíger-D; Preumb: Preumbonado; Umbon: Umbonado; Total; T: temperatura $\left({ }^{\circ} \mathrm{C}\right)$; $\mathrm{pH}$; OD: oxígeno disuelto $\left(\mathrm{mg} \mathrm{L}^{-1}\right)$; Cond: conductividad $\left(\mathrm{mS} \mathrm{cm}^{-1}\right)$; Secchi: transparencia $(\mathrm{m})$; Calcio $\left(\mathrm{mg} \mathrm{L}^{-1}\right)$; $\mathrm{Cl}$ a: Clorofila a $\left(\mathrm{mg} \mathrm{m}^{-3}\right)$; $\mathrm{Cl}$ b: Clorofila b $\left(\mathrm{mg} \mathrm{m}^{-3}\right)$; Cl c: Clorofila c $\left(\mathrm{mg} \mathrm{m}^{-3}\right)$.

\begin{tabular}{|c|c|c|c|c|c|c|c|c|c|c|c|c|c|c|}
\hline & & Velíger-D & Preumb & Umbon & Total & $T$ & $\mathrm{pH}$ & OD & Cond & Secchi & Calcio & Cl_a & Cl_b & Cl_c \\
\hline & Correlación Pearson & 1 & $0,699 * *$ & $0,547^{*}$ & $0,748 * *$ & $0,746 * *$ & 0,194 & $-0,766 * *$ & $-0,046$ & $-0,594^{*}$ & 0,002 & 0,097 & 0,267 & $-0,218$ \\
\hline \multirow[t]{3}{*}{ Velíger-D } & p (2-colas) & & 0,004 & 0,035 & 0,001 & 0,001 & 0,489 & 0,001 & 0,871 & 0,032 & 0,996 & 0,778 & 0,428 & 0,520 \\
\hline & $\mathbf{N}$ & 15 & 15 & 15 & 15 & 15 & 15 & 15 & 15 & 13 & 11 & 11 & 11 & 11 \\
\hline & Correlación Pearson & & 1 & $0,687^{* *}$ & $0,890 * *$ & $0,740 * *$ & 0,214 & $-0,801 * *$ & $-0,028$ & $-0,700 * *$ & 0,099 & 0,310 & 0,354 & 0,348 \\
\hline \multirow[t]{3}{*}{ Preumb } & p (2-colas) & & & 0,005 & 0,000 & 0,002 & 0,445 & 0,000 & 0,921 & 0,008 & 0,772 & 0,353 & 0,286 & 0,294 \\
\hline & $\mathbf{N}$ & & 15 & 15 & 15 & 15 & 15 & 15 & 15 & 13 & 11 & 11 & 11 & 11 \\
\hline & Correlación Pearson & & & 1 & $0,927^{* *}$ & $0,669 * *$ & 0,139 & $-0,537^{*}$ & 0,020 & $-0,162$ & 0,029 & 0,260 & 0,261 & 0,380 \\
\hline \multirow[t]{3}{*}{ Umbon } & p (2-colas) & & & & 0,000 & 0,006 & 0,621 & 0,039 & 0,945 & 0,598 & 0,934 & 0,440 & 0,438 & 0,249 \\
\hline & $\mathbf{N}$ & & & 15 & 15 & 15 & 15 & 15 & 15 & 13 & 11 & 11 & 11 & 11 \\
\hline & Correlación Pearson & & & & 1 & $0,783 * *$ & 0,175 & $-0,753 * *$ & $-0,040$ & $-0,452$ & 0,049 & 0,256 & 0,315 & 0,357 \\
\hline \multirow[t]{2}{*}{ Total } & $p$ (2-colas) & & & & & 0,001 & 0,532 & 0,001 & 0,887 & 0,121 & 0,887 & 0,447 & 0,345 & 0,281 \\
\hline & $\mathbf{N}$ & & & & 15 & 15 & 15 & 15 & 15 & 13 & 11 & 11 & 11 & 11 \\
\hline
\end{tabular}

**. Correlación altamente significativa a un nivel de 0,01 (2-colas).

*. Correlación significativa a un nivel de 0,05 (2-colas). 
En el río Santiago, la densidad total mostró una variabilidad mayor que la observada en el Coronda. En ese ambiente también se registraron dos picos anuales de densidad. En 2007, el primer pico se registró en mayo y fue ligeramente mayor que el segundo pico, observado en diciembre (3.000 y 2.600 ind. $\mathrm{m}^{-3}$, respectivamente). En septiembre no se registraron larvas. En 2008, el primer pico se dio en abril y el segundo en noviembre (3.420 y 1.075 ind. $\mathrm{m}^{-3}$, respectivamente). Al igual que el año anterior, las larvas estuvieron ausentes en julio y septiembre (Fig. 2.3.3). Se halló una correlación positiva entre la densidad total de larvas y la temperatura del agua. Al igual que en el río Coronda, no se observaron larvas a temperaturas menores que $15-16^{\circ} \mathrm{C}$. Por encima de $17^{\circ} \mathrm{C}$, el número de larvas se incrementó progresivamente, registrándose eventos descensos alternados de los valores (Tabla 2.4). A diferencia de lo observado en el Coronda, la densidad total no mostró correlación con el oxígeno disuelto. 


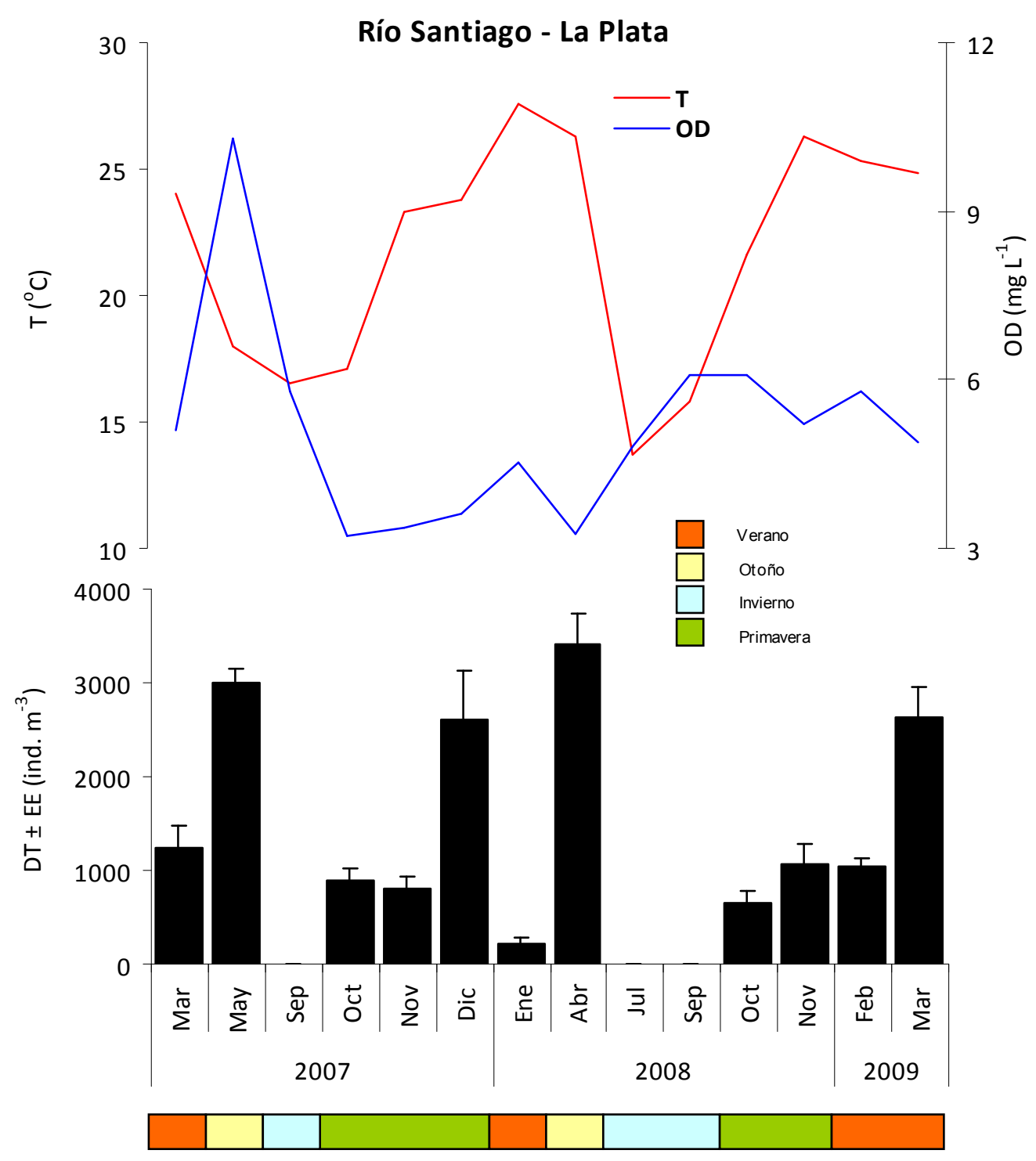

Figura 2.3.3. Variación de la densidad total (DT) \pm error estándar (EE), variación de la temperatura del agua (T) y del oxígeno (OD) durante el período de estudio en el río Santiago. 
Tabla 2.4. Resultados de la correlación de Pearson entre las variables ambientales y la densidad de larvas en río Santiago. Velíger-D; Preumb: Preumbonado; Umbon: Umbonado; Total; T: temperatura $\left({ }^{\circ} \mathrm{C}\right)$; $\mathrm{pH}$; OD: oxígeno disuelto $\left(\mathrm{mg} \mathrm{L}^{-1}\right)$; Cond: conductividad $\left(\mathrm{mS} \mathrm{cm}^{-1}\right)$; Secchi: transparencia $(\mathrm{m})$; Calcio $\left(\mathrm{mg} \mathrm{L}^{-1}\right)$; $\mathrm{Cl}$ a: $\mathrm{Clorofila} \mathrm{a}\left(\mathrm{mg} \mathrm{m}^{-3}\right)$;

$\mathrm{Cl}$ b: Clorofila b $\left(\mathrm{mg} \mathrm{m}^{-3}\right) ; \mathrm{Cl}$ c: Clorofila c $\left(\mathrm{mg} \mathrm{m}^{-3}\right)$.

\begin{tabular}{|c|c|c|c|c|c|c|c|c|c|c|c|c|c|c|}
\hline & & Velíger-D & Preumb & Umbon & Total & $T$ & $\mathrm{pH}$ & OD & Cond & Secchi & Calcio & Cl_a & Cl_b & Cl_c \\
\hline & Correlación Pearson & 1 & 0,428 & 0,326 & $0,636^{*}$ & 0,350 & $-0,091$ & 0,081 & 0,227 & $-0,598 *$ & $-0,372$ & $-0,102$ & $-0,164$ & $-0,144$ \\
\hline \multirow[t]{2}{*}{ Velíger-D } & p (2-colas) & & 0,127 & 0,256 & 0,015 & 0,220 & 0,758 & 0,784 & 0,435 & 0,040 & 0,233 & 0,752 & 0,610 & 0,656 \\
\hline & $\mathbf{N}$ & 14 & 14 & 14 & 14 & 14 & 14 & 14 & 14 & 12 & 12 & 12 & 12 & 12 \\
\hline & Correlación Pearson & & 1 & $0,716 * *$ & $0,892 * *$ & 0,500 & $-0,360$ & 0,061 & $-0,081$ & $-0,313$ & $-0,334$ & $-0,293$ & $-0,394$ & 0,282 \\
\hline \multirow[t]{3}{*}{ Preumb } & p (2-colas) & & & 0,004 & 0,000 & 0,068 & 0,206 & 0,835 & 0,782 & 0,321 & 0,288 & 0,355 & 0,205 & 0,375 \\
\hline & $\mathbf{N}$ & & 14 & 14 & 14 & 14 & 14 & 14 & 14 & 12 & 12 & 12 & 12 & 12 \\
\hline & Correlación Pearson & & & 1 & $0,873 * *$ & 0,397 & $-0,222$ & $-0,297$ & $-0,148$ & $-0,409$ & 0,043 & $-0,129$ & $-0,060$ & 0,338 \\
\hline \multirow[t]{3}{*}{ Umbon } & p (2-colas) & & & & 0,000 & 0,160 & 0,446 & 0,302 & 0,614 & 0,186 & 0,894 & 0,689 & 0,854 & 0,282 \\
\hline & $\mathbf{N}$ & & & 14 & 14 & 14 & 14 & 14 & 14 & 12 & 12 & 12 & 12 & 12 \\
\hline & Correlación Pearson & & & & 1 & $0,589 *$ & $-0,292$ & $-0,129$ & $-0,034$ & $-0,476$ & $-0,282$ & $-0,190$ & $-0,297$ & 0,286 \\
\hline \multirow[t]{2}{*}{ Total } & p (2-colas) & & & & & 0,027 & 0,312 & 0,661 & 0,908 & 0,118 & 0,375 & 0,555 & 0,348 & 0,368 \\
\hline & $\mathbf{N}$ & & & & 14 & 14 & 14 & 14 & 14 & 12 & 12 & 12 & 12 & 12 \\
\hline
\end{tabular}

**. Correlación altamente significativa a un nivel de 0,01 (2-colas).

*. Correlación significativa a un nivel de 0,05 (2-colas). 
En el río Coronda se registró un pico de densidad específica de larvas umbonadas en diciembre de 2007, mes que también produjo el valor máximo de preumbonadas. En 2008 se observó un patrón más regular, con dos picos diferenciados para el estadio preumbonado. El primero se halló en otoño (abril) y el segundo en primavera-verano (diciembre). Una variación anual similar, pero con valores de densidad más bajos, se observó para el estadio de velíger-D. El umbonado mostró una densidad estable durante fines de invierno y toda la primavera. Los valores de densidad estimados para diciembre de 2007 no se repitieron. La densidad de los diferentes estadios en la columna del agua descendió hasta desaparecer en los meses de invierno (Figura 2.3.4).

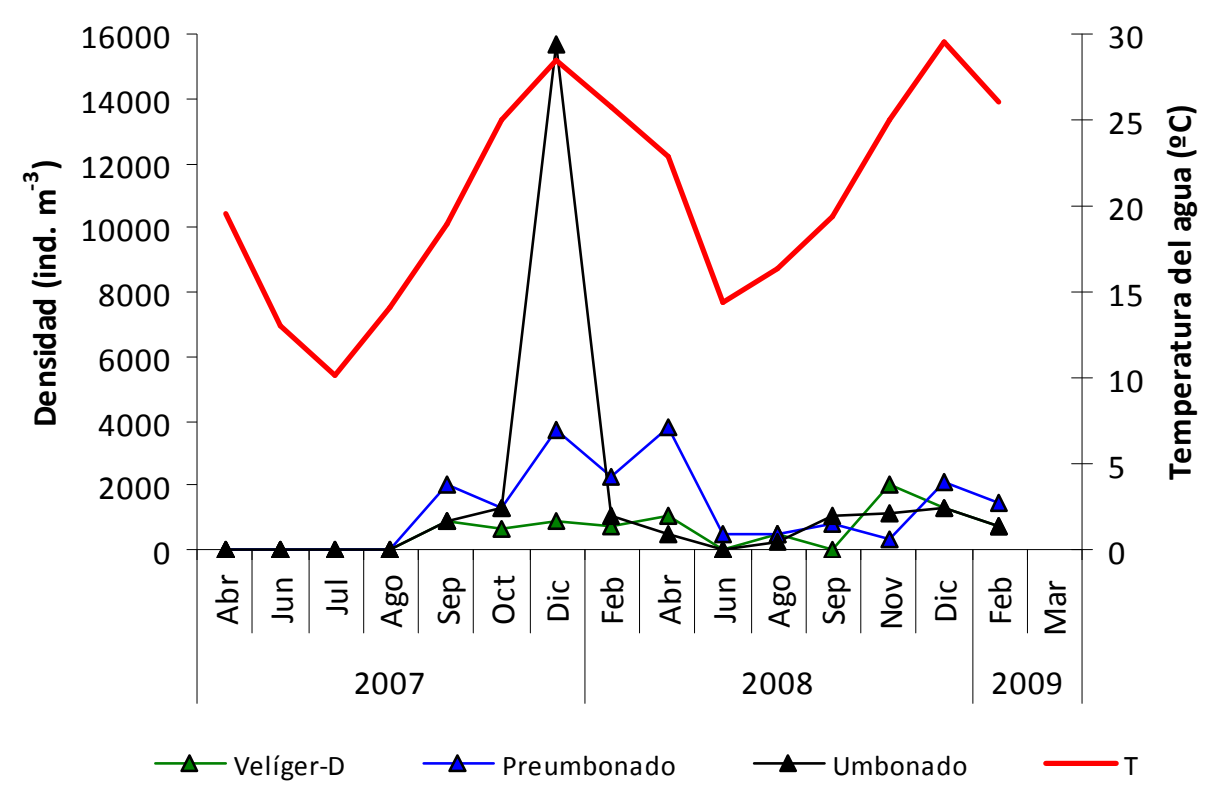

Figura 2.3.4. Variación de la densidad de los estadios larvales de Limnoperna fortunei en el río Coronda durante el período de estudio. T: temperatura del agua

La densidad de larvas de L. fortunei en el río Santiago fue más variable que la observada en el Coronda. Durante 2007 se observaron dos picos principales de densidad. En el primero, a principio de mayo (otoño), coincidieron los tres estadios, con más abundancia del preumbonado. El segundo pico principal, en diciembre (primavera-verano), estuvo caracterizado por los estadios umbonados y preumbonados. La densidad del velíger-D para ese mes fue nula. También se observó un pico intermedio de densidad en octubre. Durante el invierno no se hallaron larvas, de ningún estadio. En 2008 se observó un pico principal de 
densidad en abril (otoño), con abundancias altas de los tres estadios. En invierno, se repitió el patrón observado el año anterior, con densidades nulas, coincidentes con las bajas temperaturas. A partir de octubre se incrementó la densidad de los estadios velíger-D y preumbonado. Este último alcanzó su valor máximo en noviembre (Fig. 2.3.5).

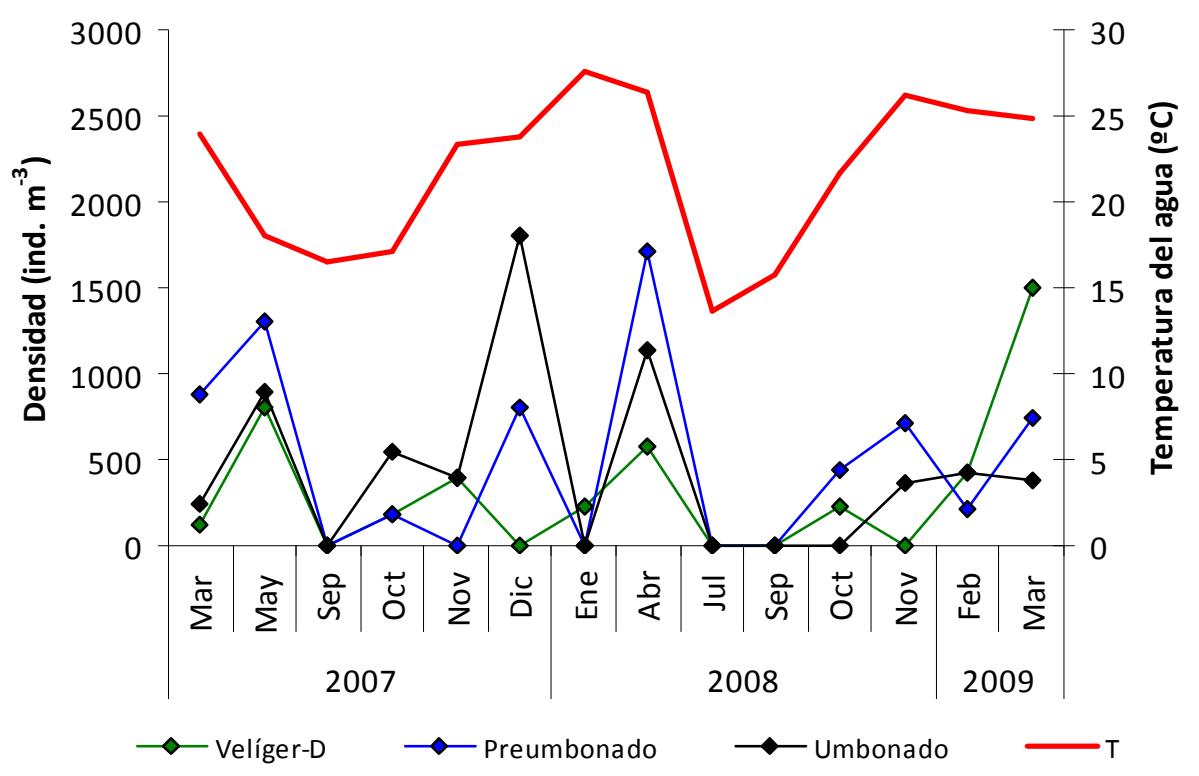

Figura 2.3.5. Variación de la densidad de los estadios larvales de Limnoperna fortunei en el río Santiago durante el período de estudio. T: temperatura del agua 


\subsection{DISCUSIÓN}

Limnoperna fortunei se reproduce continuamente durante 9 a 10 meses. Estudios realizados en distintos ambientes mostraron que la recuperación gonadal ocurre durante los meses de invierno, coincidiendo con el período de temperaturas bajas. A su vez, la liberación de gametas y la consecuente presencia de larvas en el agua se interrumpen a temperaturas menores que $16^{\circ} \mathrm{C}$ (Morton, 1977, 1982; Cataldo \& Boltovskoy, 1998, 2000; Darrigran et al., 1999, 2002, 2003; Pestana el al., 2008; Boltovskoy et al., 2009; Nakano et al., 2011). En un ambiente subtropical se observó que la producción de larvas de L. fortunei cesa de julio a septiembre, cuando la temperatura promedio para los años de estudio fue de $20^{\circ} \mathrm{C}$ (Boltovskoy et al., 2009). No obstante, el período julio-septiembre coincide con la época de bajas temperaturas en ese área de estudio (Boltovskoy et al., 2009). Estas observaciones coinciden con lo planetado por otros autores para Dreissena polymorpha y otras especies de bivalvos estuariales y marinos (Borcherding, 1991; Seed \& Suchanek, 1992; Fraleigh et al., 1993; Garton \& Haag, 1993; Nichols, 1993, 1996; McMahon \& Bogan 2001).

En América del Norte, el mejillón cebra Dreissena polymorpha muestra una distribución bimodal de larvas durante el año. La primera aparición de las larvas en el agua se detecta cuando la temperatura del agua es de $18^{\circ} \mathrm{C}$. Luego del pico de abundancia, el número de larvas disminuye a valores nulos en los meses en que la temperatura del agua es de $10^{\circ} \mathrm{C}$ (Fraleigh et al., 1993; Garton \& Haag, 1993). Estudios realizados en Europa indican que la gametogénesis se reinicia durante el invierno cuando la temperatura del agua desciende a $10^{\circ} \mathrm{C}$ aproximadamente. Este evento está indicado por un aumento del volumen de las gónadas. Inversamente, en $D$. polymorpha la disminución del volumen de las gónadas es una consecuencia directa de la liberación de gametas y ocurre cuando la temperatura alcanza los $12^{\circ} \mathrm{C}$ (Borcherding, 1991; Fraleigh et al., 1993; Nichols, 1993, 1996). En nuestro estudio, cuando la temperatura del agua fue menor que $15-16^{\circ} \mathrm{C}$, la densidad total de larvas fue nula o presentó valores muy bajos. Este patrón permite inferir que existe un umbral de temperatura mínima que determina la liberación de gametas, aunque también se detectaron descensos aislados durante el período de máxima producción larval. El gasto fisiológico de la reproducción es alto y su interrupción coincide con una disminución en el crecimiento y en la filtración (Nichols, 1993, 1996). Este período de reposo permite que el tejido gonadal se recupere luego de liberar las gametas y se prepare para el siguiente desove (Borcherding, 
1991; Seed \& Suchanek, 1992; McMahon \& Bogan 2001; Boltovskoy et al., 2009). Por último, la temperatura es un factor determinante en la coordinación de la gametogénesis y el desencadenamiento del proceso de evacuación gametas al medio (Darrigran et al., 1999, 2003).

Los valores de densidad total de larvas en el río Coronda fueron significativamente distintos a los estimados en el río Santiago. Estudios comparativos de densidad larval de $L$. fortunei en diferentes áreas y climas también detectaron diferencias de abundancia entre los ambientes estudiados (Cataldo \& Boltovskoy, 2000; Brugnoli et al., 2005; Pestana el al., 2008; Boltovskoy et al., 2009). La bibliografía coincide en sugerir que el tamaño de la población de adultos reproductores regula las densidades de larvas (Boltovskoy et al., 2009; Nakano et al., 2011). A su vez, no descarta factores adicionales, como la intensidad del tráfico naviero y el tiempo de asentamiento en el área de cada población adulta, que regulan el número de larvas en el plancton (Boltovskoy et al., 2009). En general, los invertebrados poseen larvas planctotróficas con una tasa de mortalidad que excede el $90 \%$ en esta etapa del ciclo de vida. La mortalidad cumple un rol importante en la estructura de las comunidades ya que regula el número de supervivientes que pueden reclutar en la población bentónica y alcanzar la reproducción (Maclsaac et al., 1991; Lehane \& Davenport, 2004; Porri et al., 2008; Troost et al., 2008). Las causas de mortalidad larval pueden ser bióticas o abióticas, destacándose las condiciones inadecuadas de alimento, la depredación, los factores limnológicos limitantes y la falta de sustratos adecuados para asentarse (Maclsaac et al., 1991; Lehane \& Davenport, 2004; Porri et al., 2008; Troost et al., 2008).

El aumento de la actividad industrial durante el último siglo resultó en un rápido incremento de las descargas de productos químicos en los ambientes acuáticos. La mayoría de esas sustancias son bioacumuladas en los tejidos de la biota, alcanzando concentraciones significativamente superiores a los niveles registrados en el ambiente. Además, algunos contaminantes ambientales pueden alcanzar niveles tóxicos que inducen efectos biológicos adversos. En este contexto adoptamos el criterio de que el término 'contaminación' alude a un fenómeno fisicoquímico resultante de la descarga en exceso de compuestos al ambiente, mientras que 'polución' implica efectos biológicos (Widdows \& Donkin, 1992). Los niveles de polución en el río Santiago, donde se vuelcan grandes volúmenes de hidrocarburos y metales pesados, son notablemente mayores a los del Coronda (Ringuelet, 1967; Boschi, 1988; 
Framiñán \& Brown, 1996; Kurucz et al., 1998; Steciow; 1998; Cataldo \& Boltovskoy, 2000; Ronco et al., 2001). El sistema río Santiago presenta concentraciones de metales pesados $(\mathrm{Cu}, \mathrm{Hg}$ y y $\mathrm{Pb})$ con valores máximos de $65 ; 5$ y $5 \mu \mathrm{g} \mathrm{\textrm {L } ^ { - 1 }}$, cuando las máximas sugeridas para la protección de la vida acuática son 2; 0,1 y $1 \mu \mathrm{g} \mathrm{L}^{-1}$, respectivamente. Algunos sectores de este sistema tienen una concentración de metales pesados 20 a 50 veces superior a la máxima admisible, con valores de hasta $50 \mu \mathrm{g} \mathrm{L}^{-1}$ en los sedimentos (Steciow, 1998). Los bivalvos han sido ampliamente utilizados para evaluar la calidad ambiental de los ecosistemas acuáticos, por su capacidad de bioacumular contaminantes en sus tejidos, derivado de su hábito de vida sésil y filtrador. Las respuestas fisiológicas de la mayoría de los animales expuestos a estos contaminantes tienen efectos negativos, como un aumento en la mortalidad, reducción del crecimiento de larvas y adultos, incapacidad para cerrar las valvas y menor crecimiento de los tejidos (Salazar \& Salazar, 1988; Widdows \& Donkin, 1992; Villela et al., 2006). Asimismo, la exposición de bivalvos a metales pesados puede producir efectos tóxicos que se manifiestan en todos los niveles de su organización biológica, incluyendo desarrollo anormal, reducción en la fecundidad, alteración en la alimentación, daño en los tejidos y cambio en la actividad enzimática y en la expresión de proteínas. Entre las sustancias nocivas presentes en el medio ambiente, los metales pesados se caracterizan por ser altamente persistentes y tóxicos para los organismos en pequeñas concentraciones (Boltovskoy et al., 1997; Cataldo et al., 2001; Narváez et al., 2005; Belaich et al., 2006).

El cadmio es un elemento no esencial para el funcionamiento de los organismos. La presencia de este metal pesado y otros contaminantes en el ambiente acuático corresponde principalmente a fuentes antropogénicas (Villar et al., 1999; Narváez et al., 2005; Belaich et al., 2006; Karatayev et al., 2007; Fedato et al., 2010). Los bivalvos Limnoperna fortunei, Dreissena polymorpha y Corbicula fluminea (Müller, 1774) son de distribución mundial, que habitan en ambientes de agua dulce y estuariales. Comparten una característica biológica saliente que es su elevada tasa de filtración, que los convierte en potentes biofiltradores que acumulan metales pesados y otros contaminantes en sus valvas y tejidos (Villar et al., 1999; Sylvester et al., 2005; Oliveira et al., 2006; Karatayev et al., 2007). Villar et al. (1999) detectaron niveles importantes de Cd (cadmio), Cu (cobre) y Zn (zinc) bioacumulado en $L$. fortunei en diferentes lugares. Por otro lado, Belaich et al. (2006) analizaron patrones de proteínas de individuos de L. fortunei procedentes de ambientes contaminados y no contaminados, y observaron concentraciones diferenciales de polipétidos. Detectaron una 
disminución de la concentración relativa de ciertas proteínas respecto de las proteínas totales cuando los animales se mantenían en condiciones de laboratorio sin la presencia de metales pesados. En cambio, cuando los individuos eran expuestos a metales pesados como $\mathrm{Cu}, \mathrm{Hg}$ y $\mathrm{Cd}$, se incrementaba la concentración relativa de polipéptidos. Los autores concluyeron que existen polipéptidos que son inducibles en condiciones de stress con metales pesados y tienen un efecto fisiológico negativo. También se han detectado daños en el ADN de células de la hemolinfa en ejemplares de $L$. fortunei expuestos a contaminantes ambientales (Villela et al., 2006, 2007). Otro ejemplo de efectos negativos causados por concentraciones de combustible en el agua fue descrito por Fedato et al. (2010) en ejemplares de $C$. fluminea. Los individuos analizados presentaban daño genético en hemocitos, con un incremento significativo del número de nucleótidos dañados de células branquiales en comparación con el grupo control.

Los efectos negativos de la contaminación por metales pesados, hidrocarburos, y desechos orgánicos no sólo son evidentes a nivel celular. Estudios poblacionales mostraron diferencias significativas en las tallas de dos poblaciones de $C$. fluminea estudiadas en dos ambientes diferentes, siendo hasta un 50-70 \% menores en el sitio más contaminado. También se observan diferencias en el índice de condición, que es mayor en el ambiente no contaminado. Asimismo, la ausencia de juveniles en el sitio con mayor contaminación puede deberse a la mortalidad de las postlarvas liberadas de las cámaras de cría al medio hostil (Boltovskoy et al., 1997; Cataldo et al., 2001).

Otro factor responsable de la diferente abundancia en los sitios de estudio podría ser la baja calidad del alimento disponible en el río Santiago debido a floraciones de cianobacterias. Esto podría afectar el estado fisiológico de los individuos con consecuencias directas en el éxito reproductivo. En el río Santiago se detectan floraciones algales uniespecíficas de Microcystis spp. (Echenique et al., 2006; Andrinolo et al., 2007; Oteiza et al., 2007). La interacción entre los bivalvos y la comunidad de fitoplancton es compleja porque afecta directa o indirectamente la composición de la comunidad algal. Las interacciones indirectas son debidas al impacto que generan los mejillones en los nutrientes o en el régimen de luz. Las interacciones directas están ligadas a las actividades de filtración de los bivalvos por su capacidad de alimentación selectiva. La selección de partículas está influida por la calidad del alimento y depende de las especies de algas que filtran (von Rückert et al., 2004). La presencia de las toxinas producidas por las cianobacterias hace del fitoplancton una 
dieta pobre, que afecta la filtración y la fisiología de los bivalvos. En los sistemas dulciacuícolas, las microcistinas son el grupo más importante de hepatoxinas. La coocurrencia de mejillones y cianobacterias indica que los bivalvos poseen una estrategia para superar la toxicidad por exposición a cianobacterias, para poder sobrevivir y reproducirse (Vasconcelos, 1999; Dionisio Pires et al., 2004; Juhel et al., 2006).

Para entender la reproducción y su rol en la estructuración de las comunidades, se requiere conocer los patrones de dispersión y asentamiento larval, así como la supervivencia y el éxito reproductivo. Los bivalvos filtradores dependen del suministro periódico de alimento planctónico para sostener sus demandas energéticas (Troost et al., 2008). La cantidad, calidad y frecuencia del suministro de alimento son factores críticos en la administración de energía de los mejillones y en la subsistencia de la población. El fitoplancton es considerado la principal fuente de nutrientes para las poblaciones de mejillones. Sin embargo, se necesitan fuentes adicionales de nutrientes (e.g. zooplancton) para el desarrollo, el crecimiento y la reproducción óptimos. Esta relación entre los ambientes pelágico y bentónico hace que la energía sea transferida entre los sistemas y determina cambios en la estructura poblacional de los mejillones (Alfaro, 2006a). Limnoperna fortunei y Dreissena polymorpha tienen un alto potencial de filtración. Ambas especies tienen efectos similares en los ecosistemas que invaden, alterando las propiedades físicas, químicas y biológicas del ambiente (Karatayev et al., 2007). El filtrado de grandes volúmenes de agua provoca la transferencia de energía y material desde la columna de agua hacia el bentos, generando una conexión fuerte entre los componentes planctónicos y bentónicos del ecosistema e induciendo cambios radicales en el área invadida (von Rückert et al., 2004; Alfaro, 2006a; Juhel et al., 2006; Karatayev et al., 2007; Darrigran \& Damborenea, 2011). Experiencias con mesocosmos en ambientes con elevadas concentraciones de microcistinas, revelaron que los individuos de L. fortunei permanecen con las valvas cerradas y no evidencian actividad de filtración. En ambientes libres de esta toxina, los mejillones son capaces de filtrar más del 99 \% de las algas presentes en el agua (Boltovskoy et al., 2009). Por otro lado, von Rückert et al. (2004) enfatizan que L. fortunei es capaz de filtrar células aisladas de Microcystis viridis, planteando un riesgo potencial de bioacumulación de cianotoxinas con efectos negativos en la cadena trófica.

Estudios sobre el efecto de las microcistinas en Dreissena polymorpha sugieren varios mecanismos por los que el mejillón cebra reduce su exposición a toxinas de cianobacterias. 
Dreissena polymorpha disminuye la actividad filtradora y la ingesta de Microcystis cerrando las valvas. En presencia de cultivos con células tóxicas de Microcystis la tasa de ingesta es menor que frente a cultivos que no contienen estas células. Otra estrategia es el rechazo selectivo de las colonias de cianobacterias de elevada toxicidad. El mecanismo de depuración en D. polymorpha está asociado con una mayor producción de pseudoheces compuestas por un mucus que rodea al material descartado. La producción de mucus en los mejillones tiene un costo energético elevado y provoca una disminución en el balance energético de los individuos en presencia de células tóxicas de Microcystis (Dionisio Pires et al., 2004; Juhel et al., 2006).

Un efecto asociado con la baja disponibilidad de alimento en el río Santiago podría ser la depredación intraespecífica o canibalismo, que explicaría parcialmente la diferencia de densidad de larvas. Un incremento en la presión de filtración puede reducir el número de larvas de bivalvos por canibalismo o larvifagia, con la consecuente baja en el éxito de reclutamiento. El término 'larvifagia' se refiere a la ingestión de larvas por adultos de la misma especie, pero se extendió a un concepto más amplio que incluye el consumo de larvas de bivalvos por adultos filtradores en general (Troost et al., 2008). Los ejemplares de tallas grandes tienen una mayor demanda metabólica específica y son más susceptibles a la calidad de alimento que los individuos de tallas menores. La mortalidad en las poblaciones de Dreissena está generalmente concentrada entre las fases de velíger planctónica y subadultos asentados (Maclsaac et al., 1991; Nalepa et al., 1995). Cuando el alimento es inadecuado, la densidad de adultos influye negativamente en la abundancia de larvas y en la intensidad de asentamiento larval, como consecuencia de la actividad filtradora de los adultos y por la falta de sustrato adecuado (Garton \& Haag, 1993; Nalepa et al., 1995). Maclsaac et al. (1991) observaron que los adultos de $D$. polymorpha consumen activamente varias especies de zooplancton pequeño, entre las que se encuentran larvas velíger de la misma especie. Éstas son similares a varias especies de rotíferos herbívoros en cuanto al tamaño del cuerpo y a la forma en que captan el alimento (mediante un velo ciliado y una corona ciliada, respectivamente). El tamaño máximo de las presas que puede consumir Dreissena está condicionado por el sistema de filtración de las branquias y los palpos bucales.

Este fenómeno fue estudiado con más intensidad en otras especies de bivalvos. Los mejillones son generalmente filtradores oportunistas ya que filtran e ingieren cualquier 
partícula disponible en el agua en un tiempo específico. El volumen de agua que filtran es más o menos constante; por lo tanto, el número de larvas ingeridas es proporcional a su abundancia en el agua (Alfaro, 2006a; Porri et al., 2008). Es probable que la relación cercana que existe entre las larvas y los adultos y la reducida capacidad natatoria de las primeras, facilite la entrada en las corrientes generadas en la cavidad paleal de los ejemplares mayores (Lehane \& Davenport, 2004). El análisis del contenido estomacal del bivalvo Perna canaliculus confirma su condición de filtradores oportunistas, yan que las larvas y postlarvas de la misma especie significan un $70 \%$ del consumo de partículas durante el desove. Transcurrida la época de desove, el fitoplancton y el zooplancton constituyen un $99 \%$ de la fuente de alimentación (Alfaro, 2006a). Este comportamiento también se observa en Perna perna y Mytilus galloprovincialis (Lamarck, 1819), en los que la larvifagia durante los meses de desove provoca una mortalidad del $46 \%$ de las larvas potencialmente colonizadoras (Porri et al., 2008). Otras tres especies de bivalvos, Cerastoderma edule (Linnaeus, 1758), Crassostrea gigas (Thunberg, 1793) y Mytilus edulis (Linnaeus, 1758), consumen activamente larvas de bivalvos y sólo un pequeño número de larvas es rechazado en forma de pseudoheces (Lehane \& Davenport, 2004; Troost et al., 2008). Varios autores concuerdan en que la filtración reduce significativamente el número de larvas pelágicas, con la consecuente reducción del número de larvas disponibles para asentamiento y reclutamiento (Maclsaac et al., 1991; Garton \& Haag, 1993; Nalepa et al., 1995; de Vooys, 1999; Lehane \& Davenport, 2004; Alfaro, 2006b; Porri et al., 2008; Troost et al., 2008).

No se han realizado estudios sobre canibalismo o larvifagia en L. fortunei. Rojas Molina et al. (2009), estudiaron la dieta natural de esta especie en el río Paraná y demostraron que esta especie consume materia particulada en suspensión constituida por materia animal y vegetal. La diversidad de organismos observados en los estómagos posee un rango de talla de $4 \mu \mathrm{m}$ a $1 \mathrm{~mm}$ aproximadamente. El fitoplancton es numéricamente dominante en la dieta (98,6 \%), mientras que el zooplancton representa el 1,4\% restante. La presencia de larvas de L. fortunei constituye el 0,1 \% del total de zooplancton cuantificado. El porcentaje de consumo es bajo, pero es la primera evidencia de que este bivalvo es capaz de consumir larvas de la misma especie. Sin embargo, queda por determinar si la larvifagia ocurre de manera accidental o por un proceso de selección como se observa en Dreissena polymorpha (Maclsaac et al., 1991). 


\section{CAPÍTULO 3}




\section{CAPÍTULO 3}

\section{DENSIDAD, MORFOMETRÍA Y CRECIMIENTO DE Limnoperna fortunei EN COLECTORES ARTIFICIALES}

\subsection{INTRODUCCIÓN}

Uno de los factores claves que determinan los efectos de una especie exótica en el ambiente es el tamaño de su población, que varía con el espacio y el tiempo (Darrigran \& Mansur, 2006; Strayer \& Malcom, 2006). Para entender y predecir los cambios en las distribuciones espaciales y temporales, las abundancias, tasas de crecimiento y la estructura poblacional de una especie, es necesario entender la importancia relativa de las propiedades físicas, químicas y biológicas del ambiente y el proceso que regula la dinámica de asentamiento (Sardiña et al., 2009; Nakano et al., 2011). Por lo tanto, el análisis de la tasa de crecimiento en condiciones naturales es un primer paso necesario para entender la dinámica poblacional y el balance energético de una población de bivalvos (Dorgelo, 1992). Las variaciones en el crecimiento de los individuos, dentro y entre poblaciones, se deben a diferencias bióticas y abióticas. Entre las primeras se encuentran las diferencias genéticas y la densidad de individuos de la misma especie, la calidad del alimento y la competencia inter e intraespecífica. Las condiciones fisicoquímicas como la velocidad de la corriente, la calidad del agua, la temperatura y la concentración de oxígeno inducen diferencias entre las poblaciones (Peterson \& Beal, 1989; Seed \& Suchanek, 1992; Stirling \& Okumus, 1994; Dolmer, 1998; Alfaro et al., 2008; Nakano et al., 2010a, 2011). A su vez, el conocimiento de los efectos de las condiciones ambientales en el crecimiento, la supervivencia y la reproducción de los invertebrados sésiles provee bases para predecir su capacidad para expandirse y colonizar nuevos hábitats (Peterson \& Beal, 1989; Seed \& Suchanek, 1992; Dolmer, 1998; Garton \& Johnson, 2000; Alfaro et al., 2008).

En la actualidad, el bivalvo invasor Limnoperna fortunei (Dunker, 1857) ha colonizado prácticamente toda la Cuenca del Plata. Puede ser encontrado en la Argentina, Bolivia, Paraguay, Uruguay y la cuenca del río Guaíba, en Brasil (Darrigran, 2002; Mansur et al., 2003; 
Brugnoli et al., 2005; Boltovskoy et al., 2006; Darrigran \& Mansur, 2006). Este mitílido es capaz de conformar grandes conglomerados compactos en un período corto de tiempo, debido a su elevada capacidad reproductiva, crecimiento acelerado y comportamiento gregario (Darrigran, 2002; Oliveira et al., 2006). La densidad media de L. fortunei muestra una marcada variación estacional. De septiembre a abril se registra un incremento abrupto, debido al reclutamiento de los nuevos juveniles asentados (Pastorino et al., 1993; Iwasaki \& Uryu, 1998; Darrigran, 2002; Boltovskoy et al., 2006; Sylvester et al., 2007). El asentamiento de las larvas de L. fortunei ocurre tres veces al año, con períodos de duración variable relacionados con las variaciones de la temperatura del agua y el oxígeno disuelto (Morton, 1977). Por su hábito de vida epifaunal con larva planctónica, esta especie logra una amplia distribución a diferentes profundidades. La capacidad de secretar filamentos bisales le permite adherirse a sustratos en áreas que no pueden ser ocupadas por bivalvos que no poseen glándula bisógena (Montalto \& Marchese, 2003; Sardiña et al., 2009). El asentamiento larval y el consecuente aporte de juveniles cumplen un rol importante en el reclutamiento de la población y en la estructuración de la comunidad de invertebrados bentónicos (Martel et al., 1994). El asentamiento de postlarvas de L. fortunei sobre la superficie de una amplia variedad de estructuras naturales y artificiales deriva en biofouling (o bioincrustación). Este fenómeno se ha causado serios impactos ecológicos en los ecosistemas de agua dulce invadidos. A su vez, genera complicaciones en los sistemas municipales e industriales de agua de consumo debido a la colonización y la consecuente obstrucción de las tuberías (Ricciardi, 1998; Magara et al., 2001).

En el área inferior de la Cuenca del Plata y en el Río de la Plata se estimó la tasa de crecimiento de L. fortunei mediante el modelo de von Bertalanffy, en sus versiones estacionalizada (Boltovskoy \& Cataldo, 1999) y tradicional (Maroñas et al., 2003). La longevidad estimada en ese ambiente es de tres a tres años y medio. En cambio, en la Cuenca del Guaíba, la longevidad estimada para esa población es de dos años, sin supervivientes en el tercer año (dos Santos et al., 2008). Estas observaciones coinciden con estudios realizados en China y Korea donde las poblaciones de L. fortunei muestran una capacidad reproductiva y una longevidad de dos años, con un crecimiento de 15-16 mm año-1 (Morton, 1977; Magara et al., 2001). En el lago Biwa (Japón) se observaron tres cohortes anuales Limnoperna fortunei como resultado de dos eventos de reclutamiento por año (Magara et al. (2001). Sin embargo, esa observación se contrapone con lo observado por 
Iwasaki \& Uryu (1998), en la misma región. Los autores que plantean que L. fortunei tiene un solo período reproductivo por año, que ocurre durante los meses de verano y con una tasa de crecimiento crecimiento de $20 \mathrm{~mm}$ año ${ }^{-1}$ para el primer año de vida.

La elevada densidad poblacional de individuos epifaunales influye en la forma de la valva. Las poblaciones muy densas tienen implicancia en la regulación del alimento, interferencia física o una interacción de ambas. Esto da como resultado valvas con dimensiones diferentes a las observadas en poblaciones menos densas (Alunno-Bruscia et al., 2001; Lajtner et al., 2004; Lauzon-Guay et al., 2005).

\subsubsection{OBJETIVOS}

Para conocer las variaciones espaciales y temporales de la densidad y crecimiento que sufren los individuos de L. fortunei debido a las diferencias limnológicas halladas entre los dos ambientes de estudio, se plantearon los siguientes objetivos:

- Estimar la densidad, las relaciones entre las dimensiones valvares y el crecimiento de individuos de $L$. fortunei asentados sobre colectores artificiales

- Evaluar si existen diferencias en la dinámica de las poblaciones de L. fortunei asentadas en los colectores artificiales sumergidos en los dos ambientes de estudio pertenecientes a la porción inferior Cuenca de Plata.

\subsubsection{HIPÓTESIS}

La hipótesis planteada en este capítulo, es que existen diferencias significativas en la densidad, dimensiones valvares y crecimiento de los individuos recolectados de los colectores artificiales sumergidos en ambos sitios de muestreo debido a las diferencias limnológicas que caracterizan a los dos ambientes de estudio. 


\subsection{MATERIALES Y MÉTODOS}

\subsubsection{PANELES DE CAPTACIÓN - Colectores Artificiales}

Para estimar la densidad, el reclutamiento y la estructura poblacional de tallas de $L$. fortunei se sumergieron, a 1 metro de profundidad, 12 grupos de paneles de captación en los ríos Santiago ( $34^{\circ} 51^{\prime} 5,76^{\prime \prime} \mathrm{S}-57^{\circ} 53^{\prime} 29,76^{\prime \prime}$ O) y Coronda ( $\left.31^{\circ} 41^{\prime} 26,88^{\prime \prime} \mathrm{S}-60^{\circ} 44^{\prime} 34,08^{\prime \prime} \mathrm{O}\right)$. Cada grupo estuvo conformado por tres colectores de $10 \mathrm{~cm} \times 10 \mathrm{~cm}(\mathrm{Cr} 1, \mathrm{Cr} 2, \mathrm{Cr} 3)$ consistentes en un marco de alambre y una red plástica con abertura de malla de $1 \mathrm{~mm}$ (Fig.

3.2.1). Los colectores retirados del agua fueron transportados inmediatamente al laboratorio en bolsas plásticas. Los individuos adheridos se separaron cuidadosamente y se lavaron sobre un tamiz ( $1 \mathrm{~mm}$ de abertura de malla). Las muestras se conservaron en alcohol etílico $70 \%$ hasta que los individuos fueron contados. La fecha de inicio de la experiencia para cada sitio se estableció como la fecha de muestreo anterior al primer registro de asentamiento en los colectores artificiales.
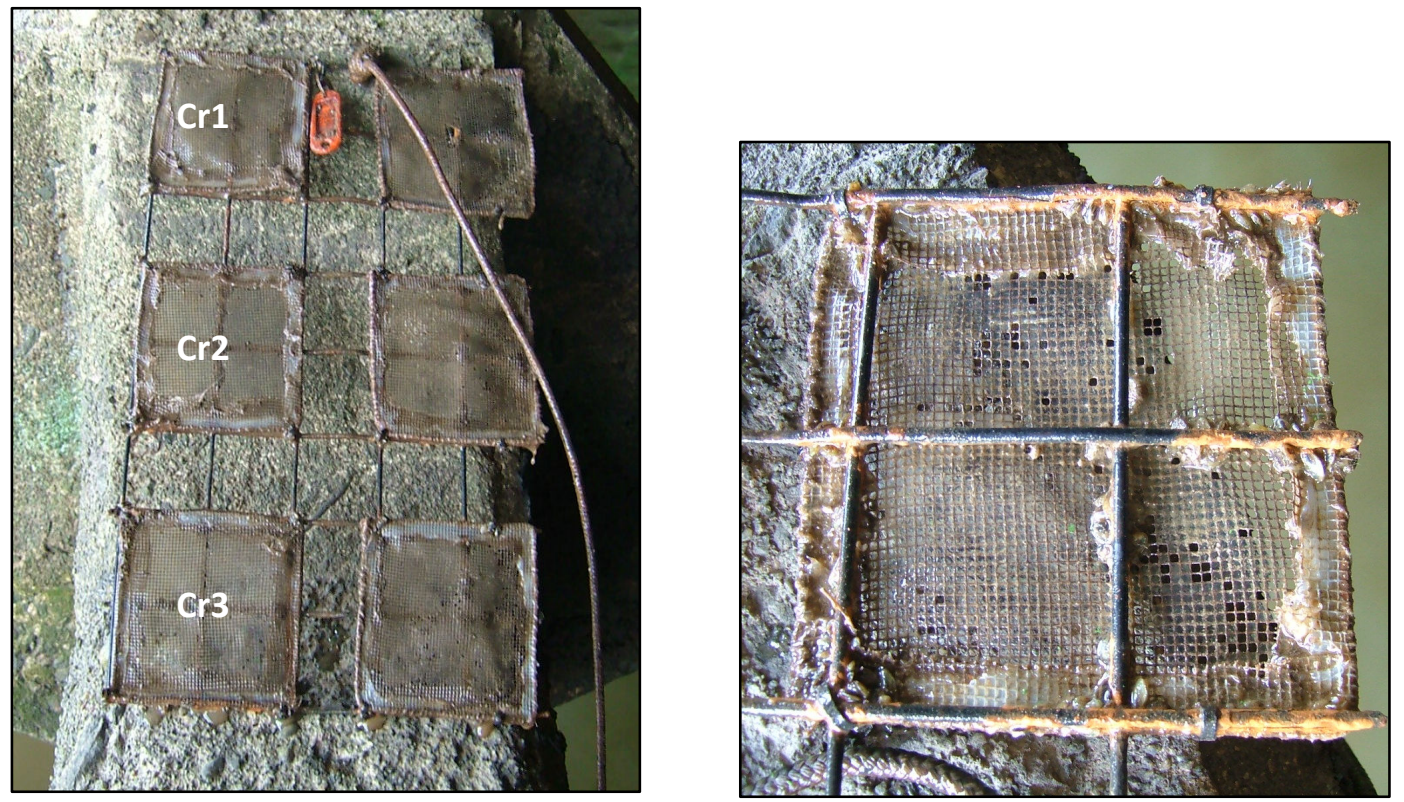

Figura 3.2.1 Panel de captación con colectores artificiales. Cr: Colector. 
En el río Santiago, el período de estudio abarcó desde diciembre de 2007 hasta abril de 2009. Los primeros colectores retirados, en enero de 2008, estuvieron expuestos a la colonización del mejillón durante un mes aproximadamente, mientras que los retirados en abril de 2009 estuvieron expuestos durante 16 meses (Tabla 3.1). En el río Coronda, la experiencia se realizó en dos etapas debido a la pérdida de los colectores sumergidos. La primera etapa abarcó desde octubre de 2007 hasta junio de 2008; la segunda, en la que se repusieron los colectores, abarcó de septiembre de 2008 a febrero de 2009 (Tabla 3.1).

Tabla 3.1. Fechas y sitios de muestreo. Inicio de la expriencia en el río Santiago: 18 de diciembre de 2007. Inicio de la primera etapa de la experiencia en el río Coronda: 30 de octubre de 2007. Inicio de la etapa de la segunda experiencia en el río Coronda: 25 de septiembre de 2008

\begin{tabular}{|c|c|c|c|c|}
\hline \multicolumn{3}{|c|}{ Río Coronda } & \multicolumn{2}{|c|}{ Río Santiago } \\
\hline 2007 & 2008 & 2009 & 2008 & 2009 \\
\hline \multirow[t]{9}{*}{ 21-Dic } & $12-F e b$ & $12-\mathrm{Feb}$ & 25-Ene & 09-Feb \\
\hline & 17-Mar & & $25-\mathrm{Feb}$ & 12-Mar \\
\hline & $24-A b r$ & & $03-A b r$ & 15-Abr \\
\hline & 12-Jun & & 08-May & \\
\hline & 31-Jul & & 10-Jun & \\
\hline & 22-Nov & & 08-Jul & \\
\hline & 17-Dic & & 14-Ago & \\
\hline & & & 26-Nov & \\
\hline & & & 18-Dic & \\
\hline
\end{tabular}

\subsubsection{DENSIDAD}

Para cada sitio de muestreo, se aplicó ANOVA con los valores de densidad estimados para cada fecha y colector. Los valores de densidad estimados en una superficie de $100 \mathrm{~cm}^{2}$ fueron recalculados para una superficie de $1 \mathrm{~m}^{2}$. Se correlacionaron linealmente la densidad total de individuos asentados y las variables ambientales. Con el objetivo de evaluar diferencias de densidad entre ambientes, se realizó un test de Student con los valores medios de densidad estimados para cada fecha y sitio de muestreo. Los valores de densidad fueron transformados a $\sqrt{(x)}$ y las variables ambientales a $\ln (x)$, o $\ln (x+1)$ según correspondiera, para aproximar a normalidad y homocedasticidad (Zar, 1996; Mörtl \& Rothhaup, 2003). 


\subsubsection{MORFOMETRÍA}

A todos los ejemplares recolectados se les midió el largo total de la valva (LT: distancia máxima desde el umbo hasta el borde posterior de la valva). Para evaluar la hipótesis de diferencias morfométricas entre los individuos de los dos ambientes, se consideraron los de LT > $3 \mathrm{~mm}$, a los que se les midió el ancho total (AT: distancia máxima lateral) y el alto total (AL: distancia máxima perpendicular al LT) (Fig. 3.2.2) (Alunno-Bruscia et al., 2001; Lajtner et al., 2004; Lauzon-Guay et al., 2005; Trichkova et al., 2008). Todas las mediciones se efectuaron con un calibre digital Mitutoyo con precisión de 0,01 $\mathrm{mm}$. Se estimó la media de cada una de las variables morfómétricas para cada colector, sitio y fecha de muestreo. Se realizó un ANOVA simple para determinar si existen diferencias entre colectores, previa transformación de las mediciones mediante In (x). Para evaluar la relación entre las variables lineales medidas en las dos poblaciones de L. fortunei, se realizó un Análisis de Componentes Principales (ACP) (Trichkova et al., 2008). Para comparar las dimensiones de las valvas entre los sitios, se calcularon los cocientes morfométricos $A T / L T, A L / L T$ y $A L / A T$, estimados para cada sitio y fecha de muestreo. Se aplicó una transformación angular (arcoseno $\sqrt{x}$ ) a los cocientes para aproximarlos a la normalidad y homocedasticidad y luego se realizó un test de Student (Zar, 1996; Lajtner et al., 2004; Trichkova et al., 2008).

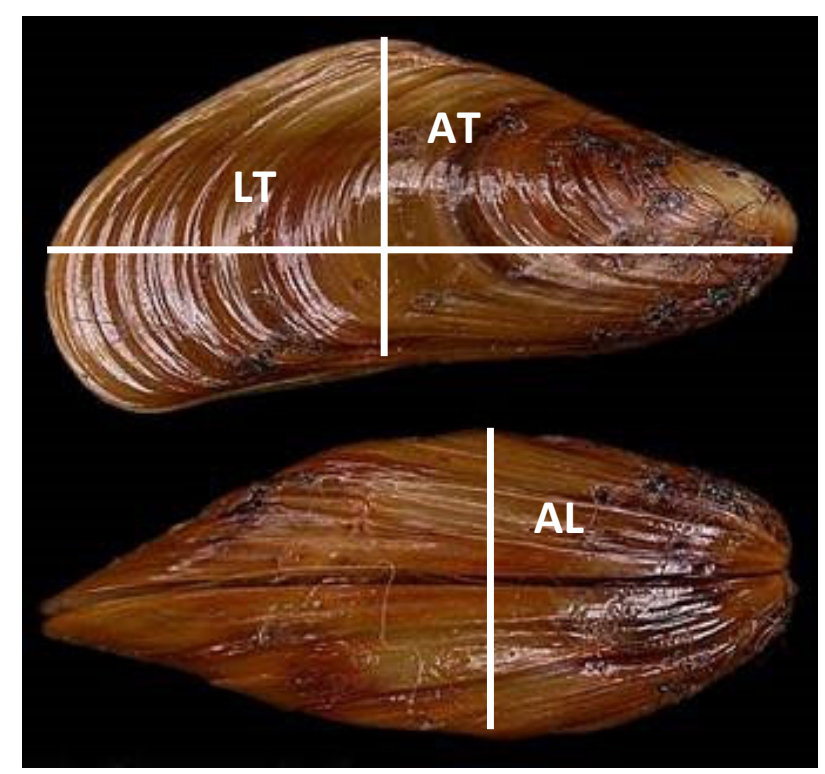

Figura 3.2.2. Mediciones morfometricas de Limnoperna fortunei. LT: largo total; AT: ancho total; AL: alto total. Imagen obtenida de http://www.edulifedesks.org/class/1303/images/1716. 


\subsubsection{CRECIMIENTO}

En función de LT se establecieron dos categorías de individuos: juveniles y adultos. Se consideraron juveniles los individuos con LT $<5 \mathrm{~mm}$ (talla mínima de diferenciación sexual; Darrigran et al., 1999; Taraborelli, 2001). Se generaron histogramas de frecuencias de tallas para cada fecha y sitio de muestreo, considerando el LT promedio estimado a partir de la agrupación de los valores de talla obtenidos para los tres colectores. El rango de cada muestra se estimó como la diferencia entre el valor máximo y el valor mínimo $(R=$ Max Mín). El intervalo de clases para cada fecha de muestreo fue determinado según el método de Sturges (1926) (ecuación 3.1), donde $k$ es el número de intervalos de clase y $n$ es el tamaño de la muestra:

$$
k=1+\log _{2} n
$$

El ancho de cada intervalo de clase se calculó mediante el uso de un valor $\varepsilon$ (épsilon) seleccionado arbitrariamente ( $\varepsilon=10 \%$ del valor del rango) (ecuación 3.2).

$$
h=\frac{\text { Rango }+\varepsilon}{k}
$$

Las distribuciones de frecuencias de talla fueron descompuestas en sus componentes modales siguiendo el método de Bhattacharya (1967) incorporado en el programa FISAT II (Version 1.1.2, FAO-ICLARM Fish Assessment Tools) (Gayanilo et al., 1996). Cada progresión modal fue confirmada con el programa NORMSEP (Pauly \& Caddy, 1985). Este método asume que los componentes están normalmente distribuidos y sirve para identificar las cohortes que pueden coexistir en los distintos muestreos durante la experiencia. También permite calcular la curva normal ajustada a cada grupo generacional, validando cada una de las cohortes detectadas mediante una prueba $X^{2}$. De este modo se obtiene la tabla con valores medios para cada cohorte en cada muestreo (Bayne \& Worral, 1980; Chícharo \& Chícharo, 2001).

Para describir el crecimiento individual, se realizó una prueba de ajuste de modelos de regresión (lineal, cuadrática y cúbica) para cada una de las cohortes. Cada ajuste fue comprobado mediante una prueba $\mathrm{F}$ de la suma de cuadrados, basada en las hipótesis estadísticas tradicionales. La hipótesis nula plantea que el modelo más simple (el de menor cantidad de parámetros) es el correcto. El aporte de un modelo más complejo está 
cuantificado como la diferencia en la suma de los cuadrados. La prueba F compara la diferencia en la suma de cuadrados entre el modelo simple y el complejo. El resultado está expresado como un cociente $F$ del que se desprende un valor de $p$ (probabilidad): si $p<0,05$, se rechaza el modelo simple (hipótesis nula) y se concluye que el modelo más complejo ajusta significativamente mejor al grupo de datos. Asimismo, este análisis permite comparar los parámetros de los modelos entre distintos grupos de datos. La hipótesis nula plantea que no hay diferencia entre los parámetros de cada modelo y sugiere parámetros globales para el conjunto de datos. La alternativa plantea diferencias entre los parámetros y sugiere ajustes independientes para cada grupo de datos (Zar, 1996; Motulsky, 2007). Para las cohortes definidas por pocos valores se asumió el modelo lineal. 


\subsection{RESULTADOS}

\subsubsection{DENSIDAD}

No se encontraron diferencias significativas de densidad entre los colectores extraídos en el río Santiago ( $p=0,769$; Apéndice 3.1) ni entre los colectores extraídos en el Coronda $(p=$ 0,639; Apéndice 3.2). Este resultado permitió agrupar los colectores y estimar una densidad promedio para cada fecha de muestreo en cada sitio de estudio.

En el río Santiago, los colectores fueron retirados en enero luego de 38 días de exposición. La densidad estimada fue $17.900 \pm 5.951$ ind. $\mathrm{m}^{-2}$, el $68 \%$ de los individuos fueron juveniles con LT promedio = 3,64 $\pm 0,13 \mathrm{~mm}$. En el siguiente muestreo, luego de 69 días de exposición, la densidad estimada fue $14.567 \pm 2.223$ ind. $\mathrm{m}^{-2}$ y los juveniles representaron el $86 \%$. El pico máximo de densidad fue $31.900 \pm 13.323$ ind. $\mathrm{m}^{-2}$ en abril, a los 107 días de exposición de los colectores y el 90 \% de los individuos muestreados fueron juveniles. En mayo, la densidad descendió y se mantuvo aproximadamente constante durante 140 días (13.800 \pm 538 ind. $\mathrm{m}^{-2}$ ). En noviembre, se observó una disminución de la densidad. Este evento coincidió con el porcentaje mínimo de juveniles asentados en los colectores (3,6 \%). En diciembre se estimó la densidad mínima, $1.167 \pm 551$ ind. $\mathrm{m}^{-2}$. A partir de febrero de 2009, la densidad total aumentó conjuntamente con la presencia de juveniles. El reclutamiento tuvo un pico máximo de densidad en marzo. Durante toda la experiencia los juveniles representaron, en promedio, el 60 \% de los individuos muestreados (Tabla 3.1; Fig. 3.3.1).

La densidad total mostró una correlación negativa con el $\mathrm{pH}(r=-0,667 ; \mathrm{p}<0,05)$ y una correlación positiva con la concentración de calcio en el agua $(r=0,668 ; p<0,05)$. El resto de las variables ambientales no mostró correlaciones significativas (Apéndice 3.3). 
Tabla 3.1. Valores de densidad total y de juveniles asentados en colectores artificiales en el río Santiago. Valores de largo de valva y porcentajes de presencia de juveniles de Limnoperna fortunei. d.exp: Días de exposición; DTM: Densidad Total Media; DMJ: Densidad Media de Juveniles; LTJ: Largo Total Juveniles; DE: Desvío Estándar. Inicio de la experiencia: 18 de diciembre de 2007.

\begin{tabular}{|c|c|c|c|c|c|c|}
\hline & \multicolumn{6}{|c|}{ Río Santiago - La Plata } \\
\hline & Muestreos & d. exp & $\mathrm{DTM} \pm \mathrm{DE}$ (ind. $\mathrm{m}^{-2}$ ) & $\mathrm{DMJ} \pm \mathrm{DE}\left(\right.$ ind. $\mathrm{m}^{-2}$ ) & \% Juveniles & $\mathrm{LTJ} \pm \mathrm{DE}(\mathrm{mm})$ \\
\hline \multirow{9}{*}{2008} & 25-Ene & 38 & $17.900 \pm 5.951$ & $12.233 \pm 5.696$ & 68,3 & $3,64 \pm 0,13$ \\
\hline & 25-Feb & 69 & $14.567 \pm 2.223$ & $12.600 \pm 2.234$ & 86,5 & $2,63 \pm 0,12$ \\
\hline & 03-Abr & 107 & $31.900 \pm 13.323$ & $28.733 \pm 13.085$ & 90,1 & $2,34 \pm 0,23$ \\
\hline & 08-May & 142 & $14.600 \pm 3.032$ & $12.767 \pm 2.802$ & 87,4 & $3,01 \pm 0,11$ \\
\hline & 10-Jun & 175 & $13.433 \pm 2.055$ & $9.800 \pm 1.179$ & 73,0 & $3,33 \pm 0,07$ \\
\hline & 08-Jul & 203 & $13.567 \pm 1.387$ & $9.567 \pm 1.553$ & 70,5 & $3,42 \pm 0,01$ \\
\hline & 14-Ago & 240 & $13.600 \pm 2.042$ & $5.533 \pm 1.002$ & 40,7 & $3,80 \pm 0,11$ \\
\hline & 26-Nov & 344 & $1.867 \pm 306$ & $67 \pm 115$ & 3,6 & 4,68 \\
\hline & 18-Dic & 366 & $1.167 \pm 551$ & $667 \pm 462$ & 48,6 & $2,84 \pm 0,57$ \\
\hline \multirow{3}{*}{2009} & 09-Feb & 419 & $7.133 \pm 2.974$ & $4.500 \pm 1.552$ & 63,1 & $3,69 \pm 0,08$ \\
\hline & 12-Mar & 450 & $13.200 \pm 8.728$ & $7.867 \pm 5.600$ & 59,6 & $3,62 \pm 0,13$ \\
\hline & $15-\mathrm{Abr}$ & 484 & $7.467 \pm 3.493$ & $5.200 \pm 2.433$ & 69,6 & $3,36 \pm 0,12$ \\
\hline
\end{tabular}

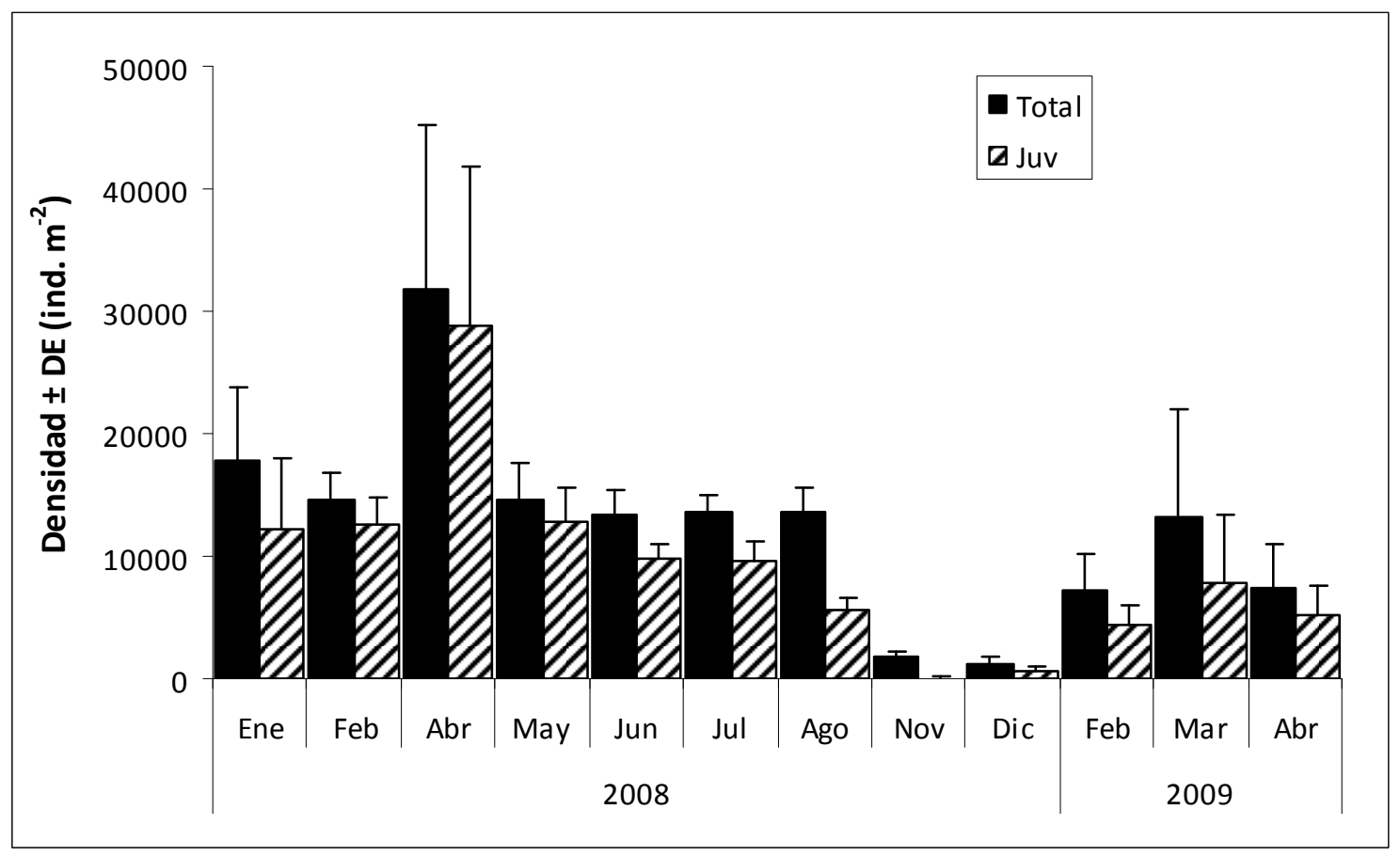

Figura 3.3.1. Variación estacional de la densidad total media y de juveniles (Juv) \pm desvío estándar (DE) de Limnoperna fortunei estimada en el río Santiago, La Plata. 
En el río Coronda, la densidad total fue de 29.600 ind. $\mathrm{m}^{-2}$ a los 52 días de exposición; el 52,3\% de los ejemplares muestreados fueron juveniles. El valor máximo de densidad total fue de 65.700 ind. $\mathrm{m}^{-2}$ en abril y el porcentaje estimado de juveniles fue el más bajo de todo el período de estudio (12,1 \%). En junio y julio se obtuvieron los valores mínimos de densidad. En la segunda etapa, el asentamiento inicial de individuos se registró en noviembre; en el muestreo siguiente la densidad aumentó y se mantuvo prácticamente constante hasta el final de la experiencia. En esta etapa el porcentaje de juveniles asentados en los colectores fue mayor que en la primera (Tabla 3.2; Fig. 3.3.2).

La densidad total mostró una correlación negativa con la transparencia del agua $(r=-$ $0,704 ; p<0,05)$. El resto de las variables ambientales no mostró correlaciones significativas (Apéndice 3.4).

Tabla 3.2. Valores de densidad total y de juveniles asentados en colectores artificiales en el río Coronda. Valores de largo de valva y porcentajes de presencia de juveniles de Limnoperna fortunei. d.exp: Días de exposición; DTM: Densidad Total Media; DMJ: Densidad Media de los Juveniles; LTJ: Largo Total Juveniles; DE: Desvío Estándar. Inicio de la experiencia (1a etapa): 30 de octubre de 2007; (2a etapa): 25 de septiembre de 2008.

\begin{tabular}{|c|c|c|c|c|c|c|}
\hline & \multicolumn{6}{|c|}{ Río Coronda - Santo Tomé } \\
\hline & Muestreos & d.exp & $\mathrm{DTM} \pm \mathrm{DE}\left(\right.$ ind. $\mathrm{m}^{-2}$ ) & $\mathrm{DMJ} \pm \mathrm{DE}\left(\right.$ ind. $\mathrm{m}^{-2}$ ) & \% Juveniles & $\mathrm{LTM} \pm \mathrm{DE}(\mathrm{mm})$ \\
\hline 2007 & 21-Dic & 52 & $29.600 \pm 11.000$ & $15.467 \pm 7.221$ & 52,3 & $3,52 \pm 0,06$ \\
\hline \multirow{7}{*}{2008} & $12-\mathrm{Feb}$ & 105 & $52.167 \pm 4.554$ & $15.833 \pm 2.371$ & 30,4 & $3,72 \pm 0,05$ \\
\hline & 17-Mar & 139 & $28.800 \pm 22.354$ & $7.633 \pm 4.508$ & 26,5 & $3,90 \pm 0,04$ \\
\hline & $24-A b r$ & 177 & $65.700 \pm 38.466$ & $7.933 \pm 4.162$ & 12,1 & $3,56 \pm 0,15$ \\
\hline & 12-Jun & 226 & $34.967 \pm 24.150$ & $6.067 \pm 2.610$ & 17,3 & $3,93 \pm 0,17$ \\
\hline & 31-Jul & 275 & $7.933 \pm 3.347$ & $3.433 \pm 58$ & 43,3 & $4 \pm 0,21$ \\
\hline & 22-Nov & 58 & $2.768 \pm 321$ & $2.133 \pm 115$ & 80,0 & $3,05 \pm 0,08$ \\
\hline & 17-Dic & 83 & $18.333 \pm 7.275$ & $14.233 \pm 7.689$ & 77,6 & $3,58 \pm 0,09$ \\
\hline 2009 & $12-F e b$ & 140 & $21.100 \pm 6.630$ & $14.339 \pm 5.150$ & 70,8 & $3,41 \pm 0,06$ \\
\hline
\end{tabular}




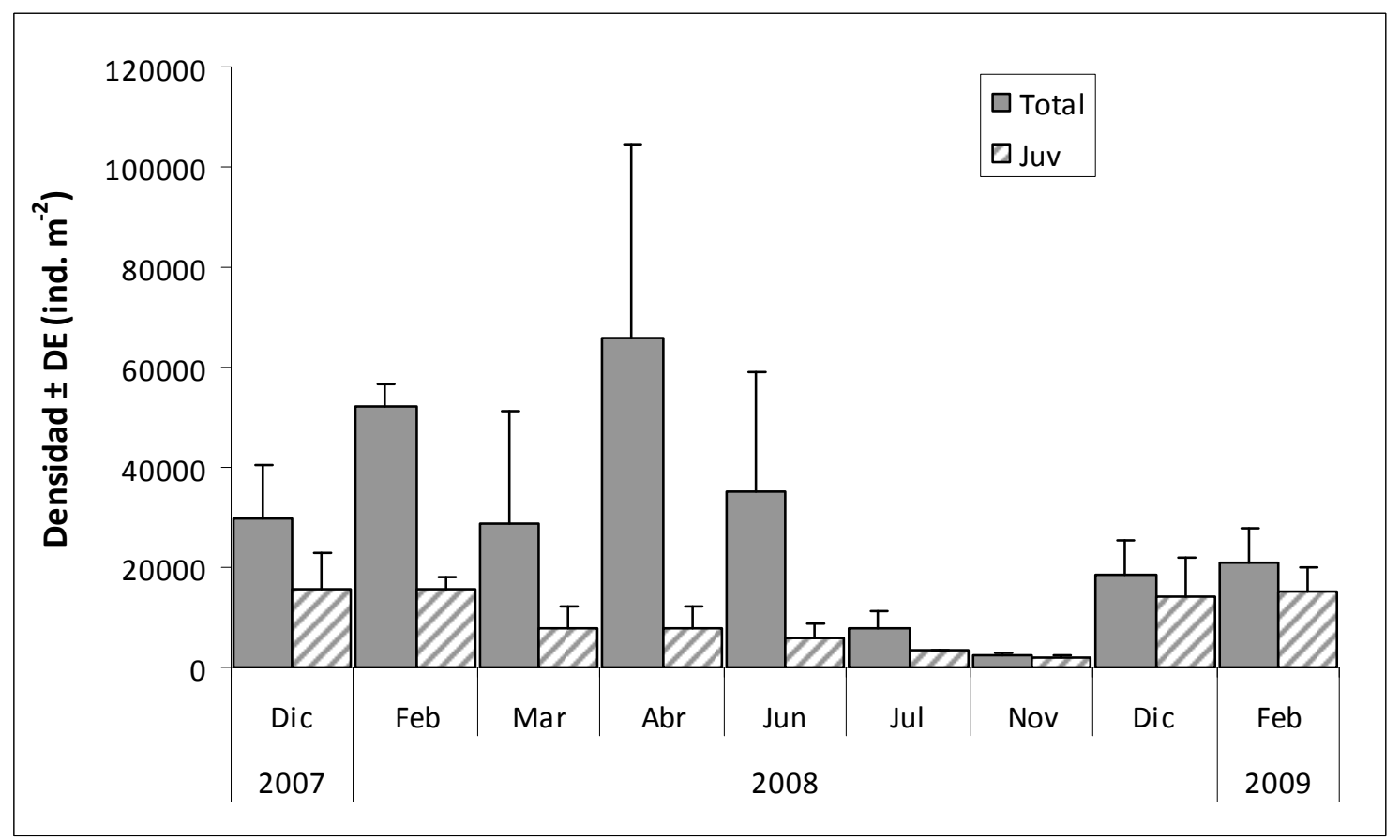

Figura 3.3.2. Variación estacional de la densidad total media y de juveniles (Juv) \pm desvío estándar (DE) de Limnoperna fortunei estimada en el río Coronda, Santo Tomé.

La comparación de la densidad total mostró diferencias significativas de abundancia entre los ríos Coronda y Santiago $\left(\mathrm{t}_{(19)}=-2,399 ; \mathrm{p}<0,05\right)$ (Fig. 3.3.3).

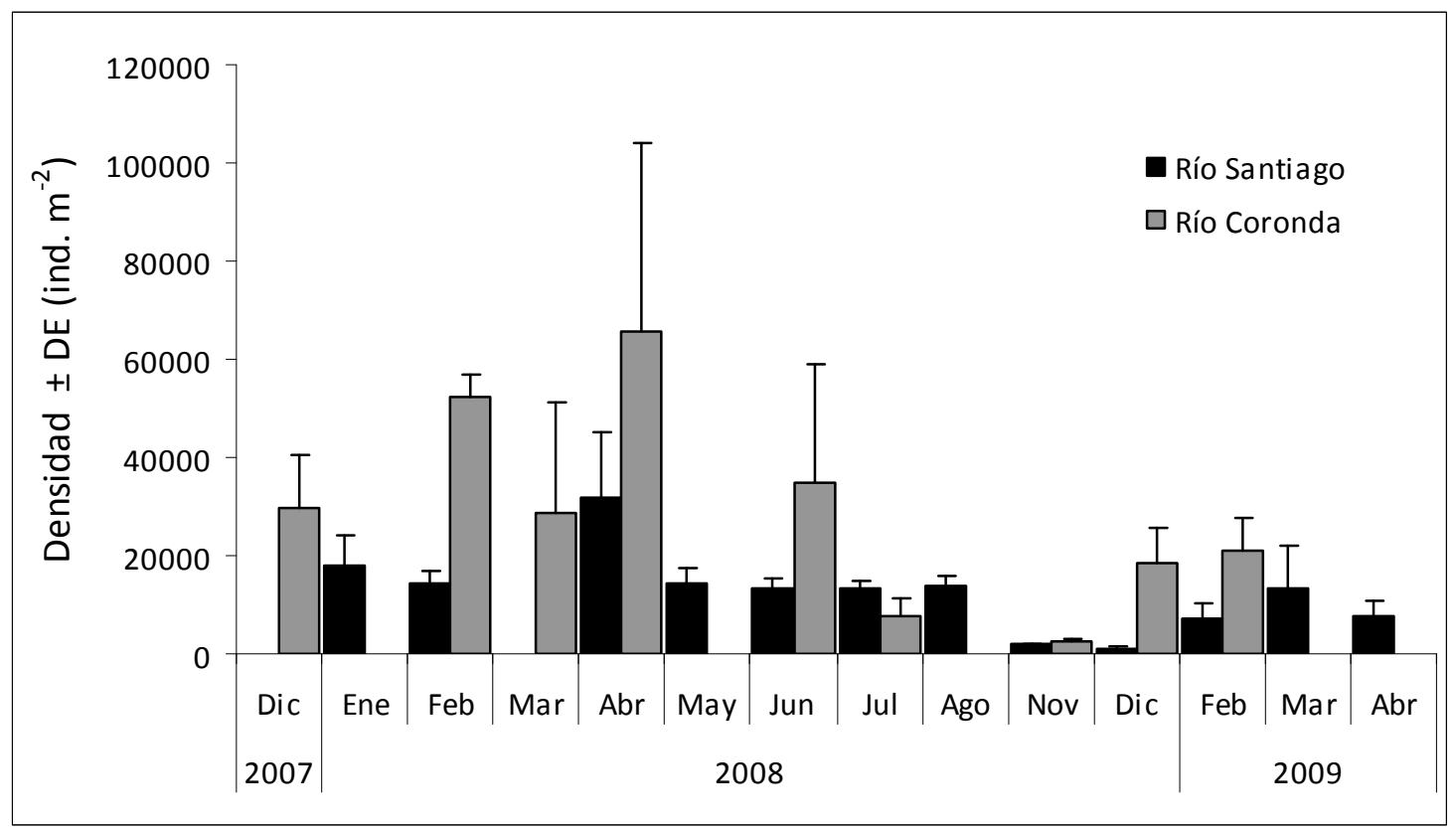

Figura 3.3.3. Variación de la densidad total en los ríos Coronda y Santiago durante el período de estudio. 


\subsubsection{MORFOMETRÍA}

Para el análisis morfométrico se consideraron dos submuestras, una de 1.850 individuos recolectados en el río Santiago y otra de 5.281 del río Coronda. Los resultados del ANOVA no mostraron diferencias significativas entre las medias de LT $(p=0,616)$, AT $(p=0,573)$ ni AL $(p=$ 0,753) entre los colectores retirados en el río Santiago (Tabla 3.3, Apéndice 3.5). Tampoco se encontraron diferencias significativas entre las variables lineales de los colectores retirados en el Coronda, LT ( $p=0,762)$, AT ( $p=0,777)$ ni AL $(p=0,753)$ (Tabla 3.3, Apéndice 3.6).

El ACP para las variables morfométricas de la población del río Santiago resultó en dos componentes principales que explicaron el $99,8 \%$ de la varianza original de la matriz de correlación. Para las variables morfométricas de los ejemplares del río Coronda, los dos primeros componentes explicaron el $99,9 \%$ de la varianza de las variables (Tabla 3.4). En ambos sitios de muestreo las variables mostraron una correlación positiva altamente significativa ( $r>0,9$ ) (Fig. 3.3.4; Tabla 3.5). Las variables mostraron una contribución similar en el componente 1 (Tabla 3.6). 


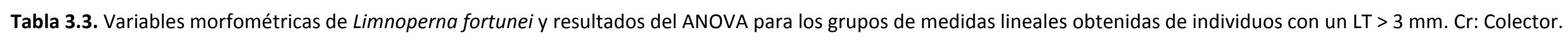

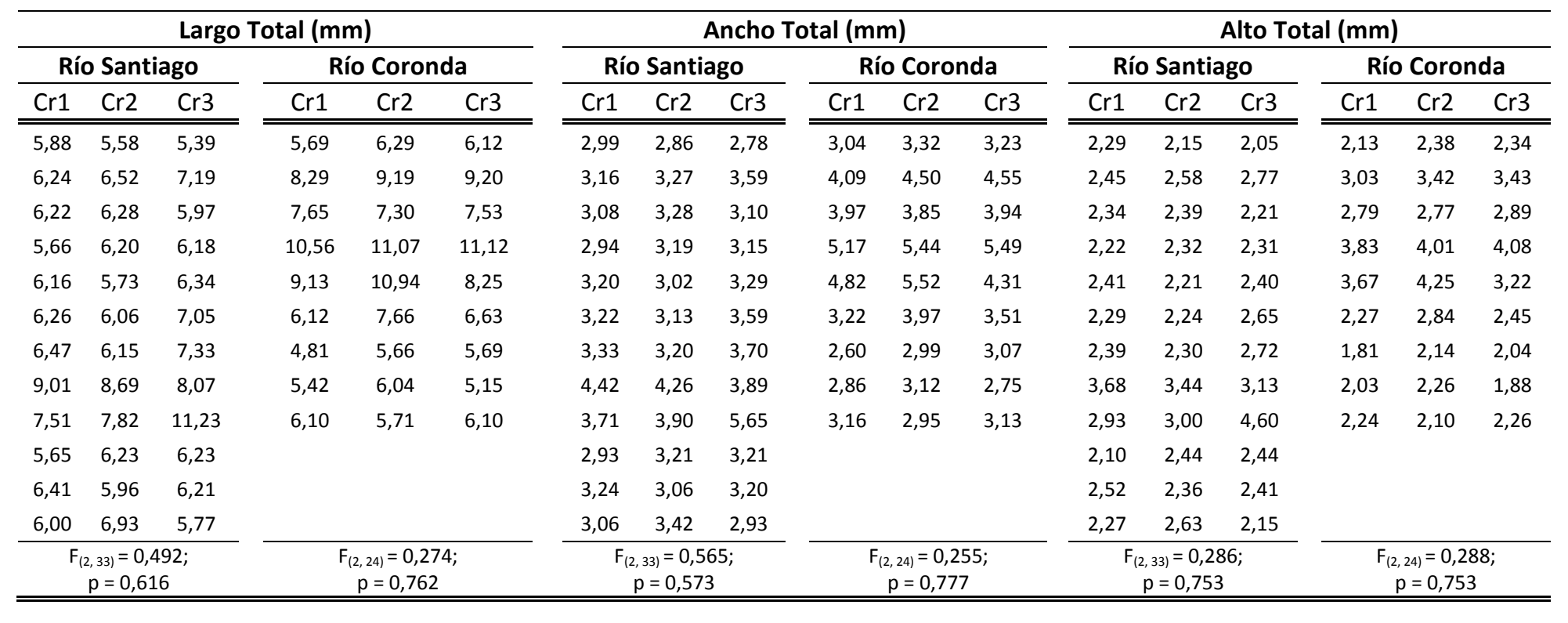


Tabla 3.4. Resultado del análisis de componentes principales: Autovalores

\begin{tabular}{ccccccccc}
\hline & \multicolumn{3}{c}{ Río Santiago } & & \multicolumn{3}{c}{ Río Coronda } \\
\cline { 2 - 4 } \cline { 7 - 8 } \cline { 6 - 8 } & C1 & C2 & C3 & & C1 & C2 & C3 \\
\hline \hline Valor propio & 2,978 & 0,017 & 0,005 & & & 2,992 & 0,005 & 0,003 \\
\hline \% varianza & 99,3 & 0,6 & 0,2 & & 99,7 & 0,2 & 0,1 \\
\hline \% acumulado & 99,3 & 99,8 & 100,0 & & 99,7 & 99,9 & 100,0 \\
\hline \hline
\end{tabular}
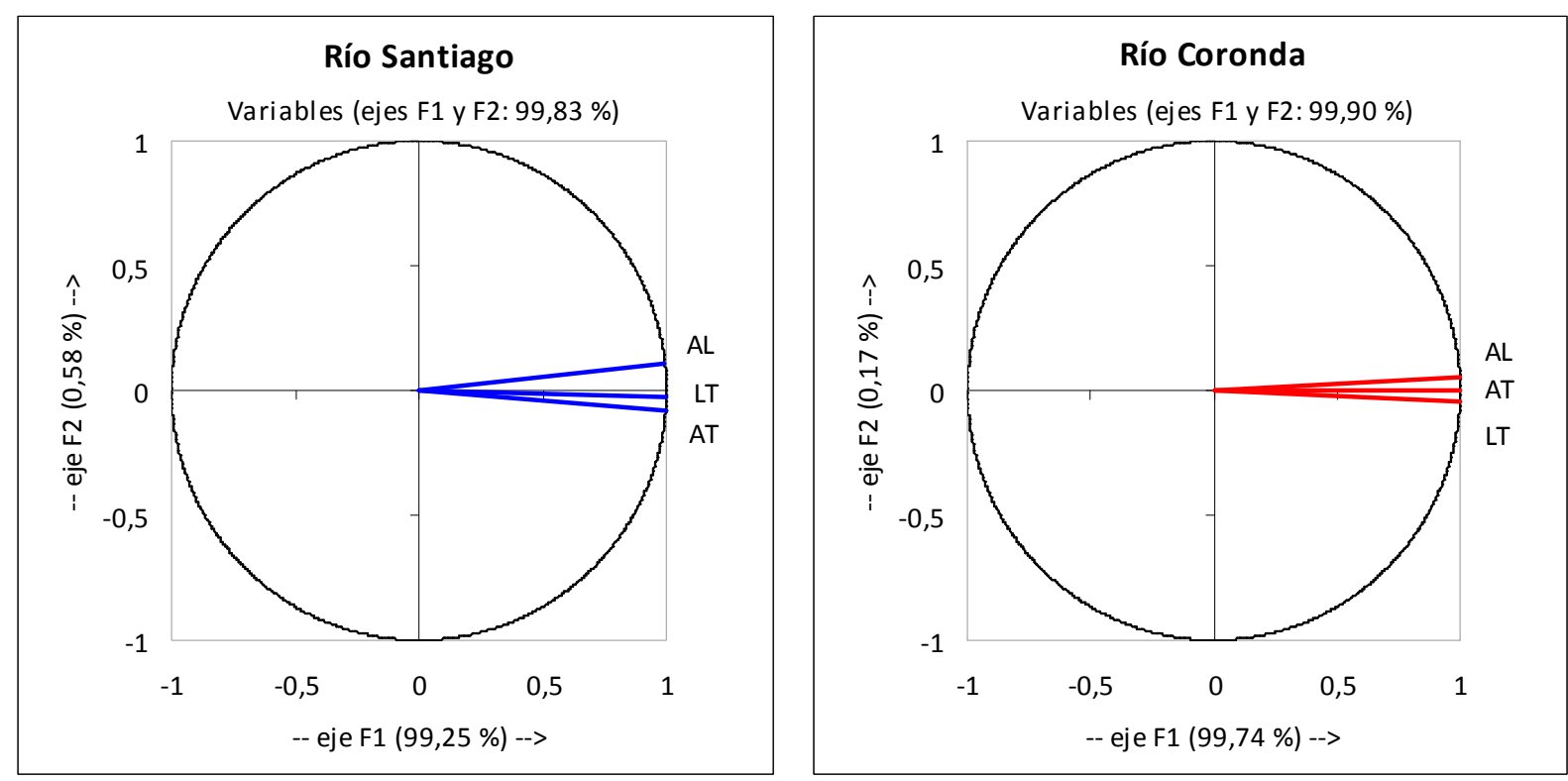

Figura 3.3.4. Correlaciones de los componentes principales 1 y 2 (F1 y F2) y sus respectivos porcentajes de explicación de la varianza original.

Tabla 3.5. Correlación entre las variables originales y los componentes principales en el ACP.

\begin{tabular}{cccccccc}
\hline & \multicolumn{3}{c}{ Río Santiago } & & \multicolumn{3}{c}{ Río Coronda } \\
\cline { 2 - 4 } \cline { 6 - 8 } & C1 & C2 & C3 & & C1 & C2 & C3 \\
\hline \hline LT & 0,998 & $-0,023$ & 0,056 & & 0,999 & $-0,048$ & $-0,024$ \\
\hline AT & 0,996 & $-0,080$ & $-0,039$ & & 0,999 & $-0,003$ & 0,044 \\
\hline AL & 0,995 & 0,103 & $-0,018$ & & 0,998 & 0,051 & $-0,020$ \\
\hline \hline
\end{tabular}

Tabla 3.6. Resultado del análisis de componentes principales: Contribuciones de las variables (\%)

\begin{tabular}{ccccccccc}
\hline & \multicolumn{3}{c}{ Río Santiago } & & \multicolumn{3}{c}{ Río Coronda } \\
\cline { 2 - 4 } \cline { 7 - 8 } & C1 & C2 & C3 & & C1 & C2 & C3 \\
\hline \hline LT & 33,5 & 2,9 & 63,6 & & 33,3 & 47,1 & 19,6 \\
\hline AT & 33,3 & 36,6 & 30,1 & & 33,4 & 0,2 & 66,5 \\
\hline AL & 33,2 & 60,5 & 6,3 & & 33,3 & 52,8 & 13,9 \\
\hline \hline
\end{tabular}


El análisis comparativo de los cocientes morfométricos AT/LT, AL/LT y AL/AT mostró diferencias significativas entre ambientes (Tabla 3.7). Los ejemplares del río Coronda tuvieron una valva más larga y ancha que los del río Santiago, y estos últimos tuvieron una valva significativamente más alta.

Tabla 3.7. Relaciones morfométricas entre las variables lineales.

\begin{tabular}{|c|c|c|c|c|}
\hline Cociente & Sitio & Media $\pm \mathrm{DE}$ & $\mathrm{N}$ & Test Student (datos transformados) \\
\hline \multirow{2}{*}{ AT/LT } & Río Santiago & $0,509 \pm 0,011$ & 36 & \multirow{2}{*}{$t_{(42)}=-2,399 ; p<0,05$} \\
\hline & Río Coronda & $0,518 \pm 0,016$ & 27 & \\
\hline \multirow{2}{*}{$\mathrm{AL} / \mathrm{LT}$} & Río Santiago & $0,384 \pm 0,011$ & 36 & \multirow{2}{*}{$t_{(61)}=3,819 ; p<0,001$} \\
\hline & Río Coronda & $0,374 \pm 0,010$ & 27 & \\
\hline \multirow{2}{*}{$\mathrm{AL} / \mathrm{AT}$} & Río Santiago & $0,754 \pm 0,031$ & 36 & \multirow{2}{*}{$t_{(61)}=4,291 ; p<0,001$} \\
\hline & Río Coronda & $0,722 \pm 0,025$ & 27 & \\
\hline
\end{tabular}

Para estimar el cambio de las variables lineales LT y AT respecto del AL, se invirtieron los cocientes. Para la población del río Santiago la relación alto : ancho : largo fue:

\section{$1: 1,33 \pm 0,01: 2,61 \pm 0,01$}

Para la población del río Coronda fue:

$$
1: 1,39 \pm 0,01: 2,68 \pm 0,01
$$

\subsubsection{CRECIMIENTO}

Para estimar el crecimiento individual se midió el LT de 4.512 ejemplares recolectados en el río Santiago. El resultado del ANOVA no encontró diferencias significativas entre los valores medios de LT estimados entre colectores ( $p=0,873$; Apéndice 3.7). Se agruparon los datos de cada colector y se generó una distribución de frecuencias de tallas para cada fecha muestreo (Fig. 3.3.5). Mediante descomposición polimodal se identificaron cinco cohortes asentadas en los colectores durante el período de estudio. Para cada fecha de muestreo se estimó el valor medio de LT (Tabla 3.8; Fig. 3.3.6). En enero de 2008 se identificaron los individuos asentados en los colectores pertenecientes a la Cohorte 1 con un LT inicial de 4,91 $\pm 1,46 \mathrm{~mm}$. La presencia de esta cohorte en los paneles se observó hasta diciembre del mismo año. Su talla 
final fue $16,13 \pm 1,19 \mathrm{~mm}$. Este valor indica un incremento de $L T=11,22 \mathrm{~mm}$ durante 328 días, lo cual representa una tasa de crecimiento de $0,034 \mathrm{~mm}$ día $^{-1}$. La talla inicial de la Cohorte 2, identificada en febrero de 2008, fue 3,16 \pm 0,76 mm. Luego de 297 días, la talla final fue $10,71 \pm 1,55 \mathrm{~mm}$ y la tasa de crecimiento para ese período de estudio fue $0,025 \mathrm{~mm}$ día $a^{-1}$. La Cohorte 3 se identificó en diciembre de 2008 con un LT inicial de 4,85 $\pm 1,54 \mathrm{~mm}$. En febrero de 2009, luego de 53 días en los colectores artificiales, este grupo de individuos alcanzó un $\mathrm{LT}=7,02 \pm 1,83 \mathrm{~mm}$. La tasa de crecimiento fue 0,041 mm día ${ }^{-1}$ (Tabla 3.8).

Tabla 3.8. Estadística descriptiva de las cohortes identificadas de Limnoperna fortunei para los colectores sumergidos en el río Santiago. LT: Largo total de la valva $(\mathrm{mm})$; DE: desvío estándar; TC ( $\mu \mathrm{m}$ día $\left.^{-1}\right)$ : tasa de crecimiento para el período de tiempo transcurrido entre una fecha de muestreo y la siguiente; N: número de individuos; ND: dato no disponible.

\begin{tabular}{|c|c|c|c|c|c|c|c|}
\hline Cohorte & Año & Estación & Muestreo & Días & $\mathrm{LT} \pm \mathrm{DE}$ & TC & $\mathbf{N}$ \\
\hline \multirow{9}{*}{1} & \multirow{9}{*}{2008} & \multirow{2}{*}{ Verano } & 25-Ene & 1 & $4,91 \pm 1,46$ & ND & 537 \\
\hline & & & 25-Feb & 32 & $6,77 \pm 2,58$ & 60,0 & 96 \\
\hline & & \multirow{3}{*}{ Otoño } & 03-Abr & 70 & $7,37 \pm 1,40$ & 15,8 & 107 \\
\hline & & & 08-May & 105 & $7,31 \pm 2,35$ & $-1,7$ & 66 \\
\hline & & & 10-Jun & 138 & $10,13 \pm 1,88$ & 85,5 & 26 \\
\hline & & \multirow{2}{*}{ Invierno } & 08-Jul & 166 & $11,41 \pm 1,15$ & 45,7 & 31 \\
\hline & & & 14-Ago & 203 & $13,5 \pm 1,87$ & 56,5 & 30 \\
\hline & & \multirow{2}{*}{ Primavera } & 26-Nov & 307 & $15,8 \pm 0,89$ & 22,1 & 6 \\
\hline & & & 18-Dic & 329 & $16,13 \pm 1,19$ & 15,0 & 3 \\
\hline \multirow{8}{*}{2} & \multirow{8}{*}{2008} & Verano & $25-F e b$ & 1 & $3,16 \pm 0,76$ & ND & 341 \\
\hline & & \multirow{3}{*}{ Otoño } & $03-\mathrm{Abr}$ & 39 & $3,3 \pm 1,37$ & 3,7 & 896 \\
\hline & & & 08-May & 74 & $3,65 \pm 0,88$ & 10,0 & 372 \\
\hline & & & 10-Jun & 107 & $4,19 \pm 0,87$ & 16,4 & 315 \\
\hline & & \multirow{2}{*}{ Invierno } & 08-Jul & 135 & $4,9 \pm 0,97$ & 25,4 & 345 \\
\hline & & & 14-Ago & 172 & $7,28 \pm 1,95$ & 64,3 & 391 \\
\hline & & \multirow{2}{*}{ Primavera } & 26-Nov & 276 & $8,73 \pm 2,02$ & 13,9 & 50 \\
\hline & & & 18-Dic & 298 & $10,71 \pm 1,55$ & 90,0 & 11 \\
\hline \multirow{2}{*}{3} & 2008 & Primavera & 18-Dic & 1. & $4,85 \pm 1,54$ & ND & 22 \\
\hline & 2009 & Verano & $09-F e b$ & 54 & $7,02 \pm 1,83$ & 40,9 & 211 \\
\hline 4 & 2009 & Verano & 12-Mar & 1 & $5,76 \pm 2,28$ & ND & 396 \\
\hline 5 & 2009 & Primavera & $15-A b r$ & 1 & $4,36 \pm 1,42$ & ND & 171 \\
\hline
\end{tabular}



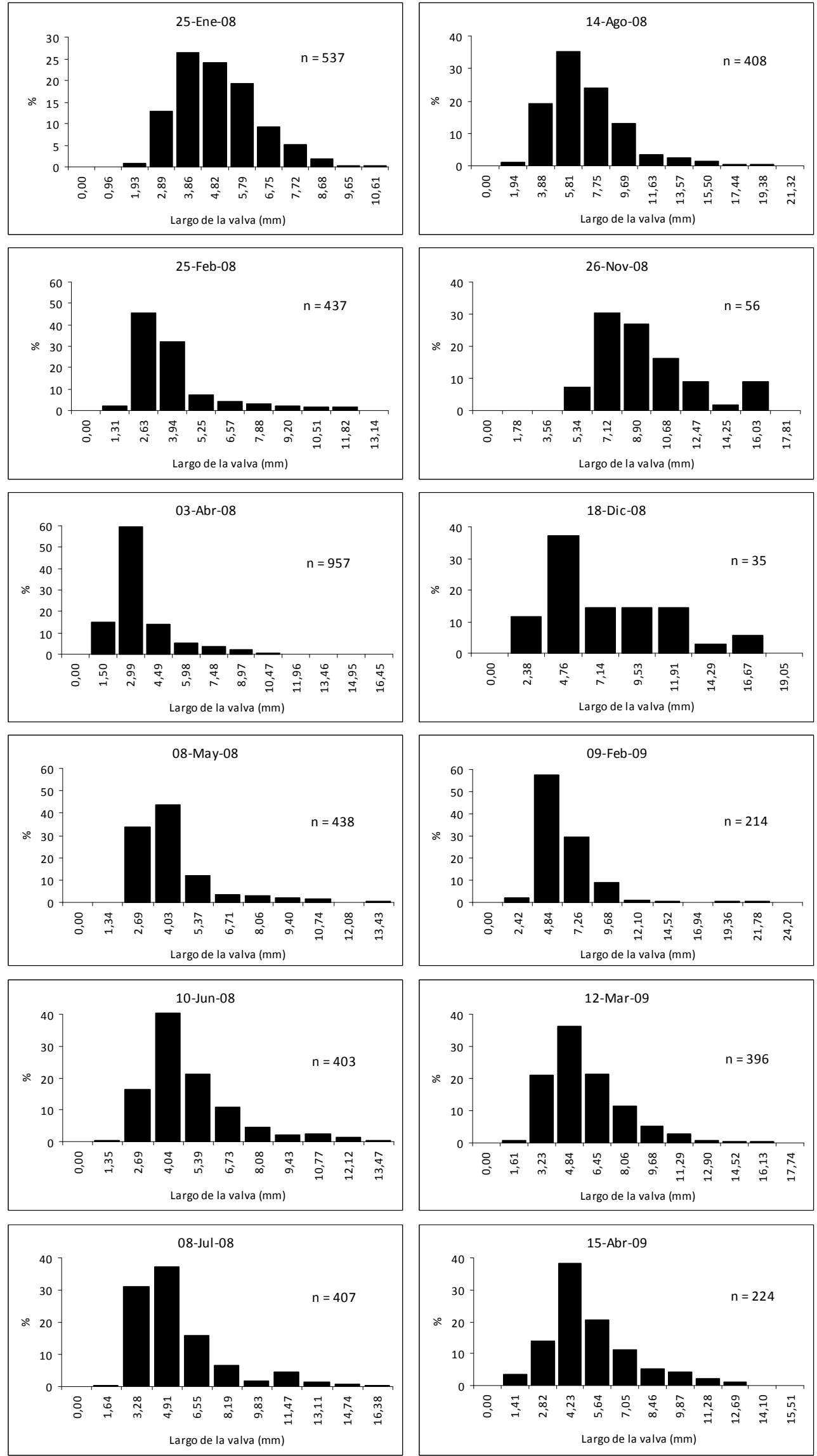

Figura 3.3.5. Variación estacional de la distribución de las frecuencias porcentuales del LT de Limnoperna fortunei en el río Santiago. 
El modelo que mejor ajustó al crecimiento de las cohortes 1 y 2 fue la regresión lineal. La cohorte 3 no pudo ser testeada por el bajo número de datos y también se le ajustó una regresión lineal (Fig. 3.3.6; Tabla 3.9). La comparación entre las pendientes de las cohortes 1 y 2 mostró diferencias significativas $\left(F_{(1,13)}=6,443 ; p<0,05\right)$ siendo la de la Cohorte 1 mayor que la de la Cohorte 2 , consistentemente con lo observado acerca de las tasas de crecimiento.

Tabla 3.9. Valores de los parámetros lineales en la ecuación $y=a x+b$. Resultados de la prueba $F$ para el mejor modelo predictivo. $R^{2}$ : valores coeficientes de determinación.

\begin{tabular}{cccccc}
\hline Cohorte & Modelo & Prueba $F$ & Pendiente & $\begin{array}{c}\text { Ordenada al } \\
\text { origen }\end{array}$ & $\mathrm{R}^{2}$ \\
\hline \hline 1 & Lineal & $\mathrm{F}_{(1,6)}=0,4316 ; \mathrm{p}=0,5356$ & 0,0353 & 5,10 & 0,96 \\
2 & Lineal & $\mathrm{F}_{(1,5)}=2,651 ; \mathrm{p}=0,1644$ & 0,0257 & 1,43 & 0,93 \\
3 & Lineal & ND & 0,0409 & $-8,57$ & 1,00 \\
\hline \hline
\end{tabular}

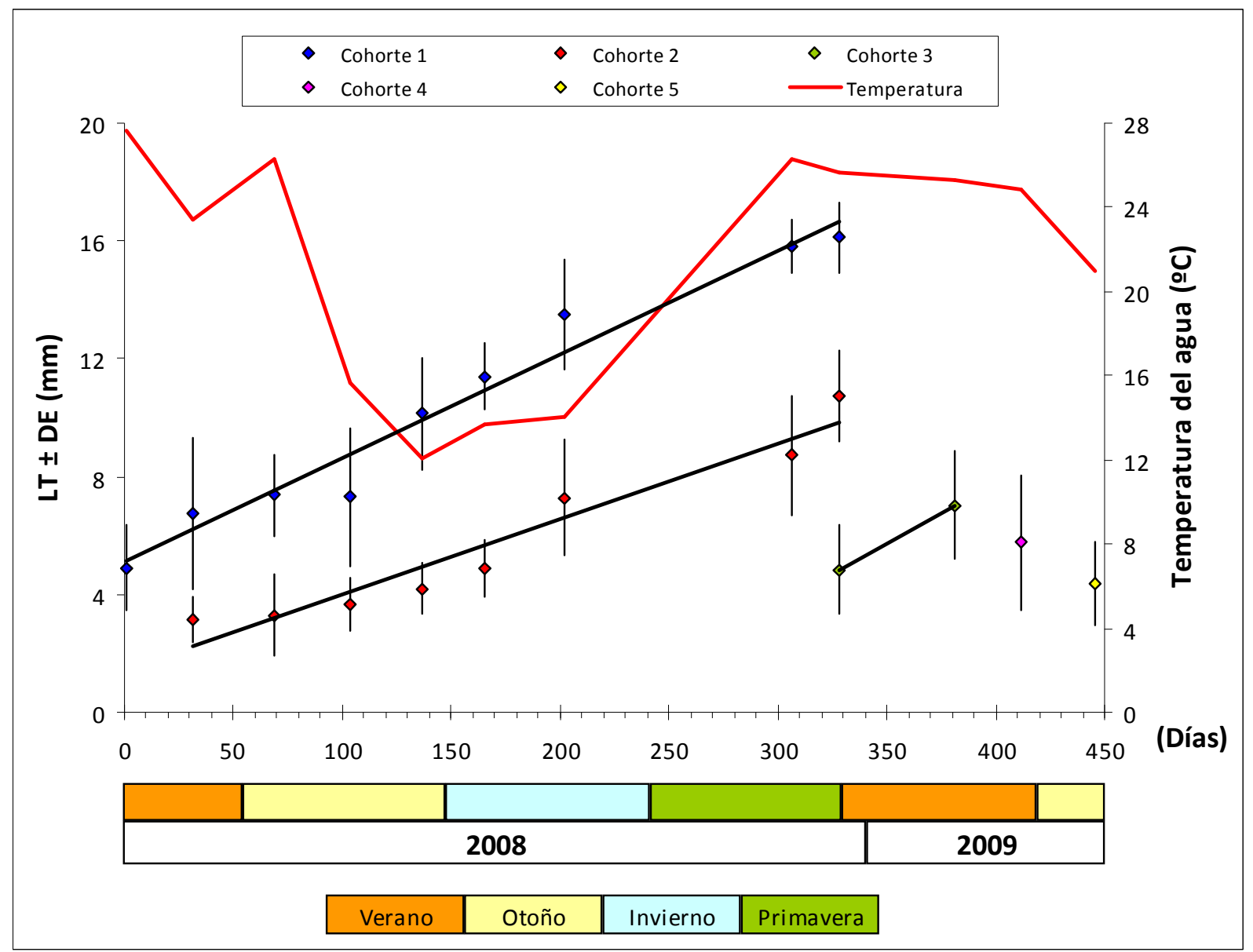

Figura 3.3.6. Modelos de crecimiento ajustados a las cohortes identificadas durante el período de estudio en el río Santiago. LT: Largo Total de la valva; DE: desvío estándar. 
En el río Coronda, el ANOVA no encontró diferencias significativas entre las medias de LT estimadas para los individuos asentados en los colectores ( $p=0,726$; Apéndice 3.8). Se agruparon los datos y se generó una distribución de frecuencias de tallas para cada fecha de muestreo (Fig. 3.3.7 A-B). En la primera etapa, se midió el LT de 6.027 individuos y se identificaron tres cohortes. Para cada fecha de muestreo se estimó el valor medio de LT (Fig. 3.3.8; Tabla 3.10). La talla inicial de los individuos de la Cohorte 1 fue $6,08 \pm 1,55 \mathrm{~mm}$ y la talla final fue $13,64 \pm 1,44 \mathrm{~mm}$. El incremento de $\mathrm{LT}$ por día fue 0,060 $\mathrm{mm}$ día $^{-1}$. La tasa de crecimiento de la Cohorte 2 fue $0,043 \mathrm{~mm} \mathrm{día}^{-1}$. La Cohorte 3 mostró un incremento por día de LT menor que lo estimado para las otras dos cohortes $\left(0,016 \mathrm{~mm}\right.$ día $\left.{ }^{-1}\right)$ durante el período definido por sus tallas inicial y final. La segunda etapa de la experiencia tuvo una duración de 140 días. Durante ese período se midieron 1.263 individuos y se identificaron tres cohortes. La Cohorte $1^{*}$ tuvo una tasa de crecimiento de $0,072 \mathrm{~mm}$ día ${ }^{-1}$ y la Cohorte $2^{*}$ de 0,048 $\mathrm{mm}$ día ${ }^{-1}$ (Fig. 3.3.8, Tabla 3.10). 
Tabla 3.10. Estadística descriptiva de las cohortes identificadas de Limnoperna fortunei para los colectores sumergidos en el río Coronda. LT: Largo total de la valva $(\mathrm{mm})$; DE: desvío estándar; TC $\left(\mu \mathrm{m}\right.$ día $\left.{ }^{-1}\right)$ : tasa de crecimiento para el período de tiempo transcurrido entre una fecha de muestreo y la siguiente; N: número de individuos; ND: dato no disponible.

\begin{tabular}{|c|c|c|c|c|c|c|c|}
\hline Cohorte & Año & Estación & Muestreo & Días & $\mathrm{LT} \pm \mathrm{DE}$ & TC & $\mathbf{N}$ \\
\hline \multirow{4}{*}{1} & 2007 & \multirow{3}{*}{ Verano } & 21-Dic & 1 & $6,08 \pm 1,55$ & ND & 669 \\
\hline & \multirow{3}{*}{2008} & & $12-\mathrm{Feb}$ & 54 & $10,31 \pm 2,60$ & 77,9 & 984 \\
\hline & & & 17-Mar & 88 & $13,64 \pm 1,44$ & 100,9 & 149 \\
\hline & & Otoño & $24-\mathrm{Abr}$ & 126 & $13,58 \pm 2,29$ & $-1,6$ & 788 \\
\hline \multirow{6}{*}{2} & \multirow[t]{3}{*}{2007} & & 21-Dic & 1 & $3,44 \pm 0,61$ & ND & 219 \\
\hline & & Verano & $12-\mathrm{Feb}$ & 54 & $4,93 \pm 1,14$ & 28,1 & 582 \\
\hline & & & 17-Mar & 88 & $7,35 \pm 2,33$ & 71,2 & 774 \\
\hline & \multirow[t]{3}{*}{2008} & \multirow{2}{*}{ Otoño } & $24-A b r$ & 126 & $9,04 \pm 1,49$ & 44,5 & 359 \\
\hline & & & 12-Jun & 175 & $12,2 \pm 2,43$ & 64,5 & 692 \\
\hline & & Invierno & 31-Jul & 224 & $13,06 \pm 1,93$ & 17,6 & 47 \\
\hline \multirow{3}{*}{3} & \multirow{3}{*}{2008} & \multirow{2}{*}{ Otoño } & 24-Abr & 1 & $4,82 \pm 1,11$ & ND & 275 \\
\hline & & & 12-Jun & 50 & $6,16 \pm 1,69$ & 27,3 & 354 \\
\hline & & Invierno & 31-Jul & 99 & $6,38 \pm 1,98$ & 4,5 & 204 \\
\hline \multirow{3}{*}{$1 *$} & \multirow{2}{*}{2008} & \multirow{2}{*}{ Primavera } & 22-Nov & 1 & $5,83 \pm 1,33$ & ND & 25 \\
\hline & & & 17-Dic & 26 & $7,6 \pm 1,59$ & 70,8 & 102 \\
\hline & 2009 & Verano & $12-F e b$ & 83 & $11,75 \pm 0,54$ & 72,8 & 1 \\
\hline \multirow{3}{*}{$2^{*}$} & \multirow{2}{*}{2008} & \multirow{2}{*}{ Primavera } & 22-Nov & 1 & $3,36 \pm 0,78$ & ND & 55 \\
\hline & & & 17-Dic & 26 & $4,67 \pm 1,11$ & 52,4 & 505 \\
\hline & 2009 & Verano & $12-F e b$ & 83 & $7,33 \pm 1,47$ & 46,7 & 129 \\
\hline $3^{*}$ & 2009 & Verano & 12-Feb & 1 & $4,15 \pm 0,95$ & ND & 504 \\
\hline
\end{tabular}



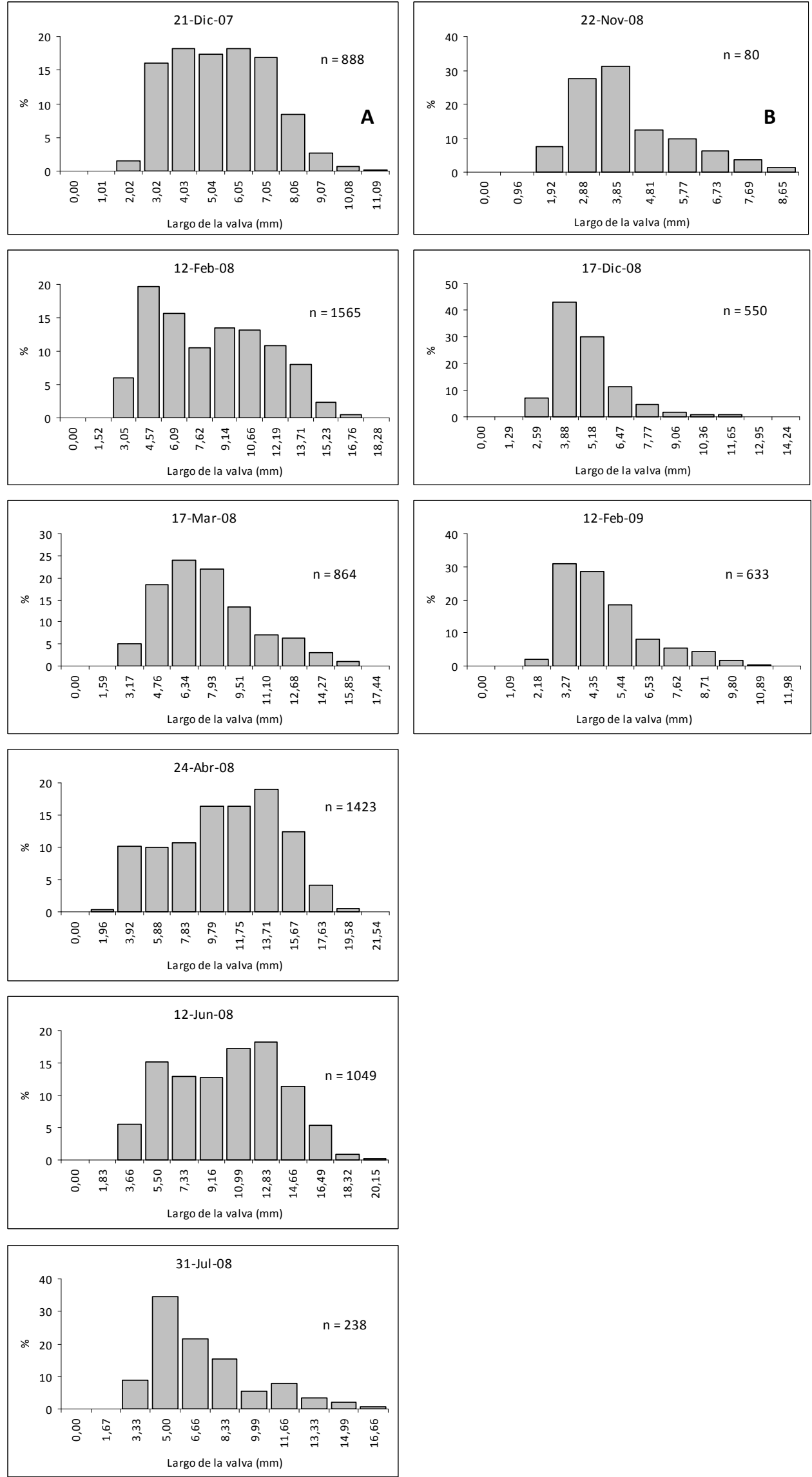

Figura 3.3.7. Variación estacional de la distribución de las frecuencias porcentuales de tallas de Limnoperna fortunei en el río Coronda. A) primera etapa; B) segunda etapa. 
El modelo que mejor ajustó a las cohortes 1 y 2 fue la regresión lineal. Las cohortes 3, 1* y 2* no pudieron ser testeadas por el bajo número de datos disponibles para ajustar una regresión cuadrática; a cada cohorte se le ajustó, entonces, una regresión lineal (Fig. 3.3.8;

Tabla 3.11). La comparación de las pendientes de las cohortes mostró diferencias significativas $\left(F_{(4,9)}=3,972 ; p<0,05\right)$.

Tabla 3.11. Valores de los parámetros lineales en la ecuación $y=a x+b$. Resultados de la prueba $F$ para el mejor modelo predictivo. $\mathrm{R}^{2}$ : valores coeficientes de determinación.

\begin{tabular}{cccccc}
\hline \multirow{2}{*}{ Cohorte } & Modelo & Prueba $F$ & Pendiente & Ordenada al origen & $\mathrm{R}^{2}$ \\
\hline \hline 1 & Lineal & $\mathrm{F}_{(1,1)}=2,487 ; \mathrm{p}=0,360$ & 0,0645 & 6,61 & 0,90 \\
2 & Lineal & $\mathrm{F}_{(1,3)}=0,102 ; \mathrm{p}=0,771$ & 0,0471 & 3,13 & 0,98 \\
3 & Lineal & ND & 0,0159 & 3,02 & 0,85 \\
\hline $1^{*}$ & Lineal & ND & 0,0723 & $-18,55$ & 1,00 \\
$2^{*}$ & Lineal & ND & 0,0481 & $-12,81$ & 1,00 \\
\hline \hline
\end{tabular}

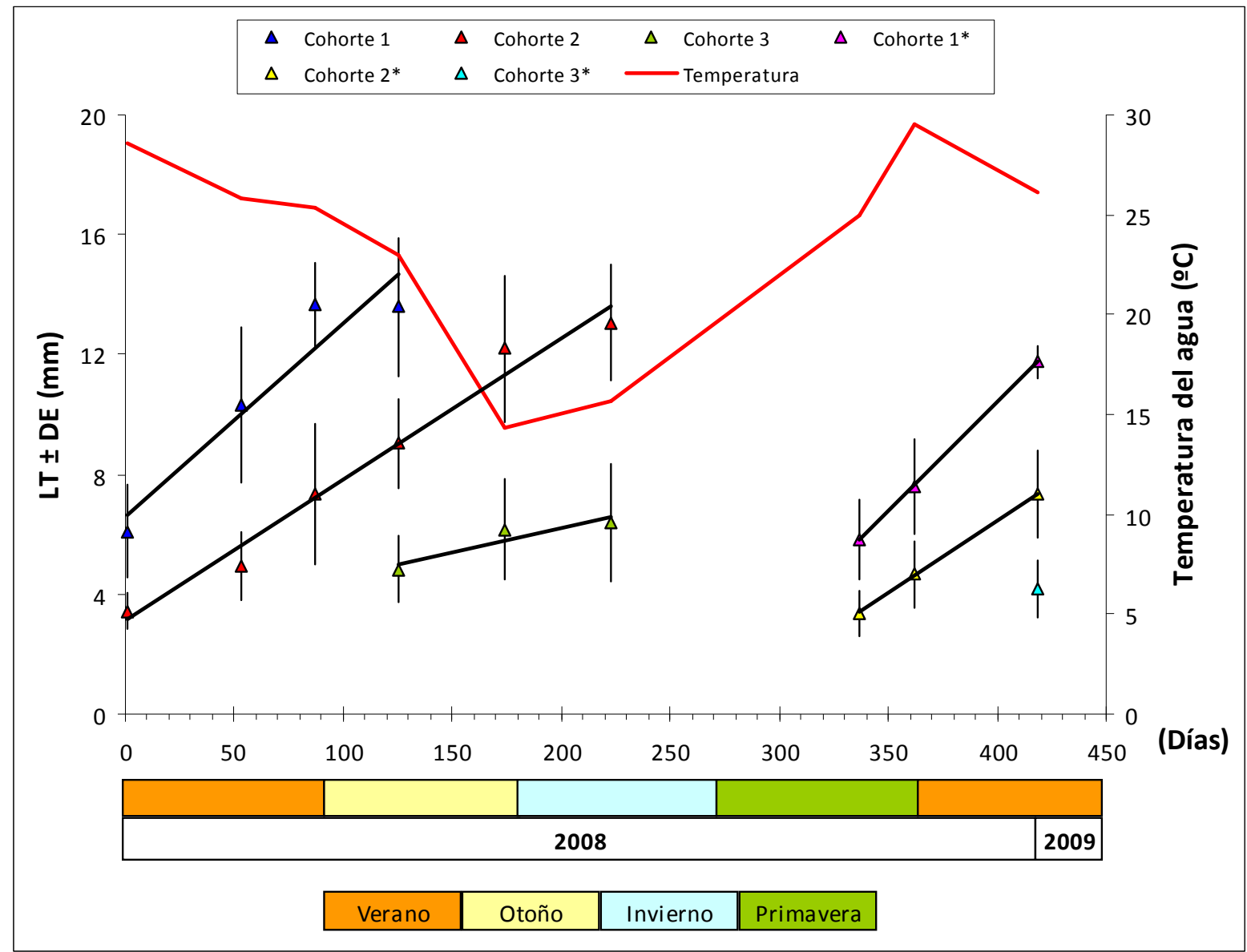

Figura 3.3.8. Modelos de crecimiento ajustados a las cohortes identificadas durante el período de estudio en el río Coronda. LT: Largo Total de la valva; DE: desvío estándar. 
La comparación de pendientes de las regresiones lineales mediante prueba F para la Cohorte 1 de ambos ríos mostró que los individuos en el Coronda tuvieron un crecimiento significativamente mayor que los del río Santiago $\left(F_{(1,9)}=7,056 ; p<0,05 ;\right.$ Fig. 3.3.9). El mismo resultado se obtuvo al comparar las pendientes de la Cohorte 2 en cada sitio $\left(F_{(1,10)}=19,76 ; p\right.$ $<0,01$; Fig. 3.3.9).
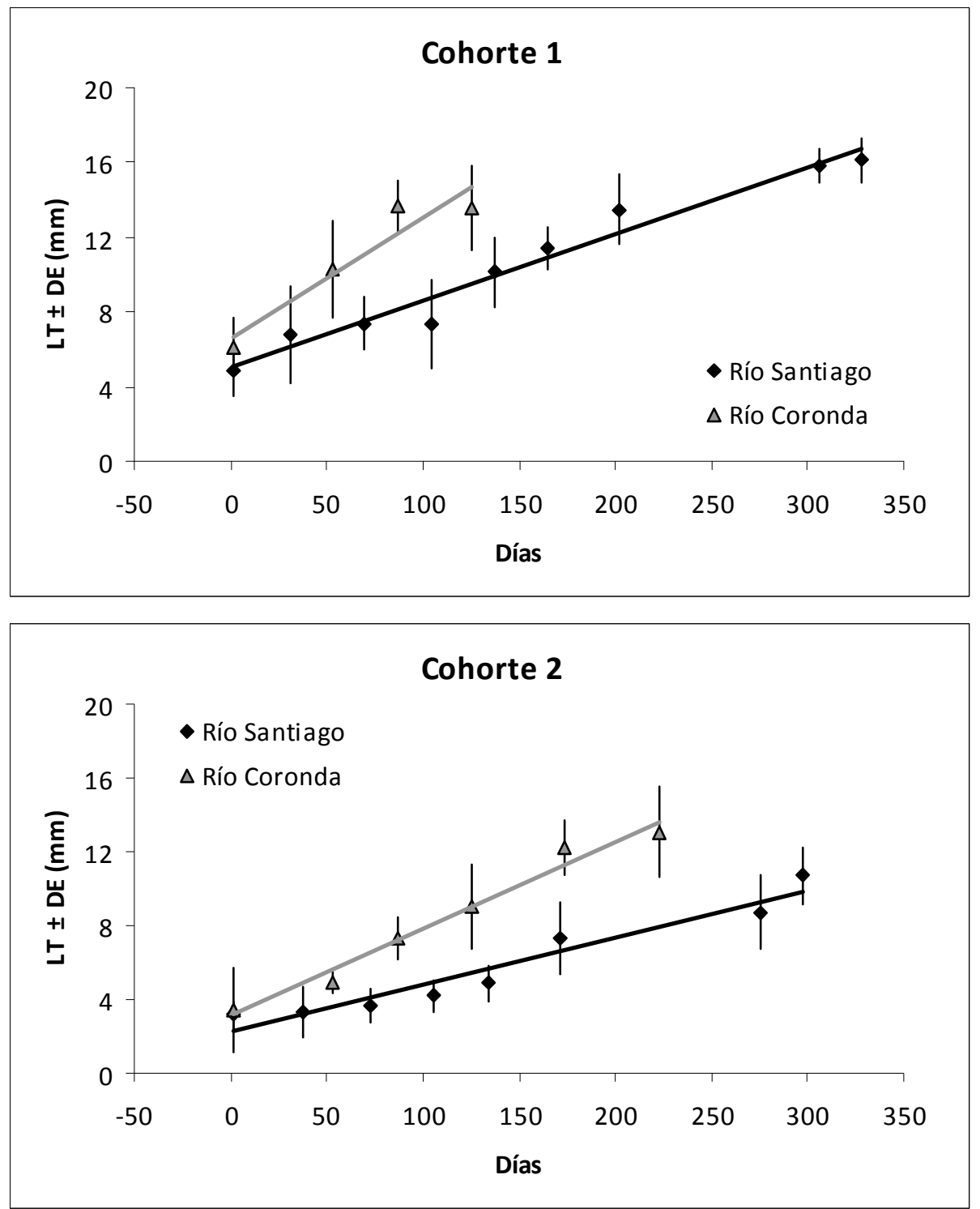

Figura 3.3.9. Comparación del crecimiento individual de las Cohortes 1 y 2 de Limnoperna fortunei durante el período de estudio en el río Coronda y en el Santiago. LT: Largo total de la valva; DE: desvío estándar. 


\subsection{DISCUSIÓN}

Las poblaciones de mejillones en general pueden diferir significativamente en su reclutamiento, crecimiento y supervivencia inclusive entre sitios muy cercanos (Stirling \& Okumus, 1994). El asentamiento y el reclutamiento definen inicialmente la estructura poblacional y subsecuentemente la estructuración de la comunidad de invertebrados bentónicos (Maclsaac et al., 1991; Martel et al., 1994; Ganesan et al., 2010). El asentamiento larval y el aporte de juveniles a la población establecida pueden variar espacial y temporalmente, reflejando la diversidad demográfica de la población.

Los términos 'asentamiento' y 'reclutamiento' a menudo son confundidos. El asentamiento es un proceso dinámico por el que la larva planctónica se adhiere a la superficie bentónica y se metamorfosea. El reclutamiento es la supervivencia de las larvas o postlarvas asentadas luego de un determinado período de tiempo (Seed \& Suchanek, 1992; Horvath \& Lamberti, 1999; Alfaro, 2006b). Las poblaciones pueden mostrar variaciones en respuesta a factores abióticos propios del hábitat específico, o a factores denso-dependientes que afectan el asentamiento y el reclutamiento de los macroinvertrebados bentónicos (Nalepa et al., 1995; Mörtl \& Rothhaup, 2003).

El análisis comparativo de la densidad total mostró diferencias significativas entre los dos sitios de estudio, siendo mayor en el río Coronda. Este resultado coincide con las diferencias observadas en la densidad de larvas, siendo significativamente mayor en el río Coronda que en el río Santiago. Asimismo, se observó que la densidad de individuos asentados en los colectores sumergidos en el río Santiago estuvo definida principalmente por un mayor número de juveniles, mientras que en el Coronda estuvo caracterizada por individuos adultos. En ambos sitios de muestreo, la presencia de juveniles en los colectores artificiales se observó durante todo el período de estudio. Por lo tanto, podemos inferir que el reclutamiento de $L$. fortunei fue variable pero continuo a lo largo del año, con picos máximos entre finales de primavera y principios de otoño. Esta observación coincide con los valores máximos de densidad de larvas en el plancton estimados en el capítulo anterior. Asimismo, la variación temporal de la densidad de los reclutas confirma lo observado por otros autores en otros ambientes (Morton, 1977; Boltovskoy \& Cataldo, 1999; Magara et al., 2001; dos Santos et al, 2008; Belz et al., 2010; Nakano et al., 2011). 
Las diferencias en la variación espacial de la densidad y el reclutamiento observadas en este estudio podrían ser el resultado de la acción de reguladores, como la presencia de sustancias químicas promotoras del asentamiento, la depredación, la competencia intraespecífica o condiciones limnológicas de los ambientes. Las sustancias químicas promotoras del asentamiento larval son producidas por individuos de la misma especie, por biofilms o por las algas. Estos promotores están libres en el agua, adsorbidos a la superficie de los sustratos o asociados a individuos de la misma especie (Hebert et al., 1991; Hadfield \& Paul, 2001; Mörtl \& Rothhaup, 2003; Alfaro et al., 2006; Sardiña et al., 2009). Los biofilms están compuestos por una alta diversidad de microorganismos (bacterias, diatomeas, protozoos) dentro de una matriz molecular compleja conformada por aminoácidos y glicoproteínas (Ganesan et al., 2010). La atracción por sustancias químicas ha sido discutida para Dreissena polymorpha, L. fortunei y varios taxa marinos, como por ejemplo Perna canaliculus (Hebert et al., 1991; Chase \& Bailey, 1999; Hadfield \& Paul, 2001; Mörtl \& Rothhaupt, 2003; Sardiña et al., 2009; Ganesan et al., 2010; Nakano et al., 2011).

En D. polymorpha la tasa de asentamiento de postlarvas está regulada por el nivel de concentración de sustancias químicas en el agua liberadas por los adultos. A concentraciones bajas de estas sustancias en el medio circundante, funcionan como atrayentes, mientras que a concentraciones altas son repelentes (Hebert et al., 1991; Mörtl \& Rothhaupt, 2003). Por otro lado, la tasa de asentamiento de Perna canaliculus se regula por promotores químicos liberados por biofilms de naturaleza bacteriana y por algas que inducen el asentamiento de larvas (Alfaro et al., 2006; Ganesan et al., 2010). Concordando con lo observado por Hebert et al. (1991), Sardiña et al. (2009) y Nakano et al. (2011) sugirieron que los promotores químicos que regulan el asentamiento larval tienen un umbral de concentración que afecta positiva o negativamente el asentamiento.

Las estructuras de tallas estimadas en este estudio difieren entre los ambientes. En el río Santiago la presencia de juveniles fue predominante con respecto a los adultos. Mientras que en el río Coronda, la presencia de individuos adultos fue mayoritaria en la primera etapa. En cambio, se observó lo opuesto durante la segunda etapa experimental cuando se sumergieron nuevos colectores. La estructura de tallas estuvo representada principalmente por juveniles, i.e., en promedio el $76 \%$ de los individuos tuvieron LT $<5 \mathrm{~mm}$. En función de estos resultados, consideramos probable que el asentamiento larval de L. fortunei, en los ambientes estudiados, esté regulado por promotores químicos liberados al medio. Sin 
embargo, no se estudió si estas sustancias son liberadas por adultos de la misma especie o por biofilms Si ocurriese lo primero, entonces una mayor densidad de adultos resultaría en una mayor producción de estas sustancias, con un consecuente aumento de la concentración en el medio. En cambio, si las sustancias fueran liberadas por biofilms, el progresivo incremento de la densidad de mejillones adultos ofrecería una superficie mayor para la formación de estos sistemas microbianos. La ocurrencia de un evento o el otro, o la acción sinérgica de ambos podría conducir a un incremento en la producción de sustancias químicas por encima del umbral óptimo e indicarían que ese sector llegó a su capacidad de carga afectando negativamente el asentamiento de las larvas.

Asimismo, las diferencias significativas de densidad y de estructura de tallas estimadas en este capítulo podrían ser consecuencia de la depredación. En los sistemas acuáticos, la depredación afecta la abundancia, la estructura de tallas de la población presa y, consecuentemente, la estructura y el funcionamiento de las comunidades (Boles \& Lipcius, 1994). La supervivencia y persistencia de las especies presa, sometidas a una intensa presión de depredación, es la conjunción de adaptaciones antidepredadoras, condiciones ambientales, características del hábitat y de la dinámica del sistema depredador-presa (Seitz et al., 2001). La introducción de poblaciones de bivalvos se incrementó dramáticamente a nivel mundial y se han documentado efectos negativos y positivos en los ecosistemas nativos. Uno de los efectos más notables de los bivalvos exóticos en los ecosistemas es su impacto en las interacciones tróficas. Varias especies exóticas son integradas como presas en la red trófica de las áreas invadidas. Los estadios larvales son consumidos activamente por adultos de la misma especie y ambos son consumidos por aves acuáticas y por otros depredadores tales como larvas y adultos de peces, entre otros (Bij de Vaate, 1991; Maclsaac et al., 1991; Nalepa et al., 1995; Karatayev et al., 2007; Paolucci et al., 2010; Nakano et al., 2011). Las interacciones mencionadas previamente se observan para L. fortunei en América del Sur (López Armengol \& Casciotta, 1998; Montalto et al., 1999; Penchaszadeh et al., 2000; Sylvester et al., 2007; Cantanhêde et al., 2008; Paolucci et al., 2010) y para Dreissena polymorpha en Europa y Norteamérica (French, 1993; Boles \& Lipcius, 1994; Molloy et al., 1994; Tucker et al., 1996; Perry et al., 1997; Mörtl \& Rothhaup, 2003). El número de juveniles en la población depende de la depredación sobre el estadio larval previo y del encuentro de sustrato firme para el asentamiento durante el estadio de post-velíger (Paolucci et al., 2007, 
$2009,2010)$. Los depredadores de larvas son principalmente los estadios larvales y juveniles de varias especies de peces de agua dulce (Bij de Vaate, 1991).

La fauna íctica de la Cuenca del Plata, con más de 400 especies y una amplia diversidad de hábitos alimenticios, incluye varias especies omnívoras (Ringuelet, 1967). Antes del arribo de especies invasoras como la almeja asiática (Corbicula fluminea) y L. fortunei, la malacofauna de la Cuenca del Plata tenía una muy baja incidencia en la dieta de los peces (Cataldo et al., 2002). Limnoperna fortunei, al poseer hábito epifaunal, presenta mayor accesibilidad para su consumo que los bivalvos autóctonos (Montalto et al., 1999). Estudios sobre la dieta de peces proponen que este mejillón es un ítem alimenticio importante para larvas y adultos de varias especies de peces, algunas de ellas ecológica y económicamente importantes (López Armengol \& Casciotta, 1998; Montalto et al., 1999; Cataldo \& Boltovskoy, 2000; Penchaszadeh et al., 2000; Cataldo et al., 2002; Boltovskoy et al., 2006). Esta observación es consistente con los resultados obtenidos en Brasil (Cantanhêde et al., 2008) y en Asia (Nakano et al., 2010 a y b). Estas evidencias indican que la invasión está asociada con un aprovechamiento de la nueva oferta alimentaria por parte de los peces, provocando una alteración en los niveles tróficos y en los roles de depredador-presa (Paolucci et al., 2007, 2009, 2010).

En este estudio, la distribución de frecuencias de tallas sobre los colectores artificiales sumergidos mostró diferencias entre los ríos Coronda y Santiago. En general, en ambos sitios la estructura fue bimodal, aunque en la población del río Coronda los picos modales fueron más definidos que en la del río Santiago. Las diferencias observadas entre ambientes puede ser el resultado de una presión de depredación selectiva diferente en cada sitio. En consecuencia, consideramos posible que en el río Santiago haya habido una mayor presión de consumo sobre ejemplares de talla mayor que $7 \mathrm{~mm}$, mientras que en el río Coronda la presión de selección habría impactado mayormente sobre ejemplares con LT $\leq 5-6 \mathrm{~mm}$.

El bivalvo Limnoperna fortunei es consumido por peces con diversos hábitos alimentarios. Sin embargo, las características morfofuncionales del aparato trófico de los peces condicionan el gradiente de digestión de este mitílido dulciacuícola. En el río Paraná, las especies ícticas ingieren ejemplares de $L$. fortunei en un amplio rango de tallas y en un número decreciente ( $\mathrm{LT}=1-6>6-15>15 \mathrm{~mm}$ ) (Montalto et al., 1999). Existe una clara relación entre el tamaño de los peces y el de $L$. fortunei. Los ejemplares de $L$. fortunei con LT $\leq 6 \mathrm{~mm}$ representan el $90 \%$ en la dieta de la boga (Leporinus obtusidens). Asimismo, en el 
bagre amarillo (Pimelodus maculatus), el mayor porcentaje de ejemplares consumidos a tallas $\leq 6 \mathrm{~mm}$ representa un $70 \%$, mientras que el moncholo (Pimelodus albicans) consume un rango más amplio de ejemplares de Limnoperna (1 a $15 \mathrm{~mm}$ ), que representan un $95 \%$ de la dieta. La longitud total de los peces y el tipo de abertura bucal se relacionan directamente con la talla de L. fortunei consumidas (Montalto et al., 1999).

En la cuenca del Río de la Plata los estudios sobre dieta de peces muestran que el $72 \%$ de los individuos de Leporinus obtusidens (boga) tuvieron fragmentos de valvas de $L$. fortunei en su estómago, intestino o ambos. El mejillón está presente en la dieta de la boga durante casi todo el año; y de octubre a febrero, su presencia en el tracto digestivo de $L$. obtusidens es máxima, con valores de 83 a $100 \%$. Los ejemplares más consumidos por este pez tienen un largo de valva de 10-15 mm (Penchaszadeh et al., 2000).

Los efectos de la depredación selectiva también se estudiaron para Dreissena polymorpha. Un estudio realizado por Petrie \& Knapton (1999) mostró que el consumo selectivo causado por aves acuáticas eliminó completamente una cohorte de la población del mejillón cebra. Como resultado, su estructura de tallas se caracterizó por un $90 \%$ de ejemplares de talla $<10 \mathrm{~mm}$ y un bajo número de individuos con una talla $>15 \mathrm{~mm}$.

Los invertebrados acuáticos muestran un amplio rango de variación morfológica en su ambiente natural. Los moluscos, como la mayoría de los organismos, exhiben cambios progresivos en sus proporciones relativas a medida que aumenta el tamaño corporal. En general, en los mejillones esas variaciones resultan de un proceso ontogénico o de una respuesta plástica a las condiciones ambientales, así como a la exposición a los depredadores o a la densidad de individuos de la misma especie. Los cambios alométricos en las proporciones relativas de la valva reflejan restricciones impuestas por la optimización de la geometría de las redes de transporte interno y respuestas a las condiciones ambientales pueden contribuir a esas restricciones (Alunno-Bruscia et al., 2001). Los individuos sometidos a una elevada densidad poblacional pueden manifestar un cociente AT/LT o AL/LT significativamente menor que los pertenecientes a poblaciones con densidades menores, resultando en una forma valvar más alargada o más chata (Hickman, 1979; Alunno-Bruscia et al., 2001; Lajtner et al., 2004; Lauzon-Guay et al., 2005). En este estudio no se pudo establecer, para ninguno de los dos sitios, una relación entre la densidad y la morfología de la valva. Sin embargo, las dimensiones valvares mostraron diferencias morfométricas entre los 
ejemplares muestreados en uno y otro sitio. Los ejemplares del río Coronda tuvieron una valva más alargada y ancha, pero menos alta. Este resultado concuerda con lo observado por Lauzon-Guay et al. (2005). El análisis de ACP para cada sitio de muestreo mostró una fuerte correlación entre las medidas lineales.

El método utilizado en la estimación del crecimiento individual de $L$. fortunei en este estudio fue diferente a los modelos propuestos por Boltovskoy \& Cataldo (1999) y Maroñas et al. (2003) en la área inferior de la cuenca del Río de la Plata. Los autores mencionados basan sus resultados en el modelo estacional y clásico de von Bertalanffy, respectivamente. Comúnmente, el modelo clásico de von Bertalanffy asume que la tasa de crecimiento de los individuos decrece con la edad y se aproxima a cero cuando alcanzan la edad máxima, y en la versión estacional se incluyen dos nuevos parámetros que tienen en cuenta la amplitud y el comienzo de las oscilaciones estacionales del crecimiento. Según Pauly (1990) los modelos de crecimiento que no consideran explícitamente las oscilaciones estacionales omiten un aspecto esencial del proceso de crecimiento.

La distribución de los valores medios de LT de cada cohorte fue prácticamente linealpositiva y las tallas máximas estimadas son inferiores a las mencionadas en los trabajos de crecimiento. A su vez, no se observaron disminuciones marcadas de la tasa de crecimiento, i.e., hubo ausencia de oscilaciones estacionales (Tabla 3.8 y 3.10; Fig. 3.3 .6 y 3.3.8). Esto coincide con lo observado en varios estudios de crecimiento de bivalvos donde los incrementos en el largo de valva son prácticamente lineales hasta que los individuos alcanzan tallas grandes (Bayne \& Worral, 1980). Por lo tanto, consideramos que la contrastación de modelos de regresión (lineal, cuadrática y cúbica) mediante una prueba $\mathrm{F}$ de la suma de cuadrados es un método apropiado para nuestro conjunto de datos. Las tasas de crecimiento en este estudio fueron similares a las estimadas en Brasil y diferentes regiones de Asia (15-20 $\mathrm{mm}$ año ${ }^{-1}$, i.e., 0,041-0,055 mm día ${ }^{-1}$ ) (Morton, 1977; Iwasaki \& Uryu, 1998; Magara et al., 2001; dos Santos et al., 2008).

La diferencia observada entre las tasas de crecimiento de las cohortes asentadas en el río Santiago y en el Coronda podría estar relacionada con la diferencia temporal en la que ocurrió el asentamiento de las postlarvas de cada cohorte en los colectores artificiales. La comparación del crecimiento entre cohortes de los dos ambientes, mostró que los mejillones 
del río Coronda crecieron a una tasa mayor que los del río Santiago. Aunque existen varios factores que afectan el crecimiento, consideramos que el determinante principal del crecimiento y de la dinámica de ambas poblaciones, puede haber sido la diferencia de calidad ambiental entre los sitios de muestreo.

Es bien conocido que las concentraciones elevadas de metales pesados son estresantes y que las respuestas fisiológicas de la mayoría de los animales expuestos a ellos tienen efectos negativos en su dinámica poblacional. Los mejillones responden al estrés cerrando las valvas, inhibiendo la producción de filamentos bisales y disminuyendo las tasas de respiración y filtración, dando como resultado una disminución del crecimiento y del peso corporal. Esto último se traduce en una baja producción o liberación de gametas (Widdows \& Donkin, 1992; Stirling \& Okumus, 1994). La diferente calidad ambiental de cada sitio da como resultado variaciones en el asentamiento o reclutamiento, en el crecimiento y en el índice de condición (Dorgelo, 1992; Abada-Boudjema \& Dauvin, 1995; Alfaro et al., 2008). Para sistemas y hábitats distintos no se esperan tasas de crecimiento iguales, porque no siempre manifiestan condiciones óptimas para el crecimiento del mejillón (Anthony et al., 2001; Alda et al., 2010). Por lo tanto, es esperable que la estimación del crecimiento varíe entre ecosistemas si varían las condiciones que influyen en el crecimiento.

Estudios sobre dinámica poblacional de Mytilus edulis confirman que el crecimiento está controlado principalmente por características ambientales como la disponibilidad de alimento y la reducción en la circulación de agua, que restringe el transporte de partículas de alimento. Además, sugieren que el crecimiento reducido resulta de la exposición de los individuos a concentraciones elevadas de metales pesados (Seed \& Suchanek, 1992; Stirling \& Okumus, 1994). Resultados similares se observaron para Perna canaliculus; cuya dinámica poblacional en un sitio con condiciones biológicas y limnológicas desfavorables es significativamente distinta respecto de poblaciones en mejores condiciones. La población muestra una baja abundancia de larvas en la columna de agua y una baja tasa de asentamiento / reclutamiento. La población del sitio con mejor calidad de agua muestra un crecimiento más rápido, un mayor índice de condición y una mejor condición sanitaria, mientras que se observa un crecimiento más lento y bajo índice de condición en la población del sitio contaminado (Alfaro, 2006b, 2008).

La tasa de acumulación de contaminantes por parte de los mejillones depende de las propiedades fisicoquímicas de los contaminantes, como su solubilidad acuosa e hidrofobici- 
dad. Además, está directamente relacionada con la tasa de filtración, el crecimiento, la composición bioquímica, la condición reproductiva y el metabolismo de los individuos (Widdows \& Donkin, 1992). Diferentes concentraciones de componentes tóxicos en el agua, como cobre, cadmio, mercurio, zinc, plomo, níquel, TBT (tributilestaño) e hidrocarburos, causan una reducción del 50 \% en el crecimiento de la valva (Laughlin et al., 1988; Salazar \& Salazar, 1988; Shim et al., 1998). Los compuestos estañosos se bioacumulan en varios organismos acuáticos. Pertenecen a la gama de químicos organo-metálicos más ampliamente usados y se utilizan como estabilizadores de calor para polímeros sintéticos (e.g., PVC), como biocidas agronómicos y aditivos en las pinturas antiincrustantes (antifouling) (Caprari, 2006). Entre los compuestos estañosos más importantes se encuentran el TBT y el TPhT (trifenilestaño), considerados compuestos químicos peligrosos por sus efectos deletéreos en organismos marinos. La producción de pinturas antifouling es la principal causante de la introducción de estos compuestos al ambiente porque constituyen un agente activo del producto (Laughlin et al., 1988; Salazar \& Salazar, 1988; Shim et al., 1998; Caprari, 2006). Generalmente, se estima que habrá una mayor tasa de crecimiento cuando la temperatura y la disponibilidad de fitoplancton son altas. Sin embargo, el TBT puede adsorberse al fitoplancton generando una mayor biodisponibilidad para los mejillones. La bioacumulación de este compuesto se incrementa cuando aumenta la temperatura a causa de una mayor tasa de filtración (Laughlin et al., 1988; Salazar \& Salazar, 1988). La incorporación de este compuesto produce efectos neurotóxicos en el control neural de los cilios de las branquias y genera un aumento en la tasa de respiración debido al desacople de la fosforilación oxidativa (Widdows \& Donkin, 1992). Estos eventos afectan directamente procesos relacionados con el crecimiento. En Crassostrea gigas se observan concentraciones elevadas de TBT en branquias y masa visceral, y concentraciones menores en el músculo aductor, el manto y la masa gonadal (Shim et al., 1998). En Mercenaria mercenaria, la reducción de crecimiento es el índice más sensible de la acción negativa del TBT; en la larva de esta almeja se observa una correlación inversa muy alta entre crecimiento y exposición a este compuesto. El fracaso de la metamorfosis de las larvas velíger y de su reclutamiento a las poblaciones bentónicas por inhibición del crecimiento, tiene efectos ecológicos significativos en la población (Laughlin et al., 1988). El efecto de del TBT también se observa en Mytilus edulis. Individuos que se encuentran en ambientes con altas concentraciones de TBT muestran una tasa de crecimiento menor y altas concentraciones bioacumuladas en los tejidos (Salazar \& Salazar, 1988). 
Un estudio realizado con el bivalvo dulciacuícola Dreissena polymorpha confirmó lo observado para especies marinas. Los individuos juveniles que viven en ambientes contaminados con TBT muestran una tasa de crecimiento menor respecto de los que viven en ambientes libres de TBT (van Slooten \& Tarradellas, 1994).

En el 2001, la Organización Internacional Marítima (OIM) adoptó el Convenio Internacional para el Control de los Sistemas Anti-incrustantes Nocivos en Barcos (AFS Convention) y prohibió el uso de estos sistemas basados en compuestos estañosos. La prohibición de aplicar estos compuestos comenzó el 01 de enero de 2001 y para el 2008 la superficie de los cascos de los barcos no debía estar tratada con estos compuestos. Sin embargo, hasta el 2005 sólo 11 naciones ratificaron la Convención representando el 8,72 \% de la flota mundial (Showalter \& Saravese, 2005).

La presencia del Astillero Río Santiago y el Puerto La Plata en el sistema del río Santiago (Fig. 3.4.1) permite hipotetizar que en el lugar podrían haber concentraciones significativas de compuestos estañosos (J. C. Colombo, comunicación personal, abril 2011). Aunque esta hipótesis debe ser puesta a prueba, la acción sinérgica entre los niveles elevados de eutrofización y la posible presencia de estos compuestos podrían afectar negativamente la dinámica de la población de Limnoperna fortunei asentada en el río Santiago. 

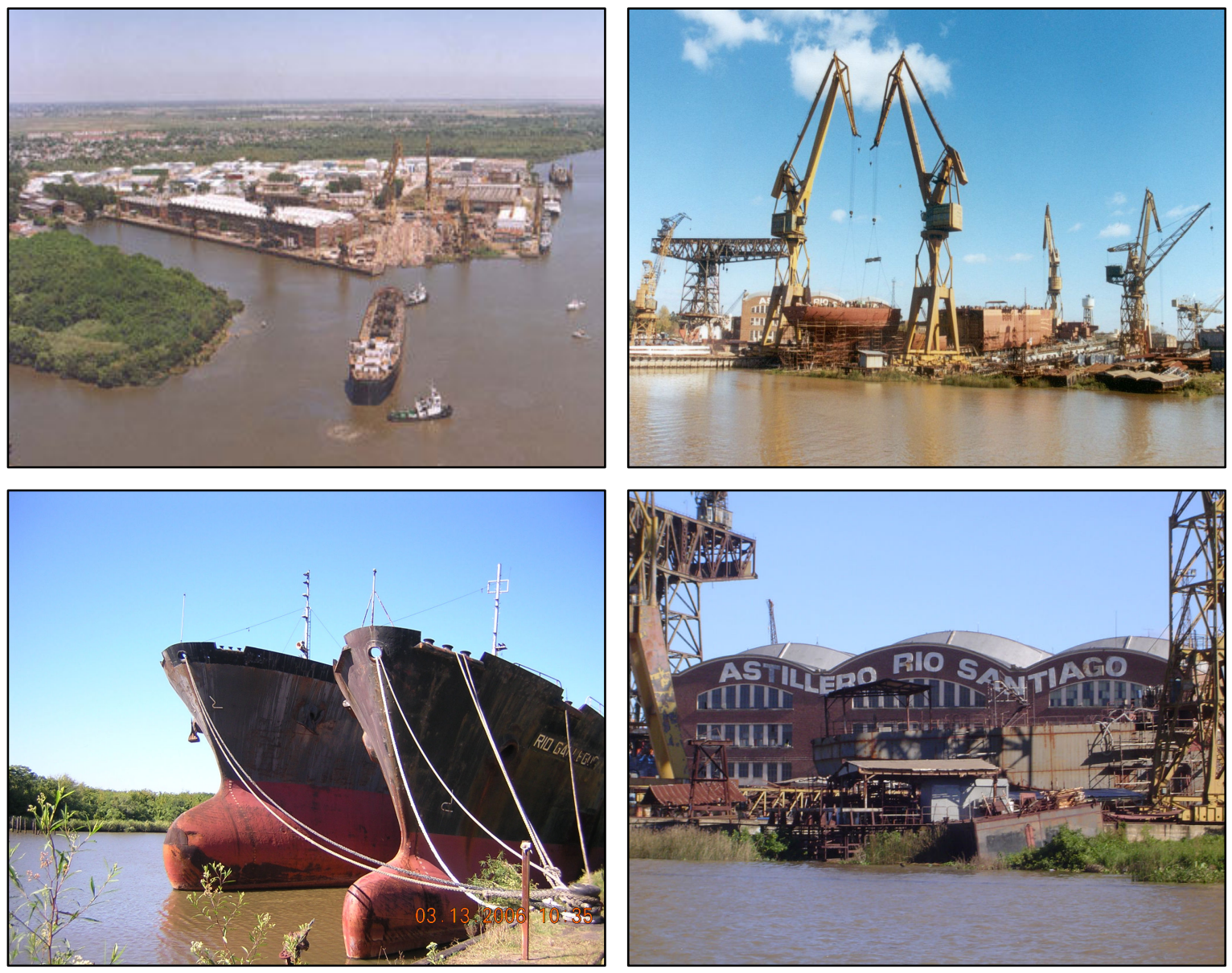

Figura 3.4.1. Astillero Río Santiago, río Santiago, La Plata, Argentina (imágenes obtenidas de Google.com). 


\section{CAPÍTULO 4}




\section{CAPÍTULO 4}

\section{MORFOMETRÍA, CRECIMIENTO E ÍNDICE DE CONDICIÓN DE Limnoperna fortunei EN JAULAS EXPERIMENTALES}

\subsection{INTRODUCCIÓN}

La mayoría de los estudios que estiman el crecimiento en bivalvos utilizan los incrementos de la valva o del peso en un período de tiempo determinado. El largo de la valva y el crecimiento del tejido no necesariamente coinciden en el tiempo. La variación de los parámetros ambientales y de los ciclos endógenos de los animales genera una desarticulación entre las tasas de crecimiento del largo de la valva y del tejido blando. Los cambios en el peso están típicamente asociados con las variaciones estacionales del alimento, el ciclo reproductivo, el almacenamiento y utilización de la energía. Por otro lado, las valvas tienen menor contenido orgánico que el tejido blando, pero dependen parcialmente del metabolismo del carbono. El crecimiento de las valvas ocurre por la deposición prolongada de materiales provenientes del agua. Por esta razón, la variación de la disponibilidad de alimento y los niveles de elementos inorgánicos en el agua pueden tener diferentes efectos sobre la tasa de crecimiento de valvas y tejidos blandos (Borrero \& Hilbish, 1988).

El estudio de los efectos de las condiciones ambientales sobre el crecimiento, la supervivencia y la producción de gametas de los invertebrados sésiles sirve de base para predecir la capacidad de las poblaciones para expandirse y explotar nuevos hábitats (van Ekrom Schurink \& Griffiths, 1993; Garton \& Johnson, 2000). El análisis de las tasas de crecimiento en condiciones naturales es un paso necesario para entender la dinámica poblacional y el balance energético de una población de bivalvos (Dorgelo, 1992).

En general, el crecimiento de los invertebrados bentónicos sésiles está influido por aspectos intrínsecos como las diferencias genéticas intra o interespecíficas. También lo afectan factores extrínsecos como la naturaleza y calidad del alimento disponible, la temperatura, la tasa de intercambio del agua y su composición química, así como la densidad poblacional (Garton \& Johnson, 2000). El estudio del ciclo de vida de un organismo implica 
conocer la división y transferencia de sus recursos energéticos para el mantenimiento, el crecimiento y la reproducción. Además, es necesario determinar cómo la asignación de sus recursos energéticos cambia con el tiempo, con la edad o la estación del año (Chase \& Bailey, 1999). El envejecimiento en los moluscos está acompañado por cambios en la transferencia de energía; el crecimiento somático disminuye mientras los procesos relacionados con la reproducción se incrementan (Sukhotin \& Pörtner, 2001). Los factores extrínsecos más citados como responsables de la reducción de las tasas de crecimiento son la baja temperatura y la escasa disponibilidad de alimento (Mallet et al., 1987). Mientras que el tamaño corporal es uno de los factores intrínsecos que determinan la tasa de gasto energético (Sukhotin \& Pörtner, 2001). Varias especies de los géneros Mytilus, Choromytilus, Aulacomya y Perna toleran un amplio rango de condiciones ambientales, con flexibilidad de respuestas fisiológicas, reflejadas en las diferentes tasas y características estacionales del crecimiento corporal (Bayne \& Worral, 1980).

Los bivalvos como la mayoría de los organismos, exhiben cambios progresivos en sus proporciones relativas a medida que se incrementa el tamaño del cuerpo (Alunno-Bruscia et al., 2001). La relación alométrica entre dos variables de tamaño se puede expresar mediante una ecuación potencial $\left(y=a x^{b}\right)$ (Seed \& Suchanek, 1992), mientras que se usan varios índices para estimar la condición como la proporción de un componente corporal respecto del peso total o volumen del animal (Borrero \& Hilbish, 1988). Comúnmente, la magnitud de peso perdido es usada como estimadora de la fecundidad o de la transferencia de recursos para la reproducción y como un índice general de la condición fisiológica de la población (Bayne \& Worral, 1980; Hilbish, 1986; Nalepa et al., 1995). Por ejemplo, este tipo de análisis se utilizó para estimar el estrés fisiológico causado por la diferencia de ambientes en Dreissena polymorpha (Nalepa et al., 1995). Sin embargo, hasta la fecha no se ha realizado ningún estudio que evalúe la variación espacial y temporal del índice de condición de Limnoperna fortunei.

La estimación de las tasas de crecimiento de bivalvos se obtiene por diferentes técnicas, como análisis de los anillos de crecimiento anuales, medición de individuos marcados, análisis de las clases de tallas de la población o por combinaciones de estos procedimientos. En la mayoría de los casos, la lectura de anillos resulta imprecisa y el método de marcado y recaptura requiere un trabajo intensivo. En un estudio del crecimiento a largo 
plazo, la distribución de frecuencias de tallas, combinada con la determinación de la edad de una submuestra, es un método efectivo (Seed \& Brown, 1978; Bij de Vaate, 1991; Dolmer, 1998; Garton \& Johnson, 2000). Sin embargo, el análisis de las estructuras de tallas sucesivas y la progresión modal puede presentar dificultades en la identificación de cohortes representadas por los individuos más viejos debido a que su baja tasa de crecimiento provoca la superposición de las distintas cohortes (Bayne \& Worral, 1980; Hilbish, 1986; Lizarralde \& Cazzaniga, 2009). Casi todos los métodos de estimación del crecimiento presentan ventajas y desventajas. El utilizado en este estudio es similar al de otros trabajos sobre crecimiento de bivalvos, pero con algunas modificaciones (Seed \& Brown, 1978; Bij de Vaate, 1991; Dolmer, 1998; Garton \& Johnson, 2000). En nuestro método no se utilizaron animales marcados, sino que se identificaron en cada ambiente varias cohortes iniciales, y se las colocó en el interior de jaulas experimentales. 


\subsubsection{OBJETIVOS}

En este capítulo se plantearon los siguientes objetivos:

- Efectuar un seguimiento de cohortes de individuos de Limnoperna fortunei colocados en el interior de jaulas experimentales y estudiar su morfometría, crecimiento individual e índice de condición.

- Discutir las posibles diferencias en las relaciones morfométricas, crecimiento individual e índice de condición entre los dos ambientes de estudio.

- Evaluar si existen diferencias en las relaciones morfométricas y en el crecimiento entre los individuos enjaulados y los recolectados de los paneles de captación (Capítulo 3).

\subsubsection{HIPÓTESIS}

Las hipótesis planteadas en este capítulo son las siguientes:

- Existen diferencias significativas en el crecimiento individual y en el índice de condición como consecuencia de las diferencias limnológicas significativas entre los ambientes de estudio.

- La tasa de crecimiento e índice de condición de Limnoperna fortunei están significativamente correlacionada con la variación estacional de los parámetros fisicoquímicos (e.g. temperatura del agua). 


\subsection{MATERIALES Y MÉTODOS}

\subsubsection{JAULAS EXPERIMENTALES}

En los ríos Coronda y Santiago, se colocaron jaulas experimentales confeccionadas con un marco de alambre y una red plástica con una abertura de malla de $1 \mathrm{~mm}$. El tamaño de abertura fue seleccionado para evitar el escape de mejillones con un largo de valva mayor que 1,4 mm y, a su vez, permitir la circulación del agua dentro de las jaulas (Seed \& Brown, 1978; Bij de Vaate, 1991; Dorgelo, 1992; Smit et al., 1992; Dolmer, 1998; Garton \& Johnson, 2000).

La experiencia se realizó en dos etapas. La primera abarcó desde junio de 2006 hasta enero de 2007 y solamente consideró el ambiente del río Santiago. En este primer período se utilizan algunos de los datos del trabajo realizado para probar la eficacia de las jaulas en el medio y en el crecimiento individual de L. fortunei (Darrigran et al., en prensa). De esta forma se garantizó la eficiencia y posterior utilización de jaulas en este de trabajo de tesis.

Durante ese período se sumergieron tres jaulas de $30 \times 30 \times 30 \mathrm{~cm}$ (Fig. 4.2.1 A), en cuyo interior se colocaron 1.000 juveniles, aproximadamente, con un largo de valva de 2 a 5 $\mathrm{mm}$. Mensualmente se recolectaron al azar, sin reposición, entre 40 y 80 individuos de cada jaula (Tabla 4.2.1). La segunda etapa se inició en marzo de 2007, cuando se sumergieron jaulas con un número de ejemplares similar a la experiencia anterior, en los ríos Coronda y Santiago (Fig. 4.2.1 B). En esta segunda etapa, sobre la base de los resultados obtenidos en relación con el tipo de jaula, se usaron jaulas tetraédricas, porque la mayor velocidad de agua en el río Coronda deformó las jaulas cúbicas (observación personal). Con este nuevo diseño se logró una menor resistencia al paso del agua y un menor deterioro de las jaulas. El período de estudio en el Santiago finalizó en abril de 2009, y en el río Coronda en diciembre de 2008 (Tabla 4.2.1). 

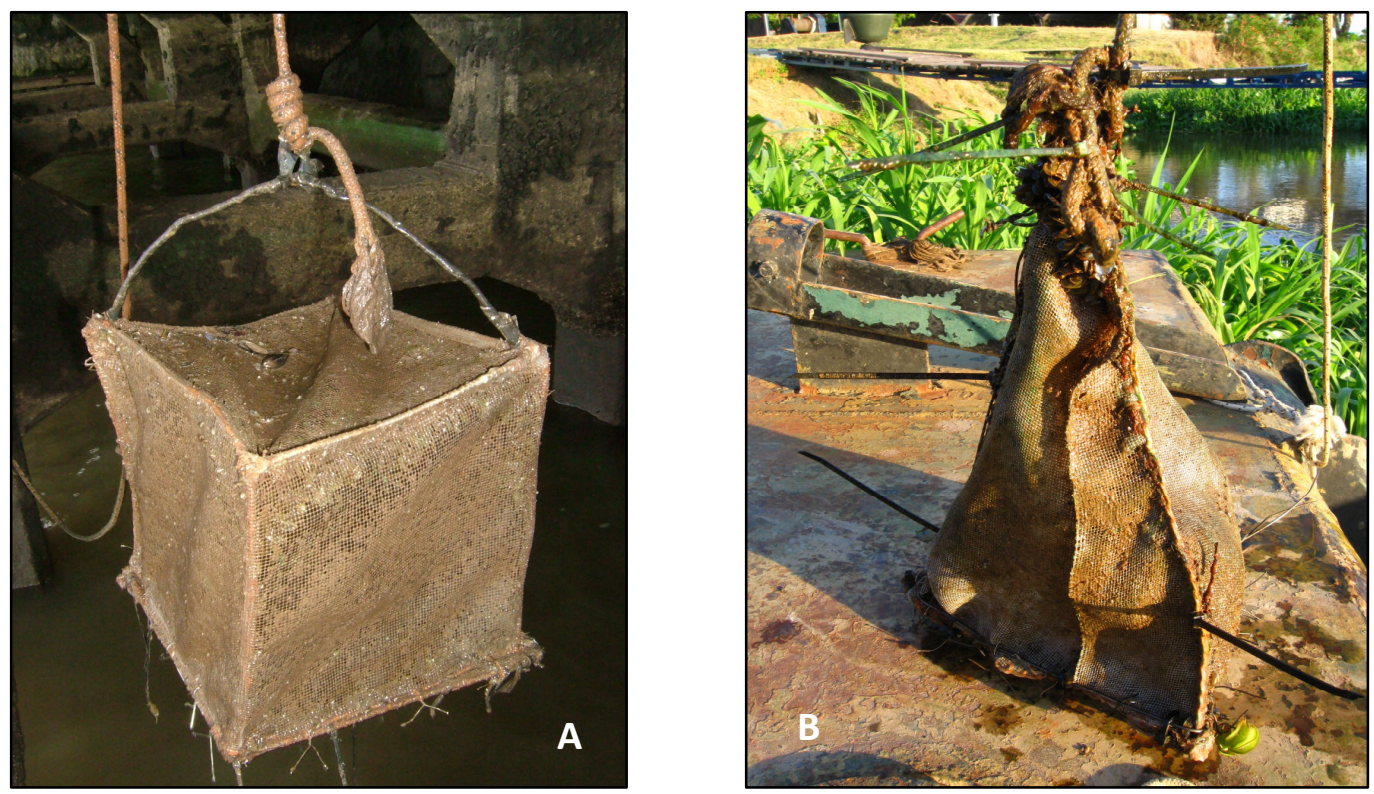

Figura 4.2.1 Jaulas experimentales. A) primera etapa; B) segunda etapa. 
Tabla 4.2.1. Fechas de muestreo y número de individuos extraídos de las jaulas experimentales sumergidas en los ríos Santiago y Coronda. ND: dato no disponible.

\begin{tabular}{|c|c|c|c|c|c|c|c|c|c|}
\hline \multicolumn{6}{|c|}{ Río Santiago } & \multicolumn{4}{|c|}{ Río Coronda } \\
\hline & Año & Meses & Jaula 1 & Jaula 2 & Jaula 3 & Año & Meses & Jaula 1 & Jaula 2 \\
\hline \multirow{8}{*}{$\begin{array}{c}\text { Primera } \\
\text { Etapa }\end{array}$} & \multirow{7}{*}{2006} & 15-Jun & 40 & 40 & 40 & \multirow{8}{*}{2007} & 30-Mar & 45 & 427 \\
\hline & & 12-Jul & 40 & 40 & 40 & & $30-A b r$ & 20 & 17 \\
\hline & & 10-Ago & 40 & 40 & 38 & & 05-Jun & 20 & 19 \\
\hline & & 12-Sep & 40 & 40 & 39 & & 31-Jul & 15 & 14 \\
\hline & & $12-O c t$ & 40 & 40 & 40 & & 23-Ago & 25 & 25 \\
\hline & & 13-Nov & 40 & 40 & 39 & & 20-Sep & 28 & 20 \\
\hline & & 21-Dic & 80 & 80 & 80 & & 30-Oct & 30 & 22 \\
\hline & 2007 & 24-Ene & 80 & 70 & 40 & & 21-Dic & 265 & 95 \\
\hline \multirow{22}{*}{$\begin{array}{l}\text { Segunda } \\
\text { Etapa }\end{array}$} & \multirow{8}{*}{2007} & 23-Mar & 457 & 410 & 452 & \multirow{9}{*}{2008} & 12-Feb & 123 & 95 \\
\hline & & 02-May & 20 & 21 & 20 & & 17-Mar & 96 & 94 \\
\hline & & 06-Jun & 20 & 20 & 18 & & $24-\mathrm{Abr}$ & 121 & 87 \\
\hline & & 18-Jul & 20 & 20 & 20 & & 12-Jun & 73 & 115 \\
\hline & & 28-Ago & 26 & 28 & 28 & & 31-Jul & 152 & 114 \\
\hline & & 25-Sep & 30 & 30 & 30 & & 21-Ago & 207 & 227 \\
\hline & & 06-Nov & 46 & 457 & 342 & & 25-Sep & 194 & 246 \\
\hline & & 18-Dic & 59 & 78 & 53 & & $20-\mathrm{Nov}$ & 384 & 332 \\
\hline & \multirow{12}{*}{2008} & 25-Ene & 60 & 71 & 59 & & 17-Dic & 332 & 334 \\
\hline & & 25-Feb & ND & 199 & 124 & & & & \\
\hline & & 03-Abr & ND & 134 & 156 & & & & \\
\hline & & 08-May & ND & 102 & 391 & & & & \\
\hline & & 10-Jun & ND & 123 & 516 & & & & \\
\hline & & 08-Jul & ND & 182 & 568 & & & & \\
\hline & & 14-Ago & ND & 130 & 503 & & & & \\
\hline & & 23-Sep & ND & 172 & 778 & & & & \\
\hline & & $22-$ Oct & ND & 192 & 433 & & & & \\
\hline & & 26-Nov & ND & 290 & 422 & & & & \\
\hline & & 18-Dic & ND & 273 & 626 & & & & \\
\hline & & 09-Feb & ND & 914 & 850 & & & & \\
\hline & \multirow[t]{2}{*}{2009} & 13-Mar & ND & 756 & 595 & & & & \\
\hline & & $15-\mathrm{Abr}$ & ND & 479 & 678 & & & & \\
\hline
\end{tabular}

\subsubsection{MORFOMETRÍA}

Para evaluar si existen diferencias morfométricas entre los individuos criados en jaulas y en los dos ambientes y comparar la morfometría con los indivivuos adheridos a los colectores artificales, se midió el LT de cada ejemplar y aquellos con una talla mayor a $3 \mathrm{~mm}$ se les midió también el ancho total (AT) y el alto total (AL) (Alunno-Bruscia et al., 2001; Lajtner et al., 
2004; Lauzon-Guay et al., 2005; Trichkova et al., 2008). En todos los casos, los individuos submuestreados se seleccionaron respetando los rangos de tallas definidos por la estructura de tallas de cada muestra. Las mediciones se efectuaron con un calibre digital Mitutoyo con una precisión de 0,01 $\mathrm{mm}$. Se estimó la media de cada variable morfómétrica correspondiente a cada jaula, sitio y fecha de muestreo. Se realizó un ANOVA simple para poner a prueba diferencias entre las jaulas de cada sitio. Previamente se transformaron las mediciones mediante $\operatorname{Ln}(\mathrm{x})$.

Para evaluar la relación entre variables lineales obtenidas de las dos poblaciones de $L$. fortunei, se realizó un Análisis de Componentes Principales (ACP) (Trichkova et al., 2008). Para comparar las dimensiones de las valvas, se calcularon los cocientes morfométricos AT/LT, AL/LT y AL/AT para cada sitio y fecha de muestreo. Se aplicó una transformación angular (arcoseno $\sqrt{x}$ ) a los cocientes para aproximarlos a la normalidad y homocedasticidad, antes de realizar un test de Student (Zar, 1996; Lajtner et al., 2004; Trichkova et al., 2008). Se realizó el mismo análisis para comparar las dimensiones morfométricas entre los individuos enjaulados y los recolectados de los paneles de captación.

\subsubsection{CRECIMIENTO}

A partir de los datos de mediciones de LT, se generaron histogramas de frecuencias porcentuales de tallas para cada fecha y sitio de muestreo (ver detalles en el Capítulo 3). Las distribuciones de frecuencia de tallas fueron descompuestas en sus componentes unimodales siguiendo el método de Bhattacharya (1967) incorporado en el programa FISAT II (Version 1.1.2, FAO-ICLARM Fish Assessment Tools) (Gayanilo et al., 1996). Cada progresión modal fue confirmada con el programa NORMSEP (Pauly \& Caddy, 1985) (ver detalles del análisis en el Capítulo 3).

Para estimar el crecimiento de cada cohorte identificada, se calculó la tasa de crecimiento como el cociente entre la diferencia de LT y el tiempo transcurrido entre un muestreo y el anterior. Se estimó la tasa media de crecimiento para cada estación del año. Para describir el crecimiento, se probó el ajuste de distintos modelos de regresión (lineal, cuadrática y cúbica) a cada una de las cohortes (Brown, 1988; Bij de Vaate, 1991; Chen et al., 1992; Smit et al., 1992; Van Ekrom Schurink \& Griffiths, 1993), validándolos mediante una 
prueba F (Chen et al., 1992; Zar, 1996; Blanchard \& Feder, 2000; Motulsky, 2007) (ver detalles del análisis en el Capítulo 3).

La tasa de crecimiento diaria fue calculada dividiendo el incremento del largo de la valva por el número de días transcurridos entre un muestreo y el siguiente (Lévêque, 1971; Borrero \& Hilbish, 1988).

\subsection{4 ÍNDICE DE CONDICIÓN}

En cada fecha de muestreo se utilizaron submuestras de ejemplares seleccionados al azar respetando las estructuras de tallas obtenidas omo se detalla en la sección anterior. A todos los individuos con un LT > $5 \mathrm{~mm}$ se les midió además, el AT, AL y, con una balanza digital de 0,1 mg de precisión, el peso total (valva + tejido) húmedo (PH), el peso total seco (PS) y el peso total seco de cenizas (PSC). Para el PS de cada individuo, los ejemplares se ubicaron en crisoles de porcelana dentro de una estufa a $60^{\circ} \mathrm{C}$ durante 48 horas (Fig. 4.2.2) (Franz, 1993; Chase \& Bailey, 1999). Para el PSC, los crisoles fueron colocados en un horno mufla a $500^{\circ} \mathrm{C}$ durante dos horas (Bij de Vaate, 1991; Hicks et al., 2001; Ramón et al., 2007). El peso seco libre de cenizas (PSLC) se estimó como la diferencia entre PS y PSC (Alunno-Bruscia et al., 2001). El tiempo necesario para obtener peso seco constante y el tiempo mínimo de muflado se estimó empíricamente, mediante pruebas preliminares. Los ejemplares con LT $<5 \mathrm{~mm}$ no se tuvieron en cuenta, porque las estimaciones preliminares de PSLC para esos ejemplares no fueron precisas.
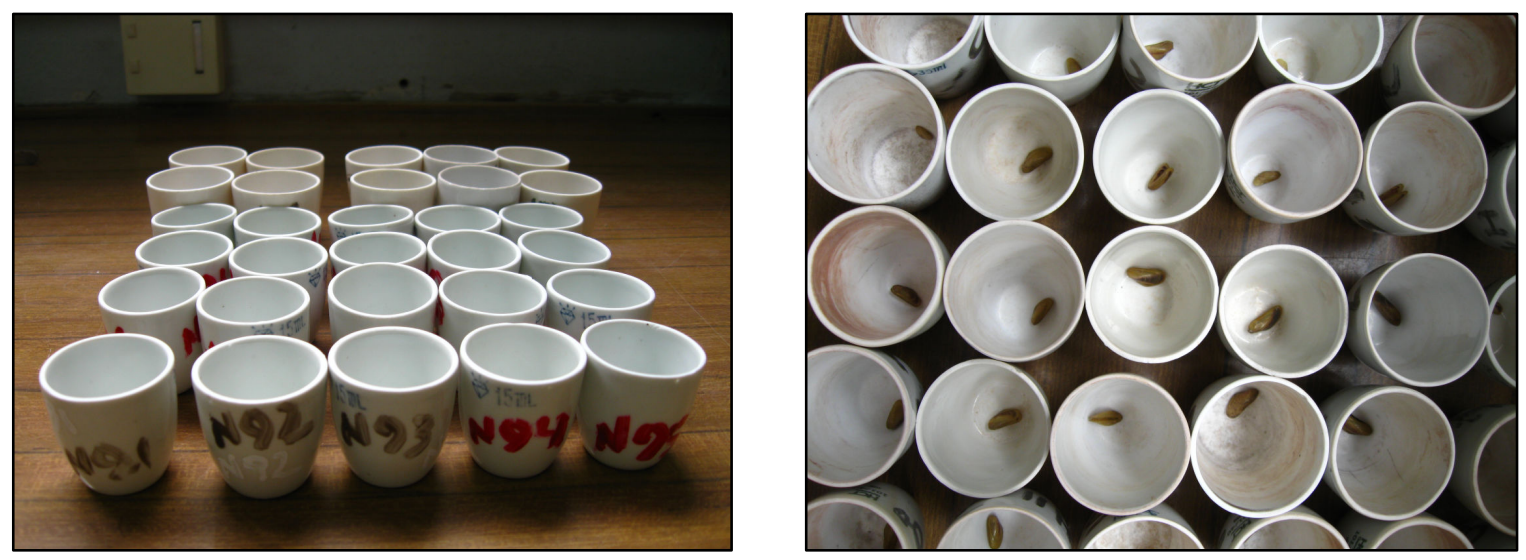

Figura 4.2.2. Crisoles de porcelana con ejemplares de Limnoperna fortunei. 
Para explicar la relación entre LT y los pesos, se ajustó un modelo potencial al conjunto de datos obtenidos para cada ambiente $\left(\mathrm{PT}=\mathrm{aLT}^{\mathrm{b}}\right.$ ) (Bayne \& Worral, 1980; Hilbish, 1986; Seed \& Suchanek, 1992; Alunno-Bruscia et al., 2001; Sukhotin \& Pörtner, 2001; Lizarralde \& Cazzaniga, 2009). Para evaluar si existieron efectos significativos de los ambientes sobre el índice de condición, se linealizaron los modelos transformando las variables con $\operatorname{Ln}(x)$ y $\operatorname{Ln}(y)$. Luego, se realizaron ANCOVAs donde PH, PS y PSLC se consideraron como variables dependientes, el LT actuó como covariable y el factor fueron los ambientes (ríos Coronda y Santiago) (Bayne \& Worral, 1980; Hilbish, 1986; Seed \& Suchanek, 1992; Chase \& Bailey, 1999). En todos los casos se testeó normalidad y homocedasticidad de los datos (Peterson \& Beal, 1989; Zar, 1996).

El índice utilizado para estimar la condición los individuos (modificado de Lundebye et al., 1997) fue:

$$
\text { IC }=(\text { PSLC/Vol Tot }) \times 100
$$

donde:

- $\quad$ PSLC (peso seco libre de cenizas, g) = PS (peso seco) - PSC (peso seco de cenizas)

- $\quad$ Vol Tot (Volumen total, $\mathrm{mm}^{3}$ ) $=\mathrm{LT} \times \mathrm{AT} \times \mathrm{AL}$ 


\subsection{RESULTADOS}

\subsubsection{MORFOMETRÍA}

En la primera etapa de la experiencia desarrollada en el río Santiago, se recolectaron y midieron 1.144 individuos. Los resultados de los ANOVAs realizados para comparar LT, AT y AT de los ejemplares de cada jaula no mostraron diferencias significativas (Tabla $4.1 \mathrm{~A}$; Apéndice 4.1). Para análisis posteriores se agruparon todos los datos obtenidos. En la segunda etapa en el río Santiago, se procesaron 7.189 individuos. Los ANOVAs entre las medidas lineales no mostraron diferencias significativas; por lo tanto, se agruparon los datos (Tabla 4.1 B; Apéndice 4.2). No se detectaron desviaciones de los supuestos de normalidad y homocedasticidad.

Tabla 4.1. Morfometría de ejemplares de Limnoperna fortunei recolectados en el río Santiago y resultados de Ios ANOVAs. LT: largo total; AT: ancho total; AL: alto total; ND: dato no disponible.

A) Primera etapa

\begin{tabular}{|c|c|c|c|c|c|c|c|c|c|}
\hline \multirow[b]{2}{*}{ Muestreos } & \multicolumn{3}{|c|}{ LT (mm) } & \multicolumn{3}{|c|}{ AT $(\mathrm{mm})$} & \multicolumn{3}{|c|}{$\mathrm{AL}(\mathrm{mm})$} \\
\hline & Jaula 1 & Jaula 2 & Jaula 3 & Jaula 1 & Jaula 2 & Jaula 3 & Jaula 1 & Jaula 2 & Jaula 3 \\
\hline 15-Jun-06 & 4,08 & 4,18 & 4,78 & 2,26 & 2,33 & 2,68 & 1,76 & 1,69 & 1,88 \\
\hline 12-Jul-06 & 5,18 & 3,86 & 5,15 & 2,80 & 2,07 & 2,76 & 2,11 & 1,54 & 2,10 \\
\hline 10-Ago-06 & 6,59 & 6,30 & 7,22 & 3,42 & 3,28 & 3,70 & 2,60 & 2,49 & 2,85 \\
\hline 12-Sep-06 & 7,70 & 8,58 & 9,38 & 4,07 & 4,35 & 4,77 & 3,17 & 3,42 & 3,62 \\
\hline 12-Oct-06 & 11,61 & 11,64 & 11,44 & 5,75 & 5,72 & 5,82 & 4,77 & 4,79 & 4,61 \\
\hline 13-Nov-06 & 15,42 & 14,73 & 14,15 & 7,49 & 7,03 & 6,86 & 6,60 & 6,02 & 5,88 \\
\hline 21-Dic-06 & 9,58 & 8,17 & 9,20 & 4,55 & 3,93 & 4,40 & 3,77 & 2,96 & 3,59 \\
\hline \multirow[t]{2}{*}{ 24-Ene-07 } & 7,75 & 10,00 & 6,09 & 3,75 & 4,76 & 2,98 & 2,63 & 3,47 & 2,06 \\
\hline & \multicolumn{3}{|c|}{$F_{(2,21)}=0,001 ; p=0,999$} & \multicolumn{3}{|c|}{$F_{(2,21)}=0,005 ; p=0,995$} & \multicolumn{3}{|c|}{$F_{(2,21)}=0,016 ; p=0,984$} \\
\hline
\end{tabular}


Tabla 4.1. Continuación....

B) Segunda etapa

\begin{tabular}{|c|c|c|c|c|c|c|c|c|c|}
\hline \multirow[b]{2}{*}{ Muestreos } & \multicolumn{3}{|c|}{ LT (mm) } & \multicolumn{3}{|c|}{ AT $(\mathrm{mm})$} & \multicolumn{3}{|c|}{$\mathrm{AL}(\mathrm{mm})$} \\
\hline & Jaula 1 & Jaula 2 & Jaula 3 & Jaula 1 & Jaula 2 & Jaula 3 & Jaula 1 & Jaula 2 & Jaula 3 \\
\hline 26-Mar-07 & 4,41 & 4,23 & 4,14 & ND & ND & ND & ND & ND & ND \\
\hline 02-May-07 & 6,43 & 6,45 & 5,88 & 3,30 & 3,25 & 3,04 & 2,38 & 2,41 & 2,12 \\
\hline 06-Jun-07 & 8,11 & 7,42 & 7,58 & 3,93 & 3,71 & 3,87 & 2,93 & 2,73 & 2,78 \\
\hline 18-Jul-07 & 8,94 & 8,04 & 7,58 & 4,47 & 4,11 & 3,87 & 3,21 & 3,08 & 2,78 \\
\hline 28-Ago-07 & 9,01 & 8,44 & 8,23 & 4,53 & 4,24 & 4,20 & 3,28 & 3,13 & 3,00 \\
\hline 25-Sep-07 & 10,70 & 10,63 & 10,47 & 5,29 & 5,26 & 5,28 & 3,87 & 3,89 & 3,80 \\
\hline 06-Nov-07 & 13,47 & 5,49 & 5,80 & 6,55 & 6,35 & 6,77 & 4,84 & 4,88 & 5,19 \\
\hline 18-Dic-07 & 7,04 & 7,62 & 9,94 & 4,16 & 4,90 & 5,05 & 3,39 & 3,79 & 3,78 \\
\hline 25-Ene-08 & 9,72 & 11,81 & 10,25 & 4,77 & 5,51 & 4,93 & 3,59 & 4,27 & 3,70 \\
\hline 25-Feb-08 & ND & 5,18 & 9,78 & ND & 3,21 & 4,76 & ND & 2,29 & 3,49 \\
\hline 03-Abr-08 & ND & 9,96 & 12,89 & ND & 4,76 & 6,01 & ND & 3,69 & 4,72 \\
\hline 08-May-08 & ND & 12,25 & 5,31 & ND & 5,87 & 6,81 & ND & 4,44 & 5,15 \\
\hline 10-Jun-08 & ND & 11,68 & 5,00 & ND & 6,03 & 6,85 & ND & 4,49 & 5,25 \\
\hline 08-Jul-08 & ND & 10,29 & 5,65 & ND & 5,73 & 7,05 & ND & 4,23 & 5,54 \\
\hline 14-Ago-08 & ND & 11,48 & 5,91 & ND & 5,81 & 6,56 & ND & 4,27 & 5,50 \\
\hline 23-Sep-08 & ND & 10,66 & 5,59 & ND & 5,63 & 5,96 & ND & 4,11 & 4,58 \\
\hline 22-Oct-08 & ND & 10,51 & 6,57 & ND & 5,84 & 5,40 & ND & 4,31 & 4,05 \\
\hline 26-Nov-08 & ND & 8,33 & 6,73 & ND & 4,74 & 4,69 & ND & 3,32 & 3,39 \\
\hline 18-Dic-08 & ND & 8,76 & 7,36 & ND & 4,73 & 3,91 & ND & 3,35 & 2,77 \\
\hline 09-Feb-09 & ND & 6,94 & 7,29 & ND & 4,63 & 4,30 & ND & 3,27 & 3,09 \\
\hline 13-Mar-09 & ND & 7,08 & 8,28 & ND & 4,10 & 4,62 & ND & 2,90 & 3,38 \\
\hline \multirow[t]{2}{*}{ 15-Abr-09 } & ND & 7,38 & 8,03 & ND & 3,83 & 4,25 & ND & 2,72 & 3,15 \\
\hline & \multicolumn{3}{|c|}{$F_{(2,50)}=1,736 ; p=0,187$} & \multicolumn{3}{|c|}{$F_{(2,48)}=1,000 ; p=0,375$} & \multicolumn{3}{|c|}{$F_{(2,48)}=1,088 ; p=0,345$} \\
\hline
\end{tabular}

(A partir del 25 de ferebro de 2008 se perdió la jaula 1, que no fue repuesta)

Por otro lado, en el río Coronda se recolectaron y midieron 3.488 ejemplares. Los tests de Student realizados para comparar las variables morfométricas no mostraron diferencias significativas entre jaulas y, por lo tanto, se agruparon los datos (Tabla 4.2). No se detectaron desviaciones de los supuestos de normalidad y homocedasticidad. 
Tabla 4.2. Morfometría de ejemplares de Limnoperna fortunei recolectados en el río Coronda y resultados de los tests de Student (referencias indicadas en la tabla anterior).

\begin{tabular}{|c|c|c|c|c|c|c|}
\hline & \multicolumn{2}{|c|}{ LT (mm) } & \multicolumn{2}{|c|}{ AT $(\mathrm{mm})$} & \multicolumn{2}{|c|}{$\mathrm{AL}(\mathrm{mm})$} \\
\hline Muestreos & Jaula 1 & Jaula 2 & Jaula 1 & Jaula 2 & Jaula 1 & Jaula 2 \\
\hline 30-Mar-07 & 4,27 & 4,12 & ND & ND & ND & ND \\
\hline 30-Abr-07 & 6,56 & 6,89 & 3,47 & 3,61 & 2,44 & 2,57 \\
\hline 05-Jun-07 & 10,45 & 9,44 & 5,48 & 5,01 & 4,02 & 3,66 \\
\hline 31-Jul-07 & 11,73 & 12,26 & 6,00 & 6,48 & 4,61 & 4,81 \\
\hline 23-Ago-07 & 13,02 & 13,51 & 6,79 & 7,08 & 5,12 & 5,33 \\
\hline 20-Sep-07 & 14,18 & 14,54 & 7,21 & 7,46 & 5,63 & 6,03 \\
\hline 30-Oct-07 & 18,04 & 16,65 & 8,66 & 8,34 & 7,03 & 6,58 \\
\hline 21-Dic-07 & 7,04 & 4,65 & 7,11 & 4,03 & 5,62 & 3,01 \\
\hline 12-Feb-08 & 9,20 & 9,66 & 4,45 & 4,70 & 3,33 & 3,54 \\
\hline 17-Mar-08 & 7,87 & 9,51 & 3,92 & 4,73 & 2,85 & 3,47 \\
\hline 24-Abr-08 & 9,35 & 11,77 & 4,73 & 5,70 & 3,40 & 4,33 \\
\hline 12-Jun-08 & 12,43 & 11,57 & 6,19 & 5,73 & 4,52 & 4,19 \\
\hline 31-Jul-08 & 10,79 & 12,08 & 5,47 & 5,98 & 3,97 & 4,33 \\
\hline 21-Ago-08 & 9,89 & 9,99 & 5,21 & 5,18 & 3,70 & 3,66 \\
\hline 25-Sep-08 & 9,68 & 8,82 & 5,29 & 5,01 & 3,73 & 3,50 \\
\hline 20-Nov-08 & 8,74 & 9,92 & 4,36 & 5,02 & 3,07 & 3,56 \\
\hline 17-Dic-08 & 9,11 & 9,45 & 4,63 & 4,99 & 3,30 & 3,60 \\
\hline & \multicolumn{2}{|c|}{$\mathrm{t}_{(32)}=-0,133 ; \mathrm{p}=0,895$} & \multicolumn{2}{|c|}{$\mathrm{t}_{(30)}=-0,011 ; \mathrm{p}=0,991$} & \multicolumn{2}{|c|}{$t_{(30)}=-0,026 ; p=0,979$} \\
\hline
\end{tabular}

- Análisis de Componentes Principales (ACP)

Se utilizaron las mediciones de 8.333 individuos recolectados en el río Santiago y 3.488 del Coronda. Sólo se consideraron los ejemplares recolectados en la segunda etapa. El ACP para las variables morfométricas de la población del río Santiago resultó en dos componentes principales que explicaron más del 99 \% de la varianza original de la matriz de correlación. Los resultados del análisis para las variables de los individuos del río Coronda, mostraron valores similares a los estimados para el río Santiago (Tabla 4.3). Las medidas lineales mostraron una correlación positiva altamente significativa entre sí $(r>0,9)$ (Fig. 4.3.1; Tabla 4.4;) y mostraron una contribución similar en el componente 1 (Tabla 4.5). 
Tabla 4.3. Resultado del análisis de componentes principales: Autovalores

\begin{tabular}{ccccccccc}
\hline & \multicolumn{3}{c}{ Río Santiago } & & \multicolumn{3}{c}{ Río Coronda } \\
\cline { 2 - 4 } \cline { 7 - 8 } & C1 & C2 & C3 & & C1 & C2 & C3 \\
\hline \hline Valor propio & 2,993 & 0,005 & 0,002 & & 2,982 & 0,013 & 0,005 \\
\hline \% varianza & 99,77 & 0,156 & 0,071 & & 99,38 & 0,45 & 0,17 \\
\hline \% acumulado & 99,77 & 99,93 & 100 & & 99,38 & 99,83 & 100 \\
\hline \hline
\end{tabular}
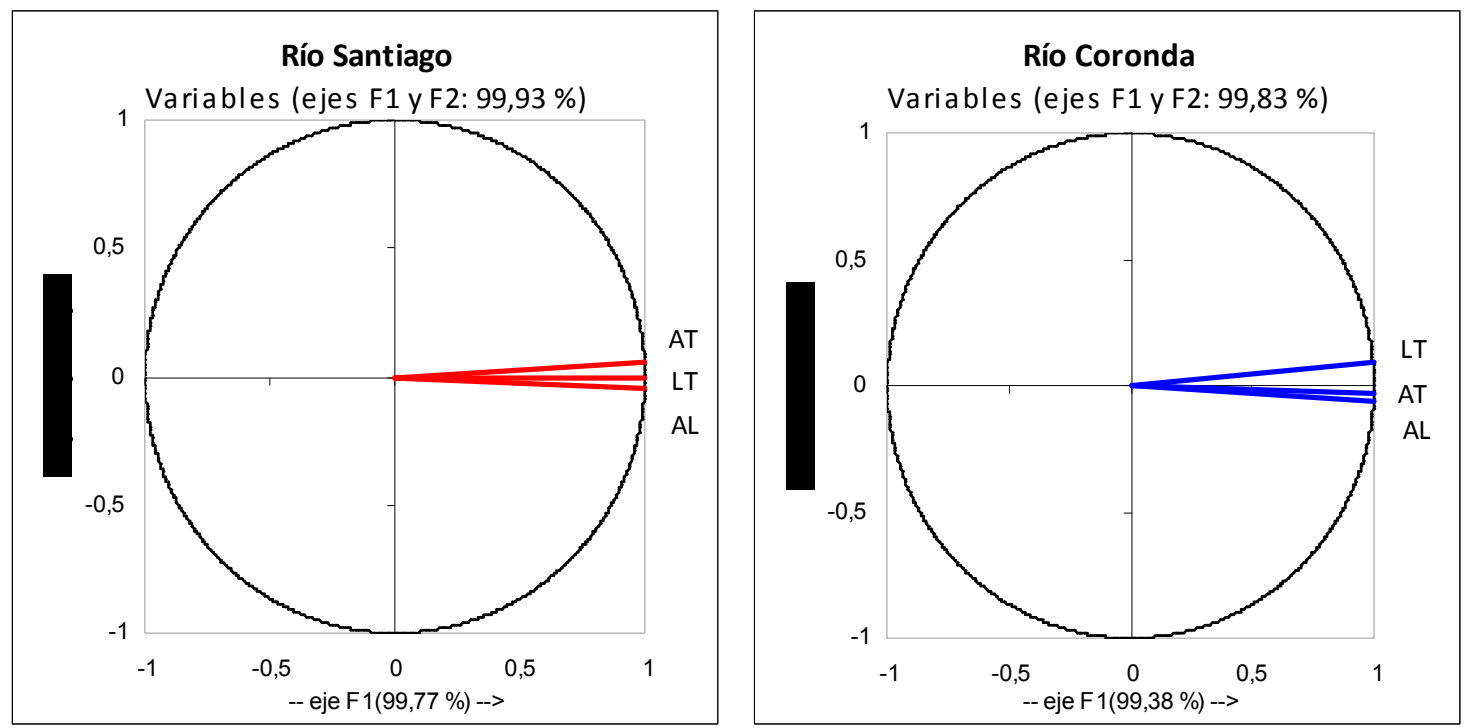

Figura 4.3.1. Correlaciones de los componentes principales 1 y 2 (F1 y F2) y sus respectivos porcentajes de explicación de la varianza original.

Tabla 4.4. Correlación entre las variables originales y los componentes principales en el ACP.

\begin{tabular}{cccccccc}
\hline & \multicolumn{3}{c}{ Río Santiago } & & \multicolumn{3}{c}{ Río Coronda } \\
\cline { 2 - 4 } \cline { 6 - 8 } & C1 & C2 & C3 & & C1 & C2 & C3 \\
\hline \hline LT & 0,999 & $-0,009$ & 0,037 & & 0,996 & 0,094 & $-0,008$ \\
\hline AT & 0,999 & 0,052 & $-0,014$ & & 0,998 & $-0,035$ & 0,054 \\
\hline AL & 0,999 & $-0,044$ & $-0,024$ & & 0,997 & $-0,059$ & $-0,046$ \\
\hline \hline
\end{tabular}

Tabla 4.5. Resultado del análisis de componentes principales: Contribuciones de las variables (\%)

\begin{tabular}{ccccccccc}
\hline & \multicolumn{3}{c}{ Río Santiago } & & \multicolumn{3}{c}{ Río Coronda } \\
\cline { 2 - 4 } \cline { 6 - 8 } & C1 & C2 & C3 & & C1 & C2 & C3 \\
\hline \hline LT & 33,36 & 1,56 & 65,08 & & 33,24 & 65,36 & 1,40 \\
\hline AT & 33,31 & 57,97 & 8,72 & & 33,40 & 9,08 & 57,52 \\
\hline AL & 33,33 & 40,46 & 26,21 & & 33,36 & 25,56 & 41,09 \\
\hline \hline
\end{tabular}


El análisis comparativo entre ambientes de los cocientes morfométricos AT/LT, AL/LT y AL/AT; no mostró diferencias significativas (Tabla 4.6).

Tabla 4.6. Relaciones morfométricas entre las variables lineales.

\begin{tabular}{ccccc}
\hline Cociente & Sitio & Media $\pm \mathrm{DE}$ & $\mathrm{N}$ & Test de Student (datos transformados) \\
\hline \hline \multirow{2}{*}{ AT/LT } & Río Santiago & $0,490 \pm 0,016$ & 20 & $\mathrm{t}_{(34)}=-1,853 ; \mathrm{p}=0,073$ \\
& Río Coronda & $0,500 \pm 0,016$ & 16 & \multirow{2}{*}{$\mathrm{t}_{(18)}=-1,410 ; \mathrm{p}=0,175$} \\
\multirow{2}{*}{ AL/LT } & Río Santiago & $0,363 \pm 0,007$ & 20 & \\
& Río Coronda & $0,370 \pm 0,018$ & 16 & $\mathrm{t}_{(34)}=0,138 ; \mathrm{p}=0,891$ \\
\multirow{2}{*}{ AL/AT } & Río Santiago & $0,741 \pm 0,022$ & 20 & \\
& Río Coronda & $0,740 \pm 0,031$ & 16 & \\
\hline \hline
\end{tabular}

Para estimar el cambio de las variables lineales LT y AT respecto de AL, se invirtieron los cocientes. Para la población del río Santiago la relación alto : ancho : largo; fue:

\section{$1: 1,35 \pm 0,04: 2,75 \pm 0,05$}

Para la población del río Coronda fue:

\section{$1: 1,35 \pm 0,06: 2,71 \pm 0,13$}

En el río Santiago, la comparación de las proporciones AT/LT y AL/LT de individuos enjaulados y de los recolectados en los paneles (Capítulo 3) mostró diferencias significativas. Los individuos enjaulados fueron significativamente más largos y menos altos (Tabla 4.7 A). En el Coronda, los individuos enjaulados fueron significativamente más largos, es decir que la relación relación AT/LT fue significativamente menor (Tabla 4.7B). 
Tabla 4.7. Relaciones morfométricas entre variables lineales de individuos criados en jaulas y ejemplares recolectados de los paneles de captación. Resultados del test de Student para datos transformados (arcoseno $\sqrt{x})$.

A) Río Santiago

\begin{tabular}{ccccc}
\hline Cociente & Sitio & Media $\pm \mathrm{DE}$ & $\mathrm{N}$ & Test Student (datos transformados) \\
\hline \hline \multirow{2}{*}{ AT/LT } & Jaula & $0,490 \pm 0,016$ & 20 & \multirow{2}{*}{$\mathrm{t}_{(30)}=-4,169 ; \mathrm{p}<0,001$} \\
& Paneles & $0,509 \pm 0,009$ & 12 & \multirow{2}{*}{ t } \\
\multirow{2}{*}{ AL/LT } & Jaula & $0,363 \pm 0,007$ & 20 & $\mathrm{t}_{(30)}=-7,317 ; \mathrm{p}<0,001$ \\
& Paneles & $0,384 \pm 0,009$ & 12 & \multirow{2}{*}{$\mathrm{t}_{(30)}=-1,500 ; \mathrm{p}=0,144$} \\
\multirow{2}{*}{ AL/AT } & Jaula & $0,741 \pm 0,022$ & 20 & \\
& Paneles & $0,755 \pm 0,029$ & 12 & \\
\hline \hline
\end{tabular}

B) Río Coronda

\begin{tabular}{ccccc}
\hline Cociente & Sitio & Media $\pm \mathrm{DE}$ & $\mathrm{N}$ & Test Student (datos transformados) \\
\hline \hline \multirow{2}{*}{ AT/LT } & Jaula & $0,500 \pm 0,016$ & 16 & \multirow{2}{*}{$\mathrm{t}_{(23)}=-2,576 ; \mathrm{p}<0,05$} \\
& Paneles & $0,517 \pm 0,016$ & 9 & \multirow{2}{*}{$\mathrm{t}_{(22)}=-0,682 ; \mathrm{p}=0,502$} \\
\multirow{2}{*}{ AL/LT } & Jaula & $0,370 \pm 0,018$ & 16 & \multirow{2}{*}{$\mathrm{t}_{(23)}=1,436 ; \mathrm{p}=0,165$} \\
& Paneles & $0,374 \pm 0,008$ & 9 & \\
\hline \multirow{2}{*}{ AL/AT } & Jaula & $0,740 \pm 0,022$ & 16 & \\
& Paneles & $0,723 \pm 0,031$ & 9 &
\end{tabular}

\subsubsection{CRECIMIENTO}

En la primera experiencia realizada en el río Santiago (junio de 2006 a enero de 2007), se midió el LT de un total de 1.146 ejemplares extraídos de las jaulas experimentales. Se agruparon las mediciones y se generó una distribución de frecuencias de tallas para cada fecha muestreo (Fig. 4.3.2). Mediante descomposición polimodal se identificaron dos cohortes. Para cada fecha de muestreo, se estimó el valor medio de LT y su desvío estándar. La estadística descriptiva de las cohortes identificadas y la tasa de crecimiento para el período de tiempo transcurrido entre una fecha de muestreo y la siguiente se resume en la tabla 4.8. 
Tabla 4.8. Estadística descriptiva de las cohortes identificadas de Limnoperna fortunei para los colectores sumergidos en el río Santiago. LT: Largo total de la valva $(\mathrm{mm})$; DE: desvío estándar; TC ( $\mu \mathrm{m}$ día $\left.{ }^{-1}\right)$ : tasa de crecimiento para el período de tiempo transcurrido entre una fecha de muestreo y la siguiente; N: número de individuos; ND: dato no disponible.

\begin{tabular}{|c|c|c|c|c|c|c|c|}
\hline Cohorte & Año & Estación & Muestreo & Días & $\mathrm{LT} \pm \mathrm{DE}$ & TC & $\mathbf{N}$ \\
\hline \multirow{7}{*}{1} & \multirow{7}{*}{2006} & Otoño & 15-Jun & 1 & $4,58 \pm 0,97$ & ND & 120 \\
\hline & & & 12 -Jul & 27 & $5,18 \pm 1,29$ & 2,2 & 120 \\
\hline & & Invierno & 10-Ago & 56 & $7,22 \pm 1,36$ & 7,0 & 118 \\
\hline & & & 12-Sep & 89 & $9,01 \pm 1,42$ & 5,4 & 119 \\
\hline & & & $12-\mathrm{Oct}$ & 119 & $12,07 \pm 1,49$ & 10,2 & 120 \\
\hline & & Primavera & 13-Nov & 151 & $15,40 \pm 1,80$ & 10,4 & 119 \\
\hline & & & 21-Dic & 189 & $18,38 \pm 2,56$ & 7,8 & 76 \\
\hline \multirow{2}{*}{2} & 2006 & Primavera & 21-Dic & 1 & $6,43 \pm 1,91$ & ND & 164 \\
\hline & 2007 & Verano & 24-Ene & 34 & $9,42 \pm 3,36$ & 8,8 & 190 \\
\hline
\end{tabular}
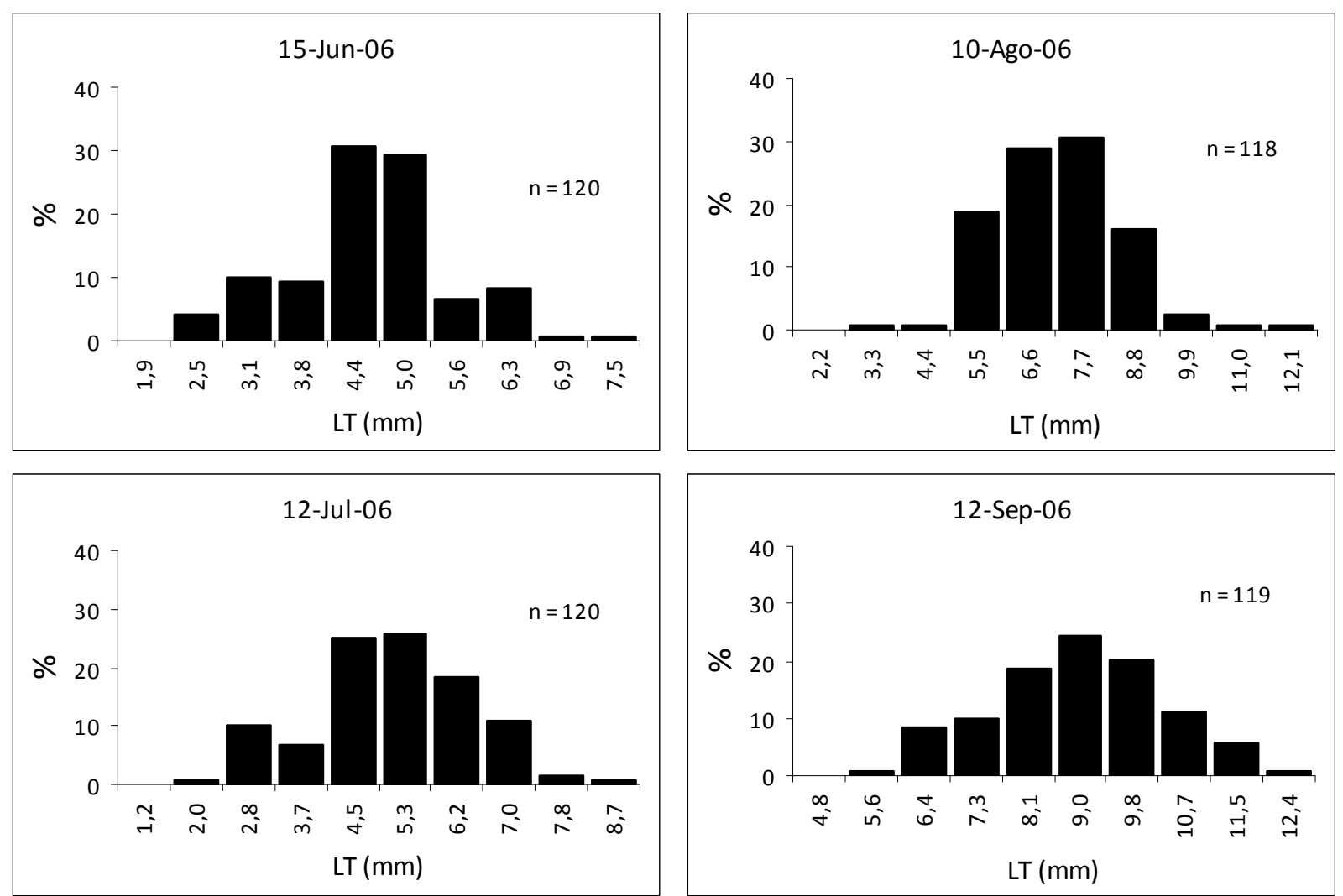

Figura 4.3.2. Distribución de las frecuencias porcentuales de LT en ejemplares de Limnoperna fortunei extraídos de las jaulas experimentales colocadas en el río Santiago. Junio de 2006 a enero de 2007. Continúa en la página siguiente. 

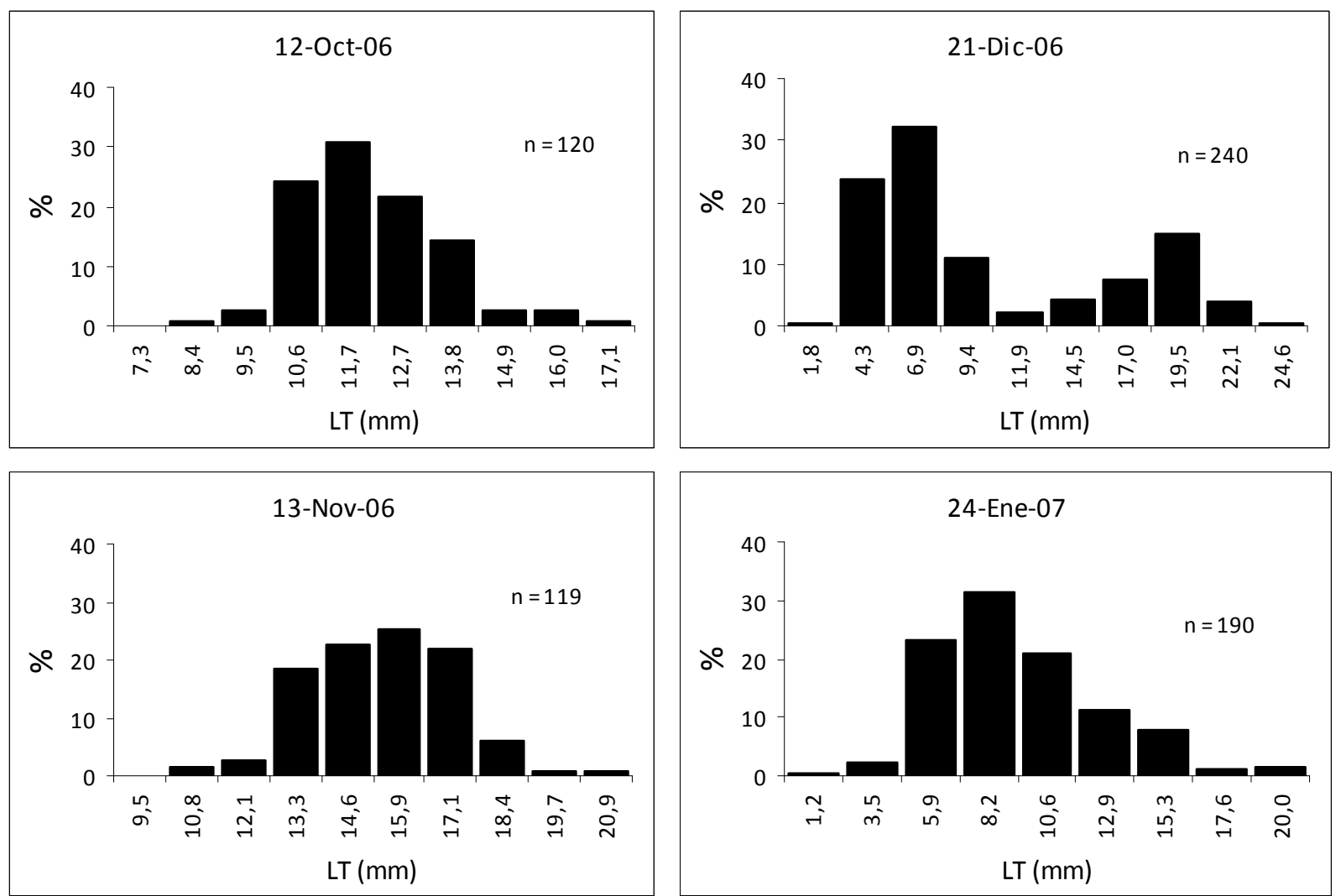

Figura 4.3.2. Continuación...

Durante la segunda etapa de la experiencia en el río Santiago (marzo de 2007 a abril de 2009) se extrajeron y midieron 13.108 individuos. Para cada fecha muestreo se generó una distribución de frecuencias de tallas, previa agrupación de los datos correspondientes a cada jaula (Fig. 4.3.3). Mediante descomposición polimodal se identificaron seis cohortes. Para cada fecha de muestreo se estimó el valor medio de LT y su desvío estándar. La estadística descriptiva de las cohortes identificadas y la tasa de crecimiento para el período de tiempo transcurrido entre una fecha de muestreo y la siguiente se resume en la tabla 4.9. 
Tabla 4.9. Estadística descriptiva de las cohortes identificadas de Limnoperna fortunei para los colectores sumergidos en el río Santiago. LT: Largo total de la valva $(\mathrm{mm})$; DE: desvío estándar; TC ( $\mu \mathrm{m}$ día $\left.^{-1}\right)$ : tasa de crecimiento para el período de tiempo transcurrido entre una fecha de muestreo y la siguiente; N: número de individuos; ND: dato no disponible.

\begin{tabular}{|c|c|c|c|c|c|c|c|}
\hline Cohorte & Año & Estación & Muestreo & Días & $\mathrm{LT} \pm \mathrm{DE}$ & TC & $\mathbf{N}$ \\
\hline \multirow{7}{*}{1} & \multirow{7}{*}{2007} & \multirow{3}{*}{ Otoño } & 23-Mar & $\overline{1}$ & $4,46 \pm 0,65$ & ND & 1319 \\
\hline & & & 02-May & 40 & $6,62 \pm 0,93$ & 5,4 & 61 \\
\hline & & & 06-Jun & 75 & $8,14 \pm 1,09$ & 4,3 & 58 \\
\hline & & \multirow{3}{*}{ Invierno } & 18-Jul & 117 & $9,03 \pm 1,37$ & 2,1 & 60 \\
\hline & & & 28-Ago & 158 & $9,19 \pm 1,6$ & 0,4 & 81 \\
\hline & & & 25-Sep & 186 & $11,18 \pm 1,33$ & 7,1 & 90. \\
\hline & & Primavera & 06-Nov & 228 & $14,20 \pm 1,94$ & 7,2 & 126 \\
\hline \multirow{5}{*}{2} & \multirow{2}{*}{2007} & \multirow{2}{*}{ Primavera } & 06-Nov & 1 & $5,58 \pm 1,51$ & ND & 719 \\
\hline & & & 18-Dic & 42 & $10,5 \pm 2,29$ & 11,7 & 153 \\
\hline & \multirow{3}{*}{2008} & & 25-Ene & 80 & $15,87 \pm 1,84$ & 14,1 & 101 \\
\hline & & Verano & $25-F e b$ & 111 & $17,71 \pm 2,21$ & 5,9 & 44 \\
\hline & & Otoño & $03-\mathrm{Abr}$ & 149 & $19,34 \pm 1,97$ & 4,3 & 98 \\
\hline \multirow{12}{*}{3} & 2007 & Primavera & 18-Dic & 1 & $3,31 \pm 1,02$ & ND & 37 \\
\hline & \multirow{11}{*}{2008} & \multirow{2}{*}{ Verano } & 25-Ene & 38 & $7,01 \pm 1,97$ & 9,7 & 89 \\
\hline & & & 25-Feb & 69 & $7,06 \pm 2,01$ & 0,2 & 259 \\
\hline & & \multirow{3}{*}{ Otoño } & $03-\mathrm{Abr}$ & 107 & $11,63 \pm 3,26$ & 12,0 & 223 \\
\hline & & & 08-May & 142 & $14,29 \pm 3,54$ & 7,6 & 169 \\
\hline & & & 10-Jun & 175 & $14,27 \pm 3,65$ & $-0,1$ & 180 \\
\hline & & \multirow{3}{*}{ Invierno } & 08-Jul & 203 & $15,56 \pm 3,95$ & 4,6 & 248 \\
\hline & & & 14-Ago & 240 & $15,81 \pm 3,88$ & 0,7 & 205 \\
\hline & & & 23-Sep & 280 & $14,25 \pm 4,13$ & $-3,9$ & 275 \\
\hline & & \multirow{3}{*}{ Primavera } & $22-O c t$ & 309 & $14,42 \pm 3,35$ & 0,6 & 204 \\
\hline & & & 26-Nov & 344 & $14,4 \pm 3,97$ & $-0,1$ & 206 \\
\hline & & & 18-Dic & 366 & $15 \pm 3,81$ & 2,7 & 189 \\
\hline \multirow{11}{*}{4} & \multirow{8}{*}{2008} & \multirow{2}{*}{ Otoño } & 08-May & 1 & $5,44 \pm 1,43$ & ND & 343 \\
\hline & & & 10-Jun & 33 & $5,27 \pm 1,12$ & $-0,5$ & 479 \\
\hline & & \multirow{3}{*}{ Invierno } & 08-Jul & 61 & $5,35 \pm 1,21$ & 0,3 & 525 \\
\hline & & & 14-Ago & 98 & $6,14 \pm 1,23$ & 2,1 & 444 \\
\hline & & & 23-Sep & 138 & $4,86 \pm 1,12$ & $-3,2$ & 675 \\
\hline & & \multirow{3}{*}{ Primavera } & $22-O c t$ & 167 & $5,99 \pm 1,2$ & 3,9 & 406 \\
\hline & & & 26-Nov & 202 & $6,17 \pm 1,52$ & 0,5 & 506 \\
\hline & & & 18-Dic & 224 & $7,33 \pm 1,78$ & 5,3 & 710 \\
\hline & \multirow{3}{*}{2009} & \multirow{2}{*}{ Verano } & 09-Feb & 277 & $11,46 \pm 4,11$ & 7,8 & 763 \\
\hline & & & 13-Mar & 309 & $12,83 \pm 2,61$ & 4,3 & 324 \\
\hline & & Otoño & $15-A b r$ & 342 & $17,36 \pm 2,89$ & 13,7 & 126 \\
\hline \multirow{3}{*}{5} & \multirow{3}{*}{2009} & \multirow{2}{*}{ Verano } & 09-Feb & 1 & $5,78 \pm 1,37$ & ND & 1000 \\
\hline & & & 13-Mar & 32 & $7,78 \pm 1,69$ & 6,3 & 1121 \\
\hline & & Otoño & $15-A b r$ & 65 & $10,27 \pm 2,48$ & 7,5 & 111 \\
\hline 6 & 2009 & Otoño & $15-A b r$ & 1 & $6,2 \pm 1,49$ & ND & 476 \\
\hline
\end{tabular}



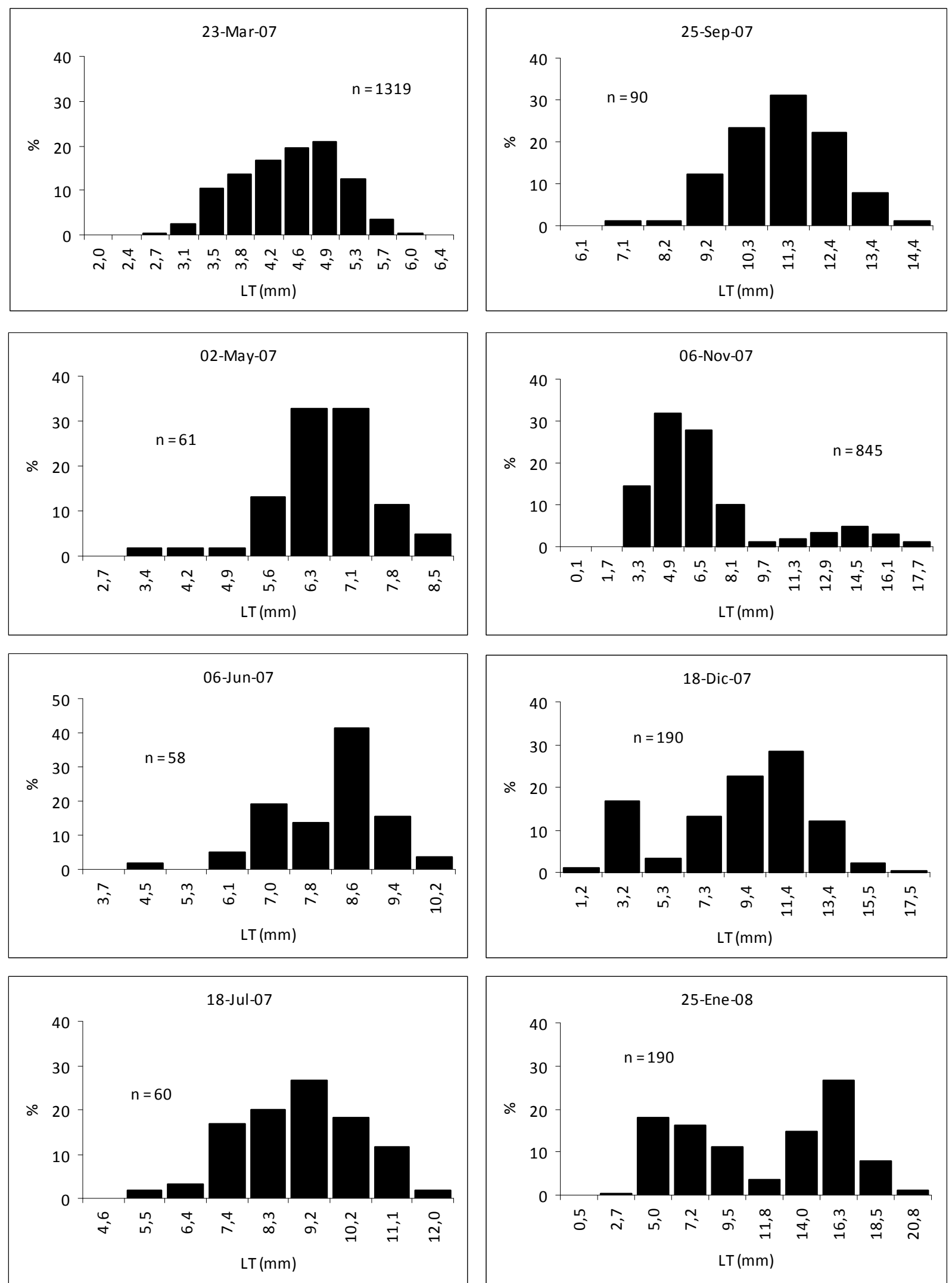

Figura 4.3.3. Distribución de las frecuencias porcentuales del LT de ejemplares de Limnoperna fortunei extraídos de las jaulas experimentales colocadas en el río Santiago. Marzo de 2007 a abril de 2009. Continúa en las páginas siguientes. 

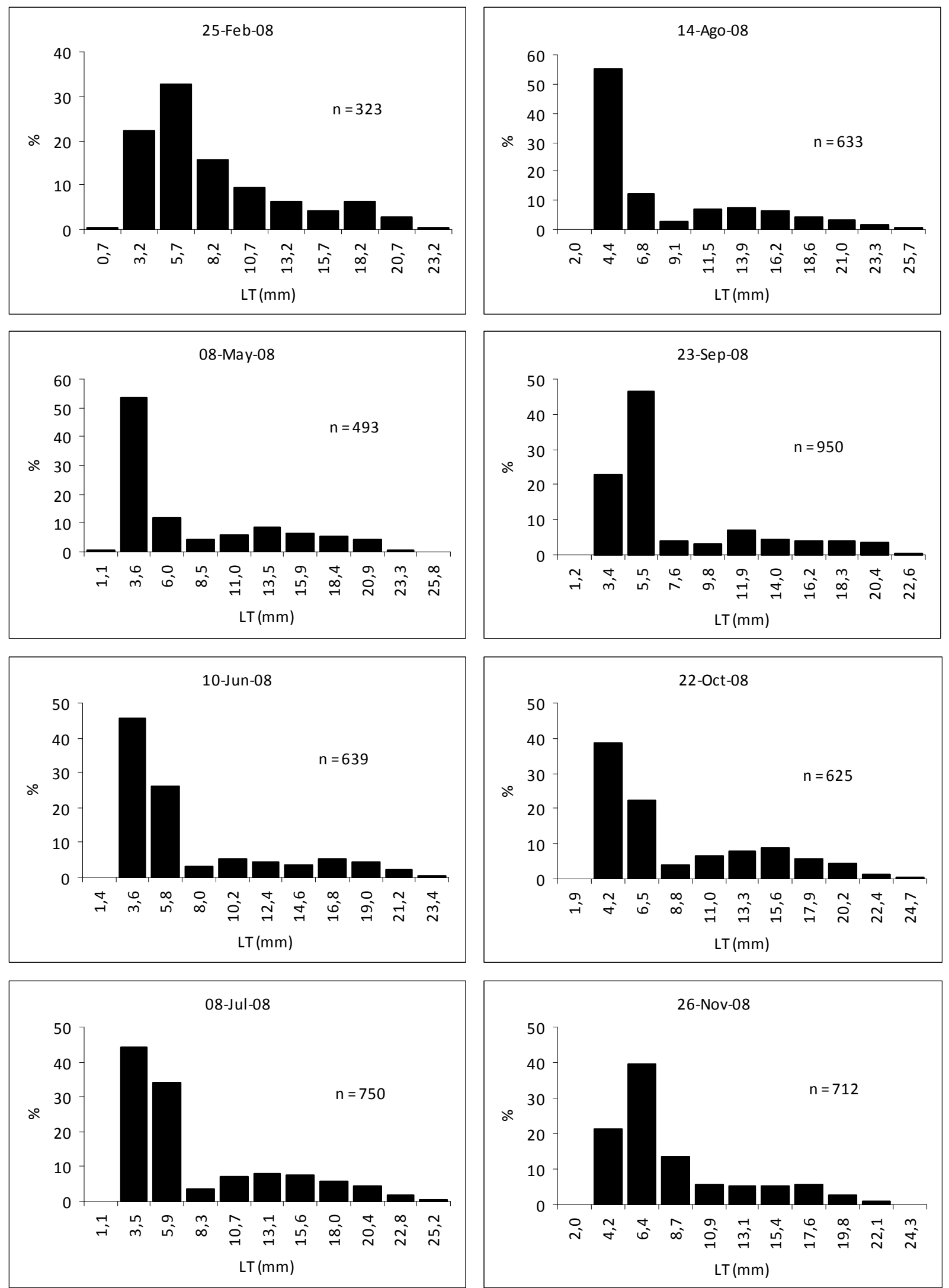

Figura 4.3.3. Continuación... 

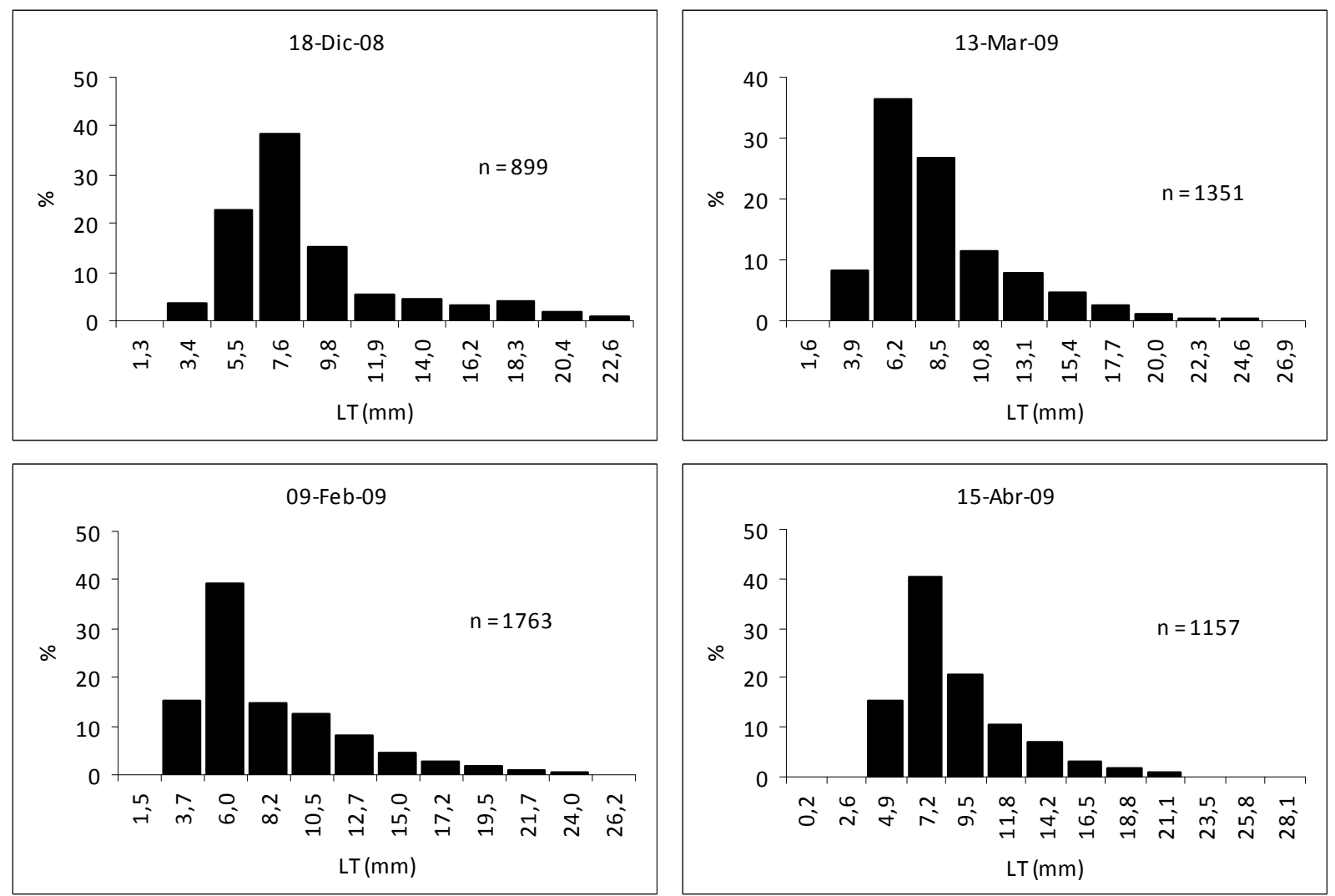

Figura 4.3.3. Continuación...

La prueba $\mathrm{F}$ mostró que los modelos que mejor describieron el crecimiento de las cohortes identificadas en el río Santiago fueron el lineal y el cuadrático. En el caso de la cohorte 4, los modelos propuestos no mostraron un ajuste satisfactorio. La tendencia de la curva se comportó según un modelo exponencial (Neumann et al., 1993), con un ajuste altamente significativo a los datos (Tabla 4.10; Fig. 4.3.4).

Tabla 4.10. Parámetros de los modelos predictivos. $R^{2}$ : valores coeficientes de determinación.

\begin{tabular}{ccccc}
\hline Período & Cohorte & Modelo & Ecuación & $\mathbf{R}^{\mathbf{2}}$ \\
\hline \hline \multirow{2}{*}{$\mathbf{2 0 0 6 - 2 0 0 7}$} & $\mathbf{1}$ & Lineal & $\mathrm{y}=0,0766 \mathrm{x}+3,3453$ & 0,98 \\
& $\mathbf{2}$ & Lineal & $\mathrm{y}=0,0879 \mathrm{x}-10,191$ & 1,00 \\
\hline & $\mathbf{1}^{*}$ & Lineal & $\mathrm{y}=0,037 \mathrm{x}-5,6863$ & 0,94 \\
& $\mathbf{2}^{*}$ & Lineal & $\mathrm{y}=0,0953 \mathrm{x}-41,98$ & 0,95 \\
$\mathbf{2 0 0 7 - 2 0 0 8}$ & $\mathbf{3}$ & Cuadrático & $\mathrm{y}=-0,0002 \mathrm{x}^{2}+0,2879 \mathrm{x}-101,85$ & 0,95 \\
& $\mathbf{4}$ & Exponencial & $\mathrm{y}=0,0046 \mathrm{e}$ & $0,132 \mathrm{x}$ \\
& $\mathbf{5}$ & Lineal & $\mathrm{y}=0,0691 \mathrm{x}-61,328$ & 1,00 \\
\hline \hline
\end{tabular}




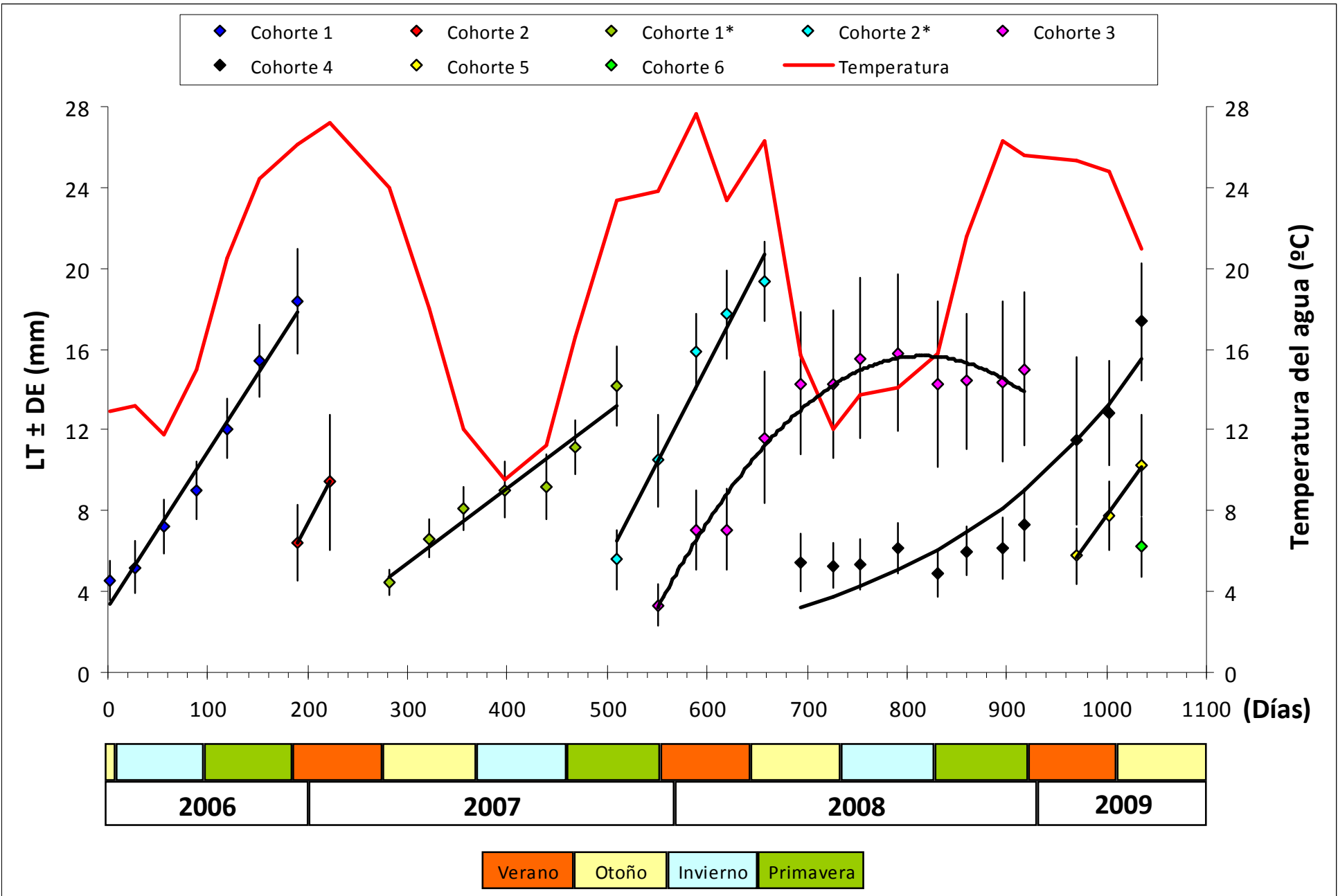

Figura 4.3.4. Modelos de crecimiento ajustados a las cohortes identificadas durante el período de estudio en el río Santiago. LT: Largo Total de la valva; DE: desvío estándar. 
En el río Coronda, durante el período marzo de 2007 a abril de 2009, se recolectaron y midieron 4.413 individuos. Para cada fecha muestreo se generó una distribución de frecuencias de tallas, previa agrupación de los datos (Fig. 4.3.5). Mediante descomposición polimodal se identificaron cuatro cohortes. Para cada fecha de muestreo, se estimó el valor medio de LT y su desvío estándar. La estadística descriptiva de las cohortes identificadas y la tasa de crecimiento para el período de tiempo transcurrido entre una fecha de muestreo y la siguiente se resume en la tabla 4.11 .
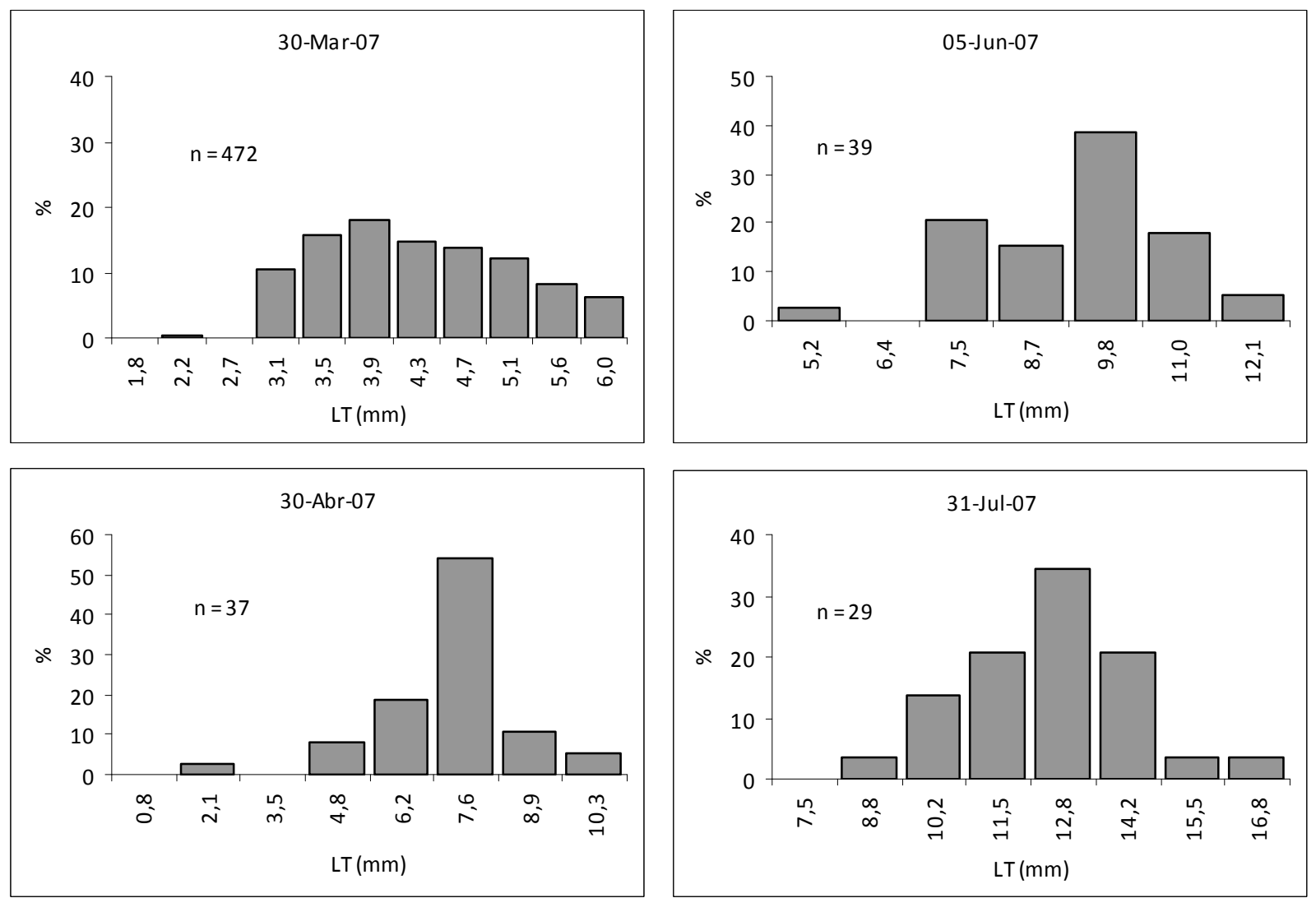

Figura 4.3.5. Distribución de las frecuencias porcentuales de LT de ejemplares de Limnoperna fortunei extraídos de las jaulas experimentales colocadas en el río Coronda. Marzo de 2007 a diciembre de 2008. Continúa en las páginas siguientes. 

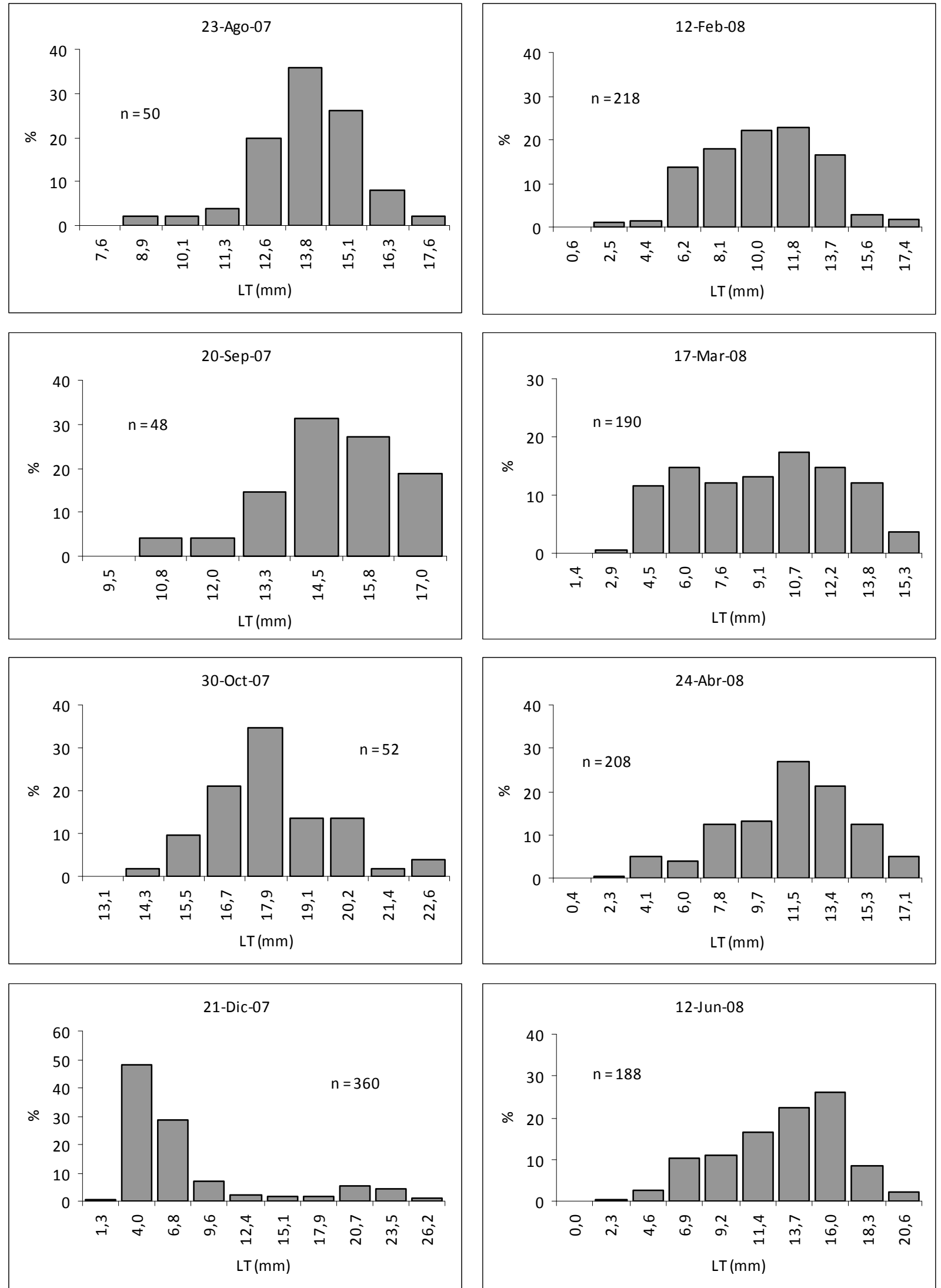

Figura 4.3.5. Continuación... 

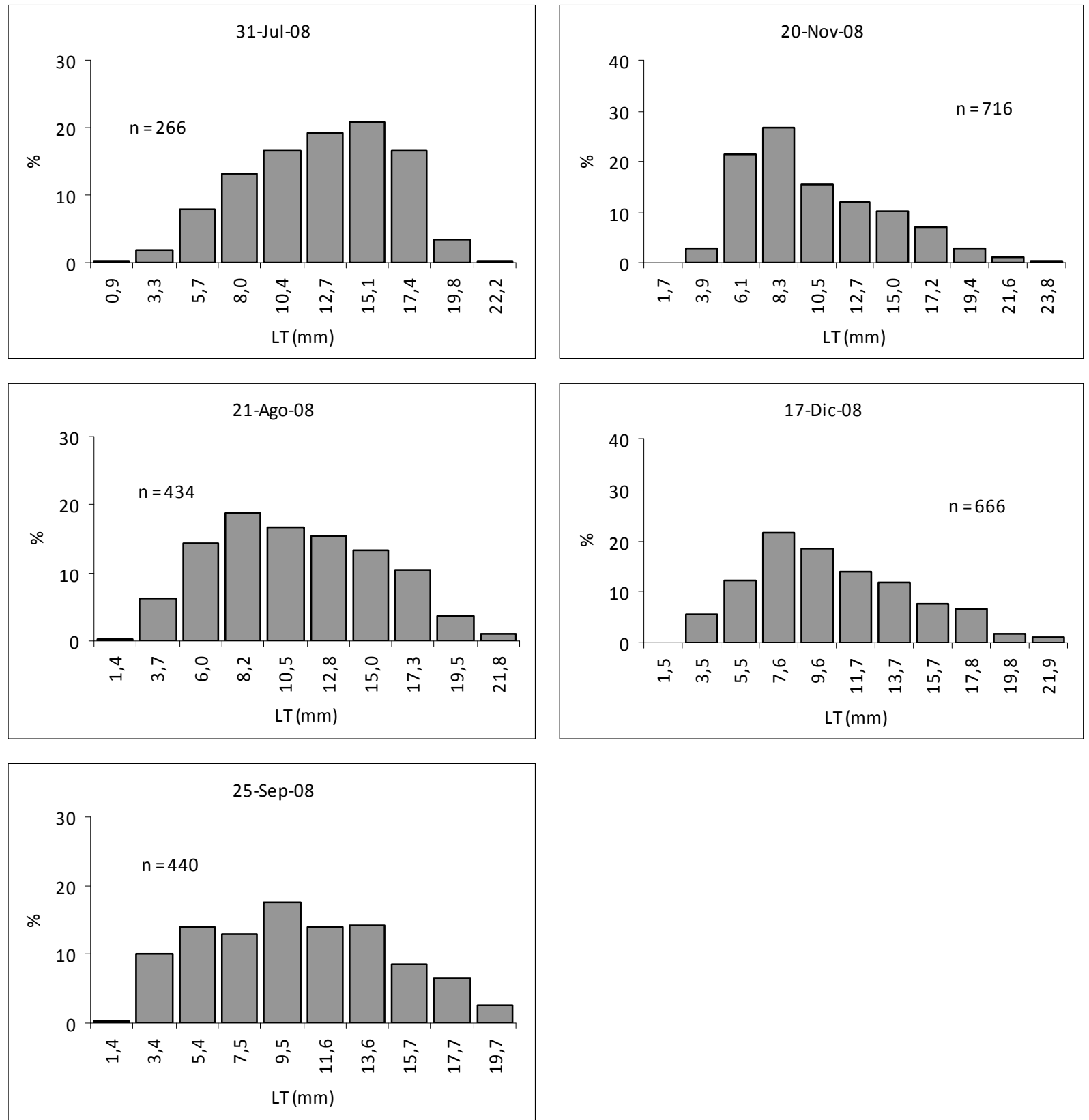

Figura 4.3.5. Continuación... 
Tabla 4.11. Estadística descriptiva de las cohortes identificadas de Limnoperna fortunei para los colectores sumergidos en el río Coronda. LT: Largo total de la valva $(\mathrm{mm})$; DE: desvío estándar; TC ( $\mu \mathrm{m}$ día $\left.{ }^{-1}\right)$ : tasa de crecimiento para el período de tiempo transcurrido entre una fecha de muestreo y la siguiente; N: número de individuos; ND: dato no disponible.

\begin{tabular}{|c|c|c|c|c|c|c|c|}
\hline Cohorte & Año & Estación & Muestreo & Días & $\mathrm{LT} \pm \mathrm{DE}$ & $\mathrm{TC}$ & $\mathbf{N}$ \\
\hline \multirow{8}{*}{1} & \multirow{8}{*}{2007} & Verano & 30-Mar & 1 & $4,32 \pm 0,85$ & ND & 472 \\
\hline & & \multirow{2}{*}{ Otoño } & 30-Abr & 31 & $7,27 \pm 1,50$ & 9,5 & 37 \\
\hline & & & 05-Jun & 67 & $10,47 \pm 1,45$ & 8,9 & 39 \\
\hline & & \multirow{3}{*}{ Invierno } & 31-Jul & 123 & $12,54 \pm 1,72$ & 3,7 & 29 \\
\hline & & & 23-Ago & 146 & $13,89 \pm 1,58$ & 5,9 & 50 \\
\hline & & & 20-Sep & 174 & $14,86 \pm 1,59$ & 3,5 & 48 \\
\hline & & \multirow{2}{*}{ Primavera } & $30-O c t$ & 214 & $18,04 \pm 1,77$ & 8,0 & 52 \\
\hline & & & 21-Dic & 266 & $19,34 \pm 4,47$ & 2,5 & 60 \\
\hline \multirow{10}{*}{2} & 2007 & Primavera & 21-Dic & 1 & $5,43 \pm 1,77$ & ND & 300 \\
\hline & \multirow{9}{*}{2008} & \multirow{2}{*}{ Verano } & $12-F e b$ & 53 & $10,28 \pm 2,89$ & 9,2 & 218 \\
\hline & & & 17-Mar & 87 & $11,19 \pm 2,24$ & 2,7 & 129 \\
\hline & & \multirow{2}{*}{ Otoño } & $24-A b r$ & 125 & $12,54 \pm 2,31$ & 3,6 & 163 \\
\hline & & & 12-Jun & 174 & $14,88 \pm 2,41$ & 4,8 & 131 \\
\hline & & \multirow{3}{*}{ Invierno } & 31-Jul & 223 & $15,78 \pm 2,21$ & 1,8 & 117 \\
\hline & & & 21-Ago & 244 & $14,6 \pm 3,06$ & $-5,6$ & 262 \\
\hline & & & 25-Sep. & 279 & $14,64 \pm 2,72$ & 0,1 & 162 \\
\hline & & \multirow{2}{*}{ Primavera } & 20-Nov & 335 & $21,16 \pm 1,77$ & 11,6 & 30 \\
\hline & & & 17-Dic & 362 & $22,91 \pm 2,51$ & 6,5 & 17 \\
\hline \multirow{8}{*}{3} & \multirow{8}{*}{2008} & Verano & 17-Mar & 1 & $5,80 \pm 1,24$ & ND & 61 \\
\hline & & \multirow{2}{*}{ Otoño } & $24-A b r$ & 38 & $7,11 \pm 2,29$ & 3,4 & 45 \\
\hline & & & 12-Jun & 87 & $8,53 \pm 2,44$ & 2,9 & 57 \\
\hline & & \multirow{3}{*}{ Invierno } & 31-Jul & 136 & $9,84 \pm 3,25$ & 2,7 & 149 \\
\hline & & & 21-Ago & 157 & $8,16 \pm 2,17$ & $-8,0$ & 244 \\
\hline & & & 25-Sep & 192 & $9,17 \pm 2,29$ & 2,9 & 192 \\
\hline & & \multirow{2}{*}{ Primavera } & 20-Nov & 248 & $15,26 \pm 2,43$ & 10,9 & 342 \\
\hline & & & 17-Dic & 275 & $14,58 \pm 2,75$ & $-2,5$ & 275 \\
\hline \multirow{3}{*}{4} & \multirow{3}{*}{2008} & Invierno & 25-Sep & 1 & $4,52 \pm 1,15$ & ND & 86 \\
\hline & & \multirow{2}{*}{ Primavera } & $20-\mathrm{Nov}$ & 56 & $8,25 \pm 1,68$ & 6,7 & 475 \\
\hline & & & 17-Dic & 83 & $8,72 \pm 2,19$ & 1,7 & 478 \\
\hline
\end{tabular}


La prueba $\mathrm{F}$ dio como resultado que el modelo lineal fue el que mejor describió el crecimiento de las cohortes identificadas en el río Coronda (Tabla 4.12; Fig. 4.3.6).

Tabla 4.12. Parámetros de los modelos predictivos. $R^{2}$ : valores coeficientes de determinación.

\begin{tabular}{cccc}
\hline Cohorte & Modelo & Ecuación & $\mathbf{R}^{\mathbf{2}}$ \\
\hline $\mathbf{1}$ & Lineal & $\mathrm{y}=0,0554 \mathrm{x}+5,5102$ & 0,97 \\
$\mathbf{2}$ & Lineal & $\mathrm{y}=0,0395 \mathrm{x}-3,603$ & 0,89 \\
$\mathbf{3}$ & Lineal & $\mathrm{y}=0,0316 \mathrm{x}-5,8441$ & 0,81 \\
$\mathbf{4}$ & Lineal & $\mathrm{y}=0,053 \mathrm{x}-24,189$ & 0,95 \\
\hline \hline
\end{tabular}

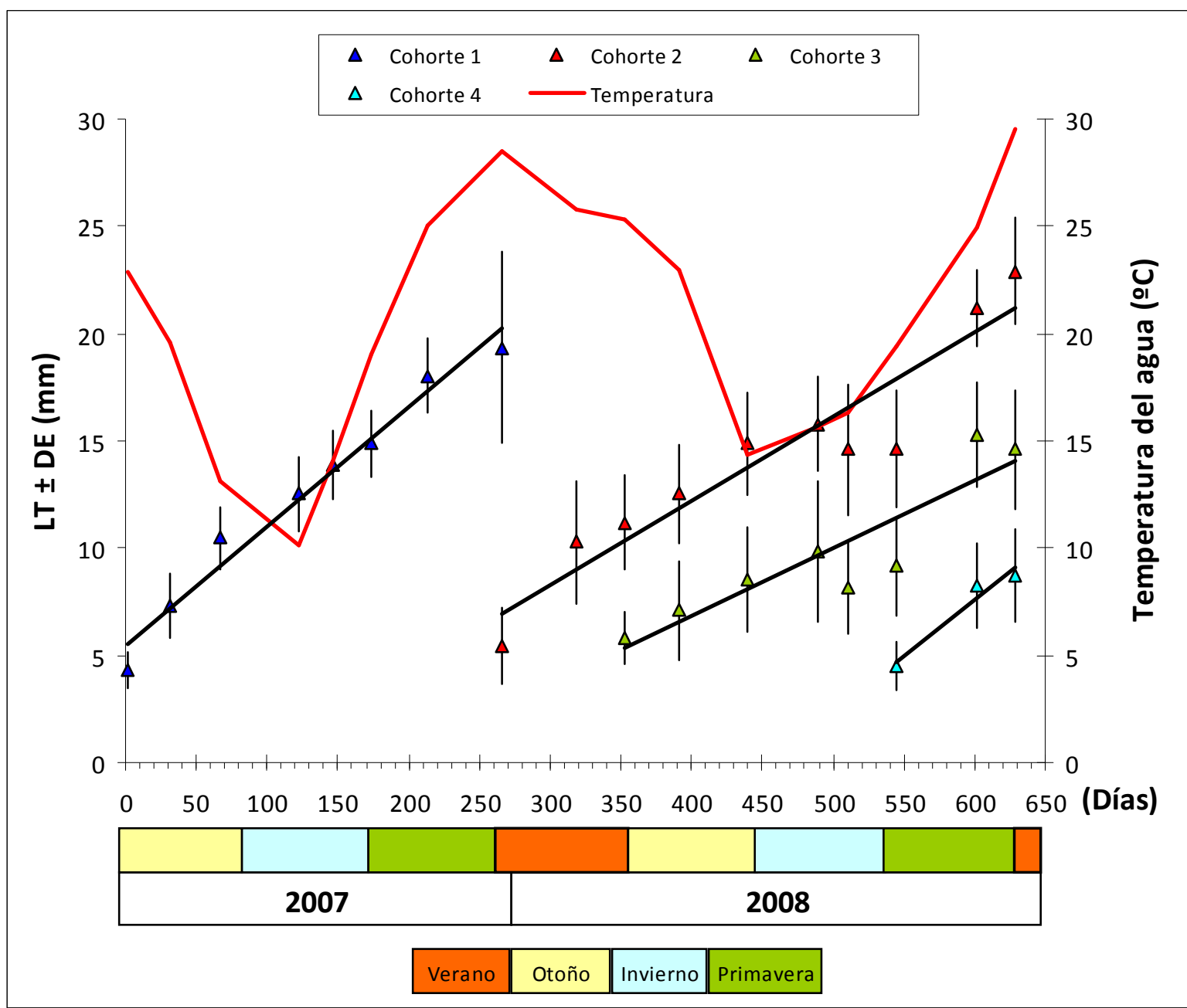

Figura 4.3.6. Modelos de crecimiento ajustados a las cohortes identificadas de marzo de 2007 a diciembre de 2008 en el río Coronda. LT: Largo Total de la valva; DE: desvío estándar. 
La diferencia de crecimiento en jaulas sumergidas en los dos ambientes se evaluó mediante una prueba F aplicada a la Cohorte 1 identificada en la segunda etapa experimental en el río Santiago y en el Coronda. La ordenada al origen de la regresión se estimó en función de la fecha de inicio, marzo de 2007, sin tener en cuenta el período de tiempo previo correspondiente a la primera etapa en el río Santiago. El análisis dio como resultado que las pendientes de las regresiones lineales fueron significativamente diferentes entre un sitio y otro $\left(F_{(2,11)}=26,98 ; p<0,0001\right.$; Fig. 4.3.7). Los individuos en el Coronda tuvieron un crecimiento significativamente mayor que el de los provenientes del río Santiago.

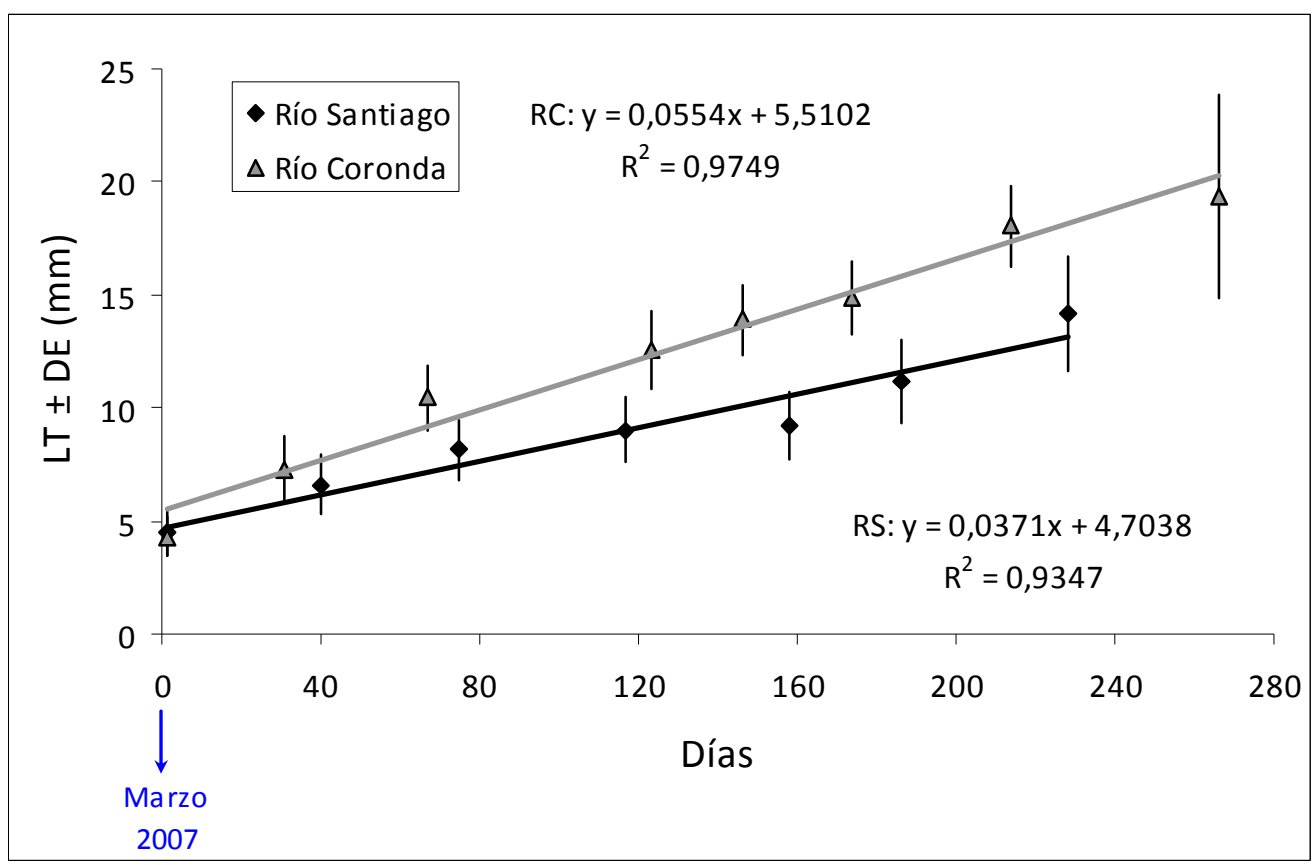

Figura 4.3.7. Comparación del crecimiento individual de la Cohortes 1 de Limnoperna fortunei en los ríos Coronda y Santiago. LT: Largo total de la valva; DE: desvío estándar. 


\subsection{3 ÍNDICE DE CONDICIÓN}

- Alometría: relación largo - peso

Para explicar alometría, se midieron y pesaron 1.310 individuos provenientes de muestras recolectadas en el río Santiago, y 729 para el Coronda. El modelo potencial mostró un ajuste altamente significativo entre LT y los distintos pesos (PH, PS y PSLC) (Tabla 4.11; Fig. 4.3.8). Se realizó una prueba F para comparar los modelos potenciales que describen la relación LT con PH, PS y PSLC, para cada ambiente. Esas regresiones fueron significativamente diferentes entre un sitio y otro $\left(F_{(2,1962)}=66,08 ; p<0,0001 ; F_{(2,2035}=70,93 ; p<0,0001 ; F_{(2,1977)}=16,36 ; p\right.$ $<0,0001$; respectivamente) (Fig. 4.3.8). Estos resultados indicaron que los pesos de los individuos en el Coronda fueron significativamente mayores que los procedentes del río Santiago. Los ANCOVAs para los modelos linealizados mostraron una interacción altamente significativa entre la covariable y el factor ( $p<0,0001$ en todos los casos) (Apéndices 4.3-5). Con estos resultados no se pudo identificar el efecto causado por los ambientes ni por el LT en el peso de los ejemplares.

Tabla 4.11. Relación potencial entre el LT y los pesos medidos en individuos submuestreados en los ríos Santiago y Coronda. PH: peso húmedo; PS: peso seco; PSLC: peso seco libre de cenizas; $\mathrm{R}^{2}$ : coeficiente de determinación; N: número de individuos.

\begin{tabular}{ccccccc}
\hline & Río Santiago & $\mathbf{R}^{2}$ & $\mathbf{N}$ & Río Coronda & $\mathbf{R}^{2}$ & $\mathbf{N}$ \\
\hline \hline PH & $\mathrm{y}=0,0001 \mathrm{x}^{2,7263}$ & 0,91 & 1268 & $\mathrm{y}=6 \mathrm{E}-05 \mathrm{x}^{2,9763}$ & 0,87 & 699 \\
PS & $\mathrm{y}=6 \mathrm{E}-05 \mathrm{x}^{2,6361}$ & 0,95 & 1310 & $\mathrm{y}=3 \mathrm{E}-05 \mathrm{x}^{2,9006}$ & 0,95 & 729 \\
PSLC & $\mathrm{y}=1 \mathrm{E}-05 \mathrm{x}^{2,6811}$ & 0,79 & 1275 & $\mathrm{y}=4 \mathrm{E}-06 \mathrm{x}^{3,0331}$ & 0,84 & 706 \\
\hline \hline
\end{tabular}



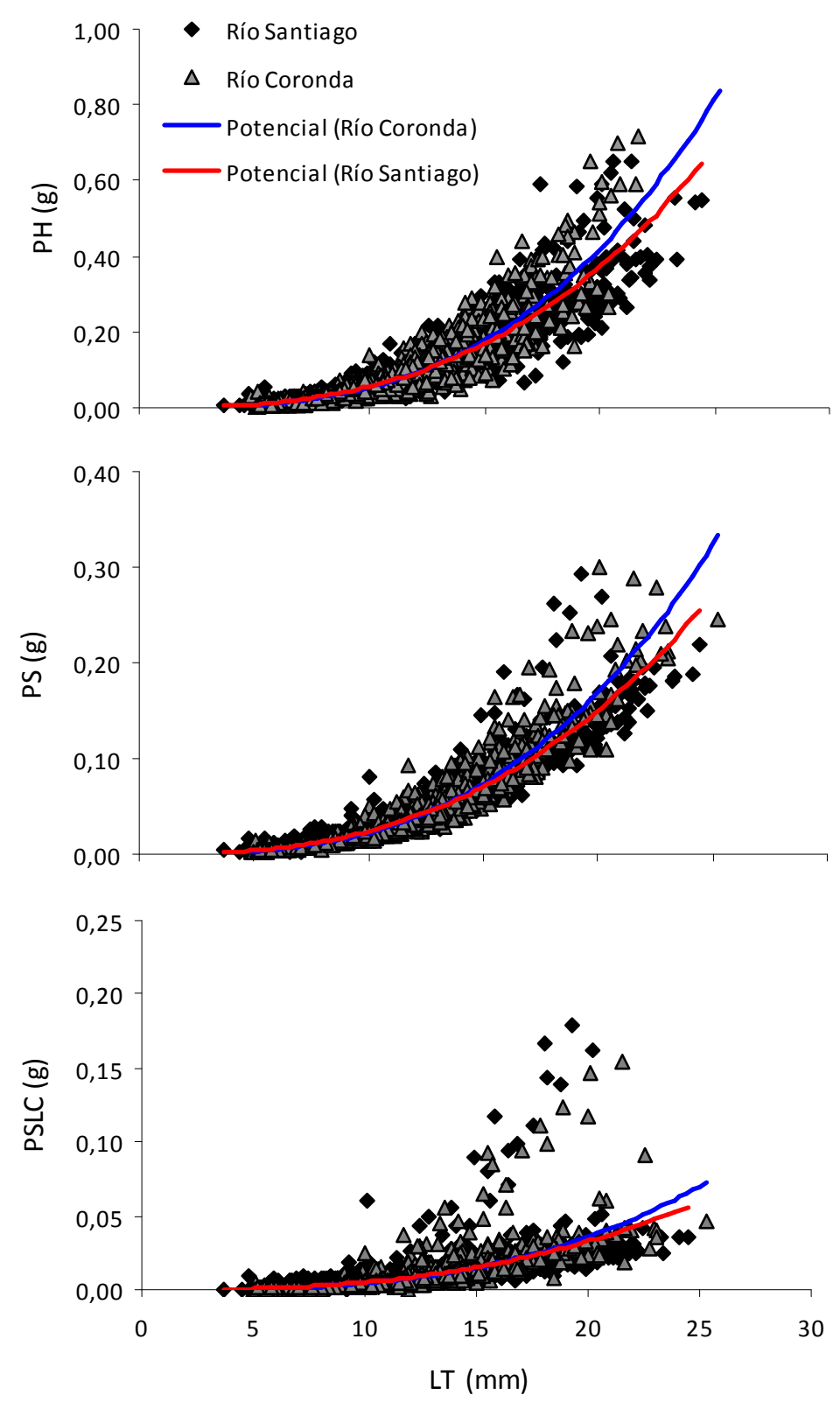

Figura 4.3.8. Relación potencial entre LT y PH, PS, PSLC. LT: largo total de la valva; PH: peso húmedo; PS: peso seco; PSLC: peso seco libre de cenizas.

En los análisis subsiguientes se utilizó PSLC por ser la medida más representativa del peso orgánico de los individuos. 
- Variación estacional del índice de condición

En el río Santiago, se estimó el IC promedio y su desvío estándar para cada fecha de muestreo. Durante 2007, el IC mostró dos picos, en agosto y diciembre, mientras que en 2008 se registró además un pico de menor magnitud en febrero. De abril a agosto de ese año, los valores se mantuvieron constantes y en septiembre el IC mostró mayor variabilidad. En noviembre se registró un segundo pico anual seguido por un descenso en diciembre (Fig. 4.3.9). Para este análisis se procesaron 1.255 individuos.

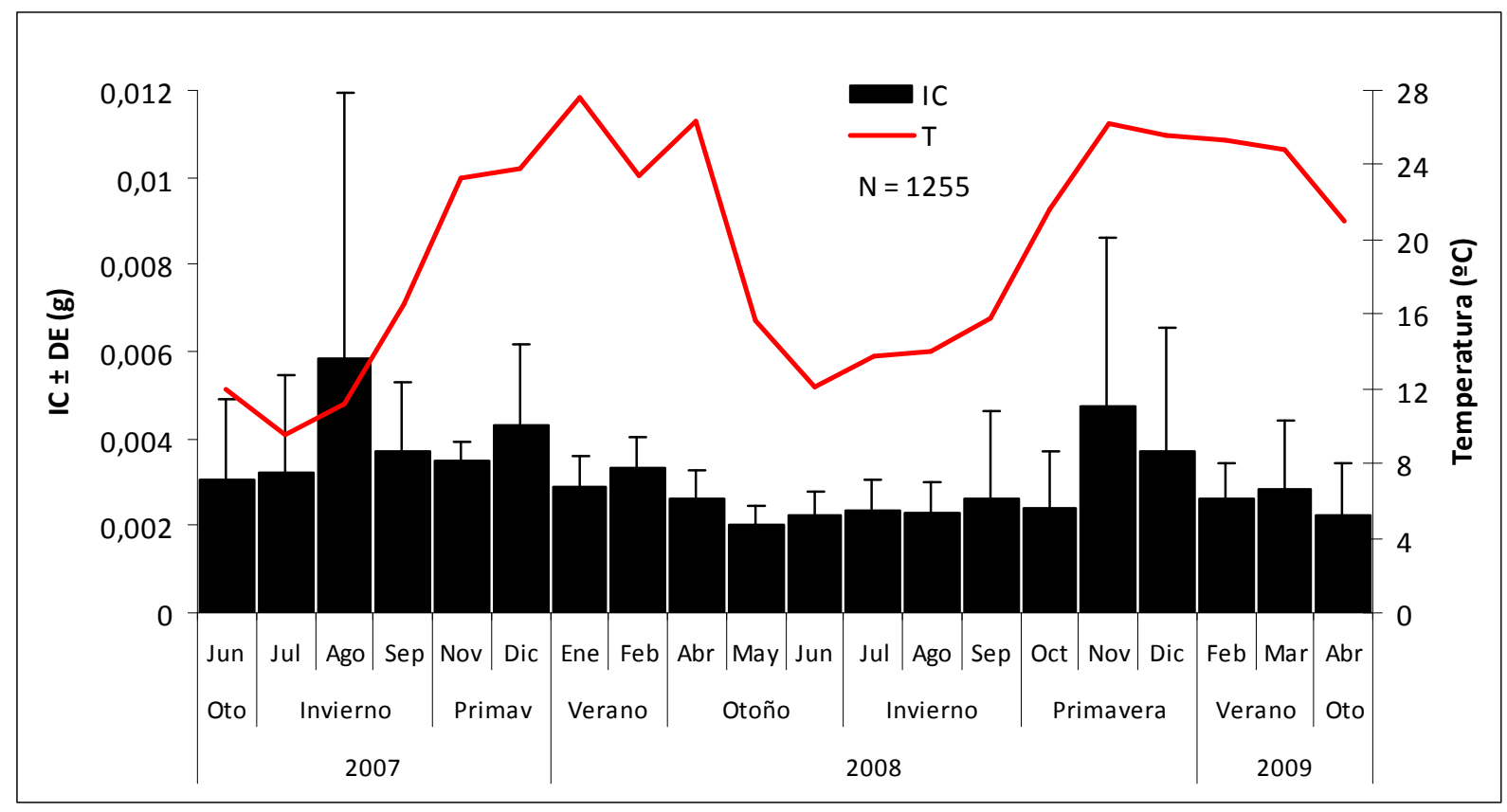

Figura 4.3.9. Variación estacional del índice de condición (IC) \pm desvío estándar en el río Santiago.

En el río Coronda se observó una variación similar del IC durante 2007. En 2008, la condición estimada fue menor que la del año anterior. Durante el invierno se observó un aumento del IC, que alcanzó un pico en agosto, seguido por una disminución en septiembre (Fig. 4.3.10). Para este análisis se procesaron 696 individuos. 


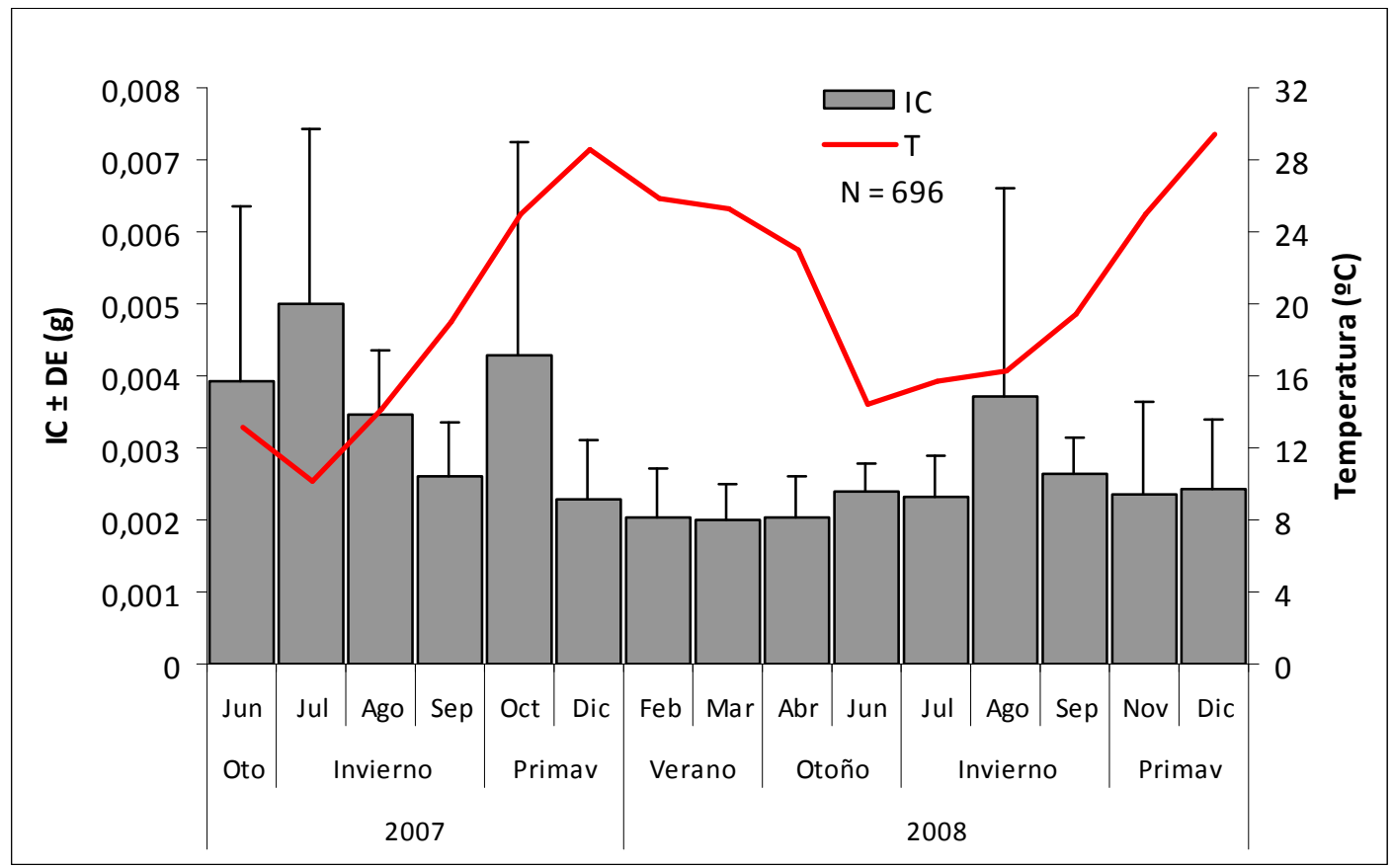

Figura 4.3.10. Variación estacional del índice de condición (IC) \pm desvío estándar en el río Coronda

El análisis de Pearson no mostró ninguna correlación significativa entre las variables ambientales y el IC estimado para los individuos del río Santiago. Por el contrario, en el río Coronda se registró una correlación negativa siginificativa entre IC y la temperatura $(r=-0,619 ; p<0,05)$ y una correlación positiva entre IC y el $\mathrm{pH}(r=0,527 ; p<0,05)$.

La estadística descriptiva de las variables lineales, de los pesos y del IC para ambos sitios de muestreo está resumida en los apéndices 4.6 y 4.7 .

La variación del PSLC fue muy amplia para individuos con un LT > $8 \mathrm{~mm}$ en ambos sitios de muestreos y para todas las cohortes identificadas (Fig. 4.3.11-12). Este patrón se observó también en la figura 4.3.8, donde el PSLC se relacionó con el LT de todos los individuos submuestreados. 

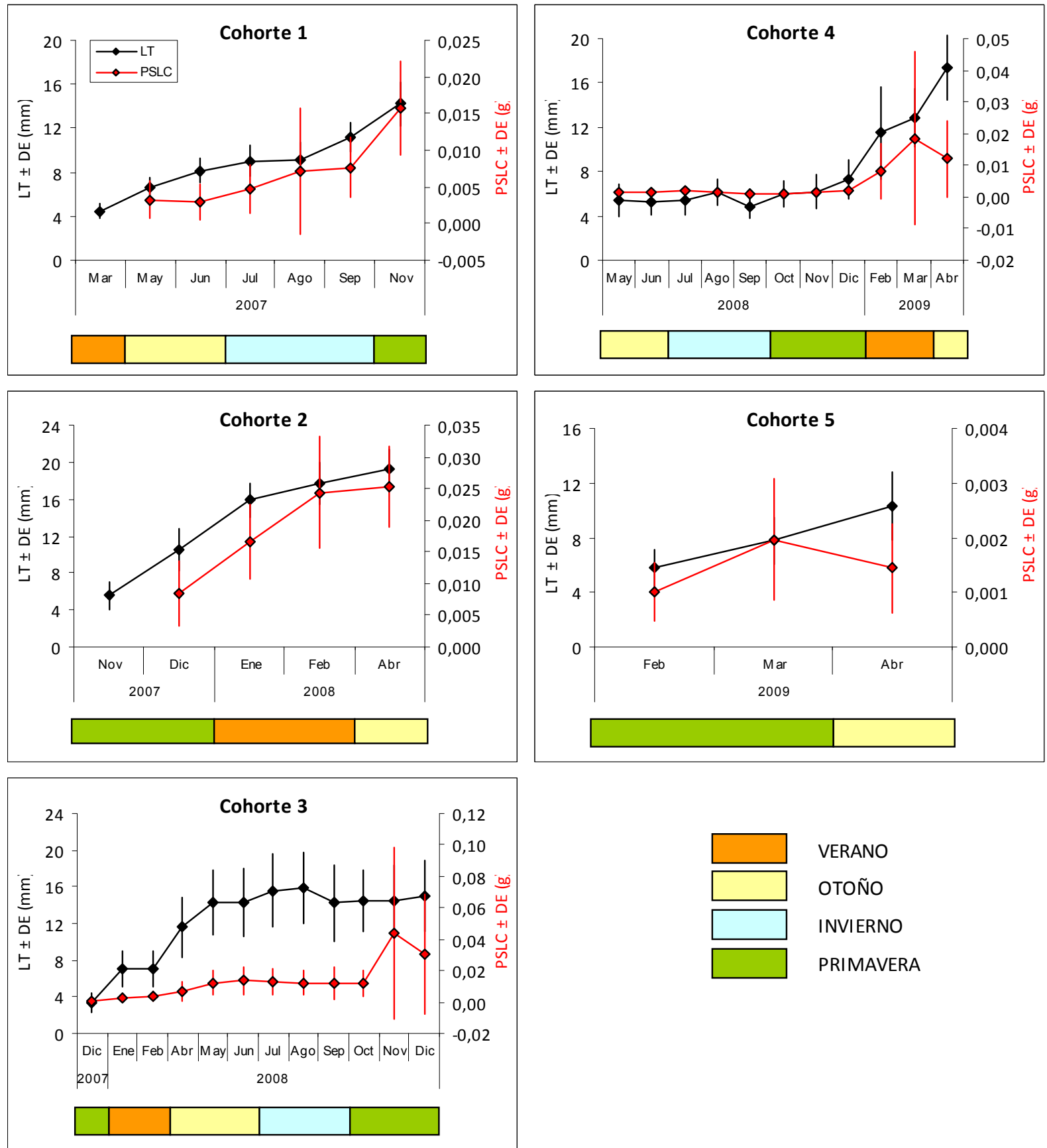

VERANO

OTOÑO

INVIERNO

PRIMAVERA

Figura 4.3.11. Variación temporal del LT y del PSLC para las cohortes de individuos de Limnoperna fortunei identificadas en el río Santiago. 

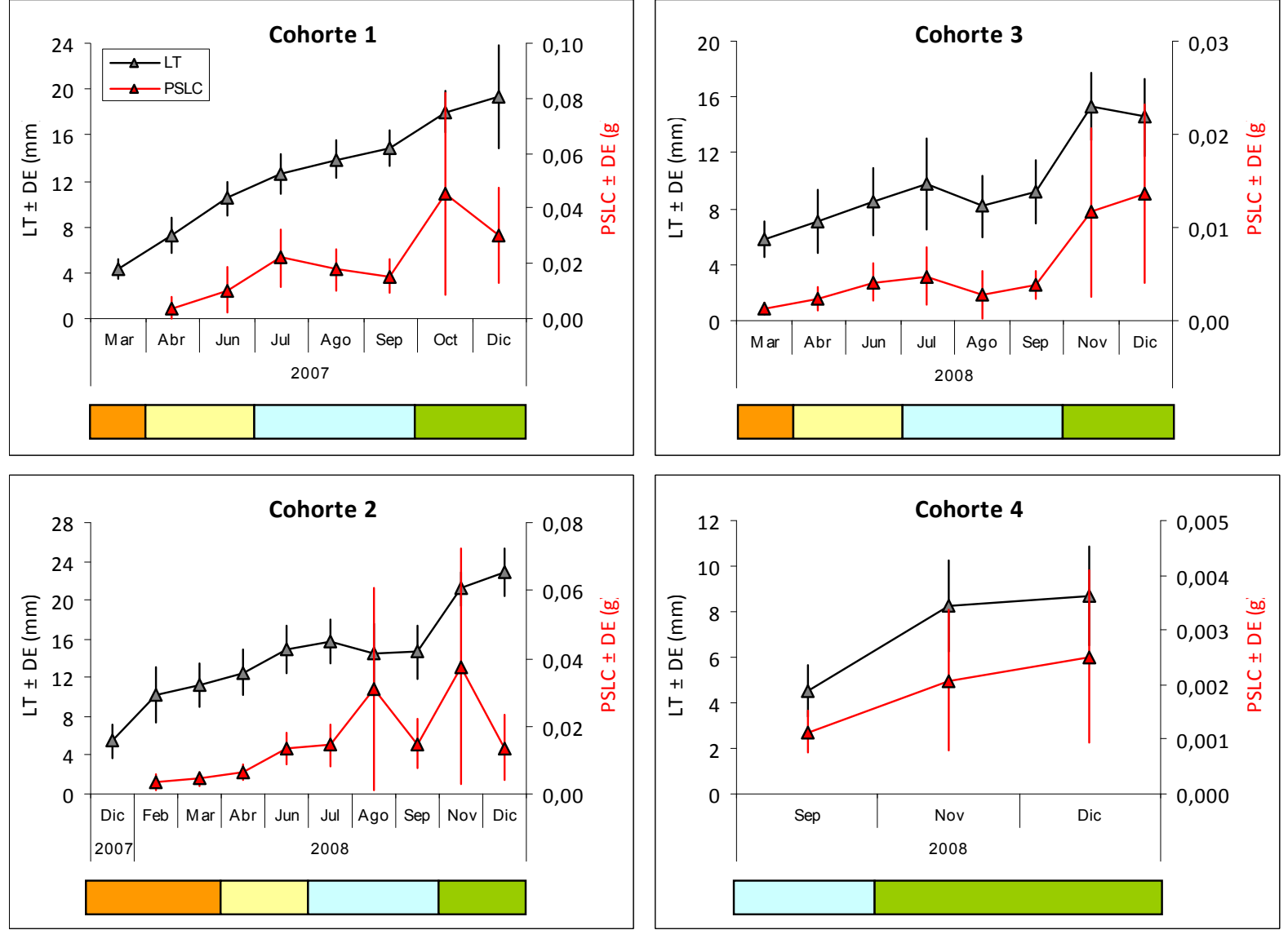

Figura 4.3.12. Variación temporal del LT y del PSLC para las cohortes de individuos de Limnoperna fortunei identificadas en el río Coronda. Referencias indicadas en la figura anterior. 


\subsection{DISCUSIÓN}

Los resultados obtenidos en este capítulo sobre relaciones morfométricas no mostraron diferencias en las dimensiones entre ambientes ni entre jaulas. Sin embargo, al comparar las dimensiones de los mejillones recolectados de los paneles colectores (Capítulo 3) con la de los individuos que crecieron en jaulas experimentales, se observaron diferencias significativas. En el río Santiago, los cocientes AT/LT y AL/LT de los mejillones enjaulados fueron menores que los valores estimados para los individuos provenientes de los paneles. Es decir, los mejillones enjaulados tuvieron un LT mayor, como fue evidente al comparar los coeficientes invertidos de la relación la relación alto : ancho : largo para cada método de estudio:

$$
\begin{gathered}
\text { Paneles - RS } \rightarrow 1: 1,33 \pm 0,01: 2,61 \pm 0,01 \\
\text { Jaulas - RS } \rightarrow 1: 1,35 \pm 0,04: 2,75 \pm 0,05
\end{gathered}
$$

En el río Coronda, el cociente AT/LT de los mejillones enjaulados fue significativamente menor que el estimado para los individuos de los paneles. Es decir, los mejillones enjaulados tuvieron un LT mayor. Las relaciones entre las variables para cada método fueron:

$$
\begin{aligned}
& \text { Paneles - RC } \rightarrow 1: 1,39 \pm 0,01: 2,68 \pm 0,01 \\
& \text { Jaulas - RC } \rightarrow 1: 1,35 \pm 0,06: 2,71 \pm 0,13
\end{aligned}
$$

La presencia de una barrera física generada por la malla de jaulas experimentales podría haber haber disminuido el intercambio de agua entre el exterior y el interior de las jaulas generando una deposición de los sedimentos en supensión y disminuyendo la cantidad de alimento disponible. A su vez, la abertura de malla $(1 \mathrm{~mm})$ de las jaulas no impidiría la entrada de postlarvas de $L$. fortunei y ofrecería un sustrato de asentamiento para las larvas ingresantes del medio, y las que fueron liberadas por los individuos que se encontraban en el interior. Asumimos que, luego de los eventos de desove y reclutamiento ocurridos durante el período de estudio, el número de individuos dentro de las jaulas podría haberse incrementado. El posible aumento de la abundancia y la imposibilidad por parte de los mejillones de trasladarse a otros sustratos podría haber resultado en una modificación de la 
abundancia inicial (1.000 individuos al comienzo de la experiencia) incrementando el valor final. En consecuencia, esta situación podría haber generado la diferencia de morfometría observada entre las jaulas y los paneles. La elevada densidad poblacional de individuos epifaunales es un factor importante que influye en la forma de la valva. Las poblaciones muy densas generan una depleción de la concentración de alimento por sobreconsumo, y en las especies con un hábito de vida gregario ocurre una competencia por el espacio que modifica la morfometría de la valva. La acción independiente o sinérgica de estos eventos resulta en el desarrollo de valvas alargadas (Alunno-Bruscia et al., 2001; Lajtner et al., 2004; Lauzon-Guay et al., 2005). Los individuos sometidos a una elevada densidad poblacional manifiestan un cociente AT/LT o un AL/LT significativamente menor que los pertenecientes a poblaciones con densidades menores, resultando en una forma más alargada de la valva o menos alta (Hickman, 1979; Alunno-Bruscia et al., 2001; Lajtner et al., 2004; Lauzon-Guay et al., 2005).

En contraposición con lo observado en el Capítulo 3, en esta experiencia, la estructura poblacional en el río Coronda mostró una mayor presencia de ejemplares con un LT $<7 \mathrm{~mm}$, mientras que en el río Santiago se observó una mayor presencia de individuos con un LT > 7 $\mathrm{mm}$. Este resultado sugiere que la utilización de jaulas pudo haber favorecido el asentamiento de las postlarvas al ofrecer una mayor superficie disponible, y evitar el desprendimiento de los ejemplares con tallas mayores y la depredación.

Las poblaciones de organismos bentónicos presentan diferencias importantes en aspectos espaciales y temporales entre un año y otro como consecuencia de una interacción íntima con diversos factores y procesos ecológicos (Lizarralde \& Cazzaniga, 2009). Los mejillones responden a todos los estímulos ambientales y, en consecuencia, esto dificulta definir el efecto de un factor aislado sobre la tasa crecimiento (Hickman, 1979). La influencia de la temperatura y la disponibilidad de alimento se han identificado como factores importantes en la determinación de la tasa de crecimiento de los bivalvos (Hickman, 1979; Chase \& Bailey, 1999). Esto coincide con lo observado para distintas especies de bivalvos marinos y de agua dulce. El mejillón Mytilus edulis presenta una mayor tasa de crecimiento de la valva durante la primavera (Hilbish, 1986). Asimismo, se produce un incremento de la valva de Geukensia demissa a lo largo del año, hasta alcanzar su máximo en los meses de verano. Luego de este período, las tasas de crecimiento de las valvas disminuyen (Borrero \& Hilbish, 1988). Lo mismo ocurre con D. polymorpha durante los meses de invierno. Sin 
embargo, se ha establecido que la ausencia de crecimiento es el resultado de las bajas temperaturas o del suministro inadecuado del alimento, o la combinación de ambos u otros factores limnológicos o poblacionales (Neumann et al., 1993). En nuestro estudio, la tasa de crecimiento de L. fortunei, estimada para cada cohorte en ambos sitios de muestreo, fue menor en invierno que en las otras estaciones del año. Los modelos de crecimiento ajustados a las cohortes identificadas en nuestro estudio describieron crecimientos distintos dependiendo la época del año en que se asentaron las postlarvas. Esto concuerda con lo observado por Neumann et al. (1993) para D. polymorpha; si el asentamiento ocurre a finales de primavera o principios de verano, el crecimiento de los juveniles es acelerado, alcanzando tallas de 12 a $14 \mathrm{~mm}$ a principios de invierno. En cambio, si la reproducción ocurre a finales de verano con un asentamiento a finales de otoño, los juveniles alcanzan una talla de $4 \mathrm{~mm}$ antes del invierno. En nuestra experiencia, un ejemplo claro lo proporcionan las cohortes identificadas en las jaulas sumergidas en el río Santiago. La Cohorte 3 con una talla inicial de $3,31 \pm 1,02 \mathrm{~mm}$ a finales de primavera 2007 tuvo a una talla de $15 \pm 3,81 \mathrm{~mm}$ a finales de la primavera de 2008, lo que significó un incremento absoluto de la valva de $11,69 \mathrm{~mm}$. El crecimiento fue explicado por un modelo cuadrático y el punto de inflexión de esta curva ocurrió a finales de otoño, coincidiendo con la disminución de la temperatura del agua. El crecimiento en el invierno fue prácticamente nulo. Por otro lado, la Cohorte 4 tuvo una talla inicial de 5,44 $\pm 1,43 \mathrm{~mm}$ a finales del otoño de 2008 y una talla de 7,33 $\pm 1,78 \mathrm{~mm}$ a finales de la primavera de ese año, es decir que el incremento total de la valva fue de $1,89 \mathrm{~mm}$. A diferencia de la cohorte anterior, el crecimiento ajustó a un modelo exponencial, donde el incremento de LT durante el invierno fue prácticamente nulo y el punto de inflexión de la curva de este modelo se observó en primavera. Exceptuando estos dos casos, el mejor ajuste posible a los datos fue el modelo lineal.

Por otro lado, el análisis comparativo del crecimiento entre ambientes mostró diferencias significativas entre los individuos criados en los ríos Coronda y Santiago. Este resultado confirma lo observado en el Capítulo 3. El crecimiento de la Cohorte 1 fue mayor en el río Coronda que en el Santiago, lo que es compatible con la hipótesis de que las condiciones limnológicas del río Santiago impactan negativamente en el crecimiento de los individuos (ver discusión Capítulo 3). No se pudo establecer una comparación de crecimiento entre los animales enjaulados y los asentados en paneles (Capítulo 3). Sin embargo, especulamos que el crecimiento de los individuos enjaulados debería ser menor que el de los 
individuos asentados en los paneles. Estos últimos, crecieron sin la influencia de alguna barrera física como es la presencia de la red de las jaulas. Varios estudios han estimado tasas de crecimiento menores en animales confinados y sugieren que este resultado es debido a las condiciones creadas por las jaulas. La presencia de la malla y el fouling causado por las algas reducen la circulación del agua a través de las jaulas y dificulta el proceso de alimentación de los individuos en su interior (Seed \& Brown, 1978; Peterson \& Beal, 1989; Bij de Vaate, 1991; Dolmer, 1998). Se ha demostrado que la velocidad de circulación del agua es un factor importante en el crecimiento de los organismos filtradores. Los mejillones que habitan sitios con mayor circulación de agua tienen una tasa de crecimiento mayor (Hickman, 1979).

La medición de la tasa de crecimiento como cambio del largo de valva subestima el crecimiento de mejillones con tallas mayores en términos de biomasa acumulada (Chase \& Bailey, 1999; Garton \& Johnson, 2000). En general, el crecimiento de la valva es continuo, pero a tasas variables en climas templados y para su estimación se tiene en cuenta una dimensión. Los períodos cíclicos de producción y liberación de gametas produce fluctuaciones amplias del peso corporal que puede no necesariamente coinciden con la talla de los individuos (van Ekrom Schurink \& Griffiths, 1993). Nuestros resultados demuestran que el análisis comparativo entre las relaciones alométricas de LT y los pesos (húmedo, seco y libre de cenizas) fueron significativamente diferentes entre los ambientes. El ANCOVA no pudo cuantificar el efecto generado por el factor (sitios). Las pendientes distintas de las rectas alométricas linealizadas indicaron que la interacción de la covariable y el factor son altamente significativos, por lo que no se pudo descartar la covariable (i.e., el ambiente y el LT modificaron conjuntamente los pesos). La prueba F mostró que los pesos (PH, PS, PSLC) de los individuos del río Coronda fueron mayores que los del río Santiago, indicando una mejor condición fisiológica. Estos resultados coincidieron con las diferencias de crecimiento de la valva entre ambientes estimadas en este capítulo y en el anterior. Las condiciones ambientales desfavorables del río Santiago podrían ser un factor determinante en la condición fisiológica de los mejillones en ese ambiente y el responsable de las diferencias de peso observadas. Estos resultados son consistentes con lo observado para D. polymorpha. La relación largo-peso de esta especie varía considerablemente entre ambientes y se considera que esa variación es un indicador de las condiciones ambientales. En ambientes donde las 
condiciones ambientales son desfavorables, la tasa de crecimiento somático es menor. En moluscos, la disminución del peso está asociada con la atrofia del tejido cuando el alimento disponible no satisface las demandas metabólicas (Nalepa et al., 1995; Chase \& Bailey, 1999). Asimismo, varios estudios sobre especies de bivalvos como Perna perna (Linnaeus, 1758), Perna canaliculus (Gmelin, 1791), Mytilus galloprovincialis y Geukensia demissa (Dilwyn, 1817), plantean que las concentraciones elevadas de metales pesados y la insuficiencia de alimento tienen un rol importante como factores estresantes. Los mejillones responden al estrés cerrando las valvas o inhibiendo la producción de biso, la respiración y la filtración; en consecuencia tienen un crecimiento menor y una disminución del peso corporal (Hickman \& Illingwoth, 1980; Franz, 1993; Abada-Boudjema \& Dauvin, 1995; Stirling \& Okumus, 1994, 1995; Alfaro et al., 2008).

La complejidad y variabilidad de los ambientes acuáticos dificultan la identificación de las relaciones causales en el sistema biológico (Lundebye et al., 1997). Una amplia variedad de factores estresantes puede inducir la síntesis de proteína del estrés, con un consecuente gasto metabólico extra. La producción de proteínas del estrés es coincidente con una disminución de la esperanza de vida de los mejillones sometidos a factores estresantes. Nuestros resultados muestran que el IC se correlaciona negativamente con la temperatura y positivamente con el $\mathrm{pH}$. En los estuarios, los niveles de $\mathrm{pH}$ están íntimamente ligados a cambios de salinidad, procesos fotosintéticos y ciclos de oxígeno disuelto (OD). Una reducción de la salinidad, derivada del aporte de agua dulce o de eventos de lluvia, está acompañada por una reducción del pH. Las actividades antropogénicas también afectan el pH y el aporte de nutrientes tiende a exacerbar la magnitud de las fluctuaciones. Los registros extremos de fluctuaciones de $\mathrm{OD}$ y $\mathrm{pH}$ en proximidad de efluentes cloacales son bastante característicos. Varían desde la anoxia hasta una extrema supersaturación, y de niveles tanto altos como bajos de $\mathrm{pH}$ en un período de $24 \mathrm{~h}$. A su vez, los efectos combinados de las toxinas y la acidosis provocan daños irreversibles en los organismos residentes (Ringwood \& Keppler, 2002; Marshall et al., 2008). Por ejemplo, la reducción de pH es deletérea para algunos moluscos como Venerupis decussata. En este bivalvo se observa disolución de la valva a un $\mathrm{pH}$ de 7,5 y fragilidad evidente hasta el punto de fractura de la valva a niveles de $\mathrm{pH}<6,0$. A pH $<7.0$ hay una supresión de la actividad alimentaria y del crecimiento de la valva y del peso del tejido (Bamber, 1987). Bivalvos como Ostrea edulis, Mytilus edulis y 
Crassostrea gigas muestran una respuesta similar a la acidez del agua causada por la descarga de efluentes industriales (Bamber, 1990).

Las variaciones temporales de los pesos reflejan cambios en la productividad, fecundidad o condición fisiológica. El incremento del tamaño corporal está acompañado por la transición de producción somática a producción gamética (Seed \& Suchanek, 1992; Nalepa et al., 1995). A su vez, el peso corporal relacionado con el volumen como dimensión cúbica del tamaño corporal ofrece una estimación más precisa (Garton \& Johnson, 2000). Es ampliamente aceptado que los cambios estacionales en la condición de varias especies de bivalvos resultan de complejas interacciones entre una variedad de factores como disponibilidad de alimento, temperatura, distribución geográfica, calidad ambiental y otros. Estos factores repercuten en las actividades metabólicas de los mejillones, más precisamente en los procesos de crecimiento y reproducción (Seed \& Brown, 1977; Hickman \& Illingwoth, 1980; Seed \& Suchanek, 1992; Ramón et al., 2007). Asimismo, se ha demostrado que la reproducción en los bivalvos es iniciada por un aumento de la temperatura, si el animal posee suficientes reservas o si hay suficiente alimento en el ambiente. Las temperaturas extremas registradas durante el invierno y el verano, junto con un bajo nivel de condición, inhiben la gametogénesis y, subsecuentemente, el desove (Bayne \& Worral, 1980).

En nuestro estudio, el índice de condición (IC) mostró una variación estacional marcada en ambos sitios de muestreo. Los picos principales de IC en los meses de invierno, probablemente relacionados con la etapa significativa de producción de gametas. En los meses cálidos se observó una disminución del IC probablemente asociada con el desove ocurrido en invierno, aunque también se observaron picos de IC de menor magnitud, probablemente relacionado con eventos donde el desove fue parcial. Como se mencionó en la discusión del Capítulo 2, L. fortunei se reproduce continuamente durante 9 a 10 meses. En los meses de invierno se observa una recuperación reproductiva con un incremento del volumen gonadal, y el desove ocurre a temperaturas mayores que $16^{\circ} \mathrm{C}$ (Morton, 1977,1982 ; Cataldo \& Boltovskoy, 1998, 2000; Darrigran et al., 2002; Pestana el al., 2008; Boltovskoy et al., 2009). En D. polymorpha, la gametogénesis y el crecimiento de las gónadas comienzan en invierno cuando la temperatura del agua es baja. El número de gametocitos se incrementa con el aumento de la temperatura. Los oocitos de las hembras de talla grande son liberados en tres veces, o lo que es lo mismo, producen tres cohortes. Si la reproducción es anual, 
cohorte es sinónimo de clase de edad (Bayne \& Worral, 1980; Chase \& Bailey, 1999). Temperaturas por debajo del umbral de desove extienden la fase de crecimiento de la gónada y favorece el aporte de energía para la reproducción. Asimismo, la disponibilidad de alimento es el segundo factor ambiental que controla el volumen y la fecundidad de la gónada. Durante el invierno, a temperaturas por debajo de $12^{\circ} \mathrm{C}$, la multiplicación de los gametocitos comienza luego una fase refractaria de las gónadas. Durante la primavera, cuando la temperatura comienza a aumentar lentamente y la disponibilidad del alimento es suficiente, las gónadas producen el número máximo de gametas (Bij de Vaate, 1991; Neumann et al., 1992; Nalepa et al., 1995). Este fenómeno se repite para otras especies de bivalvos como Perna canaliculus, Mytilus edulis, Mytilus galloprovincialis y Cerastoderma edule (Hickman, 1979; Hickman \& Illingwoth, 1980; Hilbish, 1986; Mallet et al., 1987).

El peso corporal de los bivalvos está definido por un ciclo anual desacoplado del crecimiento de la valva; pero, como se mencionó anteriormente, está relacionado con el desove y la utilización de las reservas (Stirling \& Okumus, 1995). Esto coincide con lo observado por Mallet et al. (1987) en cuanto a que el crecimiento de la valva y del tejido blando es influido por diferentes factores. Los resultados presentados en las figuras 4.3 .11 y 4.3.12 muestran que ejemplares que poseen una talla similar pueden presentar valores de PSCL muy diferentes. Este fenómeno es más evidente en individuos con tallas mayores. Esta variación del peso podría indicar que no todos los individuos desovan al mismo tiempo. Una explicación para la desarticulación entre el crecimiento de la valva y el del tejido es la existencia de un período de balance energético negativo, en el que el tejido blando muestra una disminución del peso, mientras que no ocurre lo mismo con la valva (Hilbish, 1986). Sin embargo, en algunos casos se ha observado que la pérdida de peso corporal no se corresponde con el desove, sino que está relacionado con un incremento acelerado del largo de valva (Hilbish, 1986). Por ejemplo, las tasas de crecimiento del tejido blando de Geukensia demissa son muy variables durante finales de invierno y primavera. A finales de primavera, las tasas de crecimiento son elevadas hasta que ocurre el desove en verano. A fines de la primavera, los mejillones pierden peso mientras que el crecimiento de la valva continúa a tasas altas. A su vez, en el otoño las tasas de crecimiento del tejido blando son elevadas mientras que las de las valvas disminuyen. A diferencia de los bivalvos pequeños, los individuos de mayor edad presentan un crecimiento menor de la valva y experimentan cambios anuales muy amplios en sus tejidos blandos, que están parcialmente relacionados 
con el ciclo reproductivo (Borrero \& Hilbish; 1988). La fertilidad no solo continúa hasta una edad avanzada, sino que frecuentemente se incrementa con la edad y está usualmente correlacionada con el tamaño (Bauer, 1992).

A pesar de las diferencias estimadas de densidad de larvas, densidad de juveniles y adultos, de crecimiento y de índice de condición, ambas poblaciones mostrarían patrones similares en su ciclo de vida. En las figuras 4.4 .1 y 4.4 .2 los óvalos indican los picos de índice de condición, densidad de larvas y juveniles de Limnoperna fortunei estimados en esta tesis, y las flechas representan las progresiones temporales de estos eventos principales. 


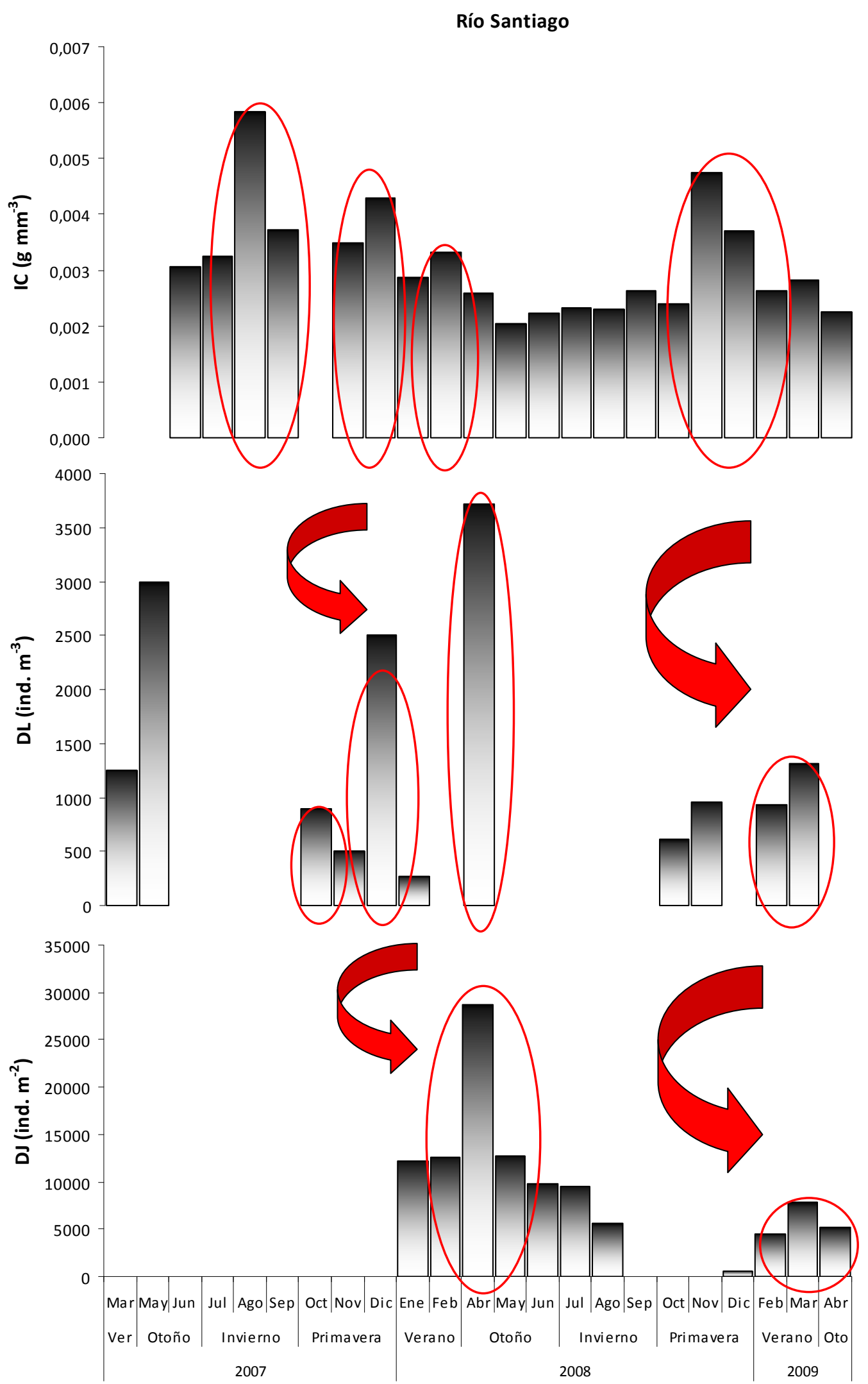

Figura 4.4.1. Dinámica poblacional de individuos de Limnoperna fortunei en el río Santiago. IC: índice de condición; DL: densidad de larvas; DJ: densidad de juveniles en colectores artificiales. Las flechas indican las progresiones temporales de los eventos principales. 


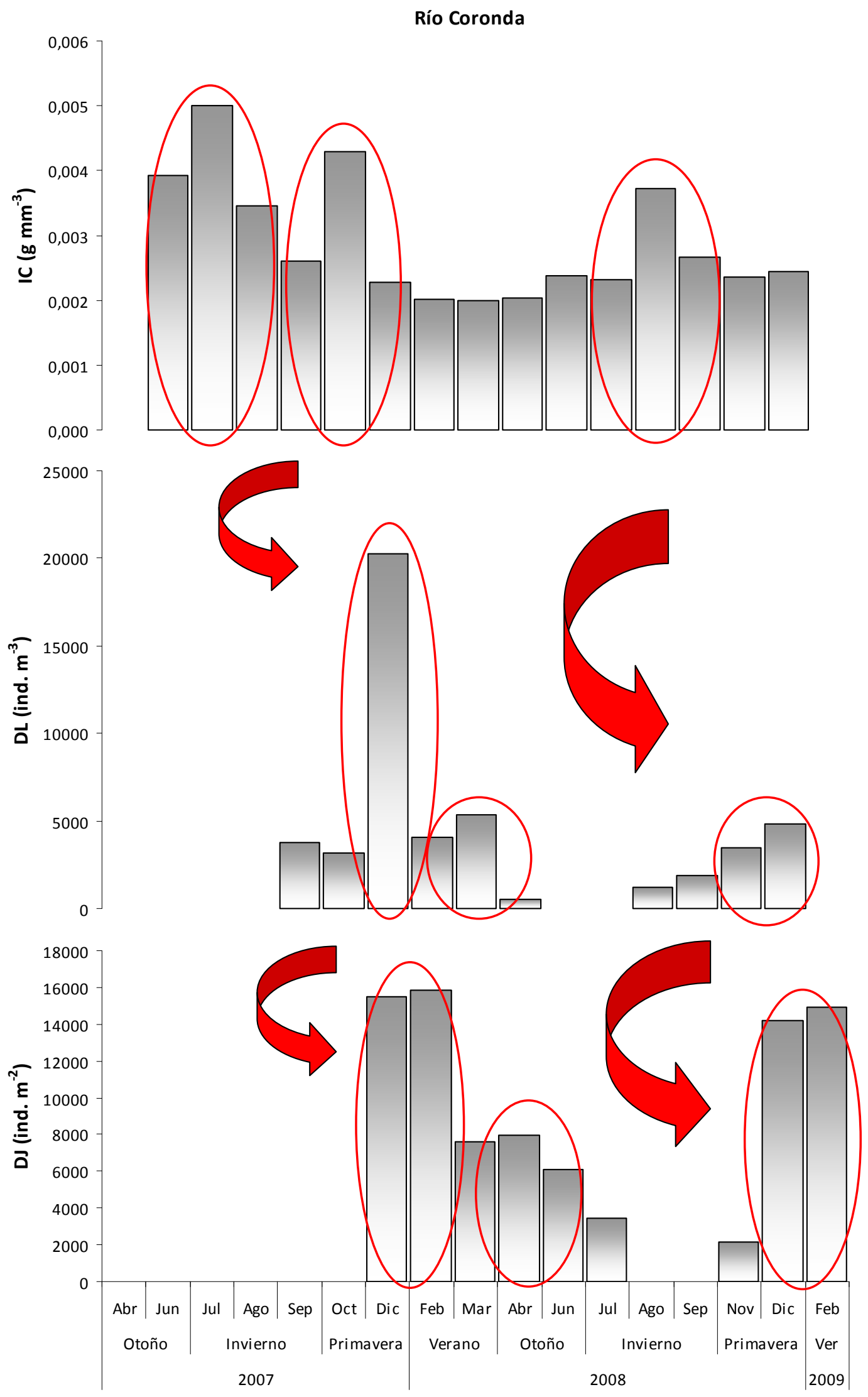

Figura 4.4.2. Dinámica poblacional de individuos de Limnoperna fortunei en el río Coronda. IC: índice de condición; DL: densidad de larvas; DJ: densidad de juveniles en colectores artificiales. Las flechas indican las progresiones temporales de los eventos principales. 
CONCLUSIONES 


\section{CONCLUSIONES}

El análisis comparativo de las variables ambientales mostró diferencias significativas en las características limnológicas entre el río Coronda y el Santiago. Un análisis discriminante permitió ordenar los sitios en función de sus variables más representativas. El río Santiago, estuvo caracterizado por una mayor conductividad, transparencia, y concentración de clorofila $a$ y $b$. Por otro lado, el río Coronda presentó valores mayores de concentración de oxígeno disuelto y pH. Por lo tanto, hemos verificado la hipótesis planteada en el Capítulo 1 de que existen diferencias significativas entre las condiciones limnológicas de los ríos Coronda y Santiago.

Simultáneamente con esas diferencias limnológicas, se verificaron las siguientes similitudes y diferencias biológicas y demográficas entre las poblaciones de Limnoperna fortunei de ambos ambientes:

1) Se observó una correlación positiva entre la densidad de larvas y la temperatura del agua. En ambos sitios de muestreo la densidad total de larvas de Limnoperna fortunei fue nula o con valores muy bajos cuando la temperatura del agua fue menor que 15$16^{\circ} \mathrm{C}$.

2) La densidad total de larvas fue significativamente mayor en el río Coronda que en el Santiago. Como la temperatura del agua no mostró diferencias significativas entre los ambientes, descartamos a esta variable como factor regulador del éxito reproductivo en los rangos de variación observados.

3) La densidad total de individuos asentados en colectores artificiales fue significativamente mayor en el río Coronda que en el río Santiago.

4) En la estructura de tallas de la población asentada en los colectores artificiales sumergidos en el río Santiago predominaron los reclutas ( $\mathrm{LT}<6 \mathrm{~mm}$ ), mientras que en el Coronda fueron dominantes los ejemplares con LT > $7 \mathrm{~mm}$.

5) Las relaciones entre las dimensiones valvares mostraron diferencias morfométricas entre los ejemplares muestreados en un sitio y otro. Los individuos asentados en los colectores sumergidos en el río Coronda tuvieron valvas más alargadas.

6) En la experiencia con colectores artificiales se observó que los individuos del río Coronda crecieron significativamente más rápido que los del río Santiago. 
7) En el ensayo con jaulas experimentales, no se encontraron diferencias significativas en las relaciones morfométricas entre los individuos que crecieron en los ríos Coronda y Santiago.

8) Se encontraron diferencias significativas al comparar las relaciones morfométricas de los mejillones asentados sobre colectores artificiales con las de los individuos que crecieron dentro de jaulas experimentales. Los cocientes de las dimensiones lineales de los mejillones enjaulados fueron menores (valvas más alargadas) que los valores estimados para los individuos provenientes de los colectores.

9) La estimación del crecimiento de los individuos colocados en jaulas experimentales mostró diferencias significativas entre los ríos Coronda y Santiago, siendo mayor para los ejemplares del primer sitio, corroborando lo hallado para los colectores artificiales.

10) Los modelos de crecimiento ajustados a las cohortes identificadas a partir de individuos extraídos de las jaulas describieron crecimientos distintos según la época del año en que se asentaron las postlarvas. Cuando el asentamiento ocurrió a fines de primavera o principios del verano, el crecimiento de los juveniles fue más acelerado. En cambio, cuando la reproducción ocurrió a fines del verano y las larvas se asentaron a fines del otoño, el crecimiento de los juveniles durante el período de bajas temperaturas fue lento y recién se aceleró en primavera.

11) La relación alométrica entre el largo y el peso de los individuos enjaulados fue significativamente diferente entre los ambientes. Los pesos (húmedo, seco y seco libre de cenizas) de los individuos en el río Coronda fueron mayores que los del río Santiago.

12) El índice de condición (IC) mostró una variación estacional marcada en ambos sitios de muestreo. Se observó que los picos de mayor IC ocurrieron en invierno y en algunos meses de primavera.

Este es el primer estudio que compara simultáneamente y con una misma metodología la dinámica poblacional de Limnoperna fortunei en ambientes limnológicamente diferentes.

Los resultados obtenidos en cada uno de los capítulos convergen hacia la idea general de que las condiciones limnológicas del río Santiago influyen negativamente en la dinámica poblacional de este bivalvo respecto de las del río Coronda, sometido a una menor actividad industrial, urbana y de tráfico naviero. 
Se prevé que haya otros factores no considerados en este trabajo que probablemente actúen, individual o sinérgicamente, regulando el éxito reproductivo, el reclutamiento, la morfología, el crecimiento y el índice de condición de esta especie.

La información obtenida en esta tesis es una contribución básica para trabajos posteriores sobre relaciones causales entre las condiciones ambientales y la dinámica poblacional de Limnoperna fortunei. 
REFERENCIAS 


\section{REFERENCIAS}

Abada-Boudjema, Y.-M. \& Dauvin, J.-C.; 1995: Recruitment and life span of two natural mussel populations Perna perna (Linnaeus) and Mytilus galloprovincialis (Lamarck) from the Algerian coast. Journal of Molluscan Studies, 61: 467-481.

AGOSBA-OSN-SIHN (Administración General de Obras Sanitarias Provincia de Buenos Aires Obras Sanitarias de la Nación - Servicio de Hidrografía Naval); 1994: Río de la Plata . Calidad de las aguas de la Franja Costera Sur (San Isidro- Magdalena) Buenos Aires, $168 \mathrm{pp}$.

Alda, P.; Bonel, N.; Cazzaniga, N. J. \& Martorelli, S. M.; 2010: Effects of parasitism and environment on shell size of the South American intertidal mud snail Heleobia australis (Gastropoda). Estuarine, Coastal and Shelf Science, 87(2): 205-310.

Alfaro, A. C.; 2006a: Evidence of cannibalism and bentho-pelagic coupling within the life cycle of the mussel, Perna canaliculus. Journal of Experimental Marine Biology and Ecology, 329: 206-217.

Alfaro, A. C.; 2006b: Population dynamics of the green-lipped mussel, Perna canaliculus, at various spatial and temporal scales in northern New Zealand. Journal of Experimental Marine Biology and Ecology, 334: 294-315.

Alfaro, A. C.; Copp, B. R.; Appleton, D. R.; Kelly, S. \& Jeffs, A. G.; 2006: Chemical cues promote settlement in larvae of the green-lipped mussel, Perna canaliculus. Aquaculture International, 14: 405-412.

Alfaro, A. C.; Webb, S. C. \& Barnaby, C.; 2008: Variability of growth, health, and population turnover within mussel beds of Perna canaliculus in northern New Zealand. Marine Biology Research, 4: 376-383.

Alunno-Bruscia, M.; Bourget, E. \& Fréchette, M.; 2001: Shell allometry and lenght-massdensity relationship for Mytilus edulis in an experimental food-regulated situation. Marine Ecology Progress Series, 219: 177-188.

Andrinolo, D.; Pereira, P.; Giannuzzi, L.; Aura, C.; Massera, S.; Caneo, M.; Caixach, J.; Barco, M. \& Echenique, R.; 2007: Ocurrence of Microcystis aeruginosa and microcystins in the Río de la Plata (Argentina). Acta Toxicológica Argentina, 15: 13-18. 
Anthony, J. L.; Kesler, D. H.; Downing, W. L. \& Downing, J. A.; 2001: Lenght-specific growth rates in freshwater mussels (Bivalvia: Unionidae): extreme longevity or generalized growth cessation? Freshwater Biology, 46: 1349-1359.

APHA, 1998: Standard methods for the examination of water and wastewater. 20 th edition. APHA/AWWA/WPCF, Washington, DC., 1220 pp.

Bamber, R. N.; 1987: The effects of acidic seawater on young carpet-shell clams Venerupis decussata (L.) (Mollusca: Veneracea). Journal of Experimental Marine Biology and Ecology, 108: 241-260.

Bamber, R. N.; 1990: The effects of acidic seawater on three species of lamellibranch mollusc. Journal of Experimental Marine Biology and Ecology, 143: 181-191.

Basu B. K. \& Pick, F. R.; 1996: Factors regulating phytoplankton and zooplankton biomass in temperate rivers. Limnology and Oceanography, 41(7): 1572-1577.

Bauer, G.; 1992: Variation in the life span and size of the freshwater pearl mussel. Journal of Animal Ecology, 61: 425-436.

Bayne, B. L. \& Worral, C. M.; 1980: Growth and production of mussels Mytilus edulis from two populations. Marine Ecology - Progress Series, 3: 317-328.

Belaich, M.; Olivier, C.; Pilloff, M. \& Porta, A.; 2006: Evaluation of a biomarker of Cd (II) exposure on Limnoperna fortunei. Environmental pollution, 144: 208-288.

Belz, C. E. ; Darrigran, G. ; Bonel, N. \& Mädder Netto, O. S.; 2010: Density, recruitment, and shell growth of Limnoperna fortunei (Mytilidae), an invasive mussel in tropical South America. Journal of Freshwater Ecology, 25(2): 227-234.

Bhattacharya, C. G.; 1967: A simple method of resolution of a distribution into Gaussian components. Biometrics, 23: 115-135.

Bij de Vaate, A.; 1991: Distribution and aspects of populations dynamics of the zebra mussel, Dreissena polymorpha (Pallas, 1771), in the lake ljsselmeer area (The Netherlands). Oecologia 86: 40-50.

Blanchard, A. \& Feder, H. M.; 2000: Shell growth of Mytilus trossulus Gould, 1850, in Port Valdez, Alaska. The Veliger, 4(1): 34-42.

Boles, L. C. \& Lipcius, R. N.; 1994: Potential for predator-memdiated biological control of the zebra mussel in the Hudson River estuary. Proceedings of the Fourth International Zebra Mussels Conference, 489-500. 
Boltovskoy, D. \& Cataldo, D. H.; 1999: Population dynamics of Limnoperna fortunei, an invasive fouling mollusc, in the lower Parana river (Argentina). Biofouling 14(3): 255263.

Boltovskoy, D.; Correa, N.; Cataldo, D.; Stripeikis, J. \& Tudino, M.; 1997: Environmental stress on Corbicula fluminea (Bivalvia) in the Paraná River delta (Argentina): complex pollution-related disruption of population structures. Archive für Hydrobiologie, 138(4): 483-507.

Boltovskoy, D.; Correa, N.; Cataldo, D. \& Sylvester, F.; 2006: Dispersion and ecological impact of the invasive freshwater bivalve Limnoperna fortunei in the Río de la Plata watershed and beyond. Biological Invasion, 00: 1-17.

Boltovskoy, D.; Sylvester, F.; Otaegui, A.; Leites, V. \& Cataldo, D. H.; 2009: Environmental modulation of reproductive activity of the invasive mussel Limnoperna fortunei: implications for antifouling strategies. Austral Ecology, 34(7): 719-730.

Borcherding, J.; 1991: The annual reproductive cycle of the freshwater mussel Dreissena polymorpha Pallas in lakes. Oecologia, 87: 208-218.

Borrero, F. J. \& Hilbish, T. J.; 1988: Temporal variation in shell and soft tissue growth of the mussel Geukensia demissa. Marine Ecology - Progress Series, 42: 9-15.

Boschi, E. E.; 1988: El ecosistema estuarial del Río de la Plata (Argentina y Uruguay). Anales del Instituto de Ciencias del Mar y Limnología. Universidad Nacional Autónoma, México, 15(2): 159-182.

Brown, S. R.; 1988: Multivariate análisis of the role of environmental factors in seasonal and site-related growth variation in the Pacific oyster Crassotrea gigas. Marine Ecology Progress Series, 45: 225-236.

Brugnoli, E.; Clemente, J.; Boccardi, L. ; Borthagaray, A. \& Scarabino, F.; 2005: Golden mussel Limnoperna fortunei (Bivalvia: Mytilidae) distribution in the main hydrographical basins of Uruguay: update and predictions. Anais da Academia Brasileira de Ciências, 77(2): 235-244.

Bucher, E.; Bonetto, A.; Boyle, T. P.; Canevari, P.; Castro, G.; Huszar, P.; Stone, T.; 1993: Un examen ambiental inicial de la vía fluvial Paraguay-Paraná. Humedales para las Américas, 10, 74pp. 
Cantanhêde, G.; Hahn, N. S.; Gubiani, É. A. \& Fugi, R.; 2008: Invasive molluscs in the diet of Pterodoras granulosus (Valenciennes, 1821) (Pisces, Doradidae) in the Upper Paraná River floodplain, Brazil. Ecology of Freshwater Fish, 17: 47-53.

Caprari, J. J.; 2006: Pinturas antiincrustantes. En: Darrigran \& Damborenea (eds.). Bioinvasión del mejillón dorado en el continente americano. Edulp, La Plata, 181-211.

Carlton, J.; 1996: Biological invasions and cryptogenic species. Ecology, 77: 1653-1655.

Cataldo, D. \& Boltovskoy, D.; 1998: Variación temporal en la actividad reproductiva de Limnoperna fortunei (Bivalvia) en el Río de la Plata (Argentina). Simpôsio Internacional sôbre Gestão de Recursos Hídricos, Instituto de Pesquisas Hidraulicas, Universidade Federal de Rio Grande do Sul, Pôrto Alegre/Gramado, Brazil, Octubre 1998.

Cataldo, D. \& Boltovskoy, D.; 2000: Yearly reproductive activity of Limnoperna fortunei (Bivalvia) as inferred from the occurrence of its larvae in the plankton of the lower Paraná river and the Río de la Plata estuary (Argentina). Aquatic Ecology, 34: 307-317.

Cataldo, D.; Boltovskoy, D.; Stripeikis, J. \& Pose, M.; 2001: Condition index and growth rates of field caged Corbicula fluminea (Bivalvia) as biomarkers of pollution grajdients in the Paraná river delta (Argentina). Aquatic Ecosystem Health \& Management, 4(2): 187201.

Cataldo, D.; Boltovskoy, D.; Marini, V. \& Correa, N.; 2002: Limitantes de Limnoperna fortunei en la Cuenca del Plata: la predación por peces. Tercera jornada sobre conservación de la fauna íctica en el río Uruguay, 1-5.

Cataldo, D.; Boltovskoy, D.; Hermosa, J. L. \& Canzi, C.; 2005: Temperature-dependant rates of larval development in Limnoperna fortunei (Bivalvia: Mytilidae). Journal of Molluscan Studies, 71: 41-46.

Chase, M. E. \& Bailey, R. C.; 1999: The ecology of the zebra mussel (Dreissena polymorpha) in the lower Great Lakes of North America: I. Populations dynamics and growth. Journal of Great Lakes Research, 25(1): 107-121.

Chen, Y.; Jackson, D. A. \& Harvey, H. H.; 1992: A comparison of von Bertalanffy and polynomial functions in modelling fish growth data. Canadian Journal of Fisheries and Aquatic Sciences, 49: 1228-1235.

Chícharo, L. \& Chícharo, M. A.; 2001: Effects of environmental conditions on planktonic abundances, benthic recruitment and growth rates of the bivalve mollusc Rudatipes deccusatus in a Portuguese coastal lagoon. Fisheries Research, 53: 235-250. 
Choi, S. S. \& Kim, J. S.; 1985: Studies on the metamorphosis and the growth of larvae in Limnoperna fortunei. Korean Journal of Malacology, 1: 13-18.

Choi, S. S. \& Shin, C. N.; 1985: Study on the early development and larvae of Limnoperna fortunei. Korean Journal of Malacology, 1: 5-12.

Claudi, R. \& Mackie, G.; 1994: Monitoring for zebra mussel infestation (chapter 2). In: Claudi \& Mackie (eds.). Practical manual for Zebra Mussel monitoring and control. Lewis publishers, 59-81.

Darrigran, G.; 2002: Potential impact of filter-feeding invaders on temperate inland freshwater environments. Biological Invasion, 4: 145-156.

Darrigran, G. \& Damborenea, C.; 2005: El mejillón dorado Limnoperna fortunei (Dunker, 1857) en la Cuenca del Plata. En: Penchaszadeh (ed.). Invasores: Invertebrados exóticos en el Río de la Plata y región marina aledaña. EUDEBA, Buenos Aires, $1^{\circ}$ ed., 39-102.

Darrigran, G. \& Damborenea, C.; 2011: Ecosystem engineering impact of Limnoperna fortunei in South América. Zoological Science, 28: 1-7.

Darrigran, G. A. \& Ezcurra de Drago, I.; 2000: Invasion of Limnoperna fortunei (Dunker, 1857) (Bivalvia: Mytilidae) in America. Nautilus, 2: 69-74.

Darrigran, G. A. \& Mansur, M. C. D.; 2006: Distribución, abundancia y dispersión. En: Darrigran \& Damborenea (eds.) Bioinvasión del mejillón dorado en el continente americano. EDULP, La Plata, 93-110.

Darrigran, G. A.; Damborenea, C. \& Penchaszadeh, P.; 1998a: A case of hermaphroditism in the freshwater invading bivalve Limnoperna fortunei (Dunker, 1857) (Mytilidae) from Río de la Plata, Argentina. Iberus, 16(2): 99-104.

Darrigran, G.; Martin, S.; Gullo, B. \& Armendáriz, L.; 1998b: Macroinvertebrates associated with Limnoperna fortunei (Dunker, 1857) (Bivalvia, Mitylidae) in Río de la Plata, Argentina. Hidrobiology, 367: 223-230.

Darrigran, G. \& Pastorino, G.; 1995: The recent introduction of asiatic bivalve, Limnoperna fortunei (Mytilidae) into South America. The veliger, 38(2): 183-187.

Darrigran, G. \& Pastorino, G.; 2004: Distribution of the golden mussel Limnoperna fortunei (Dunker, 1857), (Bivalvia, Mytilidae) after 10 years invading America. Journal of Conchology, 3: 95-101. 
Darrigran, G.; Penchaszadeh, P. \& Damborenea, C., 1999: The reproductive cycle of Limnoperna fortunei (Dunker, 1857) (Mytilidae) from a neotropical temperate locality. Journal of Shellfish Research, 18(2): 361-365.

Darrigran, G.; Penchaszadeh, P.; Damborenea, C. \& Greco, N.; 2002: Abundance and distribution of the golden mussel Limnoperna fortunei larvae in a Hydroelectic Power Plant in South America. In: Proceedings of the 11th International Aquatic Nuisance Species and Zebra Mussel Conference, Alexandria, USA, 25-28 February 2002, 312$316 \mathrm{pp}$.

Darrigran, G.; Damborenea, C.; Penchaszadeh, P. \& Taraborelli, C.; 2003: Reproductive stabilization of Limnoperna fortunei (Bivalvia Mytilidae) after ten years of invasion in the Americas. Journal of Shellfish Research, 22(1): 00-00.

Darrigran, G.; Boeger, W.; Damborenea, C. \& Maroñas, M.; 2009: Evaluation of sampling and analysis techniques for early detection of Limnoperna fortunei (Mytilidae) in limit areas of its distribution. Brazilian Journal of Biology, 69(9): 979-980.

Darrigran, G., Bonel, N.; Colautti, D. \& Cazzaniga, N. J. (en prensa): an alternative method to assess individual growth of the golden mussel in the wild. Journal of Freshwater Ecology.

Da Silva, D.; 2006: Aspectos bioecológicos do mexhilao dourado Limnoperna fortunei (Bivalvia,Mytilidae) (Dunker, 1857). Tese apresentada ao curso de pósgraduaçao em Engernharia Florestal da Universidade Federal do Parará como requisito parcial para a obtençao do título de Doutor, Curitiba.

de Vooys, C. G. N.; 1999: Numbers of larvae and primary plantigrades of the mussel Mytilus edulis in the western Dutch Wadden Sea. Journal of Sea Research, 41: 189-201.

Depetris, P. J. \& Kempe, S.; 1993: Carbon dynamics and sources in the Paraná River. Limnology and Oceanography, 38(2): 382-395.

Devercelli, M. \& Peruchet, E.; 2008: Trends in chlorophyll-a concentration in urban water bodies within differet man-used basins. Annales de Limnologie - International Journal of Limnology, 44(1): 75-84.

Dionisio Pires, L. M.; Karlsson, K.; Meriluoto, J. A. O.; Kardinaal, E.; Visser, P. M.; Siewertsen, K.; Van Donk, E. \& Ibelings, B. W.; 2004: Assimilation and depuration of microcystin-LR by the zebra mussel, Dreissena polymorpha. Aquatic Toxicology, 69: 385-396. 
Dobretsov, S. \& Miron, G.; 2001: Larval and post-larval vertical distribution of the mussel in the White Sea. Marine Ecology - Progress Series, 218: 179-187.

Dolmer, P.; 1998: Seasonal and spatial variability in growth of Mytilus edulis L. in a brackish sound: comparisons of individual mussel growth and growth of size classes. Fisheries Research, 34(1): 17-26.

Dorgelo, J.; 1992: Growth and population structure of the zebra mussel (Dreissena polymorpha) in Dutch Lakes differing in trophic state (Chapter 4). In: Nalepa \& Schloesser (eds.). Zebra mussels: Biology, impacts and control. Lewis Publishers, 129142.

dos Santos, C. P., Mansur, M. C. \& Würdig, N. L., 2008: Variações no comprimento dos indivíduos de uma população de mexhilão dourado, Limnoperna fortunei (Molusca: Bivalvia: Mytilidae), ao longo do ano, na Praia do Veludo, Lago Guaíba, Rio Grande do Sul, Brasil. Revista Brasileira de Zoologia, 25(3): 389-396.

Echenique, R.; Rodríguez, J.; Caneo, M.; Gianuzzi, L.; Barco, M.; Rivera, J.; Caixach, J. \& Andrinolo, D.; 2006: Microcystins in the drinking water supply in the cities of Ensenada and La Plata (Argentina). Congresso Brasileiro de Ficologia, 11. Simpósio Latinoamericano sobre Algas Nocivas, Itajaí, SC. Aplicações da Ficologia: Rio de Janeiro: Museu Nacional. p. 141-148.

Edmonson, W. T.; 1980: Secchi disk and chlorophyll. Limnology and Oceanography, 25(2): 378-379.

Edzwald, J. K. \& O'Melia, C. R.; 1975: Clay distributions in recent estuarine sediments. Clays and Clay Minerals, 23: 39-44.

Edzwald, J. K.; Upchurch, J. B. \& O’Melia, C. R.; 1974: Coagulation in estuaries. Environmental Science \& Technology, 8(1): 58-63.

Everbecq, E.; Gosselain, V., Viroux, L. \& Descy, J. P.; 2001: Potamon: a dynamic model for predicting phytoplankton composition and biomass in lowland rivers. Water Research, 35(4): 901-912.

Ezcurra de Drago, I.; Montalto, L. \& Oliveros, O.; 2006: Desarrollo y ecología larval de Limnoperna fortunei. En: Darrigran \& Damborenea (eds.) Bioinvasión del mejillón dorado en el continente americano. EDULP, La Plata, 83-91. 
Fedato, R. P.; Simonato, J. D.; Martinez, C. B. R. \& Sofia, S. H.; 2010: Genetic damage in the bivalve mollusk Corbicula fluminea induced by the water-soluble fraction of gasoline. Mutation Research, 700: 80-85.

Fraleigh, P.; Klerks, P.; Gubanich, G.; Matisoff, G. \& Stevenson, R.; 1993: Abundance and settling of zebra mussel (Dreissena polymorpha) veligers in western and central Lake Erie (Chapter 7). In: Nalepa \& Schloesser (eds.). Zebra mussels: Biology, impacts and control. Lewis Publishers, 129-142.

Framiñán, M. B. \& Brown, O. B.; 1996: Study of the Río de la Plata turbidity front, Part I: spatial and temporal distribution. Continental Shelf Research, 16(10): 1259-1289.

Franz, D. R.; 1993: Allometry of shell and body weight in relation to shore level in the intertidal bivalve Geukensia demissa (Bivalvia: Mytilidae). Journal of Experimental Marine Biology and Ecology, 174: 193-207.

French, J. R. P.; 1993: How well can fishes prey on zebra mussels in eastern North America? Fisheries, 18(6): 13-19.

Ganesan, M. A.; Alfaro, A. C.; Brooks, J. D. \& Higgins C. M.; 2010: The role of bacterial biolfilm and exudates on the settlement of mussel (Perna canaliculus) larvae. Aquaculture, 306: 388-392.

García de Emiliani, M. O. \& Devercelli, M.; 2004: Estructura y dinámica del fitoplancton de un río tributario (Salado) y cauces secundarios del río Paraná (Santa Fe, Coronda y El Vado) en el área de confluencia (Santa Fe, Argentina). Revista FABICIB, 8: 23-42.

Garton, D. W. \& Haag, W.; 1993: Seasonal reproductive cycles and settlement patterns of Dreissena polymorpha in western lake Erie (Chapter 6). In: Nalepa \& Schloesser (eds.). Zebra mussels: Biology, impacts and control. Lewis Publishers, 111-128.

Garton, D. W. \& Johnson, L. E.; 2000: Variation in growth rates of the zebra mussel, Dreissena polymorpha, within Lake Wawasee. Freshwater Biology, 45: 443-451.

Gayanilo, F. C. Jr.; Sparre, P. \& Pauly, D.; 1996: FAO-ICLARM Stock Assessment tools. - FAO Computerized Information Series (Fisheries), pp 23.

Gómez, N.; Hualde, P. R.; Licursi, M. \& Bauer, D. E.; 2004: Spring phytoplankton of Río de la Plata: a temperate estuary of South America. Estuarine, Coastal and Shelf Science, 61: 301-309. 
Hadfield, M. G. \& Paul, V. J.; 2001: Natural chemical cues for settlement and metamorphosis of marine invertebrate larvae. In: McClintock, J. B. \& Baker, W. (eds). Marine Chemical Ecology, CRC Press, USA, 431-461 pp.

Hair, J. F.; Anderson, Jr. R. E.; Tatham, R. L. \& Black, W. C.; 1999: Análisis Multivariante, $5^{\text {th }}$ Edition Prentice Hall Iberia, Madrid, 832 pp.

Hebert, P. D. N.; Wilson, C. C.; Murdoch, M. H. \& Lazar, R.; 1991: Demography and ecological impacts of the invading mollusc Dreissena polymorpha. Canadian Journal of Zoology, 69: 405-409.

Hickman, R. W.; 1979: Allometry and growth of the the green-lipped mussel Perna canaliculus in New Zealand. Marine Biology, 51: 311-327.

Hickman, R. W. \& Illingwoth, J.; 1980: Condition cycle of the green-lipped mussel Perna canaliculus in New Zealand. Marine Biology, 60: 27-38.

Hicks, D. W.; Tunnell, J. W. \& McMahon, R. F.; 2001: Population dynamics of the nonindigenous brown mussel Perna perna in the Gulf of Mexico compared to other worldwide populations. Marine Ecology - Progress Series, 211: 181-192.

Hilbish, T. J.; 1986: Growth trajectories of shell and soft tissue in bivalves: seasonal variation in Mytilus edulis L. Journal of Experimental Marine Biology and Ecology, 96: 103-113.

Horvath, T. G. \& Lamberti, G. A.; 1999: Recruitment and growth of zebra mussels (Dreissena polymorpha) in a coupled lake-stream system. Archive für Hydrobiologie, 145(2): 197217.

Iwasaky, K. \& Uryu, Y.; 1998: Life cycle of a freshwater mytilid mussel, Limnoperna fortunei, in Uji river, Kyoto. Venus, 57(2): 105-113.

Juhel, G.; Davenport, J.; O’Halloran, J.; Culloty, S. C.; O’Riordan, R. M.; James, K. F.; Furey, A. \& Allis, O.; 2006: Impacts of microcystins on the feding behavior and energy balance of zebra mussels, Dreissena polymorpha: A bioenergetics approach. Aquatic Toxicology, 79: 391-400.

Karatayev, A. Y.; Boltovskoy, D.; Padilla, D. K. \& Burlakova, L. E.; 2007: The invasive bivalves Dresissena polymorpha and Limnoperna fortunei: parallels, contrasts, potential spread and invasions impacts. Journal of Shellfish Research, 26(1): 205-213.

Kurucz, A.; Masello, A.; Méndez, S.; Cranston, P. \& Wells, P. G.; 1998: Calidad ambiental del Río de la Plata . En: Wells P. G. y Daborn G. R. (eds.) El Río de la Plata. Una Revisión 
Ambiental. Un informe de Antecedentes del Proyecto EcoPlata. Dalhousie University, Halifax, Nova Scotia, Canada, 256 p.

Lajtner, J.; Marušić, Z.; Klobučar, G. I. V.; Maguire, I. \& Erben, R.; 2004: Comparative shell morphology of the zebra mussel, Dreissena polymorpha in the Drava River (Croatia). Biologia, 59(5): 595-600.

Laughlin, R. B.; Gustafson, R. Jr. \& Pendoley, P.; 1988: Chronic embryo-larval toxicity of tribultyltin (TBT) to the hard shell clam Mercenaria mercenaria. Marine Ecology Progress Series, 48: 29-36.

Lauzon-Guay, J.-S.; Hamilton, D. J. \& Barbeau, M. A.; 2005: Effect of mussel density and size on the morphology of blue mussels (Mytilus edulis) grown in suspended culture in Prince Edward Island, Canada. Aquaculture, 249: 265-274.

Lehane, C. \& Davenport, J.; 2004: Ingestion of bivalve larvae by Mytilus edulis: experimental and field demonstration of larviphagy in farmed blue mussels. Marine Biology, 145: 101-107.

Lévêque, C.; 1971: Équation de von Bertalanffy et croissance des mollusques benthiques du Lac Tchad. Cahier O.R.S.T.O.M., série Hydrobiologia. 5(3-4): 263-283.

Lizarralde, Z. I. \& Cazzaniga, N. J.; 2009: Population dynamics and production of Tellina petitiana (Bivalvia) on a sandy beach of Patagonia, Argentina. Thalassas, 25(1): 45-57.

Loez, C.; 1995: Determinación de clorofila $a$. En: Lopretto \& Tell (eds.) Ecosistema de aguas continentales. Ediciones Sur, La Plata, 263-269.

López Armengol, M. F. \& Casciotta J. R.; 1998: First record of the predation of the introduced freshwater bivalve Limnoperna fortunei (Mytilidae) by the native fish Micropogonias furnieri (Sciaenidae) in the Río de la Plata estuary, South América. Iberus, 16(2): 105108.

López Laborde, J.; 1998: Marco geomorfológico y geológico del Río de la Plata. En: Wells P. G. y Daborn G. R. (eds.) El Río de la Plata. Una Revisión Ambiental. Un informe de Antecedentes del Proyecto EcoPlata. Dalhousie University, Halifax, Nova Scotia, Canada, 256 pp.

Lundebye, A. K.; Langston, W. J. \& Depledge, M. H.; 1997: Stress proteins and condition index as biomarkers of tribultyltin exposure and effect in mussels. Ecotoxicology, 6: 127136. 
Maclsaac, H. J.; Sprules, W. G. \& Leach, J. H.; 1991: Ingestion of small-bodied zooplankton by zebra mussels (Dreissena polymorpha): can cannibalism on larvae influence population dynamics? Canadian Journal of Fisheries and Aquatic Sciences, 48: 20512060.

Magara, Y.; Matsui, Y.; Goto, Y. \& Yuasa, A.; 2001: Invasion of the non-indigenous nuisance mussel, Limnoperna fortunei, into water supply facilities in Japan. Journal of Water Supply: Research and Technology-AQUA, 50(3): 13-24.

Maheu, C.; Cazenave, A. \& Mechoso, C.; 2003: Water level fluctuations in the Plata Basin (South America) from Topex/Poseidon Satellite Altimetry. Geophysical Research Letters, 30(3): 1143.

Mallet, A. L.; Carver, C. E. A.; Coffen, S. S. \& Freeman, K. R.; 1987: Winter growth of the blue mussel Mytilus edulis L.: importance of stock and site. Journal of Experimental Marine Biology and Ecology, 108: 217-228.

Mansur, M. C. D. ; dos Santos, C. P.; Darrigran, G.; Heydrich, I.; Callil, C. T. \& Cardoso, F. R.; 2003: Primeros dados quali-quantitativos do mexilhão-dourado, Limnoperna fortunei (Dunker), no delta do Jacuí, no lago guaíba e na Laguna dos Patos, Rio Grande do Sul, Brasil e alguns aspectos de sua invasão no novo ambiente. Revista Brasileira de Zoloogia, 20: 75-84.

Margalef, R.; 1983: Limnología. Barcelona, 1010 pp.

Maroñas, M.; Darrigran, G.; Sendra, E. \& Breckon, G.; 2003: Shell growth of the golden mussel, Limnoperna fortunei (Dunker, 1857) (Mytilidae), from a Neotropical temperate locality. Hydrobiologia, 495: 41-45.

Marshall, D. J.; Santos, J. H.; Leung, K. M. Y. \& Chak, W. H.; 2008: Correlations between gastropod shell dissolution and water chemical properties in a tropical estuary. Marine Environmental Research, 66: 422-429.

Martel, A.; Mathieu, A. F.; Findlay, C. S.; Nepsy, S. J. \& Leach, J. H.; 1994: Daily settlements rates of zebra mussel, Dreissena polymorpha, on an artificial substrate correlate with veliger abundance. Canadian Journal of Fisheries and Aquatic Sciences, 51: 856-861.

McMahon, R. F. \& Bogan, A. E.; 2001: Mollusca: Bivalvia. In: Thorn, J. H. \& Covich, A. P. (eds.): Ecology and Classification of North American Freshwater Invertebrate. Academic Press, San Diego, 331-429 pp. 
Menéndez, A. N.; 2001: Description and modeling of the hydrosedimentologic mechanisms in the Río de la Plata River, VII International Seminar on Recent Advances in Fluid Mechanics, Physics of Fluids and Associated Complex systems, Buenos Aires, Argentina.

Molloy, D. P.; Powell, J. \& Ambrose, P.; 1994: Short-term reduction of adult zebra mussels (Dreissena polymorpha) in the Hudson River near Castkill, New York: an effect of juvenile blue crab (Callinectes sapidus) predation? Journal of Shellfish Research, 13(2): 367-371.

Montalto, L. \& Marchese, M.; 2003: Limnoperna fortunei (Dunker, 1857) (Bivalvia: Mytilidae) tolerance to temperature and $\mathrm{pH}$ in experimental conditions. Neotrópica, 49: 26-34.

Montalto, L.; Oliveros, O. B.; Ezcurra de Drago, I. \& Demonte, L. D.; 1999: Peces del río Paraná medio predadores de una especie invasora: Limnoperna fortunei (Bivalvia, Mytilidae). Revista FABICIB, 3: 85-501.

Mörtl, M. \& Rothhaupt, K. -O.; 2003: Effects of adult Dreissena polymorpha on settling juveniles and associated macroinvertebrates. International Review of Hydrobiology, 88(6): 561-569.

Morton, B.; 1977: The population dynamics of Limnoperna fortunei (Dunker, 1857) (Bivalvia: Mytilacea) in Plover Cove reservoir, Hong Kong. Malacologia, 16(1): 165-182.

Morton, B.; 1982: The reproductive cycle in Limnoperna fortunei (Dunker, 1857) (Bivalvia, Mytilidae) fouling Hong Kong's raw water supply system. Oceanologia et Limnologia Sinica, 13(4): 319-324.

Motulsky, H. J.; 2007: Prism 5 Statistics Guide. GraphPad Software Inc., San Diego CA, www.graphpad.com.

Nagy, G. J.; Martínez, C. M.; Caffera, R. M.; Pedrosa, G.; Forbes, E. A.; Perdomo, A. C. \& López Laborde, J.; 1998: Marco hidrológico y climático del Río de la Plata. En: Wells P. G. y Daborn G. R. (Eds) El Río de la Plata. Una Revisión Ambiental. Un informe de Antecedentes del Proyecto EcoPlata. Dalhousie University, Halifax, Nova Scotia, Canada, 256 pp.

Nakano, D.; Kobayashi, T. \& Sakaguchi, I.; 2010a: Differences in larval dynamics of golden mussel Limnoperna fortunei between dam reservoirs with and without an aeration system. Landscape and Ecology Engeneering, 6: 53-60. 
Nakano, D.; Kobayashi, T. \& Sakaguchi, I.; 2010b: Predation and depth effects on abundance and size distribution of an invasive bivalve, the golden mussel Limnoperna fortunei, in a dam reservoir. Limnology, 11: 259-266.

Nakano, D.; Kobayashi, T.; Endo, N. \& Sakaguchi, I.; 2011: Growth rate and settlement of Limnoperna fortunei in a temperate reservoir. Journal of Molluscan Studies, 77(2): 142-148.

Nalepa, T. F.; Wojcik, J. A.; Fanslow, D. L. \& Lang, G. A.; 1995: Initial colonization of the zebra mussel (Dresissena polymorha) in Saginaw Bay, Lake Huron: population recruitment, density, and size structure. Journal of Great Lakes Research, 21(4): 417-434.

Narváez, N.; Lodeiros, C.; Nusetti, O.; Lemus, M. \& Martínez Maeda, A. N.; 2005: Incorporación, depuración y efecto del Cadmio en el mejillón verde Perna viridis (L. 1758) (Mollusca: Bivalvia). Ciencias Marinas, 31(1A): 91-102.

Neumann, D.; Borcherding, J. \& Jantz, B.; 1993: Growth and seasonal reproduction of Dreissena polymorpha in the Rhine River and adjacents waters (Chapter 5). In: Nalepa \& Schloesser (eds.). Zebra mussels: Biology, impacts and control. Lewis Publishers, 97109.

Nichols, S. J.; 1993: Spawning of zebra mussel (Dreissena polymorpha) and rearing of veligers under laboratory conditions (Chapter 20). In: Nalepa \& Schloesser (eds.). Zebra mussels: Biology, impacts and control. Lewis Publishers, 315-329.

Nichols, S. J.; 1996: Variations in the reproductive cycle of Dreissena polymorpha in Europe, Russia, and North America. American Zoologist, 36: 311-325.

Oliveira, M. D.; Takeda, A. M.; Fernandes de Barros, L.; Barbosa, D. S. \& Kawakami de Resende, E.; 2006: Invasion by Limnoperna fortunei (Dunker, 1857) (Bivalvia, Mytilidae) of the Pantanal wetland, Brazil. Biological Invasions, 8: 97-104.

Orensanz, J. M.; Shwindt, E.; Pastorino, G.; Bortolus, A.; Casas, G.; Darrigran, G.; Elías, R.; López Gappa, J. J.; Obenat, S.; Pascual, M.; Penchaszadeh, P.; Piriz, M. L.; Scarabino, F.; Spivak, D. S. \& Vallarino, E. A.; 2002: No longer the pristine confines of the world ocean: a survey of exotic marine species in southwestern Atlantic. Biological Invasions, 4: 115-143.

Oteiza, J. M.; Ouahid, Y.; Baron, A.; Andrinolo, D.; Echenique, R.; Giannuzzi, L.; Caneo, M. \& Fernández del Campo, F.; 2007: Utilización de marcadores moleculares para la detección de Microcystis potencialmente tóxicas en cuerpos de agua de la Provincia 
de Buenos Aires. Primer reporte. Revista Ciencia Forense Latinoamericana, 1(1): 2431.

Paolucci, E. M.; Cataldo, D. H.; Fuentes, C. \& Boltovskoy, D.; 2007: Larvae of the invasive species Limnoperna fortunei (Bivalvia) in the diet of fish larvae in the Paraná River, Argentina. Hydrobiologia, 589: 219-233.

Paolucci, E. M.; Thuesen, E. V.; Cataldo, D. H. \& Boltovskoy, D.; 2010: Veligers of an introduced bivalve, Limnoperna fortunei, are a new food resource that enhances growth of larval fish in the Paraná River (South America). Freshwater Biology, 55(9): 1831-1844.

Paolucci, E. M.; Cataldo, D. H. \& Boltovskoy, D.; 2009: Prey selection by larvae of Prochilodus lineatus (Pisces: Curimatidae): indigenous zooplankton versus veligers of the introduced bivalve Limnoperna fortunei (Bivalvia: Mitilidae). Aquatic Ecology, 45: 255267.

Pastorino, G.; Darrigran G.; Martin S. M. \& Lunaschi L.; 1993: Limnoperna fortunei (Dunker, 1857) (Mytilidae), nuevo invasor en aguas del Río de la Plata. Neotropica, 39(101102): 34 .

Pauly, D. \& Caddy, J. F.; 1985: A modification of Bhattacharya's method for analysis of mixtures of normal distributions. FAO Fisheries Circular, 781: 1-16.

Penchaszadeh, P.; Darrigran, G.; Angulo, C.; Averbuj, A.; Brignoccoli, N.; Brögger, M.; Dogliotti, A. \& Pírez, N.; 2000: Predation on the invasive freshwater mussel Limnoperna fortunei (Dunker, 1857) (Mytilidae) by the fish Leporinus obtusidens Valenciennes, 1846 (Anostomidae) in the Río de la Plata, Argentina. Journal of Shellfish Research, 19: 229-231.

Perry, W. L.; Lodge, D. M. \& Lamberti, G. A.; 1997: Impact of crayfish predation on exotic zebra mussels and native invertebrades in a lake-outlet stream. Canadian Journal of Fisheries and Aquatic Sciences, 54: 120-125.

Pestana, D.; Roberto Pie, M.; Ostrensky, A.; Boeger, W. A.; Andreoli, C.; Franceschi, F. \& Lagos, P.; 2008: Seasonal variation in larval density of Limnoperna fortunei (Bivalvia, Mytilidae) in the Iguaçu and Paraná rivers, in te region of Foz do Iguaçu, Paraná, Southern Brazil. Brazilian Archives of Biology and Technology, 51(3): 607-612.

Peterson, C. H. \& Beal, B. F; 1989: Bivalve growth and higher order interactions: importance of density, site, and time. Ecology, 70(5): 1390-1404. 
Petrie, S. A. \& Knapton, R. W.; 1999: Rapid increase and subsequent decline of zebra and quagga mussels in Long Point Bay, Lake Erie: possible influence of waterfowl predation. Journal of Great Lakes Research, 25(4): 772-782.

Pizarro, M. J. \& Orlando, A. M.; 1984: Distribución de fósforo, nitrógeno y silicio disuelto en el Río de la Plata. Servicio de Hidrografía Naval, Publicación Hidrográfica, 625: 1-57.

Porri, F.; Tembisa, J. \& McQuaid, C. D.; 2008: Does cannibalism of larvae by adults affect settlement and connectivity of mussels populations? Estuarine, Coastal and Shelf Science, 79: 687-689.

Ramón, M.; Fernández, M. \& Galimany, E.; 2007: Development of mussel (Mytilus galloprovincialis) seed from two different origins in a semi-enclosed Mediterranean Bay (N.E. Spain). Aquaculture, 264: 148-159.

Reynolds, C. S.; 1988: Potamoplankton: paradigms, paradoxes and prognoses. In: Round, F. E. (ed.): Algal and the aquatic environment. Biopress, Bristol, 285-311 pp.

Ricciardi, A.; 1998: Global range expansion of the asian mussel Limnoperna fortunei (Mytilidae): another fouling threat to freshwater systems. Biofouling, 13(2): 97-106.

Ringuelet, R. A.; 1967: Contaminación o polución del ambiente acuático con referencia especial a la que afecta el área platense. AGRO, publicación técnica, año IX, no 15: 533.

Ringwood, A. H. \& Keppler, C. J.; 2002: Water quality variation and clam growth: is pH really a non-issue in estuaries? Estuaries, 25(5): 901-907.

Rojas Molina, F.; Paggi, J. C. \& Dervecelli, M.; 2009: Zooplanktophagy in the natural diet and selectivity of the invasive mollusk Limnoperna fortunei. Biological Invasions, 12(6): 1647-1659.

Ronco, A.; Camilión, C. \& Manassero, M.; 2001: Geochemistry of heavymetals in bottom sediments from streams of the western coast of the Rio de la Plata estuary, Argentina. Environmental Geochemistry and Health, 23: 89-103.

Rumi, A.; Gutiérrez Grégoric, D.; Núñez, V. \& Darrigran, G. A.: Malacología Latinoamericana. Moluscos de agua dulce de Argentina. Revista de Biología Tropical, 56(1): 77-111.

Salazar, M. H. \& Salazar, S. M.; 1988: Tributyltin and mussel growth in San Diego Bay. Proceedings Oceans '88, Vol. 4: International Organotin Symposium, Marine Technology Society, Washington, DC. USA, pp 1188-1197. 
Sardiña, P.; Cataldo, D. H. \& Boltovskoy, D.; 2009: Effects of conspecifics on settling juveniles of the invasive golden mussel, Limnoperna fortunei. Aquatic Sciences, 71(4): 479-486.

Seed, R. \& Brown, R. A.; 1977: A comparison of the reproductive cycles of Modiolus modiolus (L.), Cerastoderma (= Cardium) edule (L.), and Mytilus edulis L. in Stramgford Lough, Northern Ireland. Oecologia, 30: 173-188.

Seed, R. \& Brown, R. A.; 1978: Growth as a strategy for survival in two marine bivalves, Cerastoderma edule and Modiolus modiolus. Journal of Animal Ecology, 47(1): 283292.

Seed, R. \& Suchanek, T. H.; 1992: Population and community ecology of Mytilus. In: Gosling, E. M. (ed.) The Mussel Mytilus: Ecology, Physiology, Genetics and Culture. Elsevier, Amsterdam, 87-169.

Seitz, R. D.; Lipcius, R. N.; Hines, A. H. \& Eggleston, D. B.; 2001: Density-dependent predation, habitat variation, and the presistence of marine bivalve prey. Ecology, 82(9): 24352451.

Shim, W. J.; Oh, J. R.; Kahng, S. H.; Shim, J. H. \& Lee, S. H.; 1998: Accumulation of Tributyland Triphenyltin compounds in Pacific Oyster, Crassostrea gigas, from the Chinhae Bay System, Korea. Archives of Environmental Contamination and Toxicology, 35: 4147.

Showalter, S. \& Saravese, J.; 2005: Restrictions on the use of marine antifouling paints containing tributyltin and copper. MASGP 04-052. http://nsglc.olemiss.edu/Advisory/ Antifouling.pdf

Smit, H.; Bij de Vaate, A. \& Fioole, A.; 1992: Shell growth of the zebra mussel (Dreissena polymorpha (Pallas)) in relation to selected physicochemical parameters in the Lower Rhine and some associated lakes. Archive für Hydrobiologie. 124(3): 257-280.

Steciow, M. M.; 1998: Variación estacional de los Oomycetes en un ambiente contaminado: río Santiago y afluentes (Buenos Aires, Argentina). Revista Iberoamericana de Micología, 15: 40-43.

Stirling, H. P. \& Okumus, I.; 1994: Growth, mortality and shell morphology of cultivated mussel (Mytilus edulis) stock cross-planted between two Scotish sea Lochs. Marine Biology, 119: 115-123. 
Stirling, H. P. \& Okumus, I.; 1995: Growth and production of mussels (Mytilus edulis L.) suspended at salmon cages and shellfish farms in two Scottish sea lochs. Aquaculture, 134: 193-210.

Strayer, D. L. \& Malcom, H. M.; 2006: Long-term demography of a zebra mussel (Dreissena polymorpha) population. Freshwater Biology, 51: 117-130.

Sturges, H. A.; 1926: The choice of a class interval. Journal of the American Statistical Association, 21: 65-66.

Sukhotin, A. A. \& Pörtner, H.-O.; 2001: Age-dependece of metabolism in mussels Mytilus edulis (L.) from the White Sea. Journal of Experimental Marine Biology and Ecology, 257: 53-72.

Sylvester, F.; Dorado, J.; Boltovskoy, D.; Juárez, A. \& Cataldo, D.; 2005: Filtration rates of the invasive pest bivalve Limnoperna fortunei as a function of size and temperature. Hydrobiologia, 534: 117-130.

Sylvester, F.; Boltovskoy, D. \& Cataldo, D. H.; 2007: Fast response of freshwater consumers to a new trophic resource: predation on the recently introduced Asian bivalve Limnoperna fortunei in the lower Paraná River, South America. Austral Ecology, 32: 403-415.

Taraborelli, A. C.; Damborenea, M. C.; Penchaszadeh, P. \& Darrigran, G.; 2001: Ciclo reproductivo del bivalvo invasor Limnoperna fortunei (Mytilidae) en la región Neotropical de clima templado. Actas Seminario Internacional sobre gestión ambiental e Hidroelectricidad, 25-33.

Thill, A.; Moustier, S.; Garnier, J. M.; Estournel, C.; Naudin, J. J. \& Bottero, J. Y.; 2001: Evolution of particle size and concentration in the Rhône river mixing zone: influence of salt flocculation. Continental Shelf Research, 21: 2127-2140.

Trichkova, T. A.; Kozoharov, D. St.; Hubenov, Z. K.; Botev, I. SI.; Zivkov, M. T. \& Cheshmedjiev, S. D.; 2008: Characteristics of zebra mussel (Dreissena polymorpha) populations in infested reservoirs, northwest Bulgaria. Journal of Natural History, 42(5-8): 619-631.

Troost, K.; Kamermans, P. \& Wolff, W. J.; 2008: Larviphagy in native bivalves and introduced oyster. Journal of Sea Research, 60: 157-163.

Tucker, J. K.; Cronin, F. A.; Soergel, D. W. \& Theiling, C. H.; 1996: Predation on zebra mussels (Dreissena polymorpha) by common carp (Cyprinus carpio). Journal of Freshwater Ecology, 11(3): 363-372. 
van Ekrom Schurink, C. \& Griffiths, C. L.; 1993: Factors affecting relative rates of growth in four South African mussel species. Aquaculture, 109: 257-273.

van Slooten, K. B. \& Tarradellas, J.; 1994: Accumulation, depuration and growth effects of tributyltin in the freshwater bivalve Dreissena polymorpha under field conditions. Environmental Toxicology and Chemistry, 13(5): 755-762.

Vasconcelos, V. M.; 1999: Cyanobacterial toxins in Portugal: effects on aquatic animals and risk fort human health. Brazilian Journal of Medical and Biological Research, 32: 249254.

Verney, R.; Lafite, R. \& Brun-Cottan, J. C.; 2009: Flocculation potential of estuarine particles: the importance of envinmental factors and of the spatial and seasonal variability of suspended particulate matter. Estuaries and Coasts, 32(4): 678-693.

Villar, C.; Stripeikis, J.; D’Huicque, L.; Tudino, M.; Troccoli, O. \& Bonetto, C.; 1999: Cd, Cu, and $\mathrm{Zn}$ concentrations in sediments and the invasive bivalves Limnoperna fortunei and Corbicula fluminea at the Río de la Plata basin, Argentina. Hydrobiologia, 416: 41-49.

Villela, I. V.; Marques de Oliveira, I.; da Silva, J. \& Pêgas Henriques, J. A.; 2006: DNA damage and repair in haemolymph cells of golden mussel (Limnoperna fortunei) exposed to environmental contaminants. Mutation Research, 605: 78-86.

Villela, I. V.; Marques de Oliveira, I.; Coelho Silveira, J.; Ferraz Dias, J.; Pêgas Henriques, J. A. \& da Silva, J.; 2007: Assesment of environmental stress by micronucleus and comet assays on Limnoperna fortunei exposed to Guaíba Hydrographic region samples (Brazil) under laboratory conditions. Mutation Research, 628: 76-86.

von Rückert, G.; de Cássia Souza Campos, M. \& Rolla, M. E.; 2004: Alimentaçao de Limnoperna fortunei (Dunker 1857): taxas de filtraçao com ênfase ao uso de Cyanobacteria. Maringá, 26(4): 421-429.

Wetzel, R. G. \& Likens, G. E.; 1991: Limnological Analysis. Springer-Verlag, New York, 391 p.

Widdows, J. \& Donkin, P.; 1992: Mussels and environmental contaminants: bioaccumulation and physiological aspects (Chapter 8). In: The Mussel Mytilus: Ecology, Physiology, Genetics and Culture. Development in Aquaculture and Fisheries Science. (Ed.) Gosling, E.- Elsevier, Amsterdam, 383-424.

Zar, J. H.; 1996: Biostatistical Analysis, $3^{\text {rd }}$ Edition Prentice Hall, New Jersey, 662 p. 


\section{APÉNDICES}


APÉNDICE 1.1. Resultados de la correlación de Pearson entre las variables medidas en el río Coronda. T: temperatura; Sat_O 2 : saturación de oxígeno; OD: oxígeno disuelto; Cond: conductividad; TDS: sólidos disueltos totales; Salin: Salinidad; Secchi: transparencia; Calcio; Cl act: clorofila activa; Feo_act: feofitina. Cl a: Clorofila a; Cl b: Clorofila b; Cl c: Clorofila c; Ind_Marg: índice de Margalef.

\begin{tabular}{|c|c|c|c|c|c|c|c|c|c|c|c|c|c|c|c|c|}
\hline & & $\mathbf{T}$ & $\mathrm{pH}$ & Sat_O ${ }_{2}$ & OD & Cond & TDS & Salin & Secchi & Calcio & Cl_act & Feo_act & Cl_a & Cl_b & Cl_c & Ind_Marg \\
\hline & Correlación Pearson & 1 & 0,093 & $-0,337$ & $-0,584^{*}$ & 0,075 & 0,082 & 0,067 & $-0,525^{*}$ & $-0,224$ & $0,577^{*}$ & 0,098 & 0,323 & 0,161 & 0,097 & 0,001 \\
\hline \multirow[t]{2}{*}{$\mathbf{T}$} & $\mathrm{p}$ (2-colas) & & 0,713 & 0,171 & 0,011 & 0,766 & 0,762 & 0,793 & 0,044 & 0,461 & 0,039 & 0,750 & 0,281 & 0,599 & 0,754 & 0,996 \\
\hline & $\mathrm{N}$ & 18 & 18 & 18 & 18 & 18 & 16 & 18 & 15 & 13 & 13 & 13 & 13 & 13 & 13 & 13 \\
\hline \multirow{3}{*}{$\mathrm{pH}$} & Correlación Pearson & & 1 & $-0,252$ & $-0,252$ & $-0,040$ & 0,266 & $-0,052$ & $-0,026$ & $-0,532$ & 0,052 & 0,409 & 0,420 & 0,473 & $-0,094$ & $-0,179$ \\
\hline & $\mathrm{p}$ (2-colas) & & & 0,314 & 0,314 & 0,875 & 0,319 & 0,838 & 0,927 & 0,061 & 0,866 & 0,165 & 0,153 & 0,103 & 0,761 & 0,558 \\
\hline & $\mathrm{N}$ & & 18 & 18 & 18 & 18 & 16 & 18 & 15 & 13 & 13 & 13 & 13 & 13 & 13 & 13 \\
\hline \multirow{3}{*}{ Sat_O${ }_{2}$} & Correlación Pearson & & & 1 & $0,960 * *$ & 0,161 & 0,060 & 0,171 & 0,464 & $-0,251$ & $-0,036$ & 0,499 & 0,484 & $-0,076$ & 0,187 & $-0,249$ \\
\hline & $\mathrm{p}$ (2-colas) & & & & 0,000 & 0,524 & 0,826 & 0,497 & 0,081 & 0,409 & 0,908 & 0,082 & 0,094 & 0,806 & 0,541 & 0,412 \\
\hline & $\mathrm{N}$ & & & 18 & 18 & 18 & 16 & 18 & 15 & 13 & 13 & 13 & 13 & 13 & 13 & 13 \\
\hline \multirow{3}{*}{ OD } & Correlación Pearson & & & & 1 & 0,130 & 0,025 & 0,141 & $0,549 *$ & $-0,066$ & $-0,308$ & 0,403 & 0,283 & $-0,126$ & 0,117 & $-0,226$ \\
\hline & $\mathrm{p}$ (2-colas) & & & & & 0,607 & 0,925 & 0,576 & 0,034 & 0,830 & 0,306 & 0,172 & 0,348 & 0,682 & 0,703 & 0,457 \\
\hline & $\mathrm{N}$ & & & & 18 & 18 & 16 & 18 & 15 & 13 & 13 & 13 & 13 & 13 & 13 & 13 \\
\hline \multirow{3}{*}{ Cond } & Correlación Pearson & & & & & 1 & $0,955^{* *}$ & $1,000 * *$ & $-0,116$ & $0,703 * *$ & $-0,289$ & $0,717^{* *}$ & $0,727 * *$ & $0,710^{* *}$ & 0,192 & $-0,564^{*}$ \\
\hline & $\mathrm{p}$ (2-colas) & & & & & & 0,000 & 0,000 & 0,681 & 0,007 & 0,338 & 0,006 & 0,005 & 0,007 & 0,530 & 0,045 \\
\hline & $\mathrm{N}$ & & & & & 18 & 16 & 18 & 15 & 13 & 13 & 13 & 13 & 13 & 13 & 13 \\
\hline \multirow{3}{*}{ TDS } & Correlación Pearson & & & & & & 1 & $0,954 * *$ & $-0,175$ & $0,610^{*}$ & $-0,133$ & $0,670^{*}$ & $0,722 * *$ & $0,621 *$ & 0,296 & $-0,504$ \\
\hline & $\mathrm{p}$ (2-colas) & & & & & & & 0,000 & 0,533 & 0,027 & 0,666 & 0,012 & 0,005 & 0,023 & 0,326 & 0,079 \\
\hline & $\mathrm{N}$ & & & & & & 16 & 16 & 15 & 13 & 13 & 13 & 13 & 13 & 13 & 13 \\
\hline \multirow{3}{*}{ Salin } & Correlación Pearson & & & & & & & 1 & $-0,116$ & $0,705^{* *}$ & $-0,294$ & $0,712 * *$ & $0,722 * *$ & $0,708^{* *}$ & 0,191 & $-0,570^{*}$ \\
\hline & $\mathrm{p}$ (2-colas) & & & & & & & & 0,682 & 0,007 & 0,330 & 0,006 & 0,005 & 0,007 & 0,532 & 0,042 \\
\hline & $\mathrm{N}$ & & & & & & & 18 & 15 & 13 & 13 & 13 & 13 & 13 & 13 & 13 \\
\hline \multirow{3}{*}{ Secchi } & Correlación Pearson & & & & & & & & 1 & $-0,166$ & 0,300 & $-0,263$ & $-0,095$ & 0,343 & $-0,119$ & 0,391 \\
\hline & $\mathrm{p}$ (2-colas) & & & & & & & & & 0,605 & 0,343 & 0,409 & 0,769 & 0,275 & 0,712 & 0,209 \\
\hline & $\mathrm{N}$ & & & & & & & & 15 & 12 & 12 & 12 & 12 & 12 & 12 & 12 \\
\hline \multirow{3}{*}{ Calcio } & Correlación Pearson & & & & & & & & & 1 & $-0,455$ & 0,345 & 0,268 & 0,257 & 0,191 & $-0,387$ \\
\hline & $\mathrm{p}$ (2-colas) & & & & & & & & & & 0,118 & 0,249 & 0,376 & 0,396 & 0,531 & 0,192 \\
\hline & $\mathrm{N}$ & & & & & & & & & 13 & 13 & 13 & 13 & 13 & 13 & 13 \\
\hline
\end{tabular}


APÉNDICE 1.1. Continuación...

\begin{tabular}{|c|c|c|c|c|c|c|}
\hline & & Feo_act & Cl_a & Cl_b & Cl_c & Ind_Marg \\
\hline & Correlación Pearson & $-0,421$ & $-0,065$ & $-0,194$ & $-0,035$ & 0,285 \\
\hline \multirow[t]{2}{*}{ Cl_act } & $\mathrm{p}$ (2-colas) & 0,152 & 0,834 & 0,525 & 0,909 & 0,344 \\
\hline & $\mathrm{N}$ & 13 & 13 & 13 & 13 & 13 \\
\hline & Correlación Pearson & 1 & $0,920 * *$ & $0,607^{*}$ & 0,259 & $-0,658^{*}$ \\
\hline \multirow[t]{2}{*}{ Feo_act } & $\mathrm{p}$ (2-colas) & & 0,000 & ,028 & 0,393 & 0,014 \\
\hline & $\mathrm{N}$ & 13 & 13 & 13 & 13 & 13 \\
\hline & Correlación Pearson & & 1 & $0,598^{*}$ & 0,226 & $-0,688 * *$ \\
\hline \multirow[t]{2}{*}{ Cl_a } & $\mathrm{p}$ (2-colas) & & & 0,031 & 0,458 & 0,009 \\
\hline & $\mathrm{N}$ & & 13 & 13 & 13 & 13 \\
\hline \multirow{3}{*}{ Cl_b } & Correlación Pearson & & & 1 & $-0,079$ & $-0,260$ \\
\hline & $\mathrm{p}$ (2-colas) & & & & 0,797 & 0,391 \\
\hline & $\mathrm{N}$ & & & 13 & 13 & 13 \\
\hline \multirow{3}{*}{ Cl_c } & Correlación Pearson & & & & 1 & 0,167 \\
\hline & $\mathrm{p}$ (2-colas) & & & & & 0,586 \\
\hline & $\mathrm{N}$ & & & & 13 & 13 \\
\hline
\end{tabular}

**. Correlación altamente significativa a un nivel de 0,01 (2-colas).

*. Correlación significativa a un nivel de 0,05 (2-colas). 
APÉNDICE 1.2. Resultados de la correlación de Pearson entre las variables medidas en el río Santiago. T: temperatura; Sat_O 2 : saturación de oxígeno; OD: oxígeno disuelto; Cond: conductividad; TDS: sólidos disueltos totales; Salin: Salinidad; Secchi: transparencia; Calcio; Cl_act: clorofila activa; Feo_act: feofitina. Cl a: Clorofila a; Cl b: Clorofila b; Cl c: Clorofila c; Ind_Marg: índice de Margalef.

\begin{tabular}{|c|c|c|c|c|c|c|c|c|c|c|c|c|c|c|c|c|}
\hline & & $\mathbf{T}$ & $\mathrm{pH}$ & Sat_O ${ }_{2}$ & OD & Cond & TDS & Salin & Secchi & Calcio & Cl_act & Feo_act & Cl_a & Cl_b & Cl_c & Ind_Marg \\
\hline & Correlación Pearson & 1 & $-0,143$ & $-0,160$ & $-0,370$ & 0,125 & $-0,040$ & 0,124 & $-0,227$ & $-0,566 *$ & 0,371 & $-0,165$ & 0,062 & $-0,493 *$ & $-0,355$ & 0,079 \\
\hline \multirow[t]{3}{*}{$\mathbf{T}$} & $\mathrm{p}$ (2-colas) & & 0,514 & 0,477 & 0,090 & 0,570 & 0,861 & 0,573 & 0,322 & 0,018 & 0,108 & 0,486 & 0,796 & 0,027 & 0,125 & 0,739 \\
\hline & $\mathrm{N}$ & 23 & 23 & 22 & 22 & 23 & 22 & 23 & 21 & 17 & 20 & 20 & 20 & 20 & 20 & 20 \\
\hline & Correlación Pearson & & 1 & 0,195 & 0,194 & 0,166 & $0,510^{*}$ & 0,162 & 0,214 & $-0,200$ & 0,236 & $0,483^{*}$ & 0,002 & $-0,026$ & 0,077 & $-0,247$ \\
\hline \multirow[t]{3}{*}{$\mathrm{pH}$} & $\mathrm{p}$ (2-colas) & & & 0,385 & 0,387 & 0,450 & 0,015 & 0,461 & 0,351 & 0,442 & 0,316 & 0,031 & 0,994 & 0,912 & 0,749 & 0,293 \\
\hline & $\mathrm{N}$ & & 23 & 22 & 22 & 23 & 22 & 23 & 21 & 17 & 20 & 20 & 20 & 20 & 20 & 20 \\
\hline & Correlación Pearson & & & 1 & $0,975^{* *}$ & 0,325 & $0,437^{*}$ & 0,326 & 0,231 & $-0,320$ & $0,515^{*}$ & $0,591 * *$ & 0,368 & 0,116 & $0,522^{*}$ & $-0,293$ \\
\hline \multirow[t]{3}{*}{ Sat_O $\mathbf{O}_{2}$} & $\mathrm{p}$ (2-colas) & & & & 0,000 & 0,140 & 0,047 & 0,139 & 0,326 & 0,210 & 0,020 & 0,006 & 0,111 & 0,626 & 0,018 & 0,210 \\
\hline & $\mathrm{N}$ & & & 22 & 22 & 22 & 21 & 22 & 20 & 17 & 20 & 20 & 20 & 20 & 20 & 20 \\
\hline & Correlación Pearson & & & & 1 & 0,300 & 0,432 & 0,301 & 0,262 & $-0,166$ & 0,383 & $0,584 * *$ & 0,315 & 0,234 & $0,558^{*}$ & $-0,285$ \\
\hline \multirow[t]{3}{*}{ OD } & $\mathrm{p}$ (2-colas) & & & & & 0,175 & 0,051 & 0,173 & 0,264 & 0,524 & 0,096 & 0,007 & 0,176 & 0,321 & 0,010 & 0,223 \\
\hline & $\mathrm{N}$ & & & & 22 & 22 & 21 & 22 & 20 & 17 & 20 & 20 & 20 & 20 & 20 & 20 \\
\hline & Correlación Pearson & & & & & 1 & $0,804 * *$ & $1,000 * *$ & 0,356 & $-0,253$ & $0,499 *$ & $0,649 * *$ & $0,469 *$ & 0,257 & 0,065 & $-0,448 *$ \\
\hline \multirow[t]{3}{*}{ Cond } & $\mathrm{p}$ (2-colas) & & & & & & 0,000 & 0,000 & 0,113 & 0,328 & 0,025 & 0,002 & 0,037 & 0,274 & 0,784 & 0,048 \\
\hline & $\mathrm{N}$ & & & & & 23 & 22 & 23 & 21 & 17 & 20 & 20 & 20 & 20 & 20 & 20 \\
\hline & Correlación Pearson & & & & & & 1 & $0,804^{* *}$ & 0,348 & $-0,298$ & 0,360 & $0,684 * *$ & 0,426 & 0,411 & 0,223 & $-0,463 *$ \\
\hline \multirow[t]{3}{*}{ TDS } & $\mathrm{p}$ (2-colas) & & & & & & & 0,000 & 0,122 & 0,245 & 0,119 & 0,001 & 0,061 & 0,072 & ,345 & 0,040 \\
\hline & $\mathrm{N}$ & & & & & & 22 & 22 & 21 & 17 & 20 & 20 & 20 & 20 & 20 & 20 \\
\hline & Correlación Pearson & & & & & & & 1 & 0,352 & $-0,256$ & $0,495^{*}$ & $0,647 * *$ & $0,468^{*}$ & 0,259 & 0,069 & $-0,450^{*}$ \\
\hline \multirow[t]{3}{*}{ Salin } & $\mathrm{p}$ (2-colas) & & & & & & & & 0,117 & 0,322 & 0,026 & 0,002 & 0,037 & 0,270 & 0,773 & 0,047 \\
\hline & $\mathrm{N}$ & & & & & & & 23 & 21 & 17 & 20 & 20 & 20 & 20 & 20 & 20 \\
\hline & Correlación Pearson & & & & & & & & 1 & 0,049 & 0,378 & $0,478^{*}$ & 0,410 & 0,276 & 0,032 & $-0,264$ \\
\hline \multirow[t]{3}{*}{ Secchi } & $\mathrm{p}$ (2-colas) & & & & & & & & & 0,852 & 0,100 & 0,033 & 0,072 & 0,239 & 0,895 & 0,261 \\
\hline & $\mathrm{N}$ & & & & & & & & 21 & 17 & 20 & 20 & 20 & 20 & 20 & 20 \\
\hline & Correlación Pearson & & & & & & & & & 1 & $-0,257$ & $-0,315$ & $-0,251$ & 0,185 & $-0,145$ & 0,385 \\
\hline \multirow[t]{2}{*}{ Calcio } & $\mathrm{p}$ (2-colas) & & & & & & & & & & 0,319 & 0,218 & 0,331 & 0,476 & 0,579 & 0,127 \\
\hline & $\mathrm{N}$ & & & & & & & & & 17 & 17 & 17 & 17 & 17 & 17 & 17 \\
\hline
\end{tabular}


APÉNDICE 1.2. Continuación...

\begin{tabular}{|c|c|c|c|c|c|c|}
\hline & & Feo_act & Cl_a & Cl_b & Cl_c & Ind_Marg \\
\hline & Correlación Pearson & $0,627^{* *}$ & $0,617^{* *}$ & $-0,053$ & 0,196 & $-0,333$ \\
\hline \multirow[t]{3}{*}{ Cl_act } & $\mathrm{p}$ (2-colas) & 0,003 & 0,004 & 0,823 & 0,407 & 0,151 \\
\hline & $\mathrm{N}$ & 20 & 20 & 20 & 20 & 20 \\
\hline & Correlación Pearson & 1 & $0,629 * *$ & 0,362 & $0,486 *$ & $-0,518^{*}$ \\
\hline \multirow[t]{3}{*}{ Feo_act } & $\mathrm{p}$ (2-colas) & & 0,003 & 0,116 & 0,030 & 0,019 \\
\hline & $\mathrm{N}$ & 20 & 20 & 20 & 20 & 20 \\
\hline & Correlación Pearson & & 1 & $0,641 * *$ & 0,416 & $-0,773 * *$ \\
\hline \multirow[t]{3}{*}{ Cl_a } & $\mathrm{p}$ (2-colas) & & & 0,002 & 0,068 & 0,000 \\
\hline & $\mathrm{N}$ & & 20 & 20 & 20 & 20 \\
\hline & Correlación Pearson & & & 1 & 0,443 & $-0,655^{* *}$ \\
\hline \multirow[t]{3}{*}{ Cl_b } & $\mathrm{p}$ (2-colas) & & & & 0,050 & 0,002 \\
\hline & $\mathrm{N}$ & & & 20 & 20 & 20 \\
\hline & Correlación Pearson & & & & 1 & $-0,344$ \\
\hline \multirow[t]{2}{*}{ Cl_c } & $\mathrm{p}$ (2-colas) & & & & & 0,137 \\
\hline & $\mathrm{N}$ & & & & 20 & 20 \\
\hline
\end{tabular}

**. Correlación altamente significativa a un nivel de 0,01 (2-colas).

*. Correlación significativa a un nivel de 0,05 (2-colas). 
APÉNDICE 3.1. Análisis de la varianza para valores de densidad obtenidos de los colectores artificiales sumergidos y retirados en el río Santiago durante 2007 a 2009.

\begin{tabular}{cccccc}
\hline & Suma de Cuadrados & gl & Cuadrado Medio & F & p \\
\hline \hline Entre Grupos & 15,430 & 2 & 7,715 & 0,265 & 0,769 \\
\hline Dentro de Grupos & 1135,814 & 39 & 29,123 & & \\
\cline { 1 - 4 } Total & 1151,245 & 41 & & \\
\hline \hline
\end{tabular}

APÉNDICE 3.2. Análisis de la varianza para valores de densidad obtenidos de los colectores artificiales sumergidos y retirados en el río Coronda durante 2007 a 2009.

\begin{tabular}{cccccc}
\hline & Suma de Cuadrados & gl & Cuadrado Medio & F & p \\
\hline \hline Entre Grupos & 46,423 & 2 & 23,211 & 0,456 & 0,639 \\
\hline Dentro de Grupos & 1222,927 & 24 & 50,955 & & \\
\cline { 1 - 4 } Total & 1269,350 & 26 & & \\
\hline \hline
\end{tabular}

APÉNDICE 3.3. Resultados de la correlación de Pearson entre las variables medidas en el río Santiago y la densidad total. T: temperatura $\left({ }^{\circ} \mathrm{C}\right)$; $\mathrm{pH}$; OD: oxígeno disuelto $\left(\mathrm{mg} \mathrm{L}^{-1}\right)$; Cond: conductividad $\left(\mathrm{mS} \mathrm{cm}^{-1}\right)$; $\operatorname{Transp}$ : transparencia $(\mathrm{m})$; Calcio $\left(\mathrm{mg} \mathrm{L}^{-1}\right) ; \mathrm{Cl}$ a: Clorofila a $\left(\mathrm{mg} \mathrm{m}^{-3}\right) ; \mathrm{Cl}$ b: Clorofila b $\left(\mathrm{mg} \mathrm{m}^{-3}\right)$; Cl c: Clorofila c $\left(\mathrm{mg} \mathrm{m}^{-3}\right)$.

\begin{tabular}{|c|c|c|c|c|c|c|c|c|c|c|}
\hline & & $T$ & $\mathrm{pH}$ & OD & Cond & Transp & Calcio & Cl_a & Cl_b & Cl_c \\
\hline \multirow{3}{*}{$\begin{array}{c}\text { Densidad } \\
\text { Total }\end{array}$} & Correlación Pearson & $-0,204$ & $-0,667 *$ & $-0,406$ & 0,124 & $-0,183$ & $0,668^{*}$ & $-0,301$ & 0,175 & $-0,441$ \\
\hline & $p$ (2-colas) & 0,547 & 0,025 & 0,216 & 0,716 & 0,591 & 0,035 & 0,368 & 0,608 & 0,175 \\
\hline & $\mathrm{N}$ & 11 & 11 & 11 & 11 & 11 & 10 & 11 & 11 & 11 \\
\hline
\end{tabular}

APÉNDICE 3.4. Resultados de la correlación de Pearson entre las variables medidas en el río Coronda y la densidad total. T: temperatura $\left({ }^{\circ} \mathrm{C}\right)$; $\mathrm{pH}$; OD: oxígeno disuelto $\left(\mathrm{mg} \mathrm{L}^{-1}\right)$; Cond: conductividad $\left(\mathrm{mS} \mathrm{cm}^{-1}\right)$; $\operatorname{Transp}$ : transparencia $(\mathrm{m})$; Calcio $\left(\mathrm{mg} \mathrm{L}^{-1}\right)$; $\mathrm{Cl}$ a: Clorofila a $\left(\mathrm{mg} \mathrm{m}^{-3}\right)$; $\mathrm{Cl}$ b: Clorofila b $\left(\mathrm{mg} \mathrm{m}^{-3}\right)$; $\mathrm{Cl} \mathrm{c}$ : Clorofila c $\left(\mathrm{mg} \mathrm{m}^{-3}\right)$.

\begin{tabular}{|c|c|c|c|c|c|c|c|c|c|c|}
\hline & & $\mathbf{T}$ & $\mathrm{pH}$ & OD & Cond & Transp & Calcio & Cl_a & Cl_b & Cl_c \\
\hline \multirow{3}{*}{$\begin{array}{c}\text { Densidad } \\
\text { Total }\end{array}$} & Correlación Pearson & 0,061 & $-0,567$ & $-0,248$ & 0,558 & $-0,704 *$ & 0,318 & 0,087 & $-0,039$ & 0,214 \\
\hline & $\mathrm{p}$ (2-colas) & 0,877 & 0,111 & 0,519 & 0,119 & 0,034 & 0,405 & 0,823 & 0,920 & 0,580 \\
\hline & $\mathrm{N}$ & 9 & 9 & 9 & 9 & 9 & 9 & 9 & 9 & 9 \\
\hline
\end{tabular}


APÉNDICE 3.5. Análisis de la varianza para valores de Largo total (LT), Ancho total (AT) y Alto total (AL) de los individuos asentados sobre colectores artificiales sumergidos y retirados en el río Santiago durante 2007 a 2009.

\begin{tabular}{|c|c|c|c|c|c|c|}
\hline & & Suma de Cuadrados & gl & Cuadrado Medio & $\mathbf{F}$ & $\mathbf{p}$ \\
\hline & Entre Grupos & 0,024 & 2 & 0,012 & 0,492 & 0,616 \\
\hline \multirow[t]{3}{*}{ LT } & Dentro de Grupos & 0,792 & 33 & 0,024 & & \\
\hline & Total & 0,816 & 35 & & & \\
\hline & Entre Grupos & 0,022 & 2 & 0,011 & 0,565 & 0,573 \\
\hline \multirow[t]{3}{*}{ AT } & Dentro de Grupos & 0,654 & 33 & 0,020 & & \\
\hline & Total & 0,677 & 35 & & & \\
\hline & Entre Grupos & 0,017 & 2 & 0,009 & 0,286 & 0,753 \\
\hline \multirow[t]{2}{*}{$A L$} & Dentro de Grupos & 0,984 & 33 & 0,030 & & \\
\hline & Total & 1,001 & 35 & & & \\
\hline
\end{tabular}

APÉNDICE 3.6. Análisis de la varianza para valores de Largo total (LT), Ancho total (AT) y Alto total (AL) de los individuos asentados sobre colectores artificiales sumergidos y retirados en el río Coronda durante 2007 a 2009.

\begin{tabular}{|c|c|c|c|c|c|c|}
\hline & & Suma de Cuadrados & gl & Cuadrado Medio & $\mathbf{F}$ & $\mathbf{p}$ \\
\hline \multirow{3}{*}{ LT } & Entre Grupos & 0,037 & 2 & 0,019 & 0,274 & 0,762 \\
\hline & Dentro de Grupos & 1,624 & 24 & 0,068 & & \\
\hline & Total & 1,661 & 26 & & & \\
\hline \multirow{3}{*}{ AT } & Entre Grupos & 0,028 & 2 & 0,014 & 0,255 & 0,777 \\
\hline & Dentro de Grupos & 1,323 & 24 & 0,055 & & \\
\hline & Total & 1,351 & 26 & & & \\
\hline \multirow{3}{*}{$A L$} & Entre Grupos & 0,040 & 2 & 0,020 & 0,288 & 0,753 \\
\hline & Dentro de Grupos & 1,680 & 24 & 0,070 & & \\
\hline & Total & 1,720 & 26 & & & \\
\hline
\end{tabular}

APÉNDICE 3.7. Análisis de la varianza para valores de Largo total de valva (LT) de los individuos asentados sobre colectores artificiales sumergidos y retirados en el río Santiago durante 2007 a 2009.

\begin{tabular}{cccccc}
\hline & Suma de Cuadrados & gl & Cuadrado Medio & F & p \\
\hline \hline Entre Grupos & 0,027 & 2 & 0,013 & 0,136 & 0,873 \\
\hline Dentro de Grupos & 3,235 & 33 & 0,098 & & \\
\cline { 1 - 4 } Total & 3,262 & 35 & & & \\
\hline \hline
\end{tabular}

APÉNDICE 3.8. Análisis de la varianza para valores de Largo total de valva (LT de los individuos asentados sobre colectores artificiales sumergidos y retirados en el río Coronda durante 2007 a 2009.

\begin{tabular}{cccccc}
\hline & Suma de Cuadrados & gl & Cuadrado Medio & F & p \\
\hline \hline Entre Grupos & 0,079 & 2 & 0,040 & 0,324 & 0,726 \\
\hline Dentro de Grupos & 2,928 & 24 & 0,122 & & \\
\cline { 1 - 4 } Total & 3,007 & 26 & & & \\
\hline \hline
\end{tabular}


APÉNDICE 4.1. Análisis de la varianza para valores de Largo total (LT), Ancho total (AT) y Alto total (AL) de los individuos extraídos de cada jaula sumergida en el río Santiago en la primera etapa (junio de 2006 a enero de 2007).

\begin{tabular}{|c|c|c|c|c|c|c|}
\hline & & Suma de Cuadrados & gl & Cuadrado Medio & $\mathbf{F}$ & p \\
\hline & Entre Grupos & 0,019 & 2 & 0,009 & 0,001 & 0,999 \\
\hline \multirow[t]{3}{*}{ LT } & Dentro de Grupos & 264,461 & 21 & 12,593 & & \\
\hline & Total & 264,480 & 23 & & & \\
\hline & Entre Grupos & 0,027 & 2 & 0,014 & 0,005 & 0,995 \\
\hline \multirow[t]{3}{*}{ AT } & Dentro de Grupos & 55,647 & 21 & 2,650 & & \\
\hline & Total & 55,674 & 23 & & & \\
\hline & Entre Grupos & 0,074 & 2 & 0,037 & 0,016 & 0,984 \\
\hline \multirow[t]{2}{*}{ AL } & Dentro de Grupos & 47,762 & 21 & 2,274 & & \\
\hline & Total & 47,836 & 23 & & & \\
\hline
\end{tabular}

APÉNDICE 4.2. Análisis de la varianza para valores de Largo total (LT), Ancho total (AT) y Alto total (AL) de los individuos extraídos de cada jaula sumergida en el río Santiago en la segunda etapa (marzo de 2007 a abril de 2009).

\begin{tabular}{|c|c|c|c|c|c|c|}
\hline & & Suma de Cuadrados & gl & Cuadrado Medio & $\mathbf{F}$ & $p$ \\
\hline & Entre Grupos & 18,336 & 2 & 9,168 & 1,736 & 0,187 \\
\hline \multirow[t]{3}{*}{ LT } & Dentro de Grupos & 264,017 & 50 & 5,280 & & \\
\hline & Total & 282,352 & 52 & & & \\
\hline & Entre Grupos & 2,483 & 2 & 1,241 & 1,000 & 0,375 \\
\hline \multirow[t]{3}{*}{ AT } & Dentro de Grupos & 59,602 & 48 & 1,242 & & \\
\hline & Total & 62,084 & 50 & & & \\
\hline & Entre Grupos & 1,816 & 2 & 0,908 & 1,088 & 0,345 \\
\hline \multirow[t]{2}{*}{ AL } & Dentro de Grupos & 40,074 & 48 & 0,835 & & \\
\hline & Total & 41,890 & 50 & & & \\
\hline
\end{tabular}

APÉNDICE 4.3. Resultado del ANCOVA. Variable dependiente: PH (peso húmedo); covariable: LT (Largo total de la valva); factor: Sitio; gl: grados de libertad.

\begin{tabular}{cccccc}
\hline Fuente & $\begin{array}{c}\text { Suma de Cuadrados } \\
\text { Tipo III }\end{array}$ & gl & $\begin{array}{c}\text { Cuadrado } \\
\text { medio }\end{array}$ & F & p \\
\hline \hline $\begin{array}{c}\text { Modelo } \\
\text { Corregido }\end{array}$ & 2161,235 & 3 & 720,412 & 5518,361 & 0,000 \\
\hline Intercepto & 3607,083 & 1 & 3607,083 & 27630,3 & 0,000 \\
\hline Sitio & 3,885 & 1 & 3,885 & 29,758 & 0,000 \\
\hline LT & 1869,793 & 1 & 1869,793 & 14322,636 & 0,000 \\
\hline Sitio * LT & 3,551 & 1 & 3,551 & 27,198 & 0,000 \\
\hline Error & 256,266 & 1963 & 0,131 & & \\
\hline Total & 17400,050 & 1967 & & & \\
\hline Total Corregido & 2417,501 & 1966 & & & \\
\hline \hline
\end{tabular}


APÉNDICE 4.4. Resultado del ANCOVA. Variable dependiente: PS (peso seco); covariable: LT (Largo total de la valva); factor: Sitio; gl: grados de libertad.

\begin{tabular}{cccccc}
\hline Fuente & $\begin{array}{c}\text { Suma de Cuadrados } \\
\text { Tipo III }\end{array}$ & gl & $\begin{array}{c}\text { Cuadrado } \\
\text { medio }\end{array}$ & F & p \\
\hline \hline $\begin{array}{c}\text { Modelo } \\
\text { Corregido }\end{array}$ & 2126,460 & 3 & 708,820 & 12382,382 & 0,000 \\
\hline Intercepto & 4415,358 & 1 & 4415,358 & 77131,915 & 0,000 \\
\hline Sitio & 4,806 & 1 & 4,806 & 83,959 & 0,000 \\
\hline LT & 1912,277 & 1 & 1912,277 & 33405,576 & 0,000 \\
\hline Sitio * LT & 4,291 & 1 & 4,291 & 74,962 & 0,000 \\
\hline Error & 116,492 & 2035 & 0,057 & & \\
\hline Total & 28449,249 & 2039 & & & \\
\hline Total Corregido & 2242,952 & 2038 & & & \\
\hline \hline
\end{tabular}

APÉNDICE 4.5. Resultado del ANCOVA. Variable dependiente: PSLC (peso seco libre de cenizas); covariable: LT (Largo total de la valva); factor: Sitio; gl: grados de libertad.

\begin{tabular}{cccccc}
\hline Fuente & $\begin{array}{c}\text { Suma de Cuadrados } \\
\text { Tipo III }\end{array}$ & gl & $\begin{array}{c}\text { Cuadrado } \\
\text { medio }\end{array}$ & F & p \\
\hline $\begin{array}{c}\text { Modelo } \\
\text { Corregido }\end{array}$ & 2153,839 & 3 & 717,946 & 2881,232 & 0,000 \\
\hline Intercepto & 5857,853 & 1 & 5857,853 & 23508,494 & 0,000 \\
\hline Sitio & 9,350 & 1 & 9,350 & 37,523 & 0,000 \\
\hline LT & 1960,720 & 1 & 1960,720 & 7868,680 & 0,000 \\
\hline Sitio * LT & 7,204 & 1 & 7,204 & 28,911 & 0,000 \\
\hline Error & 492,629 & 1977 & 0,249 & & \\
\hline Total & 55051,154 & 1981 & & & \\
\hline Total Corregido & 2646,468 & 1980 & & & \\
\hline \hline
\end{tabular}


APÉNDICE 4.6. Estadística descriptiva de las dimensiones valvares en $\mathrm{mm}$ (LT, $\mathrm{AT}, \mathrm{AL})$, los pesos en $\mathrm{g}\left(\mathrm{PH}, \mathrm{PS}, \mathrm{PSLC}\right.$ ) y del índice de condición en $\mathrm{g} \mathrm{mm}^{-3}$ (IC) para individuos muestreados en el río Santiago. DE: desvío estándar; ND: dato no disponible.

\begin{tabular}{|c|c|c|c|c|c|c|c|c|c|}
\hline Año & Fecha de muestreo & $\mathrm{LT} \pm \mathrm{DE}$ & $\mathrm{AT} \pm \mathrm{DE}$ & $\mathrm{Al} \pm \mathrm{DE}$ & $\mathbf{N}$ & $\mathrm{PH} \pm \mathrm{DE}$ & $\mathrm{PS} \pm \mathrm{DE}$ & $\mathrm{PSLC} \pm \mathrm{DE}$ & $\mathrm{IC} \pm \mathrm{DE}$ \\
\hline & 02-May & $6,32 \pm 0,98$ & ND & ND & 31 & $0,0143 \pm 0,0072$ & $0,0074 \pm 0,0038$ & $0,0033 \pm 0,0025$ & ND \\
\hline & 06-Jun & $7,95 \pm 0,95$ & $3,94 \pm 0,47$ & $2,86 \pm 0,48$ & 29 & $0,0306 \pm 0,0129$ & $0,0133 \pm 0,0042$ & $0,0030 \pm 0,0025$ & $0,0031 \pm 0,0018$ \\
\hline & 18-Jul & $8,76 \pm 1,27$ & $4,51 \pm 0,65$ & $3,25 \pm 0,50$ & 30 & $0,0557 \pm 0,0214$ & $0,0189 \pm 0,0058$ & $0,0048 \pm 0,0033$ & $0,0032 \pm 0,0022$ \\
\hline \multirow[t]{9}{*}{2007} & 28-Ago & $8,62 \pm 1,69$ & $4,33 \pm 0,78$ & $3,18 \pm 0,56$ & 50 & $0,0429 \pm 0,0265$ & $0,0221 \pm 0,0133$ & $0,0072 \pm 0,0086$ & $0,0058 \pm 0,0061$ \\
\hline & 25-Sep & $10,26 \pm 1,35$ & $5,04 \pm 0,68$ & $3,75 \pm 0,50$ & 63 & $0,0719 \pm 0,0365$ & $0,0308 \pm 0,0098$ & $0,0077 \pm 0,0041$ & $0,0037 \pm 0,0015$ \\
\hline & 06-Nov & $13,55 \pm 1,76$ & $6,38 \pm 0,79$ & $4,99 \pm 0,73$ & 98 & $0,1759 \pm 0,07,35$ & $0,0634 \pm 0,0233$ & $0,0157 \pm 0,0063$ & $0,0035 \pm 0,0004$ \\
\hline & 18-Dic & $9,45 \pm 2,36$ & $4,64 \pm 0,95$ & $3,67 \pm 0,84$ & 113 & $0,0611 \pm 0,0464$ & $0,0277 \pm 0,0167$ & $0,0080 \pm 0,0053$ & $0,0043 \pm 0,0019$ \\
\hline & 25-Ene & $12,22 \pm 3,90$ & $5,7 \pm 1,71$ & $4,49 \pm 1,54$ & 105 & $0,1046 \pm 0,0892$ & $0,0481 \pm 0,0330$ & $0,0112 \pm 0,0082$ & $0,0029 \pm 0,0007$ \\
\hline & 25-Feb & $10,35 \pm 4,45$ & $5,03 \pm 1,83$ & $3,77 \pm 1,69$ & 63 & $0,0837 \pm 0,1022$ & $0,039 \pm 0,0421$ & $0,0094 \pm 0,0105$ & $0,0033 \pm 0,0007$ \\
\hline & 03-Abr & $12,12 \pm 4,53$ & $5,62 \pm 1,86$ & $4,48 \pm 1,83$ & 60 & $0,1127 \pm 0,1029$ & $0,0478 \pm 0,0429$ & $0,0107 \pm 0,0101$ & $0,0026 \pm 0,0007$ \\
\hline & 08-May & $14,05 \pm 4,18$ & $6,62 \pm 1,75$ & $5,13 \pm 1,58$ & 60 & $0,1593 \pm 0,1337$ & $0,0634 \pm 0,0449$ & $0,0112 \pm 0,0079$ & $0,0020 \pm 0,0004$ \\
\hline & 10-Jun & $14,15 \pm 4,68$ & $6,67 \pm 1,95$ & $5,09 \pm 1,80$ & 62 & $0,1512 \pm 0,1147$ & $0,0674 \pm 0,0500$ & $0,0123 \pm 0,0088$ & $0,0022 \pm 0,0005$ \\
\hline \multirow[t]{7}{*}{2008} & 08-Jul & $14,1 \pm 4,44$ & $6,47 \pm 1,75$ & $5,08 \pm 1,75$ & 60 & $0,163 \pm 0,1332$ & $0,0674 \pm 0,0517$ & $0,0119 \pm 0,0088$ & $0,0023 \pm 0,0007$ \\
\hline & 14-Ago & $13,99 \pm 4,36$ & $6,55 \pm 1,77$ & $5 \pm 1,59$ & 61 & $0,1481 \pm 0,1175$ & $0,0648 \pm 0,0481$ & $0,0114 \pm 0,0078$ & $0,0023 \pm 0,0007$ \\
\hline & 23-Sep & $12,48 \pm 4,57$ & $6,04 \pm 1,85$ & $4,45 \pm 1,70$ & 60 & $0,1103 \pm 0,0867$ & $0,0515 \pm 0,0430$ & $0,0092 \pm 0,0101$ & $0,0026 \pm 0,0020$ \\
\hline & $22-0 c t$ & $12,55 \pm 4,89$ & $6 \pm 2,07$ & $4,53 \pm 1,82$ & 60 & $0,1138 \pm 0,1011$ & $0,0534 \pm 0,0485$ & $0,0095 \pm 0,0085$ & $0,0024 \pm 0,0013$ \\
\hline & 26-Nov & $9,88 \pm 4,46$ & $5 \pm 2,05$ & $3,48 \pm 1,56$ & 60 & $0,1066 \pm 0,1359$ & $0,0491 \pm 0,0727$ & $0,0264 \pm 0,0439$ & $0,0048 \pm 0,0039$ \\
\hline & 18-Dic & $9,31 \pm 4,22$ & $4,77 \pm 1,90$ & $3,35 \pm 1,51$ & 64 & $0,0977 \pm 0,1401$ & $0,0347 \pm 0,0517$ & $0,0230 \pm 0,0260$ & $0,0037 \pm 0,0029$ \\
\hline & 09-Feb & $9,71 \pm 3,89$ & $4,96 \pm 1,78$ & $3,54 \pm 1,40$ & 60 & $0,1020 \pm 0,1307$ & $0,03 \pm 0,0349$ & $0,0068 \pm 0,0083$ & $0,0026 \pm 0,0008$ \\
\hline \multirow[t]{2}{*}{2009} & 13-Mar & $9,23 \pm 3,78$ & $4,91 \pm 1,88$ & $3,46 \pm 1,42$ & 60 & $0,0953 \pm 0,1258$ & $0,0298 \pm 0,0405$ & $0,0049 \pm 0,0176$ & $0,0028 \pm 0,0016$ \\
\hline & $15-A b r$ & $8,46 \pm 3,03$ & $4,45 \pm 1,51$ & $3,12 \pm 1,05$ & 61 & $0,0694 \pm 0,0808$ & $0,0208 \pm 0,0248$ & $0,0034 \pm 0,0076$ & $0,0023 \pm 0,0012$ \\
\hline
\end{tabular}


APÉNDICE 4.7. Estadística descriptiva de las dimensiones valvares en $\mathrm{mm}$ (LT, AT, AL), los pesos en $\mathrm{g}$ (PH, PS, PSLC) y del índice de condición en $\mathrm{g} \mathrm{mm}^{-3}$ (IC) para individuos muestreados en el río Coronda. DE: desvío estándar; ND: dato no disponible.

\begin{tabular}{cccccccccc}
\hline Año & Fecha de muestreo & LT $\pm \mathbf{D E}$ & $\mathbf{A T} \pm \mathbf{D E}$ & $\mathbf{A l} \pm \mathbf{D E}$ & $\mathbf{N}$ & $\mathbf{P H} \pm \mathbf{D E}$ & $\mathbf{P S} \pm \mathbf{D E}$ & PSLC $\pm \mathbf{D E}$ & $\mathbf{I C} \pm \mathbf{D E}$ \\
\hline \hline \multirow{6}{*}{2007} & 30-Abr & $7,02 \pm 1,43$ & ND & ND & 17 & $0,0391 \pm 0,0169$ & $0,0110 \pm 0,0049$ & $0,0039 \pm 0,0041$ & ND \\
& 05-Jun & $9,90 \pm 1,49$ & $5,31 \pm 0,87$ & $3,81 \pm 0,67$ & 20 & $0,0803 \pm 0,0391$ & $0,0311 \pm 0,0131$ & $0,0104 \pm 0,0081$ & $0,0039 \pm 0,0024$ \\
& 31-Jul & $12,18 \pm 1,9$ & $6,41 \pm 0,90$ & $4,76 \pm 0,63$ & 20 & $0,1663 \pm 0,0679$ & $0,0597 \pm 0,0213$ & $0,0220 \pm 0,0102$ & $0,0050 \pm 0,0024$ \\
& 23-Ago & $13,32 \pm 1,71$ & $7,01 \pm 0,77$ & $5,22 \pm 0,64$ & 30 & $0,1859 \pm 0,0710$ & $0,0782 \pm 0,0247$ & $0,0177 \pm 0,0075$ & $0,0035 \pm 0,0009$ \\
& 20-Sep & $13,93 \pm 1,80$ & $7,03 \pm 0,82$ & $5,61 \pm 0,60$ & 28 & $0,1786 \pm 0,0668$ & $0,0831 \pm 0,0233$ & $0,0153 \pm 0,0063$ & $0,0026 \pm 0,0007$ \\
& 30-Oct & $17,60 \pm 1,67$ & $8,36 \pm 0,76$ & $6,89 \pm 0,63$ & 32 & $0,3935 \pm 0,1242$ & $0,1542 \pm 0,0519$ & $0,0453 \pm 0,0364$ & $0,0043 \pm 0,0029$ \\
& 21-Dic & $19,30 \pm 3,11$ & $8,82 \pm 1,28$ & $7,36 \pm 1,17$ & 30 & ND & $0,1608 \pm 0,0613$ & $0,0303 \pm 0,0171$ & $0,0023 \pm 0,0008$ \\
\hline \multirow{4}{*}{ 2008 } & 12-Feb & $9,70 \pm 2,51$ & $4,82 \pm 1,25$ & $3,57 \pm 1,01$ & 60 & $0,0557 \pm 0,0471$ & $0,0197 \pm 0,0137$ & $0,0035 \pm 0,0022$ & $0,0020 \pm 0,0007$ \\
& 17-Mar & $9,62 \pm 2,62$ & $4,85 \pm 1,20$ & $3,49 \pm 0,99$ & 60 & $0,0619 \pm 0,0493$ & $0,0197 \pm 0,0133$ & $0,0036 \pm 0,0023$ & $0,0020 \pm 0,0005$ \\
& 24-Abr & $11,01 \pm 2,74$ & $5,35 \pm 1,15$ & $3,99 \pm 1,06$ & 60 & $0,0556 \pm 0,0368$ & $0,0281 \pm 0,0166$ & $0,0052 \pm 0,0027$ & $0,0020 \pm 0,0006$ \\
& 12-Jun & $12,70 \pm 3,42$ & $6,21 \pm 1,46$ & $4,58 \pm 1,23$ & 60 & $0,0957 \pm 0,0646$ & $0,0488 \pm 0,0286$ & $0,0096 \pm 0,0060$ & $0,0024 \pm 0,0004$ \\
& 31-Jul & $12,05 \pm 3,92$ & $5,95 \pm 1,75$ & $4,25 \pm 1,42$ & 63 & $0,0947 \pm 0,0747$ & $0,0461 \pm 0,0371$ & $0,0087 \pm 0,0070$ & $0,0023 \pm 0,0006$ \\
& 21-Ago & $11,49 \pm 4,21$ & $5,73 \pm 1,90$ & $4,12 \pm 1,55$ & 63 & $0,1233 \pm 0,1325$ & $0,0520 \pm 0,0531$ & $0,0172 \pm 0,0256$ & $0,0037 \pm 0,0029$ \\
& 25-Sep & $11,17 \pm 3,88$ & $5,55 \pm 1,68$ & $4,01 \pm 1,44$ & 64 & $0,0884 \pm 0,0751$ & $0,0399 \pm 0,0358$ & $0,0086 \pm 0,0078$ & $0,0027 \pm 0,0005$ \\
& 20-Nov & $10,74 \pm 4,24$ & $5,26 \pm 1,96$ & $3,76 \pm 1,60$ & 63 & $0,1184 \pm 0,1361$ & $0,0356 \pm 0,0398$ & $0,0079 \pm 0,0141$ & $0,0024 \pm 0,0013$ \\
& 17-Dic & $10,13 \pm 3,51$ & $4,92 \pm 1,63$ & $3,52 \pm 1,28$ & 59 & $0,0867 \pm 0,0907$ & $0,0296 \pm 0,0295$ & $0,0057 \pm 0,0072$ & $0,0024 \pm 0,0010$ \\
\hline \hline
\end{tabular}

